\title{
Inclusión financiera \\ de pequeños productores rurales
}

FRANCISCO G. VILLARREAL Editor
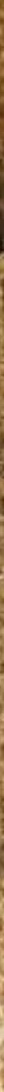

C E P A L

\section{JँّFIDA}

Invertir en la población rural 


\section{Gracias por su interés en esta}

\section{publicación de la CEPAL}

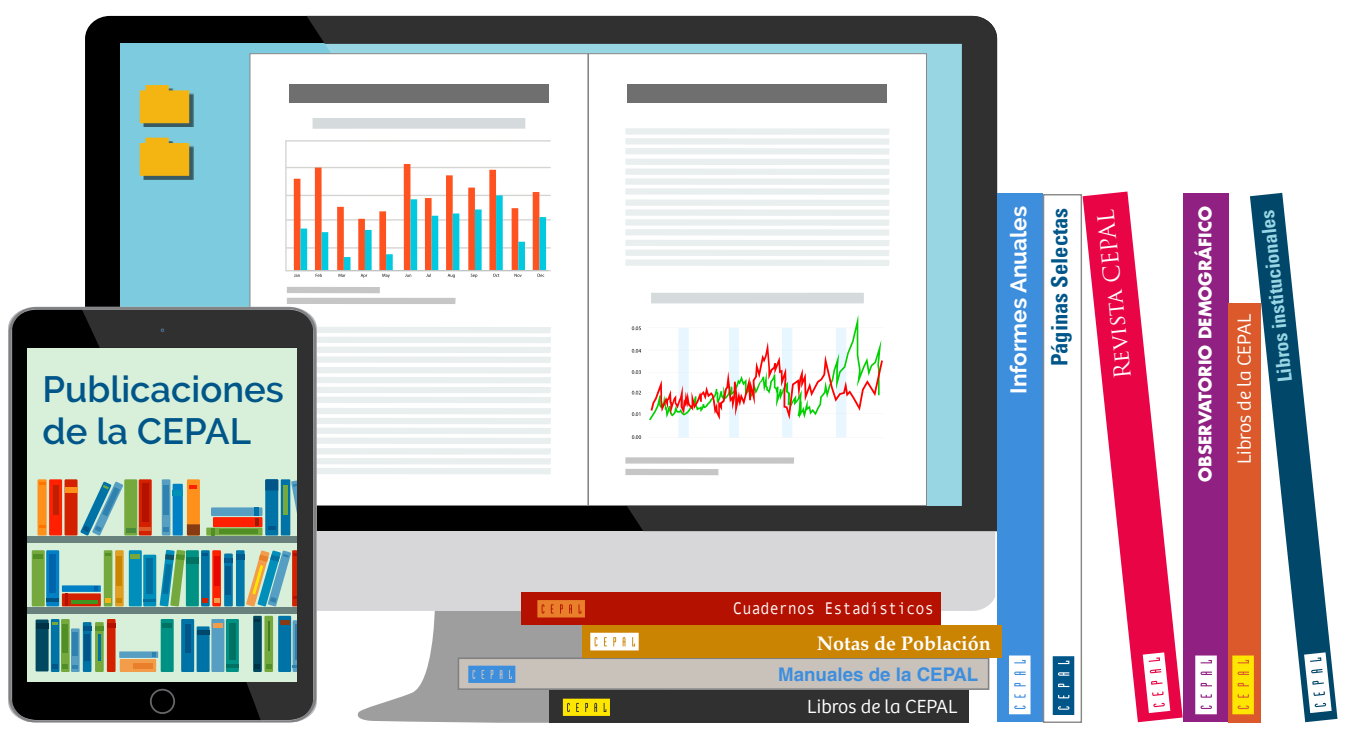

Si desea recibir información oportuna sobre nuestros productos editoriales y actividades, le invitamos a registrarse. Podrá definir sus áreas de interés y acceder a nuestros productos en otros formatos.

\section{Deseo registrarme}

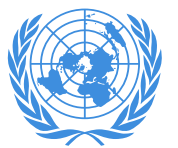

NACIONES UNIDAS

C E P \& L

\section{www.cepal.org/es/suscripciones}




\section{Inclusión financiera de pequeños productores rurales}

Francisco G. Villarreal

Editor

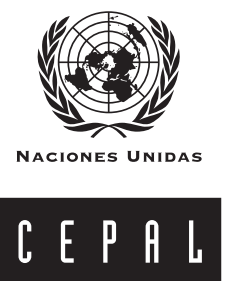

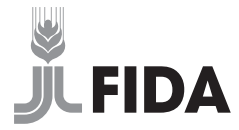

Invertir en la población rural

Comisión Económica para América Latina y el Caribe (CEPAL)

Santiago, septiembre de 2017 


\section{Libros de la CEPAL}

\section{7}

\section{Alicia Bárcena}

Secretaria Ejecutiva

\section{Antonio Prado}

Secretario Ejecutivo Adjunto

\section{Hugo Eduardo Beteta}

Director de la sede subregional de la CEPAL en México

\section{Ricardo Pérez}

Director de la División de Publicaciones y Servicios Web

Este libro fue editado por Francisco G. Villarreal, Oficial de Asuntos Económicos de la Unidad de Desarrollo Económico de la sede subregional de la Comisión Económica para América Latina y el Caribe (CEPAL) en México. La elaboración de los capítulos del libro estuvo a cargo de los siguientes funcionarios de la sede subregional de la CEPAL en México: Cameron Daneshvar, Stefanie Garry, Jesús López, Jesús Santamaría y Francisco G. Villarreal. También estuvo a cargo de los siguientes consultores: Pedro Argumedo, Melvin Bermúdez, Pilar Campos, Pablo Cotler, Daniela Cruz, Rolando Reyes, Ronald Rojas, César Valenzuela, José Antonio Vásquez C. y José Antonio Vásquez R.

La CEPAL agradece el apoyo financiero del Fondo Internacional de Desarrollo Agrícola (FIDA) para la realización de los estudios de caso sobre inclusión financiera de pequeños productores rurales y la publicación de este libro.

Los límites y los nombres que figuran en los mapas incluidos en este documento no implican su apoyo o aceptación oficial por las Naciones Unidas.

Diseño de portada: Marcela Veas

Publicación de las Naciones Unidas

ISBN: 978-92-1-121958-6 (versión impresa)

ISBN: 978-92-1-058595-8 (versión pdf)

ISBN: 978-92-1-358061-5 (versión ePub)

Número de venta: S.17.II.G.16

LC/PUB.2017/15-P

Distr.: General

Copyright (C) Naciones Unidas, 2017

Todos los derechos reservados

Impreso en Naciones Unidas, Santiago

S.17-00277

Esta publicación debe citarse como: Francisco G. Villarreal (ed.), Inclusión financiera de pequeños productores rurales, Libros de la CEPAL, No 147 (LC/PUB.2017/15-P), Santiago, Comisión Económica para América Latina y el Caribe (CEPAL), 2017.

La autorización para reproducir total o parcialmente esta obra debe solicitarse a la Comisión Económica para América Latina y el Caribe (CEPAL), División de Publicaciones y Servicios Web, publicaciones@cepal.org. Los Estados Miembros de las Naciones Unidas y sus instituciones gubernamentales pueden reproducir esta obra sin autorización previa. Solo se les solicita que mencionen la fuente e informen a la CEPAL de tal reproducción. 


\section{Índice}

Prólogo.

Capítulo I

La inclusión financiera de pequeños productores rurales:

tendencias y desafíos

Cameron Daneshvar, Stefanie Garry, Jesús López, Jesús Santamaría,

Francisco G. Villarreal

Introducción

A. La transformación rural en el contexto del cambio estructural progresivo.

B. La inclusión financiera como instrumento del desarrollo sostenible.

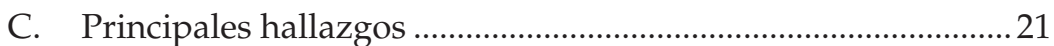

D. Las mejores prácticas .....................................................................24

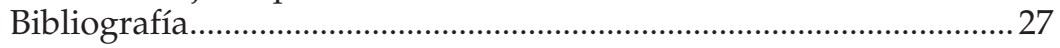

Capítulo II

La inclusión financiera en América Latina

Pablo Cotler.

Introducción

A. La inclusión como una estrategia de formalización......................33

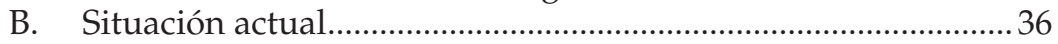

C. Una revisión de la literatura ........................................................4

D. Estrategias de inclusión financiera .............................................51

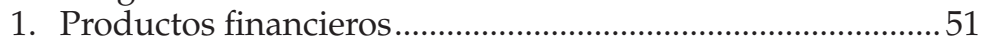

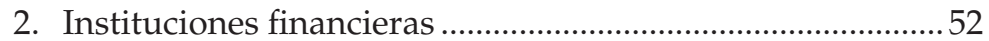

3. Canales de distribución ..........................................................54 


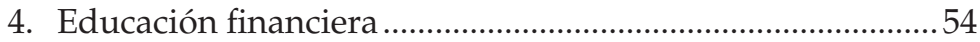

5. Marco regulatorio …………............................................... 55

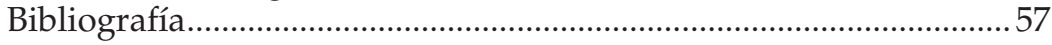

Capítulo III

Evolución reciente, situación actual y perspectivas de inclusión financiera de los pequeños productores rurales en Costa Rica José Antonio Vásquez R., Melvin Bermúdez, Ronald Rojas, José Antonio Vásquez C.

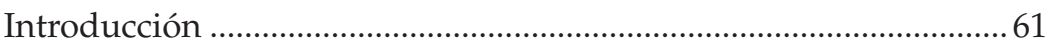

A. Evolución reciente del acceso y uso de servicios financieros.

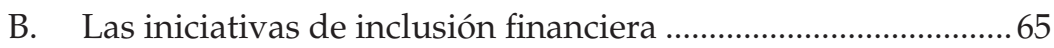

1. Composición productiva del medio rural................................65

2. La evolución del sistema financiero.......................................67

3. La apertura de las telecomunicaciones y su papel en la inclusión financiera ........................................................... 72

4. Alcance logrado por las iniciativas públicas para fomentar la inclusión financiera ...................................... 76

C. Arquitectura institucional .............................................................78

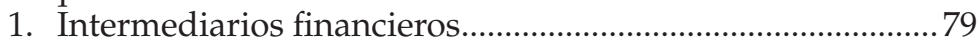

2. Servicios financieros y canales de distribución .......................80

3. Sistemas de pago ...................................................................... 82

4. Mecanismos de protección a usuarios de servicios financieros

D. Instrumentos de política pública para fomentar la inclusión financiera de pequeños productores rurales ............................... 82

1. La banca de segundo piso ...................................................... 82

2. Garantías de crédito para productores rurales.......................84 84

3. Instrumentos de fomento productivo al sector rural ............84

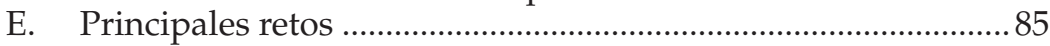

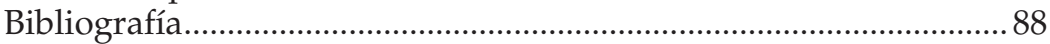

Capítulo IV

La inclusión financiera en El Salvador

Pedro Argumedo

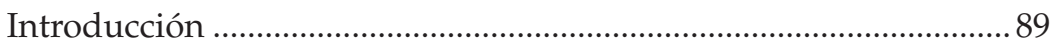

A. Evolución reciente y situación actual del acceso y uso de servicios financieros.

1. Acceso y uso de servicios financieros .....................................92

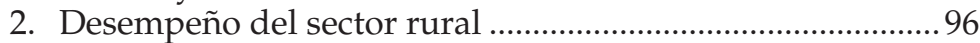

B. La estrategia de inclusión financiera ...........................................100

C. Rasgos de la arquitectura institucional ......................................... 102

1. Política regulatoria y de supervisión .....................................102

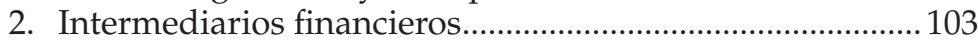

3. Sistemas de pago ................................................................ 105 
4. Servicios financieros y canales de distribución ....................107

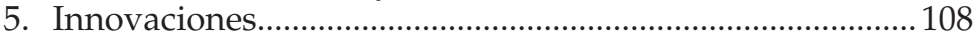

6. Mecanismos de protección a usuarios ................................... 110

7. Estado de derecho y administración de justicia................... 110

D. Identificación y análisis de los instrumentos

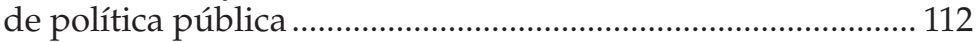

1. Banca de desarrollo ................................................................. 112

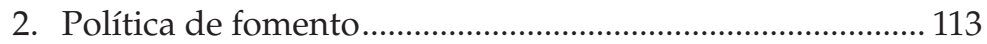

3. Garantía de crédito ................................................................. 113

4. Fortalecimiento de capacidades ............................................. 114

E. Principales retos para la inclusión financiera de pequeños productores rurales................................................ 114

1. El reto de la coordinación entre instituciones financieras públicas y privadas ............................................ 115

2. El reto de la información financiera entre oferentes y demandantes ....................................................................... 116

3. El reto de la regulación y la interoperabilidad de las nuevas tecnologías .................................................... 117

Bibliografía.

Capítulo V

La inclusión financiera de pequeños productores rurales en Honduras

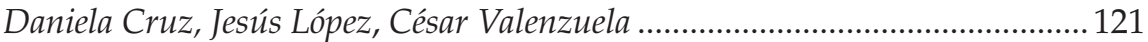

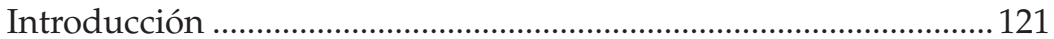

A. Situación actual del sector financiero y la inclusión financiera en Honduras....

1. Posición de la inclusión financiera en Honduras en el contexto internacional ................................................124

2. Situación actual del sistema financiero en Honduras ........126

3. Cobertura geográfica de los oferentes de servicios financieros

4. Brechas de inclusión financiera en el ámbito rural............. 135

B. Estrategia Nacional de Inclusión Financiera (ENIF) .................138

C. Arquitectura institucional ............................................................ 144

1. Política regulatoria y de supervisión ...................................... 144

2. Los sistemas de pago................................................................ 145

3. Los mecanismos de protección a los usuarios de los productos y servicios financieros................................. 146

4. Infraestructura coadyuvante para la inclusión financiera de los productores rurales ................................... 146

D. Instrumentos de política pública ............................................. 147

1. La política de fomento ......................................................... 147

2. Las garantías de crédito mobiliarias y recíprocas para incrementar el acceso al crédito. 
3. El desarrollo de las capacidades de los micro y pequeños empresarios

E. Conclusiones

Bibliografía.

Capítulo VI

Panorama y perspectivas de la inclusión financiera

en la República Dominicana

Rolando Reyes, Cameron Daneshvar. 155

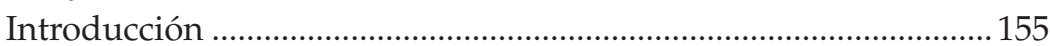

A. Situación de la inclusión financiera ...........................................157

1. Situación con respecto al contexto internacional .................157

2. Situación a nivel nacional ..................................................... 158

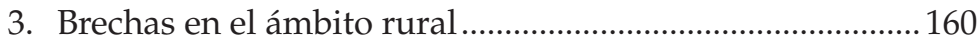

B. Iniciativas de inclusión financiera ..............................................161

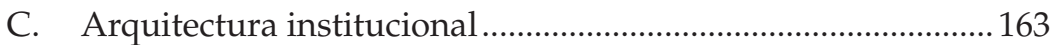

1. Regulación y supervisión del sistema financiero...................163

2. Intermediarios financieros..................................................164

3. Principales productos y canales de distribución....................166

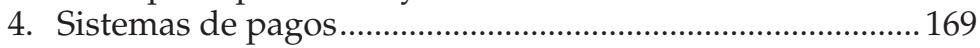

5. Mecanismos de protección de usuarios..................................172

6. Infraestructura complementaria...........................................172

D. Instrumentos de política pública .............................................173

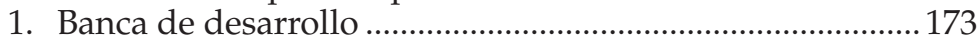

2. Política regulatoria y de supervisión ......................................174

3. Desarrollo de capacidades......................................................175

E. Conclusiones y recomendaciones ...............................................176

1. Reforma para la regulación y supervisión de las cooperativas de ahorro y crédito................................177

2. Nueva arquitectura del Banco Agrícola y del FEDA.......... 178

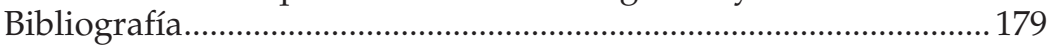

Capítulo VII

Arquitectura de la inclusión financiera rural en México

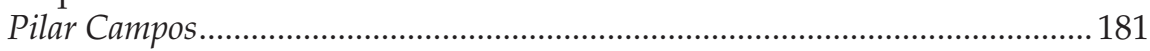

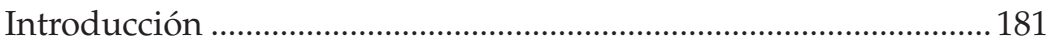

A. La arquitectura institucional de la inclusión

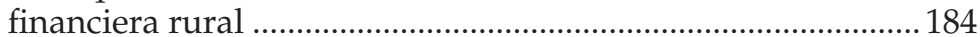

1. Entidades de Ahorro y Crédito Popular ...............................186

2. Instituciones de crédito no reguladas ....................................189

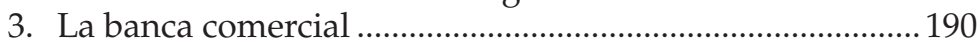

4. Los corresponsales bancarios, los cajeros automáticos y las terminales punto de venta ...................... 192

B. La banca de desarrollo en la arquitectura financiera rural........194

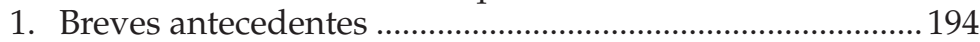

2. Financiera Nacional de Desarrollo Agropecuario, Rural, Forestal y Pesquero. 
3. Banco del Ahorro Nacional y Servicios Financieros........... 196

4. Fideicomisos Instituidos en Relación con la Agricultura.... 198

C. Retos que enfrentan los usuarios y las entidades financieras en el ámbito rural ......................................................201

1. Evolución de los puntos de acceso en el sector rural .........201

2. Sobre los productos y los usuarios........................................202

3. Los retos de las entidades financieras no bancarias en el sector rural.....................................................................203

4. Educación financiera ............................................................205

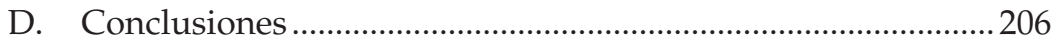

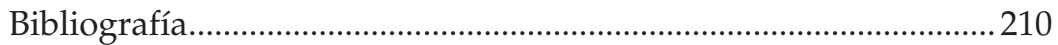

Publicaciones recientes de la CEPAL............................................................213

\section{Cuadros}

II.1 América Latina y el Caribe: indicadores de acceso a los canales de distribución de los productos financieros.

II.2 América Latina y el Caribe: uso de productos financieros de los hogares, 2014

II.3 América Latina y el Caribe: uso de productos financieros por parte del $40 \%$ de los hogares más pobres, 2014.

II.4 América Latina y el Caribe: uso de productos financieros por parte de la población rural, 2014

II.5 Estimaciones de uso de productos financieros..................................... 44

II.6 América Latina y el Caribe: brechas de inclusión y ahorro, 2011 ...... 46

III.1 Costa Rica, América Latina y el Caribe y resto del mundo: indicadores seleccionados de inclusión financiera, 2011-2014

III.2 Costa Rica: entidades financieras supervisadas por la Superintendencia General de Entidades Financieras (SUGEF) / sistema financiero nacional, 2000, 2005, 2009 y 2016 .......................... 79

III.3 Costa Rica: oferta de servicios financieros ........................................... 81

IV.1 El Salvador: inclusión financiera total y rural, 2011, 2014 y 2016...... 93

IV.2 El Salvador: financiamiento a las actividades agropecuarias, 2010 y 2014

IV.3 El Salvador: crédito otorgado por intermediarios financieros formales, 2015.

IV.4 El Salvador: agencias y puntos de pago …………............................... 106

V.1 Honduras: instituciones que componen el sistema financiero, por tipo de regulación y origen del capital

V.2 Honduras: activos, pasivos y patrimonio de las principales instituciones financieras, diciembre de 2015.

V.3 Honduras: productos y servicios financieros ofertados, por tipo de institución y nivel de acceso

V.4 Honduras: componentes y actores clave del sector público y privado en la Estrategia Nacional de Inclusión Financiera (ENIF). 
V.5 Honduras: metas como indicadores de impacto de mediano plazo de la Estrategia Nacional de Inclusión Financiera (ENIF) .... 142

VI.1 República Dominicana y América Latina y el Caribe: población con cuentas en instituciones financieras, 2011 y 2014......................... 158

VI.2 República Dominicana: relación entre PIB, préstamos y depósitos, 2007-2015.

VI.3 República Dominicana: tipo de producto o servicio financiero utilizado, por zona geográfica, 2014

VI.4 República Dominicana: población que posee actualmente distintos tipos de productos financieros, 2014 ..

VI.5 República Dominicana: productos y servicios financieros utilizados, por nivel de ingreso, 2014

VI.6 República Dominicana: volumen y valores de los pagos electrónicos ejecutados mediante el Sistema de Pagos, 2010-2016.

VI.7 República Dominicana: evaluación de la cartera de instituciones especializadas en microcréditos, 2009-2015 .

VII.1 Resumen de la arquitectura de leyes y oferentes financieros relacionados con la inclusión financiera.

VII.2 Comparación entre tres programas públicos de crédito dirigidos a población rural para apoyar la inclusión financiera, 2014-2016

\section{Gráficos}

II.1 América Latina y el Caribe: depósitos en bancos comerciales, 2014.

II.2 América Latina y el Caribe: cartera de crédito de la banca comercial, 2014

II.3 América Latina: índice de inclusión financiera para tres poblaciones distintas, 2014

III.1 Costa Rica: cantidad de fincas por censo, 1950-2014 ..........................66

IV.1 El Salvador: crédito a sectores productivos de fuentes internas (bancos, instituciones financieras no bancarias y sociedades de ahorro y crédito), 2002-2015

IV.2 El Salvador: dispositivos electrónicos en puntos de venta de tarjetas de crédito y débito, 2003-junio de 2012

V.1 Honduras, América Latina y el Caribe y el mundo: adultos mayores de 15 años con servicios o productos financieros básicos a nivel nacional y en áreas rurales, 2014.

V.2 Centroamérica y la República Dominicana: adultos mayores de 15 años con servicios o productos financieros básicos a nivel nacional y en áreas rurales, 2014.

VII.1 México: sucursales bancarias en municipios rurales, 2010-2016.

VII.2 México: sucursales de entidades reguladas en municipios con menos de 15.000 habitantes, 2010-2016 


\section{Diagramas}

IV.1 El Salvador: inclusión financiera rural de personas mayores

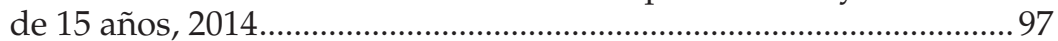

IV.2 El Salvador: estrategia de inclusión financiera, 2008-2015 .............100

V.1 Honduras: estructura organizacional para la implementación de la Estrategia Nacional de Inclusión Financiera (ENIF)............... 139

V.2 Honduras: entorno regulatorio y de supervisión de los proveedores de productos y servicios financieros

\section{Mapa}

V.1 Honduras: distribución de los puntos de servicio, 2011 y 2015 ..... 134 



\section{Prólogo}

Pese a los recientes avances, los países de América Latina y el Caribe siguen caracterizándose por tener elevados niveles de pobreza. Además, existen amplias desigualdades entre diversos segmentos de la población, que se acentúan en áreas rurales donde, de acuerdo con las últimas estimaciones, la incidencia de la pobreza duplica la observada en áreas urbanas. Las desigualdades entre los ámbitos urbano y rural también se hacen patentes en otras dimensiones del bienestar, como la salud, la educación, la inserción en el mercado laboral y el acceso a la seguridad social.

La Agenda 2030 para el Desarrollo Sostenible supone un cambio de paradigma debido a que se trata de una agenda universal que integra las dimensiones económica, social y ambiental como pilares centrales del desarrollo sostenible. Es transformadora porque implica cambios profundos en los modos de producción y de consumo, y, en general, en los estilos de vida y convivencia contemporáneos. Fija un horizonte claro en el tiempo y traza un camino hacia la igualdad entre géneros y generaciones, a la vez que reconoce la importancia de erradicar la pobreza en los años venideros.

En sus trabajos más recientes, la Comisión Económica para América Latina y el Caribe (CEPAL) ha fijado la igualdad como el horizonte a perseguir y ha apostado a la transformación de la estructura productiva hacia actividades y procesos productivos que sean intensivos en conocimiento, que estén vinculados a mercados dinámicos, de manera que estimulen la actividad económica y la generación de empleo, y que favorezcan la sostenibilidad ambiental como camino y la política pública como instrumento.

Un componente fundamental de dicho cambio estructural progresivo es la transformación incluyente del ámbito rural, que eleva la productividad de las actividades primarias, incrementando las capacidades de pequeños 
productores rurales para generar excedentes comercializables y acceso a mercados. Esta transformación demanda estrategias para aprovechar la innovación y promover la diversificación de actividades productivas y medios de vida.

La transformación del ámbito rural enfrenta tres fuerzas globales que generan nuevas oportunidades y plantean nuevos desafíos: i) el crecimiento económico, que ha significado una reducida participación de las actividades primarias en el producto de los países; ii) la globalización, que ha transformado no solo la organización de los mercados, sino también la configuración y participación de los productores rurales en las cadenas de valor agroalimentarias; y iii) la creciente urbanización, que se ha traducido en una reorganización de los territorios, no solo a nivel nacional, sino también en las zonas rurales, subrayando su complementariedad con los centros urbanos.

El compromiso de un desarrollo rural sostenible con la igualdad en el centro y la articulación de políticas productivas y sociales puede allanar el camino de la necesaria adaptación para mitigar las amenazas planteadas por el cambio climático y la degradación ambiental, que incluyen incrementos de temperatura, la intensificación de episodios de sequía y lluvias intensas, y la reducción en la disponibilidad de agua. El cambio estructural progresivo en el ámbito rural requiere estrategias innovadoras y herramientas para su implementación, así como una mayor capacidad de articulación entre múltiples actores e instrumentos, donde el sector público ocupa un lugar estratégico para actuar como agente catalizador.

La evidencia histórica indica que ningún país ha logrado superar la pobreza sin haber alcanzado grandes incrementos en la productividad de las actividades primarias, que facilitan la producción de los excedentes de alimentos, trabajo e incluso recursos financieros necesarios para apuntalar la industrialización y urbanización de un país. Si bien en el largo plazo esta transformación supone la convergencia de productividad entre sectores productivos, en el corto y mediano plazo el proceso puede tener un impacto negativo en las poblaciones rurales. Por ello es absolutamente necesario diseñar e implementar políticas públicas que doten a los pequeños productores rurales de las herramientas para superar las barreras que enfrentan en el acceso a recursos productivos, conocimiento, financiamiento y mercados. El resultado esperado es un amplio espectro de oportunidades originado en un cambio estructural progresivo y renovadas capacidades de los pequeños productores rurales para aprovecharlas.

La inclusión financiera, definida como el acceso de la población actualmente desatendida (donde se destacan los habitantes pobres de áreas rurales) a una oferta amplia de servicios financieros adaptados a sus necesidades y ofrecidos por una variedad de proveedores de servicios financieros regulados, es una herramienta que potencia la generación de 
oportunidades que fortalezcan la capacidad de alcanzar los Objetivos de Desarrollo Sostenible.

A través de la posibilidad de realizar y recibir pagos, así como de acumular activos de manera segura, de apalancar los activos disponibles para invertir en educación, salud y capital, y de mitigar los riesgos, la inclusión financiera tiene el potencial de facilitar el logro de mayores niveles de bienestar económico y social por parte de los hogares, así como de un mayor nivel de productividad y crecimiento por parte de las empresas. Además, a nivel regional y nacional, mediante una mejor asignación de recursos, la inclusión financiera promueve la movilización de recursos para la innovación, la diversificación de actividades productivas y la generación de empleos, lo que contribuye a un mayor crecimiento y una mejor distribución del ingreso.

El logro del potencial ofrecido por la inclusión financiera, sin embargo, supone la existencia de una amplia variedad de servicios financieros, proveedores de estos servicios y canales de distribución que se adecuen a las necesidades de las poblaciones actualmente excluidas. Su desarrollo requiere de la decidida acción de políticas públicas orientadas a la implementación y el fortalecimiento de dichos ecosistemas financieros inclusivos.

En este libro se busca fortalecer el análisis y la formulación de políticas públicas que fomenten un ecosistema diverso de proveedores de servicios financieros comercialmente viables, que incrementen el acceso sostenible de los pequeños productores rurales en América Latina a una amplia gama de servicios financieros. Para ello, se identifican las mejores prácticas en materia de políticas públicas, que surgen del contraste de la experiencia de cinco países que se encuentran en diferentes fases del proceso de formulación e implementación de estrategias integrales de inclusión financiera.

\author{
Alicia Bárcena \\ Secretaria Ejecutiva \\ Comisión Económica para \\ América Latina y el Caribe (CEPAL)
}



Capítulo I

\title{
La inclusión financiera de pequeños productores rurales: tendencias y desafíos
}

\author{
Cameron Daneshoar ${ }^{1}$ \\ Stefanie Garry ${ }^{2}$ \\ Jesús López ${ }^{3}$ \\ Jesús Santamaría \\ Francisco G. Villarreal ${ }^{5}$
}

\section{Introducción}

Entre 1980 y 2002, el número de pobres de América Latina creció casi en 90 millones de personas y alcanzó los 225 millones, cifra equivalente al 43,9\% de la población de la región (CEPAL, 2015). Gracias a un entorno económico favorable, mejoras en el mercado laboral y el efecto de la priorización de la política social en el combate a la pobreza y la desigualdad, a partir de 2002 la pobreza bajó 15,7 puntos porcentuales y descendió al 28,1\% en 2012 (CEPAL, 2015). Durante el mismo período, la mayoría de los países de la

\footnotetext{
Oficial Asociado de Asuntos Económicos de la Unidad de Desarrollo Económico de la sede subregional de la Comisión Económica para América Latina y el Caribe (CEPAL) en México.

2 Oficial Asociado de Asuntos Económicos de la Unidad de Desarrollo Económico de la sede subregional de la CEPAL en México.

3 Unidad de Desarrollo Económico de la sede subregional de la CEPAL en México.

4 Unidad de Desarrollo Económico de la sede subregional de la CEPAL en México.

5 Oficial de Asuntos Económicos de la Unidad de Desarrollo Económico de la sede subregional de la CEPAL en México.
} 
región también lograron reducir la desigualdad en materia de ingresos. Sin embargo, desde 2012 tanto los niveles de pobreza como de desigualdad se han mantenido relativamente constantes (CEPAL, 2016b).

No obstante los avances logrados, al cierre de 2015 había aún 175 millones de personas pobres en América Latina, 75 millones de las cuales vivían en condiciones de indigencia (CEPAL, 2016b). Asimismo, persisten marcadas desigualdades entre amplios segmentos de la población, que se acentúan en el ámbito rural, donde, según los datos más recientes, la incidencia de la pobreza e indigencia prácticamente duplican lo observado en zonas urbanas (CEPAL, 2016b). Ello implica que, a pesar de aglutinar a menos del 20\% de la población total, el entorno rural concentra una tercera parte de los pobres y casi la mitad de los indigentes de la región. Las disparidades entre los ámbitos urbano y rural también se manifiestan en otras dimensiones del bienestar, como la salud, la educación y la protección social (CEPAL/FAO/IICA, 2015).

Con la finalidad de ordenar el diseño de instrumentos de política pública orientados a cerrar estas brechas y materializar los Objetivos de Desarrollo Sostenible (Naciones Unidas, 2015), la Comisión Económica para América Latina y el Caribe (CEPAL) ha planteado el concepto de cambio estructural progresivo, que consiste en un proceso de transformación de la estructura productiva hacia actividades y procesos productivos que sean intensivos en conocimientos, que estén vinculados a mercados dinámicos de manera que estimulen la actividad económica y la generación de empleo, y que favorezcan la sostenibilidad ambiental (Bárcena y Prado, 2016; CEPAL, 2016a).

La conceptualización del cambio estructural progresivo como hoja de ruta hacia la igualdad demanda una transformación rural inclusiva que aumente la productividad de las actividades primarias y que incremente la capacidad de originar excedentes comercializables y acceso a los mercados al tiempo que diversifica las actividades productivas y los medios de vida (FIDA, 2016a).

Existe un creciente volumen de evidencia que indica que el fomento de la inclusión financiera tiene efectos positivos tanto a nivel de los hogares como a nivel macroeconómico (Banco Mundial, 2014; Cull, Ehrbeck y Holle, 2014; Barajas y otros, 2015). En vista de ello, la inclusión financiera se constituye en una herramienta con el potencial para contribuir a la transformación inclusiva del medio rural (CFI, 2011 y 2012; FIDA, 2009, 2016a, 2016b y 2016c; Kloeppinger-Todd y Sharma, 2010; Timmer, 2009; Vargas Hill y Torero, 2009). La inclusión financiera supone la existencia de un ecosistema variado de servicios, proveedores y canales de distribución (FIDA, 2009). Sin embargo, el desarrollo de un ecosistema con dichas características, enfocado en atender las necesidades de las poblaciones excluidas, en general, y de los pequeños productores rurales, en particular, no ocurre de manera automática (Doran, 
McFadyen y Vogel, 2009; Höllinger, 2011). Para ello, es necesario contar con políticas públicas que fomenten el desarrollo de ecosistemas financieros inclusivos (Ehrbeck, Pickens y Tarazi, 2012).

Dado el carácter transversal de la inclusión financiera, las políticas públicas relevantes para su fomento trascienden aquellas directamente vinculadas con el sector financiero. Dependiendo del ámbito de incidencia de las políticas públicas, estas pueden clasificarse en tres niveles (FIDA, 2009). En el nivel macro, se encuentran las políticas que definen el entorno de actuación de las entidades públicas y privadas que participan en el desarrollo y funcionamiento del sistema financiero. En el nivel intermedio se ubican las políticas que determinan la disponibilidad y los mecanismos de acceso a diversos componentes de la infraestructura financiera y a herramientas de fomento productivo, así como a componentes de la infraestructura y redes de distribución que permiten a los pequeños productores rurales incrementar su productividad, ventas y márgenes de ganancia. Finalmente, en el nivel micro, las políticas relevantes están orientadas a fortalecer las capacidades tanto de los usuarios de servicios financieros como de quienes los proveen, y de las autoridades responsables de la regulación y supervisión del sistema.

Con este libro se busca fortalecer el análisis y la formulación de políticas públicas de modo que fomenten un ecosistema diverso de proveedores de servicios financieros comercialmente viables y que incrementen el acceso de los pequeños productores rurales de América Latina a una amplia gama de servicios financieros. Para ello, se identifican las mejores prácticas en materia de políticas públicas, que surgen del contraste de la experiencia de cinco países en diferentes fases del proceso de formulación e implementación de estrategias integrales de inclusión financiera.

En este primer capítulo, se exponen los motivos del trabajo y se resalta la importancia del proceso de transformación rural en el contexto del cambio estructural progresivo promovido por la CEPAL (Bárcena y Prado, 2016; CEPAL, 2016a). Posteriormente, se analiza el potencial de la inclusión financiera como herramienta de desarrollo y se identifican los mecanismos mediante los cuales es posible ampliar las capacidades de los pequeños productores rurales para alcanzar los Objetivos de Desarrollo Sostenible. El capítulo concluye con un resumen de los principales hallazgos y un análisis de las mejores prácticas identificadas a partir de ellos.

A continuación, en el capítulo II, Pablo Cotler contextualiza la necesidad de fomentar la inclusión financiera, identifica las características generales que debe incluir una estrategia de política pública para alcanzar dicho objetivo y expone cuáles son sus efectos previsibles. En los capítulos restantes se resumen los principales hallazgos de los estudios de caso sobre la arquitectura institucional disponible para fomentar la inclusión financiera realizados en 
Costa Rica (Vásquez Rivera y otros, 2017), El Salvador (Argumedo, 2017), Honduras (Valenzuela y Cruz, 2017), la República Dominicana (Reyes Luna, 2017) y México (Campos, 2017).

\section{A. La transformación rural en el contexto del cambio estructural progresivo}

A partir de la segunda mitad del siglo XX, el ámbito rural experimentó una profunda transformación impulsada por diversos factores, a saber: el crecimiento económico, que ha traído aparejado un peso cada vez menor de las actividades primarias en la actividad económica; la globalización, que ha transformado la configuración de las cadenas de valor agroalimentarias; y una creciente urbanización, que ha implicado una reorganización del territorio no solo a nivel nacional sino también local (Berdegué, Rosada y Bebbington, 2014; Timmer, 2009).

No obstante la creciente diversificación de actividades y medios de vida, los pequeños productores siguen dominando el espacio productivo rural (OCDE, 2007). Es por ello que la Agenda 2030 para el Desarrollo Sostenible (Naciones Unidas, 2015) subraya la urgente necesidad de facilitar a los pequeños productores rurales los medios que les permitan superar las barreras que limitan su acceso a recursos productivos, insumos especializados, conocimiento, financiamiento y mercados (FIDA, 2016a). A dichas barreras se suma el desafío de satisfacer la creciente demanda de alimentos, pienso y fibra de manera sostenible (FIDA, 2015).

La evidencia histórica indica que ningún país ha logrado una reducción de la pobreza sin incrementar la productividad del sector agropecuario (Timmer, 2009). Dicho proceso es resultado de un cambio estructural impulsado por una mayor productividad agropecuaria donde existe suficiente alimento, excedentes de mano de obra e, incluso, de recursos financieros para impulsar el proceso de urbanización e industrialización del país.

Aunque en el largo plazo dicho proceso de cambio estructural supone la convergencia de la productividad entre los sectores (Timmer y Akkus, 2008), en el corto y mediano plazo la transformación puede tener efectos negativos para la población rural (Timmer, 2009). Por ello, para promover una transformación rural inclusiva, es necesario formular e implementar políticas públicas que amplíen tanto el espectro de oportunidades planteadas para los pequeños productores rurales fruto del proceso de cambio estructural, como su capacidad para aprovechar dichas oportunidades (FIDA, 2016a). 


\section{B. La inclusión financiera como instrumento del desarrollo sostenible}

De acuerdo con la Organización de Cooperación y Desarrollo Económicos y la Red Internacional de Educación Financiera (OCDE/INFE, 2012), la inclusión financiera consiste en la promoción de un acceso asequible, oportuno y adecuado a una gama de productos y servicios financieros regulados, así como la expansión de su uso por parte de todos los segmentos de la sociedad a través de la implementación de acciones personalizadas e innovadoras que incluyan educación y conocimientos financieros con el fin de promover el bienestar, y la inclusión económica y social.

De dicha definición se desprenden cuatro dimensiones clave. La primera, relacionada con el acceso, se refiere a la disponibilidad de servicios financieros en localidades específicas (Claessens y Perotti, 2007), de modo que la falta de acceso se vincula con la ausencia de intermediarios financieros en ciertos territorios (Beck, Demirgüç-Kunt y Martínez Peria, 2008). La segunda, correspondiente al uso, se refiere al consumo de servicios financieros, por lo que es resultado tanto de la oferta como de la demanda (Claessens, 2006). Cabe subrayar que la falta de uso de servicios financieros por parte de los individuos no refleja necesariamente una falta de acceso, pues algunas personas tal vez tengan acceso a servicios financieros a precios asequibles, pero eligen no usarlos por diversos motivos.

La tercera dimensión tiene que ver con las capacidades necesarias para lograr que se satisfagan la demanda y la oferta de servicios financieros. Existe un amplio reconocimiento acerca de la importancia de fortalecer las capacidades de los usuarios para poder aprovechar los beneficios potenciales de la inclusión financiera (García y otros, 2013; Roa y otros, 2014). Sin embargo, de igual relevancia son las capacidades de los reguladores y supervisores del sector financiero para promover un entorno favorable para la inclusión financiera, así como las capacidades de los proveedores de servicios financieros para identificar las necesidades del mercado y diseñar productos adecuados (Arnold y Rhyne, 2016).

Finalmente, la cuarta dimensión está relacionada con la finalidad de la inclusión financiera. Existe una amplia literatura teórica y empírica según la cual la inclusión financiera es una herramienta con el potencial de ampliar las capacidades de los individuos para incrementar su bienestar (Barajas y otros, 2015; Beck, Demirgüç-Kunt y Levine, 2007; Claessens y Perotti, 2007; Cull, Ehrbeck y Holle, 2014; Galor y Moav, 2004; King y Levine, 1993a y 1993b; Schumpeter, 1976). Gracias a la posibilidad de acumular activos de manera segura, de apalancar los activos disponibles para realizar inversiones tanto en capital humano como en capital físico, y de gestionar los riesgos, la 
inclusión financiera de pequeños productores rurales contribuye al logro de por lo menos los siguientes Objetivos de Desarrollo Sostenible (FIDA, 2016b):

- Objetivo 1: Poner fin a la pobreza en todas sus formas y en todo el mundo mediante un perfil de consumo menos vulnerable a la ocurrencia de contingencias;

- Objetivo 2: Poner fin al hambre, lograr la seguridad alimentaria y la mejora de la nutrición y promover la agricultura sostenible mediante el incremento de la productividad de los pequeños productores;

- Objetivo 3: Garantizar una vida sana y promover el bienestar de todos a todas las edades incrementando los recursos destinados a la educación y la salud;

- Objetivo 5: Lograr la igualdad de género y empoderar a todas las mujeres y las niñas mejorando el acceso de las mujeres a los servicios financieros;

- Objetivo 8: Promover el crecimiento económico sostenido, inclusivo y sostenible, el empleo pleno y productivo y el trabajo decente para todos mejorando la asignación de los recursos disponibles de tal forma que una mayor inversión genere un mayor crecimiento económico y redunde en la creación de empleo;

- Objetivo 9: Construir infraestructuras resilientes, promover la industrialización inclusiva y sostenible y fomentar la innovación promoviendo la incorporación de pequeños productores en cadenas de valor, adoptando las mejores prácticas y el acceso a insumos especializados, $\mathrm{y}$

- Objetivo 10: Reducir la desigualdad en los países y entre ellos, incrementando el acceso de los grupos desfavorecidos y reduciendo los costos de las transferencias públicas.

Los retos que limitan la inclusión financiera de poblaciones excluidas a nivel nacional se acentúan en el ámbito rural (De Olloqui, Andrade y Herrera, 2015). Por una parte, la baja densidad poblacional, así como los deprimidos niveles de ingreso, ofrecen márgenes muy bajos para compensar los altos costos operacionales que plantea la incorporación de poblaciones excluidas, sobre todo con esquemas de negocios tradicionales. Por otra parte, las limitadas capacidades financieras de los usuarios restringen la demanda, mientras que aquellas de los proveedores de servicios financieros constriñen la oferta efectiva ante la ausencia de productos adecuados a las necesidades y condiciones de los pequeños productores rurales. A ello se suman la persistencia de incentivos perversos de no pago asociados a intervenciones de política pública de corte clientelista (Campos, 2017), la vulnerabilidad del ámbito rural a la ocurrencia de riesgos de diversa índole (Argumedo, 
2017; CEPAL/FAO/ IICA, 2015), la baja titularidad que limita los activos que pueden ser ofrecidos en garantía (Valenzuela y Cruz, 2017) y las limitaciones tanto en términos de la cobertura como de la calidad de la infraestructura disponible (Reyes Luna, 2017).

\section{Principales hallazgos}

Como se analiza en el capítulo II, en América Latina y el Caribe se ha observado un significativo avance de los indicadores de acceso a servicios financieros, que también se confirma, aunque en menor medida, para los indicadores de uso. A nivel regional, la banca comercial es el principal intermediario financiero, el principal captador de ahorro y la principal fuente de financiamiento del sector privado. Sin embargo, cabe destacar que los niveles de penetración de la banca comercial en el entorno rural son muy limitados. No obstante los avances recientes, la región en su conjunto aún se encuentra rezagada con respecto a otras regiones en desarrollo.

Un reto adicional enfrentado por la inclusión financiera es que no se observa una clara correspondencia entre la tenencia de una cuenta y la utilización de otros productos de ahorro, crédito o seguros. Esta situación sugiere que los servicios financieros ofrecidos se utilizan, sobre todo, como medio transaccional para recibir y retirar dinero. Si bien tal medio transaccional puede verse beneficiado por mejores vehículos de transmisión (celulares y corresponsales), las cuentas no parecen ser un producto vinculado a las decisiones relativas al ahorro o a los préstamos. El acotado uso de los productos y servicios financieros es más agudo entre los ciudadanos que pertenecen al $40 \%$ más pobre y entre aquellos que habitan zonas rurales.

De acuerdo con Pablo Cotler (véase el capítulo II), una estrategia de inclusión financiera debe articularse en torno a los siguientes cuatro ejes:

i) productos financieros apropiados a las características de la población de menores recursos;

ii) instituciones financieras caracterizadas por una sólida estructura de gobierno, financieramente viables e interesadas en participar en mercados desatendidos;

iii) el diseño y la diseminación de información relevante y comprensible que permita combatir la desconfianza, mejorar la toma de decisiones y desarrollar productos congruentes con las necesidades y restricciones de los potenciales usuarios, $\mathrm{y}$

iv) la construcción de un marco legal propicio para un desarrollo adecuado de la infraestructura financiera, de modo que la estrategia de inclusión financiera no atente contra la estabilidad del sistema financiero. 
Como se mencionó, los cinco países analizados se encuentran en diferentes fases del proceso de formulación e implementación de una estrategia pública integral de inclusión financiera. En Costa Rica — caso que José Antonio Vásquez Rivera, Melvin Bermúdez, Ronald Rojas y José Antonio Vásquez Castro abordan en el capítulo III—, pese a los niveles de acceso a servicios financieros relativamente favorables y la existencia de diversas iniciativas orientadas a promover la inclusión financiera, no fue hasta 2016 cuando se anunció la intención de adoptar una estrategia integral bajo el liderazgo del Banco Central de Costa Rica y el apoyo técnico de la Alianza para la Inclusión Financiera.

En el capítulo IV, Pedro Argumedo analiza la experiencia de El Salvador, donde desde 2011 el Banco Central de Reserva, con apoyo de la Alianza para la Inclusión Financiera y del Departamento del Tesoro de los Estados Unidos, ha liderado el desarrollo de una agenda sobre inclusión financiera, en la que han colaborado instituciones públicas y privadas. Como resultado, en 2015 entró en vigor la Ley para facilitar la inclusión financiera y se crearon unidades especializadas en temas de inclusión financiera tanto en el seno del Banco Central de Reserva como de la Superintendencia del Sistema Financiero. Desde 2016, el Banco Central de Reserva ha venido realizando una serie de encuestas de hogares y empresas para diagnosticar empíricamente el estado y los desafíos de la inclusión financiera.

En Honduras, cuya experiencia es examinada por Daniela Cruz, Jesús López y César Valenzuela en el capítulo V, concluyó en 2015 el proceso de formulación de la Estrategia Nacional de Inclusión Financiera. Esta estrategia parte de un diagnóstico basado en evidencia que identifica las principales causas de la exclusión, plantea componentes específicos para atender las diferentes causas, identifica los actores relevantes en el marco de una estructura de coordinación institucional liderada por la figura de un comisionado presidencial de inclusión financiera, y define metas verificables de corto y mediano plazo. No obstante, hasta principios de 2017 la estrategia aún no había sido puesta en marcha.

Tal como plantean Rolando Reyes y Cameron Daneshvar en el capítulo VI, en el caso de la República Dominicana el esfuerzo de las autoridades del Banco Central de la República Dominicana se ha concentrado en la formulación de una Estrategia Nacional de Educación Económica y Financiera, que se nutre de los hallazgos de la Encuesta de Cultura Económica y Financiera y cuyos detalles fueron dados a conocer a principios de 2017.

Finalmente, el caso de México es estudiado por Pilar Campos en el capítulo VII. Desde 2009 se han realizado esfuerzos por diagnosticar el estado de la inclusión financiera en el país y formular acciones de gobierno basadas en evidencia, a partir de una robusta institucionalidad coordinada por el Consejo Nacional de Inclusión Financiera, con el liderazgo de la 
Comisión Nacional Bancaria y de Valores a partir de 2011. Dichos esfuerzos culminaron con la adopción de la Política Nacional de Inclusión Financiera a mediados de 2016.

Un primer elemento de las cinco experiencias analizadas que cabe poner de relieve es la existencia de diferencias marcadas entre las estrategias recientes de inclusión financiera y las iniciativas previas. Entre ellas, destaca el enfoque puesto en una canasta amplia de servicios financieros orientados a atender las necesidades de los pequeños productores rurales y no solamente en la provisión de crédito para actividades primarias. Por otra parte, se busca desarrollar un entorno que incentive la provisión privada de servicios con criterios de sostenibilidad, tanto en relación con los usuarios y proveedores de los servicios financieros a nivel individual, como respecto del sistema financiero en su conjunto. Un elemento clave de las nuevas estrategias es el desarrollo y fortalecimiento de las capacidades de todos los actores involucrados.

Un segundo elemento es que existe una serie de factores comunes en el diagnóstico de los determinantes de la exclusión financiera, en general, y de los pequeños productores rurales, en particular. Estos se pueden clasificar en dos grupos: los elementos que limitan la oferta de servicios financieros y los que obstaculizan la demanda. En el primer grupo se identifican el alto costo operativo de ofrecer servicios financieros a poblaciones ubicadas en zonas de baja densidad demográfica y con niveles de ingresos relativamente acotados, así como el elevado riesgo de financiar actividades poco diversificadas que enfrentan riesgos productivos y de mercado. A estos se suma el riesgo moral que no puede ser paliado mediante garantías tradicionales debido a la baja titularidad de activos. Entre los factores que afectan la demanda, destacan las dificultades para acceder a servicios financieros a través de canales tradicionales en el ámbito rural, la escasa e inadecuada oferta de productos disponibles, así como las limitadas capacidades empresariales y financieras de los usuarios.

En tercer lugar, se identifican algunos componentes comunes en las estrategias que buscan atender los factores de exclusión, que se detallan a continuación.

Con la finalidad de reducir el costo operativo de atender a poblaciones excluidas, se han introducido cuentas de expediente simplificado, que exigen una documentación menos onerosa a cambio de una funcionalidad más acotada, así como corresponsales bancarios, por conducto de los cuales se ofrecen algunos servicios financieros.

Asimismo, con el objeto de garantizar la estabilidad sistémica, se observa un reconocimiento de la necesidad de ampliar el universo regulatorio y de adecuar su aplicación a fin de incluir a entidades que tradicionalmente 
han ofrecido servicios financieros sin estar reguladas. Es el caso de las cooperativas y los nuevos actores que brindan servicios financieros por medio de plataformas digitales, por ejemplo, empresas de telecomunicaciones que prestan dinero móvil y servicios de pago, o empresas tecnofinancieras (fintech) que proporcionan servicios financieros en línea.

De particular relevancia para la inclusión de pequeños productores rurales y con la finalidad de reducir el riesgo, en todos los países analizados se ha fortalecido la legislación que abre la posibilidad de ofrecer garantías móviles, aunque el avance en la creación de registros centralizados es heterogéneo.

Además, se observa un decidido esfuerzo por fortalecer el papel de la banca de desarrollo en la promoción de la inclusión financiera. De manera complementaria, destaca el esfuerzo de la mayoría de los países para digitalizar las transferencias y pagos públicos, lo que reduce los costos administrativos e incentiva la utilización de instrumentos financieros.

Finalmente, sobresale el amplio reconocimiento de la importancia de fortalecer las capacidades financieras de los usuarios de servicios financieros, que, sin embargo, se ha traducido en esfuerzos dispersos de efecto incierto.

\section{Las mejores prácticas}

Como se analizó, las políticas públicas y las mejores prácticas en ese ámbito pueden clasificarse según su campo de incidencia. A nivel macro, en los cinco países se reconoce que una estrategia integral de inclusión financiera requiere la articulación de políticas públicas que trasciendan la regulación y supervisión del sistema financiero, entre las que destacan las políticas monetaria, financiera, de fomento productivo, y de desarrollo rural y territorial. Ello exige diagnósticos detallados y basados en evidencia, que identifiquen los determinantes y las consecuencias de la exclusión financiera. En este sentido, sobresalen los casos de El Salvador, México y la República Dominicana, países que han instrumentado diversas encuestas especializadas para conocer el estado de la inclusión financiera de los hogares y las empresas.

Un segundo elemento clave es la necesidad de contar con un decidido liderazgo político al más alto nivel, así como con la institucionalidad relevante para garantizar la coordinación entre las diferentes entidades involucradas. Como se expuso, en los cinco países ha habido un claro liderazgo por parte de los bancos centrales de Costa Rica, El Salvador y la República Dominicana, y por parte de las autoridades supervisoras del sistema financiero de Honduras y México. Sin embargo, los mecanismos de coordinación pertinentes solo están previstos explícitamente en Honduras, por conducto del órgano ejecutor del comisionado presidencial de inclusión financiera, y en México, 
por medio del Consejo Nacional de Inclusión Financiera, el cual es el único que opera efectivamente.

Uno de los principales retos es garantizar la continuidad del esfuerzo inicial de diagnóstico, formulación e instrumentación de políticas mediante el monitoreo de los logros y el ajuste de las políticas. En este sentido, destaca la clara definición de responsabilidades y metas de la Estrategia Nacional de Inclusión Financiera en Honduras. En México ya se cuenta con una segunda ronda de la Encuesta Nacional de Inclusión Financiera, que da cuenta del progreso logrado entre 2011 y 2015 y, en principio, debería representar un insumo clave de los ajustes que necesariamente debe tener la instrumentación de la Política Nacional de Inclusión Financiera.

En lo que respecta a la regulación y la supervisión financieras, uno de los principales retos es encontrar el balance adecuado entre los objetivos de promover la inclusión financiera y garantizar la estabilidad del sistema en su conjunto. Este reto se complica por los riesgos y las oportunidades que plantea el uso de plataformas tecnológicas para ofrecer nuevos servicios financieros y nuevos canales de distribución. Aquí cabe poner de relieve los esfuerzos de El Salvador por regular la operación de dinero electrónico en el país, así como la ampliación del uso de corresponsales por parte de las entidades de ahorro y crédito popular en el caso de México.

No obstante la heterogeneidad observada en la experiencia de los cinco países estudiados, en el nivel intermedio se pueden identificar tres áreas clave. La primera es la necesidad de fortalecer el acceso de los proveedores de servicios financieros que atienden a pequeños productores rurales a componentes esenciales de infraestructura financiera, como la información de centrales de crédito, sistemas de pago, registros centralizados de garantías móviles, seguros de depósito y mecanismos de protección al consumidor. En este ámbito destaca el desarrollo del sistema de pagos al detalle SINPE Móvil en Costa Rica. En cuanto a los mecanismos de protección al consumidor, sin duda el referente regional es la Comisión Nacional para la Protección y Defensa de los Usuarios de Servicios Financieros de México.

La segunda área clave es la creación y el fortalecimiento de los servicios de desarrollo empresarial que complementan los esfuerzos orientados a fomentar la inclusión financiera, promoviendo una mayor productividad de los pequeños productores rurales. Entre dichos servicios, se incluyen los de extensión y suministro de insumos especializados, la red de telecomunicaciones, así como la infraestructura asociada a la distribución y el almacenamiento de productos, y los sistemas de información. En este campo, las zonas rurales de los países analizados presentan rezagos pronunciados, no obstante la amplia cobertura de las telecomunicaciones en Costa Rica, El Salvador y la República Dominicana. 
La tercera área crítica de las políticas públicas en el nivel intermedio está relacionada con los instrumentos de apoyo del sector público, donde existen amplias oportunidades de mejora, sobre todo con respecto a la focalización y cobertura de los instrumentos, y la coordinación entre las diferentes entidades del sector público. En este ámbito destaca el hecho de que, ante la escasa penetración de la banca comercial en el entorno rural y los múltiples retos a los que se enfrentan los sectores cooperativo y microfinanciero para satisfacer las necesidades de los pequeños productores rurales, la banca de desarrollo de los cinco países estudiados ha jugado un papel determinante en el fomento de la inclusión financiera. Ello se logra mediante una combinación de instrumentos, tanto de primer como de segundo piso, y el funcionamiento de esquemas de fondos de garantías y diversos fideicomisos especializados.

A nivel micro, el principal desafío de la política pública es fortalecer las capacidades tanto de los usuarios de servicios financieros como de los proveedores de estos servicios, en particular de aquellos que atienden primordialmente al ámbito rural. Como se mencionó, aunque existe una diversidad de iniciativas de educación financiera, estas suelen estar desarticuladas y se limitan a transmitir algunos conceptos básicos y no necesariamente a fortalecer de manera integral las capacidades de los usuarios (García y otros, 2013). En esta temática, destaca la Estrategia Nacional de Educación Económica y Financiera de la República Dominicana, que plantea el desarrollo de capacidades financieras a partir de la incorporación de los temas relevantes para el sistema educativo nacional y la formulación de un esquema de gobernanza institucional para su implementación.

Con respecto al fortalecimiento de capacidades de los proveedores de servicios financieros, sobresale el Programa de Asistencia Técnica a las Microfinanzas Rurales instrumentado en México. El Programa, operado por el Banco del Ahorro Nacional y Servicios Financieros, brinda asistencia técnica a entidades de ahorro y crédito popular para lograr la inclusión financiera de clientes rurales de zonas de alta marginación.

Una asignatura pendiente en el desarrollo de capacidades es la sensibilización de las autoridades regulatorias y supervisoras en lo concerniente al entorno de negocios enfrentado por la mayoría de las entidades financieras que atienden a pequeños productores rurales, para quienes resulta oneroso el costo de cumplir con un marco normativo que no siempre refleja el riesgo representado por este tipo de instituciones. 


\section{Bibliografía}

Argumedo, P. (2017), "Inclusión financiera de pequeños productores rurales: estudio de caso en El Salvador" (LC/MEX/W.21), Documentos de Proyectos, Ciudad de México, Comisión Económica para América Latina y el Caribe (CEPAL)/Fondo Internacional de Desarrollo Agrícola (FIDA), enero.

Arnold, J. y E. Rhyne (2016), A Change in Behavior: Innovations in Financial Capability, ACCION Internacional/JPMorgan Chase \& Co, abril.

Banco Mundial (2014), Global Financial Development Report 2014: Financial Inclusion, Washington, D.C.

(2013), Global Financial Development Report 2013: Rethinking the Role of the State in Finance, Washington, D.C.

Barajas, A. y otros (2015), "Financial Inclusion: Can It Meet Multiple Macroeconomic Goals?", Staff Discussion Notes, No 15/17, Washington, D.C., Fondo Monetario Internacional (FMI), septiembre.

Bárcena, A. y A. Prado (2016), El imperativo de la igualdad: por un desarrollo sostenible en América Latina y el Caribe, Buenos Aires, Comisión Económica para América Latina y el Caribe (CEPAL)/Siglo Veintiuno Editores, mayo.

Beck, T., A. Demirgüç-Kunt y R. Levine (2007), "Finance, inequality and the poor", Journal of Economic Growth, vol. 12, N 1, Berlín, Springer.

Beck, T., A. Demirgüç-Kunt y M. S. Martinez Peria (2008), “Banking Services for Everyone? Barriers to Bank Access and Use around the World", The World Bank Economic Review, vol. 22, No 3, Oxford, Oxford University Press.

Berdegué, J., T. Rosada y A. Bebbington (2014), "The rural transformation", International Development: Ideas, Experience, and Prospects, B. Currie-Adler y otros (eds.), Oxford, Oxford University Press.

Campos, P. (2017), "Inclusión financiera de pequeños productores rurales: estudio de caso en México"(LC/MEX/TS.2017/20), Documentos de Proyectos, Ciudad de México, Comisión Económica para América Latina y el Caribe (CEPAL)/Fondo Internacional de Desarrollo Agrícola (FIDA), en prensa.

CEPAL (Comisión Económica para América Latina y el Caribe) (2016a), Horizontes 2030: la igualdad en el centro del desarrollo sostenible (LC/G.2660/ Rev.1), Santiago, julio. (2016b), Panorama Social de América Latina 2015 (LC/G.2691-P), Santiago, octubre. (2015), Desarrollo social inclusivo. Una nueva generación de políticas para superar la pobreza y reducir la desigualdad en América Latina y el Caribe (LC.L/4056/Rev.1), Santiago, enero.

CEPAL/FAO/IICA (Comisión Económica para América Latina y el Caribe/ Organización de las Naciones Unidas para la Alimentación y la Agricultura/ Instituto Interamericano de Cooperación para la Agricultura) (2015), Perspectivas de la agricultura y del desarrollo rural en las Américas: una mirada hacia América Latina y el Caribe 2015-2016, San José.

CFI (Corporación Financiera Internacional) (2012), Innovative Agricultural SME Finance Models, Washington, D.C., Alianza Mundial para la Inclusión Financiera (GPFI)/ Corporación Financiera Internacional (CFI), noviembre.

(2011), Scaling Up Access to Finance for Agricultural SMEs. Policy Review and Recommendations, Washington, D.C., Alianza Mundial para la Inclusión Financiera (GPFI)/Corporación Financiera Internacional (CFI), octubre. 
Claessens, S. (2006), "Access to Financial Services: A Review of the Issues and Public Policy Objectives", The World Bank Research Observer, vol. 21, N² 2, Oxford, Oxford University Press, agosto.

Claessens, S. y E. Perotti, (2007), "Finance and Inequality: Channels and Evidence", Journal of Comparative Economics, vol. 35, N 4, Amsterdam, Elsevier.

Cotler, P. (2017), "La inclusión financiera en América Latina”, La inclusión financiera de pequeños productores rurales, F. Villarreal (ed.), Santiago, Comisión Económica para América Latina y el Caribe (CEPAL).

Cull, R., T. Ehrbeck y N. Holle (2014), "La inclusión financiera y el desarrollo: pruebas recientes de su impacto", Enfoques, No 92, Washington, D.C., Grupo Consultivo de Ayuda a la Población más Pobre (CGAP), abril.

De Olloqui, F., G. Andrade y D. Herrera (2015), “Inclusión financiera en América Latina y el Caribe: coyuntura actual y desafíos para los próximos años", IDB Discussion Paper, N ${ }^{\circ}$ 385, Washington, D.C., Banco Interamericano de Desarrollo (BID).

Doran, A., N. McFadyen y R. Vogel (2009), "The Missing Middle in Agricultural Finance. Relieving the Capital Constraint on Smallholder Groups and Other Agricultural SMEs", Oxfam Research Report, Oxford, Oxfam International, diciembre.

Ehrbeck, T., M. Pickens y M. Tarazi (2012), "Ecosistemas financieros inclusivos: la función de los gobiernos en la actualidad", Enfoques, N ${ }^{\circ}$ 76, Washington, D.C., Grupo Consultivo de Ayuda a la Población más Pobre (CGAP), febrero.

FIDA (Fondo Internacional de Desarrollo Agrícola) (2016a), Rural Development Report 2016. Fostering inclusive rural transformation, Roma, septiembre.

(2016b), "Rural finance: sustainable and inclusive financing for rural transformation", Roma, junio.

(2016c), "Servicios financieros inclusivos en las zonas rurales. Nota sobre la ampliación de escala", Roma, agosto.

(2015), "Getting to work: financing a new agenda for rural transformation", Roma, junio.

(2009), Financiación rural: política, Roma, agosto.

Galor, O. y O. Moav (2004), "From Physical to Human Capital Accumulation: Inequality and the Process of Development", Review of Economic Studies, vol. 71, $\mathrm{N}^{\mathrm{o}} 4$, Oxford, Oxford University Press.

García, N. y otros (2013), "La educación financiera en América Latina y el Caribe. Situación actual y perspectivas", serie Políticas Públicas y Transformación Productiva, $\mathrm{N}^{\mathrm{o}} 12$, Corporación Andina de Fomento (CAF).

Höllinger, F. (2011), Agricultural Finance. Trends, Issues and Challenges, Agencia Alemana de Cooperación Internacional (GIZ), Eschborn, julio.

King, R. y R. Levine (1993a), "Finance, entrepreneurship and growth. Theory and evidence", Journal of Monetary Economics, vol. 32, $\mathrm{N}^{\mathrm{o}} 3$, Amsterdam, Elsevier, diciembre.

(1993b), "Finance and Growth: Schumpeter Might Be Right", The Quarterly Journal of Economics, vol. 108, N³, Cambridge, MIT Press, agosto.

Kloeppinger-Todd, R. y M. Sharma (eds.) (2010), "Innovations in Rural and Agriculture Finance", 2020 Focus, $\mathrm{N}^{\mathrm{o}}$ 18, Washington, D.C., Instituto Internacional de Investigación sobre Políticas Alimentarias (IFPRI)/Banco Mundial, julio.

Naciones Unidas (2015), "Transformar nuestro mundo: la Agenda 2030 para el Desarrollo Sostenible" (A/RES/70/1), Nueva York. 
OCDE (Organización de Cooperación y Desarrollo Económicos) (2007), “Promoting Pro-Poor Growth: Policy Guidance for Donors", DAC Guidelines and Reference Series, París.

OCDE/INFE (Organización de Cooperación y Desarrollo Económicos/Red Internacional de Educación Financiera) (2012), "Principios de Alto Nivel de la OCDE/INFE sobre Estrategias Nacionales de Educación Financiera", agosto.

Reyes Luna, R. (2017), “Inclusión financiera de pequeños productores rurales: estudio de caso en la República Dominicana" (LC/MEX/W.24), Documentos de Proyectos, Ciudad de México, Comisión Económica para América Latina y el Caribe (CEPAL)/ Fondo Internacional de Desarrollo Agrícola (FIDA), enero.

Roa, M. J. y otros (2014), Educación e inclusión financieras en América Latina y el Caribe: programas de los bancos centrales y las superintendencias financieras, Ciudad de México, Centro de Estudios Monetarios Latinoamericanos (CEMLA)/Banco de la República de Colombia (BRC).

Schumpeter, J. (1976), La teoría del desenvolvimiento económico: Una investigación sobre ganancias, capital, crédito, interés y ciclo económico, Ciudad de México, Fondo de Cultura Económica (FCE).

Timmer, C. (2009), A World Without Agriculture: The Structural Transformation in Historical Perspective, Washington, D. C., AEI Press, febrero.

Timmer, C. y S. Akkus (2008), "The Structural Transformation as a Pathway out of Poverty: Analytics, Empirics and Politics", Working Paper, N 150, Washington, D.C., Center for Global Development (CGD), julio.

Valenzuela, C. y D. Cruz (2017), "Estudio de caso sobre estrategias para promover la inclusión financiera de pequeños productores rurales en Honduras" (LC/MEX/W.22), Documentos de Proyectos, Ciudad de México, Comisión Económica para América Latina y el Caribe (CEPAL)/Fondo Internacional de Desarrollo Agrícola (FIDA), enero.

Vargas Hill, R. y M. Torero (eds.) (2009), "Innovations in insuring the poor", 2020 Focus, $\mathrm{N}^{\mathrm{o}}$ 17, Washington, D.C., Instituto Internacional de Investigación sobre Políticas Alimentarias (IFPRI), diciembre.

Vásquez Rivera, J.A. y otros (2017), "Evolución reciente, situación actual y perspectivas de inclusión financiera de pequeños productores rurales en Costa Rica" (LC/MEX/W.23), Documentos de Proyectos, Ciudad de México, Comisión Económica para América Latina y el Caribe (CEPAL)/Fondo Internacional de Desarrollo Agrícola (FIDA), enero. 

Capítulo II

\section{La inclusión financiera en América Latina}

Pablo Cotler ${ }^{1}$

La capacidad financiera de los pobres se ve limitada no solo por los bajos ingresos, sino también por las características de los instrumentos a los que pueden acceder ${ }^{2}$.

\section{Introducción}

Una de las facetas que distingue a América Latina es su pronunciada desigualdad del ingreso, fruto - entre otros factores- de la concentración de la propiedad de activos productivos, la desigual calidad de los servicios educativos y la inequitativa penetración de productos financieros apropiados para la acumulación y el aseguramiento. Dichos elementos conducen a una concentración económica con ramificaciones políticas que limitan la movilidad social y convierten a la desigualdad en una característica estructural de la economía.

Varias son las causas que explican la desigualdad en el acceso a los productos que ofrece el sistema financiero. Entre las más importantes están las dificultades para alcanzar una economía de redes en comunidades de

\footnotetext{
1 Académico de tiempo completo del Departamento de Economía de la Universidad Iberoamericana, Ciudad de México. Correo electrónico: pablo.cotler@ibero.mx. El autor agradece el apoyo prestado por el Lic. Rodrigo Carrillo.

2 "The financial capacity of the poor is constrained not just by low incomes but also by the characteristics of the instruments available to them." (Collins y otros, 2009).
} 
baja densidad poblacional, las diferencias en los costos operativos medios (producto de la desigual distribución del ingreso), la existencia de productos financieros que no se ajustan a las necesidades y restricciones presupuestales de la población de bajos ingresos, la ausencia y las asimetrías de información y la desconfianza hacia las instituciones financieras, que obedece tanto a malas experiencias como a la falta información adecuada.

Debido a ello, en muchos países de América Latina vienen gestándose estrategias, tanto por parte del Estado como del sector privado, orientadas a que un mayor porcentaje de la población pueda utilizar los productos y servicios que ofrecen las instituciones financieras formales. Como afirma Soto (2015, pág. 4), "la inclusión financiera busca brindar servicios a la población tradicionalmente excluida de los servicios financieros formales, utilizando productos y servicios que se adecuen a sus necesidades y que no son necesariamente brindados por los bancos, sino también por otras instituciones como cooperativas, sociedades de ahorro y crédito. Todo ello con el propósito de que las personas mejoren su calidad de vida".

En este sentido, entre las actuales estrategias de inclusión financiera y aquellas que seguían los Gobiernos de América Latina en el pasado existen cinco grandes diferencias. Una primera diferencia radica en que el énfasis no está solo en aumentar la provisión de financiamiento, sino que se trata más bien de potenciar la oferta de una canasta de productos financieros en donde se destacan los de ahorro, los de seguros y los de financiamiento. En segundo lugar, no se trata de construir una entidad financiera del Estado que supla a las instituciones del sector privado; se trata, más bien, de generar un marco institucional que incentive la presencia de entidades bancarias y no bancarias del sector privado y el sector social que hagan posible una oferta que se ajuste a las necesidades de la población de bajos recursos. En tercer término, se busca diseñar e implementar estrategias de educación financiera que tengan un impacto en la oferta y demanda de los productos y servicios financieros. Por el lado de la oferta, dichas iniciativas deben coadyuvar a generar productos financieros apropiados para las necesidades y restricciones de las poblaciones de bajos ingresos y a producir información adecuada sobre dichos productos. Por el lado de la demanda, la estrategia de educación financiera debe dirigirse a la difusión de conocimientos, que permita que los potenciales usuarios tomen decisiones más acertadas. En cuarto lugar, se busca que la oferta de productos financieros sea rentable y pueda ofrecerse de manera permanente, para lo que es necesario construir un marco que promueva la competencia y la innovación tecnológica. Tanto la tercera como la cuarta estrategia son necesarias, además, para lograr reducir la desconfianza que amplios sectores de la población tienen sobre muchas de las entidades financieras existentes y que se constituye en una barrera que impide una mayor inclusión. Como quinto punto, la estrategia de inclusión financiera no debe constituirse en una amenaza a la estabilidad 
financiera. Se trata pues de una estrategia que, teniendo un riesgo acotado, busca ser una herramienta para reducir las vulnerabilidades de los sectores poblacionales más pobres y permite construir una economía más incluyente.

En este capítulo se contextualiza la necesidad de alcanzar una mayor inclusión y se busca describir qué características generales debe adoptar una estrategia para alcanzar dicho objetivo y cuáles son sus efectos previsibles. Con ese objeto, el resto del capítulo está dividido en cuatro secciones. Considerando la existencia de una importante oferta de productos que se contratan de manera informal, en la sección A se apunta a entender por qué una estrategia de inclusión es, en primera instancia, una estrategia de formalización. En la sección B se hace una descripción del estado actual del acceso y uso de los servicios financieros formales en distintos países de América Latina. Una vez expuesta la situación actual, en la sección C se revisa la literatura económica para contextualizar los beneficios esperados de una mayor inclusión financiera por parte de la población más pobre. Por último, en la sección D se analiza cuál ha sido la estrategia gubernamental más seguida para ampliar la inclusión financiera y se presentan sus objetivos, sus fortalezas y los posibles espacios de mejora en los diseños.

\section{A. La inclusión como una estrategia de formalización}

Una de las principales características de la vida es la incertidumbre económica. No se sabe cuándo se enfrentará una reducción de los ingresos, cuándo surgirá una oportunidad para aumentarlos ni cuándo se incurrirá en gastos inesperados. En caso de que dichos imprevistos no puedan ser atendidos, es muy probable que la persona y su entorno familiar sufran una pérdida de bienestar. Para tratar de minimizar esa pérdida, se recurre a los servicios financieros que ofrecen instituciones y particulares (Collins y otros, 2009; Banerjee y Duflo, 2007; Rutherford, 2000).

Con ese propósito, se establecen arreglos contractuales tanto de manera formal como informal. El ofrecimiento de particulares de resguardar ahorros, la participación en mecanismos de reciprocidad como las tandas y los préstamos que ofrecen personas físicas son ejemplos de transacciones hechas bajo arreglos contractuales de carácter informal, pues carecen de un marco regulatorio que las rija y que proteja a las contrapartes de abusos de orden financiero. En el caso de los oferentes institucionales existen arreglos contractuales hechos bajo marcos formales e informales. Así, hay instituciones financieras que están autorizadas a ofrecer productos de ahorro, crédito o seguros, otras que, a pesar de solo estar facultadas para ofrecer financiamiento, también ofrecen productos de ahorro, y otras más que operan aun cuando no cumplen con lo establecido en el marco regulatorio correspondiente. Por otra parte, hay instituciones no financieras que, si bien están legalmente 
constituidas, ofrecen productos financieros que carecen de un marco regulatorio expedido por una autoridad financiera. Ejemplos de ello pueden ser la captación de ahorro por parte de organizaciones de la sociedad civil o el crédito de proveedores. Sobre esto último, véase Cotler (2015).

Para el caso de América Latina, el Banco Mundial (2015a) informa que, aun cuando el $40 \%$ de la población ahorraba, solo el 13\% lo hacía en una institución financiera. En lo que se refiere a préstamos, el 32\% de la población pidió prestado, pero solo el $11 \%$ solicitó un préstamo a una institución financiera. En lo que se refiere a transferencias entre privados - donde se destacan las remesas-, López-Moctezuma (2013) estima que en México solo el $40 \%$ de las transferencias se hacían a través de intermediarios formales. Bajo el supuesto implícito de que el uso de productos financieros adquiridos de manera informal genera un bienestar inferior, la estrategia de inclusión financiera es, en primera instancia, una estrategia que persigue un mayor nivel de bienestar ${ }^{3}$.

Ahora bien, para que los productos de ahorro que se ofrecen de manera formal sean atractivos, en particular para los usuarios de servicios financieros informales, se requiere, en primer lugar, contar con la confianza de los ahorristas y, en segundo lugar, que los productos sean lo suficientemente líquidos y rentables. Al ser el ahorro un bien preciado, un rasgo esencial que determinará dónde colocarlo es la confianza. En este sentido, en las zonas donde los pobladores han interactuado muy poco con instituciones financieras formales, la existencia de un órgano gubernamental que supervise dichas instituciones no es algo que facilite mucho la inclusión financiera. Esto significa que la formalidad de las instituciones no mitiga la percepción del riesgo, sobre todo cuando esta se basa en el desconocimiento de sus reglas de operación. En este sentido, la complejidad institucional lleva como reto la diseminación de información que sea relevante y factible de ser entendida. Además de la información, la desconfianza se reduce cuando se da una cierta reciprocidad de estas instituciones en su convivencia en las comunidades ${ }^{4}$.

Respecto de la liquidez, vale la pena considerar que en muchos países los cajeros automáticos tienen dos características que reducen la liquidez de los depósitos: la existencia de un monto mínimo de retiro y los múltiplos de dicho monto. En el caso de México, por ejemplo, esto hace que las personas que ganan un salario mínimo no puedan retirar todo su dinero a través de este canal ni obtener fracciones de dicho dinero en caso de haber ahorrado.

Esto es consistente con el supuesto de que el uso de transacciones financieras informales debe obedecer a problemas de acceso, a la falta de información adecuada o a una inadecuada educación financiera.

4 En cierta manera, esto es similar al proceso de adopción de nuevas tecnologías en zonas rurales. Aun cuando un nuevo proceso productivo o una nueva maquinaria cuente con todos los avales oficiales, su adopción en zonas rurales dependerá de cuál haya sido la experiencia de los líderes comunitarios con la nueva tecnología. 
En lo que respecta al financiamiento, las poblaciones de escasos recursos pueden contar con acceso a préstamos que los prestamistas informales y las casas de empeño ofrecen por montos pequeños y por un corto plazo (Bazán Levy y Saraví, 2012). Asimismo, pueden recurrir a los préstamos de amigos y familiares que, si bien pueden no cobrar una tasa explícita de interés, pueden exigir condiciones que implican un costo para el deudor. Algo similar ocurre muchas veces en el caso del financiamiento que ofrecen los proveedores: no se cobran intereses explícitos, pero puede existir la exigencia de aceptar prácticas anticompetitivas (por ejemplo, coaccionando al receptor del crédito para que no utilice o comercialice productos de la competencia).

Para que se prefiera el financiamiento formal antes que el informal es necesario que se cumplan algunas de las siguientes condiciones: i) que la documentación exigida guarde correspondencia con las características del entorno socioeconómico; ii) que los procesos de decisión sean rápidos; iii) que las condiciones del financiamiento - en particular, monto, tasa, plazo y periodicidad de pago- sean convenientes, y iv) que exista certeza de que la oferta de financiamiento proveniente del sector formal sea perdurable en el tiempo (que haya ganancias de bienestar derivadas de una buena reputación crediticia). No hay duda de que estas condiciones son más fáciles de cumplir cuando los oferentes del financiamiento están institucionalmente desarrollados, pues tendrán una mayor capacidad para ofrecer productos adecuados a las características de la población, alcanzar economías de escala y organización, y lograr una mayor diversificación del riesgo crediticio.

Si se piensa en las ventajas y desventajas de los servicios financieros informales, no debería sorprender que haya personas y negocios que utilicen tanto los servicios financieros formales como los informales (CAF, 2011; Dabla-Norris y otros, 2015a; Fang, Ke y Zhou, 2015). Más aún, hay estrategias que se caracterizan por utilizar productos financieros de ambos mercados y situaciones en las que se entra y sale de uno u otro mercado (Cotler y RodríguezOreggia, 2010). En este contexto, la estrategia de inclusión financiera permite elevar el acceso a nuevas canastas de productos financieros. Sin embargo, la decisión de qué tipo de producto financiero se utilizará dependerá de las preferencias y restricciones de los individuos que se busca incluir, de las características de los productos que se ofrecen, de la información que tengan los potenciales usuarios y de la educación financiera que posean para procesar dicha información.

Ante ello, la estrategia de inclusión financiera debe centrarse en desarrollar: a) productos financieros que se ajusten a las características de la población de menos recursos; b) instituciones financieras caracterizadas por contar con una sólida estructura de gobierno, financieramente viables e interesadas en participar en mercados desatendidos; c) el diseño y la difusión de información relevante y comprensible que permita combatir 
la desconfianza, mejorar la toma de decisiones y generar productos que se adecuen a las necesidades y restricciones de los potenciales usuarios, y d) la construcción de un marco legal que sea propicio para un desarrollo adecuado de la infraestructura financiera, de modo que la estrategia de inclusión financiera no atente contra la estabilidad del sistema financiero.

\section{B. Situación actual}

En América Latina, los bancos comerciales son los principales intermediarios financieros, pues captan una importante fracción del ahorro voluntario y son los principales oferentes de financiamiento al sector privado ${ }^{5}$. Considerando que tanto el nivel de depósitos como de préstamos tiende a ser mayor conforme mayor es la riqueza y el nivel de desarrollo económico, ambos indicadores se expresan como porcentaje del PIB per cápita a paridad del poder adquisitivo (PPA) ${ }^{6}$.

Aunque en principio es de esperarse que cuanto mayor sea el PIB per cápita, mayor será el uso de los productos y servicios financieros, en los gráficos II.1 y II.2 se observa que no hay una clara correspondencia entre el valor de los depósitos o de la cartera crediticia como porcentaje del PIB y el nivel de desarrollo económico. Si se considera la distribución sumamente desigual del ingreso que existe en la gran mayoría de los países latinoamericanos, una visión macroeconómica es insuficiente para conocer cuánto participa la población en el mercado financiero, qué rasgos tiene la población que participa, qué trabas pueden limitar el acceso y qué determina el uso de los distintos productos ${ }^{7}$. En parte es por ello que para complementar la información provista por medidas de profundidad financiera se utilizan indicadores que dan cuenta de la inclusión financiera ${ }^{8}$.

Al considerar únicamente el ahorro voluntario, se deja de lado el ahorro forzoso al que están sujetos los trabajadores formales para financiar la jubilación. Si bien en muchos países de América Latina existe una bolsa de valores, la participación ciudadana - a diferencia de lo que acontece por ejemplo en los Estados Unidos- es ínfima, por lo que también se deja de lado. Por último, si bien hay muchas entidades financieras no bancarias que captan el ahorro y prestan, su participación en el mercado continúa siendo muy pequeña en casi todos los casos.

6 Si bien comparar acervos con flujos quizás no sea lo mejor, es una estandarización muy utilizada en la literatura.

7 Según cifras del Banco Mundial, el 20\% más rico de América Latina detentaba, en promedio, el $55 \%$ del consumo. Para países como Alemania, los Estados Unidos, Francia y el Reino Unido, dicha cifra era, en promedio, del 41\% (véase Banco Mundial [en línea] http://data.worldbank. org/indicator).

8 El concepto de profundidad financiera busca medir el valor de agregados financieros con respecto a algún indicador de actividad económica, como se describe en los gráficos II.1 y II.2. Aun cuando la profundidad en una zona geográfica puede ser grande, ello no refleja cuánto usa la población de esa zona los productos y servicios financieros. 


\section{Gráfico Il.1}

América Latina y el Caribe: depósitos en bancos comerciales, 2014 (En porcentajes del PIB per cápita)

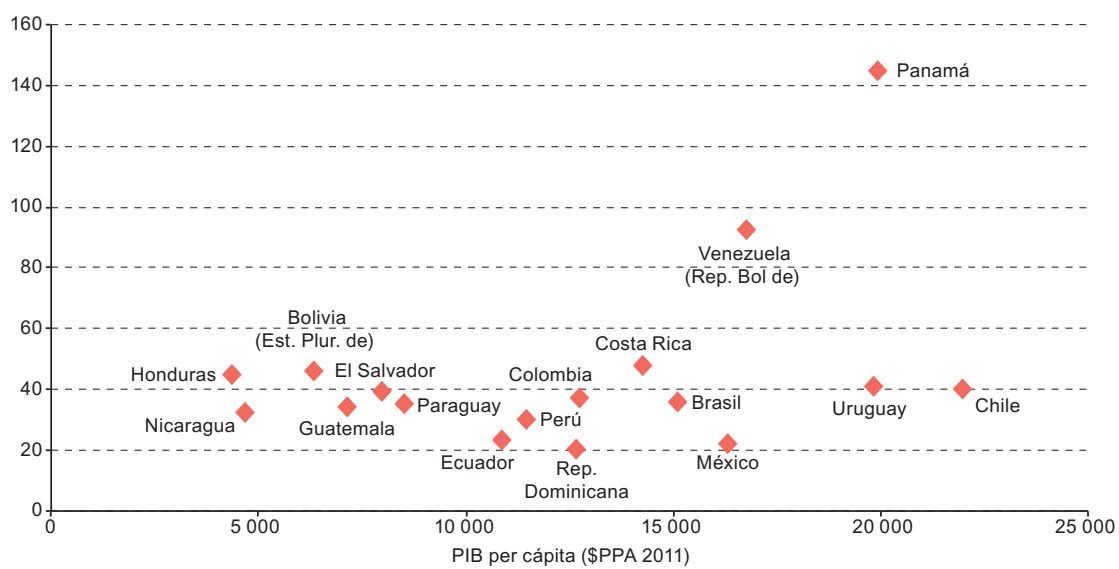

Fuente: Elaboración propia, sobre la base de Banco Mundial, World Development Indicators, 2015 [base de datos en línea] http://data.worldbank.org/data-catalog/world-development-indicators y Fondo Monetario Internacional (FMI), 2015.

Nota: Los datos de "depósitos en bancos comerciales" para El Salvador y el Paraguay corresponden a 2013.

\section{Gráfico Il.2}

América Latina y el Caribe: cartera de crédito de la banca comercial, 2014 (En porcentajes del PIB per cápita)

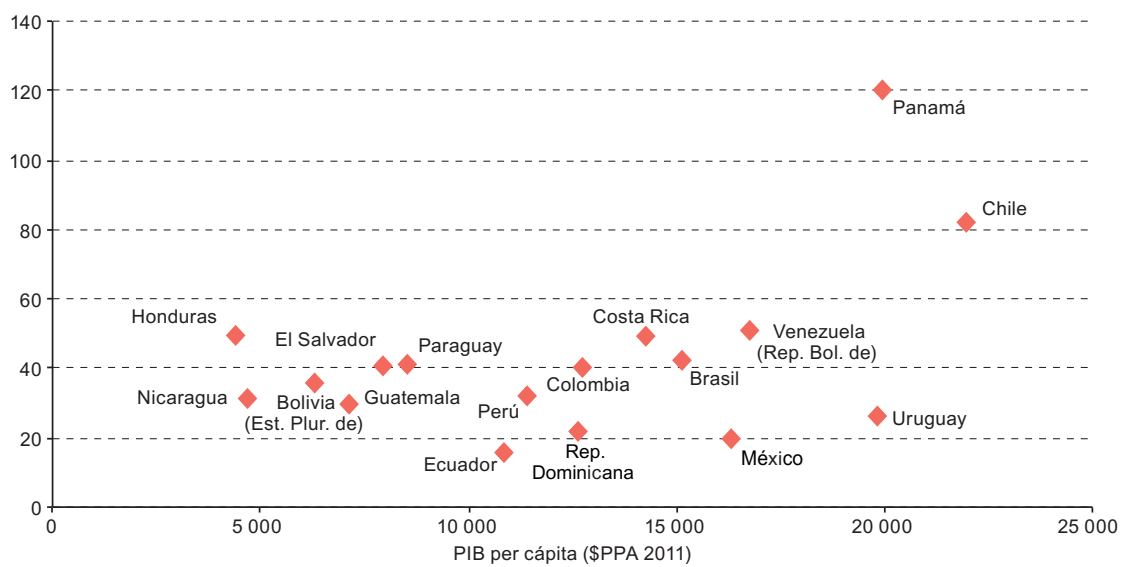

Fuente: Elaboración propia, sobre la base de Banco Mundial, World Development Indicators, 2015 [base de datos en línea] http://data.worldbank.org/data-catalog/world-development-indicators y Fondo Monetario Internacional (FMI), 2015.

Nota: El dato de "cartera de crédito" para El Salvador corresponde a 2013. 
Para entender la participación de la población en el sector financiero formal es necesario analizar en primer lugar el grado de acceso a los canales de distribución de los productos financieros. En el cuadro II.1 se muestra el grado de acceso a las tres principales formas de interacción con los oferentes de los servicios financieros formales: las oficinas o sucursales bancarias, los cajeros automáticos e Internet. Una primera mirada a los datos del cuadro II.1 da cuenta de la gran heterogeneidad que existe entre los países de América Latina, donde, por ejemplo, el número de sucursales por cada 100.000 adultos va de 253 en Colombia a solo 7 en Nicaragua. El contraste del valor de esta variable a nivel nacional con el de la ciudad más grande de cada país mide el grado de descentralización, donde también se observa una importante heterogeneidad. En este sentido, el número agregado de sucursales no necesariamente refleja el grado de acceso que existe en un país.

Los avances tecnológicos y los cambios regulatorios han permitido que las instituciones financieras busquen apoyarse cada vez más en el uso de cajeros automáticos y en las transacciones electrónicas para ofrecer sus servicios. A este respecto, todos los países latinoamericanos quedan muy por debajo de los países europeos. Mientras que en Francia e Italia existen más de 100 cajeros por $\mathrm{km} 2$, el promedio ponderado de los países latinoamericanos considerados en el cuadro II.1 es de apenas 20. Tal disparidad puede ser la causa de que algunos países latinoamericanos tengan un número de sucursales per cápita que supera con creces a los registrados en Alemania y Francia, que tienen 14 y 38 sucursales por cada 100.000 adultos, respectivamente. En este sentido, el indicador apropiado para medir el acceso no es una variable estática en el tiempo, pues depende del grado de desarrollo de la economía. En lo que se refiere a usuarios de Internet, los datos dan cuenta de la existencia de una correlación muy alta $(0,87)$ entre el uso de Internet y el ingreso per cápita del país, por lo que podría intuirse que una mayor oferta de acceso a productos financieros por vía electrónica no tendría necesariamente un gran impacto en el aumento de la inclusión financiera de sectores poblacionales de bajos ingresos.

El uso de servicios financieros formales depende de las posibilidades de acceso a dichos servicios y del interés que puedan concitar. Con el fin de evaluar cuánto se usan los productos y servicios que ofrecen las instituciones financieras formales, en el cuadro II.2 se muestra que no hay una clara correspondencia entre la posesión de una cuenta y la utilización de productos para ahorrar y pedir prestado. Parecería que los servicios financieros que ofrece la banca en muchos casos se utilizan como medio transaccional: se posee una cuenta para recibir y retirar dinero. Si bien ese medio transaccional se puede ver beneficiado por la disponibilidad de mejores vehículos de transmisión (celulares y corresponsales), las cuentas no parecen ser un producto que se asocie con las decisiones de ahorro y préstamo. 


\section{Cuadro II.1}

\section{América Latina y el Caribe: indicadores de acceso a los canales de distribución de los productos financieros}

\begin{tabular}{|c|c|c|c|c|c|c|}
\hline & $\begin{array}{c}\text { Sucursales } \\
\text { bancarias, } \\
2014 \\
\text { (por cada } \\
100000 \\
\text { adultos) }\end{array}$ & $\begin{array}{c}\text { Cajeros } \\
\text { automáticos, } \\
2014 \\
(\text { por cada } \\
\left.1000 \mathrm{~km}^{2}\right)\end{array}$ & $\begin{array}{l}\text { Población en } \\
\text { la ciudad más } \\
\text { grande, } 2015 \\
\text { (en porcentajes } \\
\text { de la población } \\
\text { total) }\end{array}$ & $\begin{array}{c}\text { Sucursales } \\
\text { de bancos } \\
\text { comerciales en } \\
\text { la ciudad más } \\
\text { grande, } 2015 \\
\text { (en porcentajes } \\
\text { del total } \\
\text { nacional) }\end{array}$ & $\begin{array}{l}\text { Sucursales } \\
\text { bancarias, } \\
2015 \\
\text { (por cada } \\
100000 \\
\text { habitantes } \\
\text { en la ciudad } \\
\text { más grande) }\end{array}$ & $\begin{array}{c}\text { Usuarios } \\
\text { de } \\
\text { Internet, } \\
2014 \\
\text { (por } \\
\text { cada 100 } \\
\text { personas) }\end{array}$ \\
\hline Argentina & 13,2 & 6,9 & 35,0 & n.d. & n.d. & 64,7 \\
\hline $\begin{array}{l}\text { Bolivia (Estado } \\
\text { Plurinacional de) }\end{array}$ & 15,1 & 2,3 & 19,6 & 14,8 & 7,6 & 39,0 \\
\hline Brasil & 46,3 & 23,9 & 10,1 & 8,3 & 9,0 & 57,6 \\
\hline Chile & 16,7 & 10,7 & 36,3 & 48,9 & 16,7 & 72,4 \\
\hline Colombia & 253,2 & 13,0 & 20,2 & 49,3 & 30,8 & 52,6 \\
\hline Costa Rica & 22,3 & 57,3 & 24,3 & 60,8 & 10,3 & 49,4 \\
\hline Ecuador & 77,2 & 18,0 & 16,8 & 27,4 & 11,1 & 43,0 \\
\hline El Salvador & 11,8 & 72,1 & 17,9 & n.d. & n.d. & 29,7 \\
\hline Guatemala & 34,5 & 31,8 & 17,9 & 34,4 & 41,1 & 23,4 \\
\hline Honduras & 23,3 & 11,9 & 13,9 & 25,9 & 72,2 & 19,1 \\
\hline México & 14,8 & 22,5 & 16,5 & 18,4 & 18,4 & 44,4 \\
\hline Nicaragua & 7,6 & 4,0 & 15,7 & 42,4 & 16,7 & 17,6 \\
\hline Panamá & 23,0 & 23,2 & 42,6 & 69,2 & 24,7 & 44,9 \\
\hline Paraguay & 10,8 & 2,8 & 35,5 & 37,5 & 9,0 & 43,0 \\
\hline Perú & 8,0 & 9,6 & 31,5 & 52,4 & 11,4 & 40,2 \\
\hline $\begin{array}{l}\text { República } \\
\text { Dominicana }\end{array}$ & 11,6 & 51,0 & 28,0 & 42,1 & 19,4 & 49,6 \\
\hline Uruguay & 12,2 & 8,0 & 49,7 & 33,3 & 18,4 & 61,5 \\
\hline $\begin{array}{l}\text { Venezuela } \\
\text { (República } \\
\text { Bolivariana de) }\end{array}$ & 16,6 & 11,0 & 9,4 & 25,8 & 31,2 & 57,0 \\
\hline
\end{tabular}

Fuente: Elaboración propia, sobre la base de Fondo Monetario Internacional (FMI), 2015, Banco Mundial, World Development Indicators, 2015 [base de datos en línea] http://data.worldbank.org/datacatalog/world-development-indicators, y datos de los bancos centrales, superintendencias y comisiones bancarias de los países.

Nota: Los datos de "sucursales de bancos comerciales en la ciudad más grande, 2015 (en porcentajes del total nacional)" y "sucursales bancarias, 2015 (por cada 100000 habitantes en la ciudad más grande)" son a septiembre de 2015, excepto en los casos de Chile (agosto de 2015), el Ecuador (marzo de 2014), Honduras (2014), Nicaragua (2014), Panamá (diciembre de 2015) y Venezuela (República Bolivariana de) (enero de 2016). En Honduras, además de sucursales bancarias se incluyen ventanillas, corresponsales y otros puntos de servicio. La expresión "ciudad más grande" se refiere al tamaño de una aglomeración en términos poblacionales. Los datos de sucursales son para áreas metropolitanas a excepción del Brasil (no se especifica), Costa Rica y Panamá (provincias) y Honduras (departamento). 
Cuadro II.2

América Latina y el Caribe: uso de productos financieros de los hogares, 2014

(En porcentajes)

\begin{tabular}{|c|c|c|c|c|c|c|c|}
\hline & $\begin{array}{c}\text { Índice de } \\
\text { inclusión } \\
\text { global }\end{array}$ & $\begin{array}{l}\text { Cajero } \\
\text { automático } \\
\text { como } \\
\text { principal } \\
\text { medio de } \\
\text { retiro }\end{array}$ & $\begin{array}{l}\text { Cuenta } \\
\text { en una } \\
\text { institución } \\
\text { financiera }\end{array}$ & $\begin{array}{l}\text { Tarjeta de } \\
\text { débito }\end{array}$ & $\begin{array}{c}\text { Ahorro } \\
\text { en una } \\
\text { institución } \\
\text { financiera }\end{array}$ & $\begin{array}{l}\text { Crédito } \\
\text { de una } \\
\text { institución } \\
\text { financiera }\end{array}$ & $\begin{array}{l}\text { Tarjeta } \\
\text { de } \\
\text { crédito }\end{array}$ \\
\hline Argentina & 35,2 & 78,0 & 50,2 & 44,2 & 4,1 & 8,3 & 26,6 \\
\hline $\begin{array}{l}\text { Bolivia (Estado } \\
\text { Plurinacional de) }\end{array}$ & 25,6 & 40,3 & 40,7 & 23,1 & 23,5 & 19,7 & 6,2 \\
\hline Brasil & 43,2 & 75,4 & 68,1 & 59,2 & 12,3 & 11,9 & 32,0 \\
\hline Chile & 42,8 & 80,8 & 63,2 & 54,1 & 15,0 & 15,6 & 28,1 \\
\hline Colombia & 31,8 & 80,9 & 38,4 & 30,0 & 12,3 & 15,6 & 13,7 \\
\hline Costa Rica & 42,1 & 83,2 & 64,6 & 53,6 & 24,2 & 12,7 & 14,5 \\
\hline Ecuador & 25,3 & 46,5 & 46,2 & 25,6 & 14,3 & 13,4 & 5,7 \\
\hline EI Salvador & 27,2 & 66,5 & 34,6 & 21,8 & 14,0 & 18,2 & 8,0 \\
\hline Guatemala & 22,1 & 36,9 & 40,8 & 16,2 & 15,2 & 17,2 & 6,3 \\
\hline Honduras & 16,8 & 23,7 & 30,0 & 14,2 & 14,5 & 12,3 & 6,1 \\
\hline México & 29,5 & 69,1 & 38,7 & 26,8 & 14,5 & 9,7 & 17,8 \\
\hline Nicaragua & 19,0 & 57,9 & 18,9 & 11,3 & 8,1 & 14,3 & 3,5 \\
\hline Panamá & 28,8 & 63,5 & 43,4 & 25,3 & 20,4 & 10,4 & 9,8 \\
\hline Perú & 22,9 & 51,8 & 29,0 & 21,4 & 12,3 & 11,2 & 11,7 \\
\hline $\begin{array}{l}\text { República } \\
\text { Dominicana }\end{array}$ & 27,5 & 39,5 & 54,0 & 22,6 & 26,5 & 11,8 & 10,9 \\
\hline Uruguay & 40,2 & 84,9 & 45,4 & 37,7 & 12,5 & 21,0 & 39,8 \\
\hline $\begin{array}{l}\text { Venezuela } \\
\text { (República } \\
\text { Bolivariana de) }\end{array}$ & 38,6 & 78,9 & 56,9 & 49,6 & 22,8 & 2,0 & 21,5 \\
\hline $\begin{array}{l}\text { América Latina } \\
\text { y el Caribe }\end{array}$ & 34,8 & 71,1 & 51,1 & 40,4 & 13,5 & 11,3 & 21,6 \\
\hline
\end{tabular}

Fuente: Elaboración propia, sobre la base de Banco Mundial, Base de datos Global Findex, 2014 [en línea] http://datatopics.worldbank.org/financialinclusion.

Nota: El índice de inclusión global se obtiene como promedio simple de las siguientes variables: porcentaje de población mayor de 15 años que tiene cuenta en una institución financiera formal, que utiliza el cajero automático como principal medio de retiro, que tiene tarjeta de débito, que tuvo un préstamo de una institución financiera el año anterior, que tuvo dinero ahorrado en una institución financiera el año anterior y que posee una tarjeta de crédito. Se omitió al Paraguay porque no hay datos disponibles.

Ante la dificultad de utilizar una sola variable para medir el grado de inclusión, se propone un índice que refleje el uso global de los distintos tipos de productos y servicios financieros formales. Dicho índice de inclusión global se construye a partir de un promedio simple de las seis variables que se muestran en el cuadro II.2 (Martínez Pería, 2014; DablaNorris y otros, 2015a). Los resultados indican que los países más pobres (Honduras y Nicaragua) son los que tienen una menor inclusión global. 
Tomando en cuenta la distribución muy desigual del ingreso en América Latina, en el cuadro II.3 se desagregan los datos del cuadro II.2 con el fin de evaluar la situación del $40 \%$ más pobre de cada país, mientras que en el cuadro II.4 se desagregan los datos para la población que habita en zonas rurales. Los resultados indican que las cuentas en instituciones financieras son menos utilizadas entre la población más pobre y la que vive en zonas rurales. Si bien las cuentas en dichas instituciones son medios importantes para captar el ingreso percibido por el trabajo o por las transferencias, la evidencia indica que la población no las considera un instrumento útil en la gestión de sus recursos.

\section{Cuadro Il.3}

América Latina y el Caribe: uso de productos financieros por parte del $40 \%$ de los hogares más pobres, 2014

(En porcentajes)

\begin{tabular}{|c|c|c|c|c|c|c|}
\hline & $\begin{array}{l}\text { Índice de } \\
\text { inclusión } \\
\text { global }\end{array}$ & $\begin{array}{c}\text { Cuenta } \\
\text { en una } \\
\text { institución } \\
\text { financiera }\end{array}$ & $\begin{array}{l}\text { Tarjeta } \\
\text { de débito }\end{array}$ & $\begin{array}{c}\text { Ahorro } \\
\text { en una } \\
\text { institución } \\
\text { financiera }\end{array}$ & $\begin{array}{c}\text { Crédito } \\
\text { de una } \\
\text { institución } \\
\text { financiera }\end{array}$ & $\begin{array}{c}\text { Tarjeta } \\
\text { de crédito }\end{array}$ \\
\hline Argentina & 20,4 & 44,4 & 36,6 & 1,1 & 4,6 & 15,4 \\
\hline $\begin{array}{l}\text { Bolivia (Estado } \\
\text { Plurinacional de) }\end{array}$ & 12,4 & 25,6 & 11,7 & 11,3 & 10,5 & 2,7 \\
\hline Brasil & 26,8 & 58,5 & 42,9 & 5,7 & 7,5 & 19,6 \\
\hline Chile & 29,2 & 56,4 & 45,2 & 10,3 & 13,1 & 20,9 \\
\hline Colombia & 11,1 & 23,4 & 14,7 & 5,7 & 6,4 & 5,2 \\
\hline Costa Rica & 29,3 & 61,3 & 46,8 & 16,1 & 9,7 & 12,8 \\
\hline Ecuador & 13,7 & 32,4 & 13,7 & 9,1 & 12,1 & 1,4 \\
\hline EI Salvador & 10,5 & 21,6 & 11,1 & 4,1 & 13,5 & 2,3 \\
\hline Guatemala & 9,7 & 26,7 & 4,6 & 7,0 & 7,2 & 3,3 \\
\hline Honduras & 7,5 & 18,4 & 5,2 & 6,6 & 5,9 & 1,3 \\
\hline México & 13,3 & 28,6 & 15,3 & 7,0 & 6,5 & 9,1 \\
\hline Nicaragua & 5,4 & 8,3 & 5,5 & 2,9 & 9,3 & 1,1 \\
\hline Panamá & 15,1 & 32,1 & 15,8 & 14,8 & 8,8 & 4,1 \\
\hline Perú & 9,6 & 18,4 & 11,2 & 5,8 & 7,4 & 5,3 \\
\hline República Dominicana & 17,7 & 41,8 & 11,9 & 16,0 & 13,7 & 5,2 \\
\hline Uruguay & 22,1 & 35,0 & 25,8 & 5,3 & 19,0 & 25,4 \\
\hline $\begin{array}{l}\text { Venezuela (República } \\
\text { Bolivariana de) }\end{array}$ & n.d. & 48,0 & 39,6 & 18,8 & n.d. & 13,7 \\
\hline $\begin{array}{l}\text { América Latina } \\
\text { y el Caribe }\end{array}$ & 18,9 & 40,9 & 27,6 & 6,9 & 6,9 & 12,3 \\
\hline
\end{tabular}

Fuente: Elaboración propia, sobre la base de Banco Mundial, Base de datos Global Findex, 2014 [en línea] http://datatopics.worldbank.org/financialinclusion.

Nota: Se omitió al Paraguay porque no hay datos disponibles. 
Cuadro II.4

América Latina y el Caribe: uso de productos financieros por parte de la población rural, 2014

(En porcentajes)

\begin{tabular}{|c|c|c|c|c|c|c|}
\hline & $\begin{array}{l}\text { Índice de } \\
\text { inclusión } \\
\text { global }\end{array}$ & $\begin{array}{c}\text { Cuenta } \\
\text { en una } \\
\text { institución } \\
\text { financiera }\end{array}$ & $\begin{array}{l}\text { Tarjeta } \\
\text { de débito }\end{array}$ & $\begin{array}{c}\text { Ahorro } \\
\text { en una } \\
\text { institución } \\
\text { financiera }\end{array}$ & $\begin{array}{c}\text { Crédito } \\
\text { de una } \\
\text { institución } \\
\text { financiera }\end{array}$ & $\begin{array}{c}\text { Tarjeta } \\
\text { de crédito }\end{array}$ \\
\hline Argentina & 21,2 & 38,1 & 33,9 & 3,6 & 8,5 & 21,7 \\
\hline $\begin{array}{l}\text { Bolivia (Estado } \\
\text { Plurinacional de) }\end{array}$ & 11,7 & 20,8 & 6,3 & 14,2 & 14,6 & 2,4 \\
\hline Brasil & 25,4 & 54,1 & 33,0 & 9,4 & 10,1 & 20,3 \\
\hline Chile & 18,1 & 37,1 & 18,8 & 13,4 & 6,8 & 14,4 \\
\hline Colombia & 13,9 & 26,9 & 15,3 & 8,5 & 12,6 & 6,3 \\
\hline Costa Rica & 27,5 & 51,4 & 45,2 & 18,2 & 11,6 & 11,3 \\
\hline Ecuador & 15,4 & 35,3 & 13,0 & 13,7 & 9,2 & 5,8 \\
\hline El Salvador & 7,9 & 12,1 & 8,8 & 9,9 & 3,8 & 5,1 \\
\hline Guatemala & 11,5 & 20,4 & 9,2 & 9,8 & 13,3 & 4,9 \\
\hline Honduras & 7,6 & 16,2 & 7,7 & 5,9 & 5,5 & 2,9 \\
\hline México & 8,4 & 13,6 & 10,9 & 4,8 & 6,2 & 6,3 \\
\hline Nicaragua & 5,5 & 10,3 & 4,3 & 4,9 & 6,4 & 1,7 \\
\hline Panamá & 12,6 & 22,7 & 8,2 & 14,2 & 9,8 & 8,2 \\
\hline Paraguay & 7,5 & 13,3 & 5,1 & 5,7 & 10,5 & 3,0 \\
\hline Perú & 9,9 & 14,3 & 9,8 & 7,1 & 13,2 & 4,8 \\
\hline República Dominicana & 12,8 & 29,6 & 12,2 & 3,8 & 13,5 & 5,0 \\
\hline Uruguay & 16,0 & 21,0 & 14,4 & 5,3 & 15,4 & 24,0 \\
\hline $\begin{array}{l}\text { Venezuela (República } \\
\text { Bolivariana de) }\end{array}$ & 18,8 & 41,4 & 34,2 & 10,6 & 1,6 & 6,1 \\
\hline $\begin{array}{l}\text { América Latina } \\
\text { y el Caribe }\end{array}$ & 17,4 & 35,0 & 22,2 & 8,5 & 9,2 & 12,2 \\
\hline
\end{tabular}

Fuente: Elaboración propia, sobre la base de Banco Mundial, Base de datos Global Findex, 2014 [en línea] http://datatopics.worldbank.org/financialinclusion.

Sobre la base de los datos de los cuadros II.2, II.3 y II.4 es posible comparar para cada país el índice de inclusión global, el índice para la población de menores ingresos y el índice de los habitantes de las zonas rurales. Como se muestra en el gráfico II.3, el bajo uso de los productos y servicios financieros es más agudo entre los ciudadanos que pertenecen al $40 \%$ más pobre y entre quienes habitan en zonas rurales. En este sentido, la estrategia de inclusión financiera debería estar centrada de manera prioritaria en las poblaciones de bajos ingresos y sobre todo en quienes habitan en zonas rurales. 
Gráfico II.3

América Latina: índice de inclusión financiera para tres poblaciones distintas, 2014

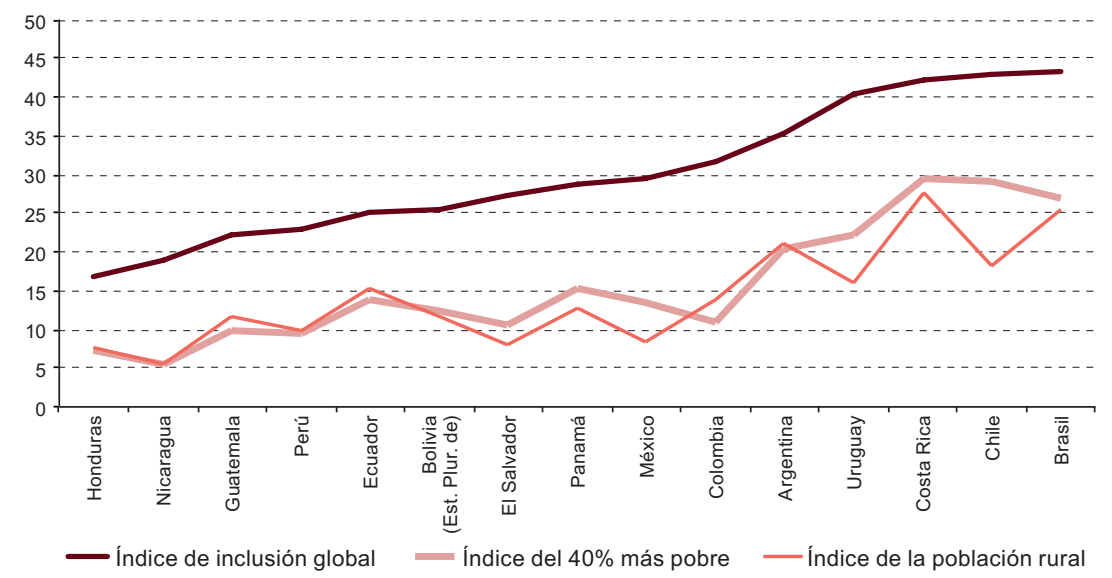

Fuente: Elaboración propia, sobre la base de Banco Mundial, Base de datos Global Findex, 2014 [en línea] http://datatopics. worldbank.org/financialinclusion.

Nota: Se omitieron el Paraguay y Venezuela (República Bolivariana de) porque no hay datos disponibles.

En los cuadros II.2, II.3 y II.4 se da cuenta de una cierta heterogeneidad en el grado de inclusión financiera alcanzado en cada país para los distintos segmentos poblacionales. En todos se destacan los casos de Costa Rica, como el país que tiene uno de los mayores grados de inclusión, y México, que, a pesar de su gran actividad económica, tiene un grado de inclusión muy bajo. Los datos muestran que la menor inclusión está centrada en aquellos lugares donde habita la población más pobre y en zonas rurales.

Martínez Pería (2014) y Dabla-Norris y otros (2015a) proponen la construcción de un índice de inclusión potencial que se elabora a partir del pronóstico resultante de estimaciones econométricas 9 . Dicha estimación permite construir una brecha que resulta de restar el índice potencial del valor del índice observado, de manera que una brecha positiva (negativa) significa que su nivel de inclusión es inferior (superior) al que debería tener para estándares internacionales.

Con datos de 146 países de América Latina, Asia y Europa para 2011, se realizaron estimaciones que consideraban tres tipos de variables asociadas al grado de inclusión financiera. La primera corresponde al índice global que se analizó con anterioridad, la segunda es el porcentaje de personas que ahorran en una institución financiera y la última es el porcentaje de personas que son deudoras de una institución financiera. Entre las variables

\footnotetext{
Véase una metodología más desagregada en Beck y Feyen (2013).
} 
explicativas de estas tres aproximaciones se consideran el logaritmo del PIB per cápita a precios de paridad de compra, dos variables relacionadas con el cumplimiento de la ley y una referente al acceso a cajeros automáticos ${ }^{10}$. Para la estimación se consideraron tres muestras poblacionales distintas: una que incorpora a la población total, otra que corresponde al $40 \%$ más pobre y una última que comprende a la población que habita en zonas rurales (véase el cuadro II.5).

\section{Cuadro II.5}

\section{Estimaciones de uso de productos financieros}

\begin{tabular}{|c|c|c|c|c|c|c|c|c|c|}
\hline & \multicolumn{3}{|c|}{ Población total } & \multicolumn{3}{|c|}{$40 \%$ más pobre } & \multicolumn{3}{|c|}{ Población rural } \\
\hline & $\begin{array}{c}\text { Inclusión } \\
\text { global }\end{array}$ & Ahorro & Préstamo & $\begin{array}{c}\text { Inclusión } \\
\text { global }\end{array}$ & Ahorro & Préstamo & $\begin{array}{l}\text { Inclusión } \\
\text { global }\end{array}$ & Ahorro & Préstamo \\
\hline \multirow{2}{*}{$\begin{array}{l}\text { América } \\
\text { Latina y } \\
\text { el Caribe }\end{array}$} & $-11,49$ & $-1,23$ & 0,90 & $-15,08$ & $-1,74$ & $-1,04$ & $-11,27$ & $-0,44$ & 0,48 \\
\hline & $(-3,83)$ & $(3,10)$ & $(1,36)$ & $(4,41)$ & $(2,94)$ & $(1,30)$ & $(4,39)$ & $(3,06)$ & $(1,41)$ \\
\hline \multirow{2}{*}{$\begin{array}{l}\text { Imperio de } \\
\text { la ley }\end{array}$} & 0,30 & 0,37 & 0,06 & 0,38 & 0,35 & 0,06 & 0,34 & 0,42 & 0,08 \\
\hline & $(0,14)$ & $(0,09)$ & $(0,06)$ & $(0,16)$ & $(0,08)$ & $(0,06)$ & $(0,16)$ & $(0,09)$ & $(0,07)$ \\
\hline \multirow{2}{*}{$\begin{array}{l}\text { Cajeros } \\
\text { automáticos } \\
\text { por cada } \\
100000 \\
\text { adultos }\end{array}$} & 0,14 & 0,00 & 0,00 & 0,15 & 0,00 & 0,01 & 0,14 & 0,00 & 0,01 \\
\hline & $(0,04)$ & $(0,03)$ & $(0,01)$ & $(0,04)$ & $(0,03)$ & $(0,02)$ & $(0,05)$ & $(0,03)$ & $(0,01)$ \\
\hline \multirow{2}{*}{$\begin{array}{l}\text { Log PIB per } \\
\text { cápita real }\end{array}$} & 22,61 & 5,45 & 1,59 & 22,58 & 5,89 & 1,40 & 22,33 & 5,23 & 0,72 \\
\hline & $(4,31)$ & $(2,91)$ & $(1,63)$ & $(4,70)$ & $(2,75)$ & $(1,70)$ & $(4,81)$ & $(2,80)$ & $(1,80)$ \\
\hline \multirow{2}{*}{$\begin{array}{l}\text { Economía } \\
\text { informal }\end{array}$} & $-0,30$ & $-0,29$ & $-0,05$ & $-0,33$ & $-0,20$ & $-0,01$ & $-0,32$ & $-0,21$ & $-0,05$ \\
\hline & $(0,17)$ & $(0,09)$ & $(0,07)$ & $(0,17)$ & $(0,08)$ & $(0,07)$ & $(0,17)$ & $(0,09)$ & $(0,08)$ \\
\hline \multirow{2}{*}{ Constante } & $-42,38$ & $-8,12$ & 2,96 & $-52,43$ & $-17,40$ & 0,62 & $-45,45$ & $-14,55$ & 4,33 \\
\hline & $(14,78)$ & $(9,31)$ & $(6,14)$ & $(15,15)$ & $(7,96)$ & $(6,37)$ & $(15,26)$ & $(8,73)$ & $(6,92)$ \\
\hline Observaciones & 128 & 126 & 126 & 126 & 126 & 126 & 122 & 122 & 122 \\
\hline $\begin{array}{l}\text { R-cuadrado } \\
\text { ajustado }\end{array}$ & 0,80 & 0,63 & 0,15 & 0,81 & 0,64 & 0,13 & 0,78 & 0,63 & 0,13 \\
\hline
\end{tabular}

Fuente: Elaboración propia, sobre la base de Banco Mundial, Base de datos Global Findex, 2014 [en línea] http://datatopics.worldbank.org/financialinclusion.

Nota: Método: mínimos cuadrados ordinarios. Errores estándar robustos entre paréntesis.

En negrita se resaltan los parámetros que resultaron ser estadísticamente significativos.

Variables independientes: a) ALC. Indicador dicotómico con valor 1 para los países que se encuentran en América Latina y el Caribe; b) Imperio de la ley. Variable que está en una escala de 0 a 100, donde 100 es el máximo nivel posible de confianza en el cumplimiento de la ley. Véase Banco Mundial [en línea] http://databank.worldbank.org/data/reports.aspx?source=global-financial-development [fecha de consulta: 27 de octubre de 2015]; c) Economía informal. Porcentaje estimado de la producción de bienes y servicios - como proporción del PIB - que durante el período 1999-2007 se ocultó deliberadamente de las autoridades por alguna de las siguientes razones: i) evitar el pago de impuesto sobre la renta, sobre el valor agregado $u$ otro; ii) evitar el pago de contribuciones a la seguridad social; iii) evitar cumplir con ciertas normas laborales, como salarios mínimos, horas de trabajo y normas de seguridad, y iv) evitar cumplir con ciertos procedimientos administrativos, como completar cuestionarios estadísticos u otros formularios administrativos. Véase Schneider, Buehn y Montenegro (2010); d) Dada la heterogeneidad de países, se probó con una muestra de países que fuera más homogénea. Para ello, se excluyeron todos los países cuyo ingreso per cápita superaba al más rico de América Latina y también aquellos que eran más pobres que el más pobre de América Latina. Los resultados no cambiaron de manera significativa.

10 También se consideró el nivel de escolaridad de la población adulta, el grado de desigualdad, la volatilidad inflacionaria y la concentración bancaria como posibles variables explicativas. Sin embargo ninguna de ellas resultó ser estadísticamente significativa. Las estimaciones que figuran en el cuadro II.5 no las incluye. 
Para el caso de la variable dependiente denominada "índice de inclusión global" descrita anteriormente, los resultados del cuadro II.5 correspondientes a la población total son compatibles con las teorías convencionales. Así, independientemente del tipo de muestra poblacional considerado, se observa que menores niveles de ingreso, el menor grado de cumplimiento de la ley y el mayor tamaño de la economía informal están asociados con un menor grado de inclusión financiera. Aun cuando también se controló por una variable que mide la infraestructura bancaria, la variable binaria utilizada para identificar a América Latina y el Caribe (ALC) tiene un coeficiente que sugiere que la pertenencia a la región latinoamericana deprime el índice de inclusión potencial. A este respecto, si América Latina en su conjunto aumentara el número de cajeros y lo llevara a la media de Europa y Asia, si el PIB per cápita de la región se asemejara al de Colombia y si la informalidad empresarial de la región fuera como la de México, la inclusión potencial podría subir 8,6 puntos porcentuales ${ }^{11}$. En el caso del grado de inclusión potencial entre la población perteneciente al $40 \%$ más pobre y la que vive en zonas rurales, un ejercicio similar permitiría incrementar el grado de inclusión 8,6 y 7,6 puntos porcentuales, respectivamente.

Con respecto al uso de la variable dependiente que mide cuánto se utilizan los productos de ahorro, las estimaciones para la población total indican que esta se asocia positivamente al nivel de ingreso y el cumplimiento del marco legal ${ }^{12}$. Resulta interesante constatar que ninguna de las variables explicativas consideradas para explicar el índice de participación en los mercados formales de crédito resultó ser estadísticamente significativa. Esto puede obedecer, en parte, a la heterogeneidad de las metodologías crediticias con que operan las entidades bancarias y no bancarias, a las distorsiones que pudiera introducir la operación crediticia de la banca pública y, en general, a la ausencia de variables relacionadas con garantías crediticias y características del proyecto y de los préstamos.

Sobre la base de los resultados presentados en el cuadro II.5 se puede extrapolar cuál debería ser el grado de inclusión global y del uso de productos de ahorro para cada uno de los países de América Latina. Esto permite construir una brecha que mide la diferencia entre el índice potencial y observado (Martínez Pería, 2014; Dabla-Norris y otros, 2015a). En este sentido, un signo positivo para esa brecha implica que el

11 Dichas medidas implicarían que el número de cajeros en la región tendría que incrementarse un $64 \%$, el grado de informalidad empresarial tendría que bajar 9 puntos porcentuales y el PIB per cápita debería subir 1 punto porcentual.

12 Si bien este resultado tiene sentido, en caso de que se contara con más información, sería interesante constatar si el grado de confianza en el cumplimiento del marco legal está asociado al uso de productos de ahorro informal. 
país en cuestión tiene un índice de inclusión inferior al potencial para estándares internacionales ${ }^{13}$.

En el cuadro II.6 se muestra que de los 17 países de América Latina, 7 tienen un grado de inclusión - utilizando cualquiera de las tres muestras poblacionales- que está por debajo de su potencial. Entre estos países hay tres que llaman la atención: Chile, México y Uruguay. Ello se debe a que son tres de los seis países con mayor ingreso per cápita y Chile, además, es el país con mayor penetración crediticia. Esto supone que el grado de desarrollo económico o la penetración crediticia no es sinónimo del grado de inclusión ni tampoco de qué tan lejana está la frontera de posibilidades. Por otra parte, el tamaño de la brecha de inclusión global no necesariamente refleja lo que sucede en las poblaciones más pobres. En los casos de Chile, México, el Perú y el Uruguay, por ejemplo, las brechas a nivel nacional son inferiores a las que se encuentran en las poblaciones con menores ingresos. Este resultado es importante pues sugiere la necesidad de contar con políticas de inclusión financiera que quizás deberían ser focalizadas.

En términos generales, las distintas realidades de los países de América Latina impiden tener una historia única de las causas que dan espacio a las brechas existentes de inclusión financiera. Así, por ejemplo, no necesariamente los países más prósperos dan cuenta de una brecha menor $\mathrm{y}$, por otra parte, el signo y tamaño de esta brecha parece depender del tipo de población que se esté analizando (total, rural o $40 \%$ más pobre). Sin embargo, a pesar de esas heterogeneidades, los datos indican que un mejor estado de derecho, una infraestructura financiera más adecuada y un incremento en la actividad económica son variables que pueden ayudar a elevar el grado de inclusión global y el porcentaje de la población que ahorra en el sistema financiero formal.

Cuadro II. 6

América Latina y el Caribe: brechas de inclusión y ahorro, 2011

\begin{tabular}{|c|c|c|c|c|c|c|}
\hline \multirow{2}{*}{ País } & \multicolumn{2}{|c|}{ Población total } & \multicolumn{2}{|c|}{$40 \%$ más pobre } & \multicolumn{2}{|c|}{ Población rural } \\
\hline & Inclusión & Ahorro & Inclusión & Ahorro & Inclusión & Ahorro \\
\hline $\begin{array}{l}\text { Bolivia (Estado } \\
\text { Plurinacional de) }\end{array}$ & $-10,2$ & $-8,5$ & $-9,5$ & $-6,2$ & $-6,3$ & $-7,5$ \\
\hline Brasil & $-2,7$ & 10,1 & 3,7 & 8,1 & $-3,7$ & 9,7 \\
\hline Chile & 19,5 & 22,5 & 24,4 & 20,4 & 23,2 & 20,8 \\
\hline Colombia & 3,7 & 6,5 & 9,7 & 7,3 & 4,3 & 6,3 \\
\hline Costa Rica & $-10,9$ & $-4,7$ & $-8,1$ & 1,0 & $-15,2$ & $-5,6$ \\
\hline
\end{tabular}

13 Esta metodología es sensible a las variables explicativas utilizadas pues la brecha corresponde al error en la estimación. A este respecto, al considerar 146 países, se está incorporando a economías y sociedades muy dispares y se asume que, en principio, todas deberían seguir una misma senda de desarrollo financiero. Sin embargo, ello es discutible. Además, el uso de un corte transversal impide corregir problemas de endogeneidad. 
Cuadro II.6 (conclusión)

\begin{tabular}{|c|c|c|c|c|c|c|}
\hline \multirow{2}{*}{ País } & \multicolumn{2}{|c|}{ Población total } & \multicolumn{2}{|c|}{$40 \%$ más pobre } & \multicolumn{2}{|c|}{ Población rural } \\
\hline & Inclusión & Ahorro & Inclusión & Ahorro & Inclusión & Ahorro \\
\hline Ecuador & $-7,5$ & $-4,7$ & $-6,6$ & $-5,3$ & $-9,7$ & $-6,2$ \\
\hline El Salvador & 12,0 & $-3,7$ & 7,6 & $-0,5$ & 10,2 & $-1,3$ \\
\hline Guatemala & $-2,9$ & $-5,4$ & $-5,7$ & $-4,7$ & $-4,8$ & $-5,5$ \\
\hline Honduras & $-4,3$ & $-3,1$ & n.d. & n.d. & $-3,6$ & $-0,9$ \\
\hline México & 15,9 & 10,8 & 20,2 & 8,8 & 26,6 & 10,9 \\
\hline Nicaragua & 0,4 & 1,0 & $-3,0$ & 0,3 & 1,0 & 2,1 \\
\hline Panamá & 9,3 & $-1,3$ & 3,4 & $-3,0$ & 8,1 & $-1,4$ \\
\hline Paraguay & $-1,5$ & $-0,6$ & 2,9 & 1,6 & 3,6 & 2,2 \\
\hline Perú & 3,9 & $-1,6$ & 6,9 & 1,5 & 6,4 & 0,5 \\
\hline $\begin{array}{l}\text { República } \\
\text { Dominicana }\end{array}$ & $-4,3$ & $-1,8$ & $-16,8$ & $-7,0$ & $-15,5$ & $-9,1$ \\
\hline Uruguay & 18,5 & 14,3 & 22,5 & 13,7 & 18,4 & 15,9 \\
\hline $\begin{array}{l}\text { Venezuela } \\
\text { (República } \\
\text { Bolivariana de) }\end{array}$ & $-12,0$ & $-6,1$ & $-11,4$ & $-4,7$ & $-13,3$ & $-5,8$ \\
\hline
\end{tabular}

Fuente: Elaboración propia, sobre la base de Banco Mundial, Base de datos Global Findex, 2014 [en línea] http://datatopics.worldbank.org/financialinclusion.

Nota: Una brecha positiva denota una situación en la que el país está por debajo de su potencial (en negritas).

\section{Una revisión de la literatura}

Los estudios teóricos muestran que la presencia de fricciones en los mercados financieros puede inhibir la acumulación de capital humano y físico, afectar las decisiones ocupacionales y generar trampas de pobreza (Banerjee y Newman, 1993; Aghion y Bolton, 1997). Por otra parte, los estudios empíricos indican que un mayor acceso a productos crediticios puede tener efectos positivos en el ingreso y el consumo (Karlan y Zinman, 2010), ayudar a reducir la pobreza (Beck, Demirgüç-Kunt y Levine, 2007), disminuir la vulnerabilidad a choques de ingreso (Lensink, Servin y Van Den Berg, 2015) y elevar la acumulación de activos productivos (Cotler y Woodruff, 2008; Cotler y Rodríguez-Oreggia, 2010).

Si bien desde un punto de vista macroeconómico, trabajos como los de Beck, Demirgüç-Kunt y Levine (2007) muestran la importancia de una mayor profundidad financiera, el impacto que tiene sobre el crecimiento depende de un conjunto de factores. Así, por ejemplo, la aversión al riesgo por parte de los potenciales deudores (Zeller y Sharma, 2002), el uso y la eficiencia de los burós de crédito (Beck, Demirgüç-Kunt y Martínez Pería, 2007), el capital humano de los emprendedores (Karlan y Valdivia, 2011) y la intensidad de la competencia entre los oferentes de los productos financieros son factores que influyen en el impacto que tienen la disponibilidad y utilización de servicios financieros formales sobre la actividad económica. 
No obstante lo anterior, la evidencia del impacto del financiamiento a nivel de los hogares y los individuos no es concluyente. Los trabajos de Pitt y Khandker (1998), Morduch (1998), Banerjee y Duflo (2004), Alexander-Tedeschi y Karlan (2006), Duflo y otros (2013), Hermes y Lensink (2011) y Khandker y Samad (2014) constituyen una muestra de la amplitud de investigaciones en las que se analiza el impacto que tiene el acceso al financiamiento formal en el bienestar de los individuos atendidos. Los resultados encontrados en dicha literatura se caracterizan por ser sumamente heterogéneos y de ahí que no exista en la literatura una afirmación concluyente respecto de si los préstamos tienen un efecto positivo y perdurable en el bienestar de su clientela.

Esta heterogeneidad en los resultados quizás no debería constituir una sorpresa, pues obedece al uso de distintas metodologías para medir el impacto, a las variadas decisiones que pueden tomar los deudores respecto de cómo usar el financiamiento, a qué variables se consideran al medir el bienestar y al horizonte temporal de los estudios empíricos. Sin embargo, la evidencia indica que los productos crediticios pueden ser un medio para impulsar la inversión y la generación de nuevos ingresos. En este sentido, pueden percibirse como una palanca local para el crecimiento de sectores poblacionales de bajos ingresos que ayudaría a aliviar carencias como las de vivienda y alimentación, dos dimensiones que constituyen el foco de atención de la política social.

Pero, si eso es así, ¿por qué es tan baja la utilización de los productos crediticios que ofrecen las instituciones formales? Con el fin de responder a esta pregunta es necesario recordar los conceptos de acceso y participación. Como explican Beck, Demirgüç-Kunt y Martínez Pería (2007), el acceso se tiende a definir bajo una dimensión geográfica, de modo que una falta de acceso se asocia a la ausencia de instituciones financieras en determinadas ubicaciones. Por otra parte, según Claessens (2006), el uso de productos crediticios es resultado tanto de la oferta como de la demanda. Esta diferenciación es importante pues permite considerar la posibilidad de que un bajo uso de servicios financieros pueda provenir de un bajo acceso o de un racionamiento en el mercado de crédito. Sin embargo, también es necesario saber si dicho racionamiento es voluntario, porque la persona no necesita financiamiento o porque se autoexcluye por la presunción de que será rechazada, o más bien resulta involuntario debido a su alto riesgo, a la incompatibilidad entre la tasa de interés y el proyecto, a la existencia de productos no compatibles con las necesidades o a una simple discriminación.

Así, en un contexto de pleno acceso, la demanda de dichos productos es la que determinará la decisión de participar o no de los servicios financieros institucionales. Siguiendo a Dabla-Norris y otros (2015b), en un contexto de pleno acceso, hay dos factores que limitan la demanda de financiamiento formal: la calidad de las garantías crediticias y la presencia de información asimétrica. 
El deficiente marco legal que caracteriza a muchos países de América Latina lleva a las entidades financieras a exigir una garantía mayor, con lo que tiende a bajar la demanda de financiamiento, con posibles efectos regresivos sobre la distribución de dichos fondos. Por otra parte, según el trabajo seminal de Stiglitz y Weiss (1981), las fricciones ocasionadas por la existencia de información asimétrica entre las instituciones bancarias y los deudores potenciales hacen que las primeras se vean a obligadas a monitorear a los segundos. Si se considera que las personas en situación de pobreza y las que trabajan en condiciones informales, así como las empresas menos productivas y las que tienen menos eslabonamientos empresariales, son las que más probablemente serán monitoreadas, el costo de intermediación es una fuente adicional que deprime la demanda, genera efectos regresivos y puede ser fuente de ineficiencia y de exclusión voluntaria.

Ante esta situación, Dabla-Norris y otros (2015b) plantean que hay dos canales mediante los cuales una mayor inclusión financiera puede incidir en la actividad económica y la desigualdad. Primero, porque al permitirse una distribución más eficiente de los fondos crediticios (esto es, una distribución más orientada por el talento empresarial que por el patrimonio), se eleva el producto. Segundo, porque al contar con contratos más eficientes, se reducen los costos originados en las fricciones y con ello aumenta el acceso a los productos crediticios y su uso. Estos dos canales conducen a que los préstamos se dirijan a los empresarios más talentosos y con mejores proyectos. Si bien esto debería aumentar la actividad económica, no está claro qué sucede con la desigualdad. En primera instancia, puede ser que se produzca un incremento de la desigualdad porque los empresarios talentosos ya recibían mayores ingresos. Sin embargo, el mayor acceso también puede dar espacio a que personas y empresarios antes racionados ahora puedan hacer uso de estos recursos crediticios debido a que, como es sabido, muchas microempresas tienen un alto rendimiento marginal. En este sentido, una mayor inclusión financiera no solo contribuye a la reducción de la pobreza (por medio del crecimiento), sino que también puede ayudar a disminuir la desigualdad de oportunidades y de ingresos (Beck, Demirgüç-Kunt y Levine, 2007).

En esta misma línea se puede caracterizar el bajo uso de productos formales de ahorro por parte de la población de bajos ingresos. Por ejemplo, Karlan, Lakshmi y Zinman (2014) describen una barrera que restringe el acceso: los altos costos de transacción. Frente a los bajos y erráticos montos de ahorro que mantienen dichas poblaciones, los costos de entrada y de operación de estas entidades financieras son altos y ello desincentiva la presencia en algunas localidades (Dupas y Robinson, 2013). A este respecto, no es casual que en algunos países se hayan introducido medidas legislativas conducentes a obligar a los bancos comerciales a crear cuentas básicas que tienen como características esenciales que no se cobra por la apertura de la cuenta ni tampoco por el número de transacciones, pero tienen un tope respecto del saldo que se mantiene. 
Además de los bajos incentivos a la oferta, también hay factores que llevan a que haya una baja demanda de productos formales de ahorro. La ausencia de productos que busquen captar bajos y erráticos flujos de ingreso, las normas sociales que premian la construcción de capital social y, por ende, incentivan el uso de arreglos informales y la presencia de preferencias intertemporales muy cargadas al presente son factores que merman el nivel de ahorro buscado y el uso de productos formales (Xu y Zia, 2012; Karlan, Lakshmi y Zinman, 2014).

Las características de los productos formales de ahorro y crédito, su potencial complementariedad o sustituibilidad respecto de los productos financieros informales, la fungibilidad del financiamiento y las preferencias y restricciones de los individuos son algunos de los factores a considerar a la hora de tratar de entender los mecanismos mediante los cuales el uso de los servicios financieros formales puede incidir en el bienestar.

Discernir sobre qué variables impactará la posibilidad de un mayor acceso a productos y servicios financieros no es fácil. Sin embargo, si los productos son adecuados y accesibles, tienen un bajo costo de transacción, son ofrecidos por instituciones financieras supervisadas y cuentan con metodologías apropiadas, el impacto más probable sería un incremento en el uso de los servicios financieros formales. En la medida en que la utilización de dichos servicios permita atender las fluctuaciones del ingreso con una mayor seguridad y esta participación sea voluntaria, el bienestar aumentará.

Combatir la baja inclusión financiera y mostrar resultados es importante desde un punto de vista socioeconómico y político. A este respecto, la unidad de medida para conocer el éxito de la estrategia debería ser, por ejemplo, el número de personas que deseaban tener una cuenta en una institución financiera y la abrieron gracias a la presencia de más puntos de venta. Sin embargo, las métricas utilizadas son aquellas en que se mide la utilización de un determinado producto (es decir, el número de cuentas por cada 100.000 personas). Una medida de esta naturaleza no permite saber si un incremento en su valor corresponde a personas que estaban excluidas o autoexcluidas y que - como resultado de la estrategia de inclusión financiera- deciden libremente modificar su relación con el sistema financiero. Ahora bien, tomando en consideración los beneficios políticos de corto plazo que puede deparar un incremento en la inclusión financiera, las métricas tradicionales pueden inducir a las autoridades a obligar a determinados grupos poblacionales a que abran una cuenta bancaria aun cuando no les sea atractivo. Piénsese por ejemplo en la apertura de cuentas para recibir transferencias públicas. Aunque puede haber una justificación válida para tal medida, esta ofrecería una imagen distorsionada de la inclusión financiera. Casos como este vuelven necesaria la introducción de un nuevo término: la inclusión financiera efectiva, que surgiría de excluir del cálculo a las cuentas inactivas y aquellas que son solo utilizadas como medios de disposición para recibir una transferencia pública. 


\section{Estrategias de inclusión financiera}

En términos generales, las estadísticas indican que en América Latina se registra un bajo uso de los servicios que ofrece el sistema financiero formal. Más aún, tal carencia se agudiza cuando se analiza la situación de la población más pobre y de aquella que habita en zonas rurales. Al considerar las posibles ventajas de utilizar los productos y servicios que ofrecen las instituciones financieras formales frente a las alternativas informales, se concluye que las poblaciones más pobres y aquellas que habitan en zonas rurales son más vulnerables a choques de ingreso y más propensas a enfrentar restricciones crediticias. Los problemas de información asimétrica, las externalidades generadas por una distribución del ingreso muy desigual y la dificultad para alcanzar una economía de redes en comunidades de baja densidad poblacional son algunas de las causas que generan dicha situación, por lo que se vuelve necesario contar con una política pública que apunte a atender estas cuestiones.

El éxito de una estrategia de inclusión financiera implica aumentar la posibilidad de acceder a dichos servicios y, al mismo tiempo, hacerlos lo suficientemente atractivos como para que exista una demanda. En términos generales, ello supone mejorar la infraestructura financiera - especialmente en zonas rurales-y procurar el desarrollo de productos financieros que sean compatibles con la estacionalidad que aún incide en la actividad del ámbito rural, con los bajos y erráticos montos que ahorra la población de bajos ingresos y a precios compatibles con los niveles de ingreso de la población objetivo. Buscando asegurar que dicha meta se alcance de manera sostenible, es necesario que las estrategias para lograrlo conlleven un riesgo acotado, de modo de garantizar la estabilidad del sistema financiero. Con ese propósito, a continuación se plantean cinco estrategias.

\section{Productos financieros}

Una primera estrategia consiste en el diseño de productos financieros que se ajusten más a las necesidades de la población de bajos recursos y de aquella que vive en zonas rurales. Esta estrategia obedece a las características básicas de estas poblaciones: ingresos bajos, erráticos o estacionales, impredecibles y difícilmente comprobables, y activos poco comerciables.

Para una población con las características descritas es necesario que existan productos financieros con características alineadas a los cambios de liquidez de la población objetivo (Labie, Laureti y Szafarz, 2013). No obstante, esta no es una faceta típica de los productos bancarios tradicionales ni tampoco de los productos que ofrecen las instituciones que utilizan técnicas microfinancieras. Los primeros ofrecen productos de ahorro con un saldo mínimo y con límites en el número de transacciones. Asimismo, ofrecen productos crediticios previa documentación, lo que está reñido con 
la informalidad en que vive la población y con los tiempos requeridos para atender necesidades urgentes. Por otra parte, en el caso de la gran mayoría de las entidades no bancarias que utilizan técnicas microfinancieras, lo común son los préstamos de corta duración, con pagos periódicos (a la semana de recibir el préstamo) de sumas constantes, con préstamos escalonados y cero tolerancia al quebranto. Estas características atentan contra la puesta en marcha de proyectos de mayor maduración, obligan a la toma de varios préstamos y no consideran la alta vulnerabilidad a choques de ingreso.

Esta falta de flexibilidad de las instituciones que utilizan técnicas microfinancieras obedece, en cierto modo, a la búsqueda de disciplina por parte del cliente y a un mecanismo orientado a aminorar los costos operativos. Sin embargo, dadas las características antes esgrimidas de la población a la que se busca incluir, cierta flexibilidad en los productos financieros puede beneficiar a los potenciales clientes y a las instituciones financieras que los atienden. Una flexibilidad apropiada puede dar espacio a una mayor probabilidad de repago, incentivar la colocación de fondos en proyectos de alta rentabilidad y mitigar el atractivo de los prestamistas informales (Mallick, 2012). Pearlman (2012), por ejemplo, muestra que uno de los motivos de la baja penetración de las microfinancieras es la dificultad de mitigar el riesgo de los potenciales usuarios. En este sentido, entre otras cosas, debería contemplarse la implementación de productos crediticios que contengan cláusulas de protección contra el riesgo.

\section{Instituciones financieras}

Para coadyuvar al objetivo de volver más atractivos los productos financieros entre la población pobre, una segunda estrategia pasa por el impulso a la conformación de instituciones financieras que sean más afines a lograr una mayor inclusión. Si bien existen instituciones financieras bancarias y no bancarias que pueden ayudar a la consecución de ese objetivo, la política pública ha tendido a centrarse en la búsqueda de mecanismos para alcanzar una mayor penetración bancaria. La focalización en los bancos obedece, en buena medida, a dos factores: un primer factor basado en los niveles de activos que poseen los bancos frente a las instituciones no bancarias (como las sociedades cooperativas de ahorro y préstamo, y aquellas que operan con técnicas de microfinanzas) y un segundo factor relacionado con el poco conocimiento que tienen las autoridades financieras en muchos países respecto de la forma de operar de estas entidades no bancarias. Sin embargo, debido a que este movimiento de inclusión se inició en un contexto donde la crisis financiera internacional estallaba, la autoridad procuraba una mayor inclusión, al tiempo que aseguraba una normatividad regulatoria para la banca que buscaba evitar una inestabilidad financiera. 
El potencial conflicto entre inclusión y estabilidad financiera y el bajo interés - con ciertas excepciones- por parte de los directivos de la banca de hacer modificaciones institucionales han conducido a que la estrategia dominante haya sido la expansión mediante el uso de corresponsales y sucursales móviles. Sin embargo, como ya se explicó, el principal limitante para lograr incluir a un importante sector de la población rural y de bajos ingresos reside en su metodología crediticia y en las características de sus principales productos. Esto lleva a que sea necesario plantearse si la política pública en favor de la inclusión financiera debería estar articulada en torno a las entidades bancarias.

La gran mayoría de las entidades financieras no bancarias se caracteriza por utilizar técnicas de microfinanzas u operar bajo reglas cooperativas, y tiene como nicho de mercado a personas que por distintos motivos están excluidas del sistema financiero. En este sentido, deberían ser artífices cruciales para lograr una mayor inclusión. En muchos países, sin embargo, esta industria está muy concentrada y muchas de las entidades financieras que la conforman son demasiado pequeñas para alcanzar economías de escala, además de presentar problemas de administración de riesgos y falta de una sólida estructura de gobierno. En situaciones como la descrita, es necesario encontrar mecanismos que promuevan una mayor competencia, pues ello puede dar lugar a una mayor demanda de servicios financieros formales. Para tal fin, la política pública debería centrarse en buscar mecanismos para incentivar la fusión de entidades que permitan consolidar una industria más competitiva y menos concentrada. Un ejemplo puede ser el uso de apoyos financieros para que las entidades financieras no bancarias mejor organizadas y con mayor solidez financiera puedan acceder a la línea de fondeo del banco central y participar en las redes de cajeros. Si bien este tipo de medida puede dar espacio a una mayor concentración, también puede servir de aliciente para la conformación de alianzas entre entidades de tamaño medio.

Otra forma común de entidad financiera no bancaria que existe en diversos países de la región son las denominadas sociedades cooperativas de ahorro y préstamo. En algunos países, estas entidades han logrado construir una estructura de gobierno que les ha permitido sortear crisis financieras de carácter sistémico. Al condicionar los servicios crediticios a la capacidad de ahorro, este tipo de instituciones ofrece ventajas y desventajas frente a las entidades bancarias y a aquellas que recurren a técnicas microfinancieras. Entre sus ventajas sobresale la oferta de servicios básicos de ahorro y préstamo, el cobro de tasas activas de intereses más bajas por sus préstamos y el pago, por lo general, de tasas pasivas más altas por los ahorros. Entre sus desventajas se destacan dos: que las personas con baja capacidad de ahorro difícilmente pueden recurrir al financiamiento y que la capacidad institucional para lograr un crecimiento sostenido de la cartera crediticia está restringida por 
la capacidad de captar ahorros. En este sentido, las reglas de operación de estas instituciones cooperativas pueden llegar a ser incompatibles con las políticas de inclusión financiera.

Como puede observarse, todas las instituciones financieras que pueden ser artífices de una mayor inclusión tienen ventajas y desventajas. Por ello, se puede decir que la mejor estrategia es aquella que no recae en un solo tipo de entidad financiera y que se caracteriza por promover las alianzas entre las distintas figuras $\mathrm{y}$, al mismo tiempo, generar un contexto caracterizado por un entorno competitivo ${ }^{14}$.

\section{Canales de distribución}

Para lograr una provisión más eficiente de productos financieros se requiere de un marco institucional que propicie el desarrollo de nuevas tecnologías financieras que permitan un abaratamiento en la provisión de servicios financieros. En este sentido, una tercera estrategia radica en la promoción de la figura de los corresponsales (también denominados agentes bancarios) como mecanismo para reducir el costo operativo de mantener sucursales de las entidades financieras y bajar los costos de transacción en que incurren tanto oferentes como demandantes ${ }^{15}$. Un corresponsal o agente es un tercero que establece una relación de negocios con una institución financiera con el fin de representarla y así poder ofrecer productos y servicios de dicha institución ${ }^{16}$. Al abaratarse la operación, se espera un incremento en el acceso y en el uso, con lo que el grado de inclusión debería aumentar. A los efectos de lograr una mayor inclusión, es necesario que esta estrategia de expansión se centre en las zonas rurales - donde hay menor densidad poblacional — y ofrezca de manera preponderante productos financieros que sirvan para el ahorro y el crédito.

\section{Educación financiera}

El surgimiento de nuevas instituciones y nuevos productos siempre causa temor e incertidumbre entre las poblaciones con reciente acceso a ellos. En este sentido, una cuarta estrategia consiste en la provisión de servicios de educación financiera. Para que esta estrategia sirva como mecanismo para aumentar la inclusión quizás sea necesario separarla en dos partes. Una primera subestrategia debería tener por objeto mostrar las ventajas

14 Tómese a modo de ejemplo los resultados a que llegan Vanroose y D'Espallier (2013), quienes utilizando datos a nivel mundial muestran que las tasas de interés que cobran las microfinancieras tienden a ser menores conforme mayor es la presencia de las entidades bancarias en los mercados relevantes.

15 En varios países, al comienzo solo los bancos podían contar con corresponsales. Esto se fue flexibilizando para considerar a otras entidades no bancarias legalmente establecidas.

16 En paralelo a la creación de dicha figura, esta estrategia incluye también la creación de sucursales móviles que se caracterizan por permitir la realización de operaciones financieras por medio de la telefonía móvil. 
de utilizar los productos financieros que ofrecen las entidades financieras formales. Esto es, debería centrarse en mostrar sus bondades frente a lo que se ofrece de manera informal. Ello implica una labor que recae sobre todo en las instituciones públicas encargadas de la regulación y supervisión de las instituciones financieras. En este sentido, además de diseñar una regulación adecuada y una buena supervisión, estos organismos deberían destinar recursos a una campaña mediática permanente centrada en mostrar las bondades de participar en el sistema financiero formal haciendo especial énfasis en los productos financieros que ofrecen aquellas instituciones financieras cuyo nicho de mercado son las poblaciones de bajos ingresos.

Una segunda subestrategia se orienta a proporcionar elementos para la toma de decisiones financieras más apropiadas. Si bien esta estrategia, en la que tienden a participar de manera activa tanto los reguladores como las propias instituciones financieras, también puede ayudar a mostrar las ventajas de los productos formales, por lo general ha estado más orientada a proveer servicios educativos a personas que muchas veces ya estaban incluidas. Aun cuando esta subestrategia tiene sus bondades, en diversos estudios se da cuenta de que, en aras de aumentar la inclusión, una estrategia que logre reducir el costo de entrada y participación es superior a la provisión de educación financiera. Así, por ejemplo, Cole, Sampson y Zia (2010) encuentran que la educación financiera no tiene un efecto discernible en la apertura de una cuenta de ahorro, pero un programa basado en subsidios financieros que pueden elevar la tasa pasiva de interés sí tiene un efecto significativo.

\section{Marco regulatorio}

Por último, buscando asegurar que las estrategias planteadas no pongan en riesgo el sistema financiero, como quinta estrategia es necesaria la puesta en marcha de un conjunto de medidas que apuntan a reducir los problemas de información asimétrica que pueden llegar a impactar en el riesgo crediticio y la solvencia financiera de las instituciones oferentes de crédito. Entre estas se destaca, en primer lugar, el fortalecimiento de la industria de sociedades crediticias de información (también conocidas como burós de crédito) de modo que provea información positiva y negativa de los clientes y logre extender su ámbito de acción a las operaciones financieras que se realizan en el sector rural. En segundo lugar, en muchos países, el gobierno tiene una importante presencia en la oferta de financiamiento. Ante ello, se vuelve fundamental una racionalización de dicha oferta con el fin de impedir un proceso de sobreendeudamiento y retrasar el desarrollo financiero. Con esta finalidad también es necesario que las instituciones y los programas públicos que ofrecen financiamiento compartan su información crediticia con los burós de crédito. Esta última medida busca reducir el costo que acarrea la información asimétrica que afecta de manera desproporcionada a 
aquellos sectores poblacionales que no participan en los mercados formales de trabajo ni de bienes y que, por lo general, son sectores poblacionales de bajos ingresos o poblaciones que habitan en zonas rurales ${ }^{17}$.

Un segundo tipo de medidas pasa por reexaminar las secciones del marco regulatorio que rigen las operaciones de las entidades financieras que puedan incidir negativamente en el acceso a los productos y servicios financieros. Es necesario revisar, por ejemplo, la pertinencia de una regulación que limita el otorgamiento de crédito a negocios que tengan menos de dos años de existencia. Por otra parte, también es necesario analizar los motivos que dan pie a una regulación que aumenta innecesariamente las provisiones que una institución bancaria debe constituir cuando se trata de créditos grupales. En lo que se refiere al ahorro, la regulación acota los incentivos para captar el ahorro privado en virtud del costo regulatorio que han generado algunas medidas que intentan impedir la canalización de dinero proveniente de actividades ilícitas. A este respecto, es necesario analizar si dicha regulación logra reducir las actividades ilícitas o si su principal costo es lograr menores incentivos a la captación.

Finalmente, una tercera medida pasa por el establecimiento de regulaciones para proteger al consumidor. Esto es de suma importancia pues existe evidencia que da cuenta de que - incluso cuando hay transparencia en la información - la vulnerabilidad al abuso es mayor conforme menor es la riqueza y el nivel educativo de los potenciales clientes.

Aun cuando se realizaran adaptaciones en la oferta de productos financieros y se lograra incrementar su demanda, es necesario recordar que la causalidad entre crecimiento económico y desarrollo financiero va del primero al segundo (Levine, 2005). En este sentido, para aumentar la inclusión potencial y cerrar la brecha no basta con cambios de índole financiera; también es necesario lograr cambios que le den validez social al estado de derecho y realizar modificaciones que posibiliten una mayor productividad de las actividades productivas ${ }^{18}$.

17 Existen otras medidas que buscan aumentar la rentabilidad de los proyectos en el sector rural, así como mitigar el impacto de los riesgos climáticos. Dada la naturaleza del presente trabajo, estas no se mencionan aquí. Véase información sobre este tipo de medidas, por ejemplo, en el CFI (2011).

18 En el caso de los pequeños productores rurales resulta necesario analizar las propuestas que hace el CFI (2011) para constituir asociaciones de productores como método para lograr una mayor productividad. Si bien en América Latina no hay antecedentes exitosos respecto de este tipo de asociaciones, es importante reflexionar en torno a los motivos por los cuales en muchos países desarrollados la historia es totalmente opuesta. A este respecto, se recomienda revisar la vasta literatura disponible en la revista Annals of Public and Cooperative Economics. 


\section{Bibliografía}

Aghion, P. y P. Bolton (1997), "A theory of trickle-down growth and development", The Review of Economic Studies, vol. 64, № 2, Estocolmo, Universidad de Estocolmo, abril.

Alexander-Tedeschi, G. y D. Karlan (2006), "Microfinance impact: bias from dropouts", Financial Access Initiative/Innovations for Poverty Action.

Allen, F. y otros (2012), "The foundations of financial inclusion: understanding ownership and use of formal accounts", Policy Research Working Paper, N 6290, Washington, D.C., Banco Mundial.

Ayyagari, M., A. Demirgüç-Kunt y V. Maksimovic (2010), “Formal versus informal finance: evidence from China", Review of Financial Studies, vol. 23, No 8, Oxford, Oxford University Press.

Banco Mundial (2015a), The Little Data Book on Financial Inclusion 2015, Washington, D.C [en línea] http://data.worldbank.org/products/data-books/little-databook-on-financial-inclusion.

(2015b), World Development Indicators [base de datos en línea] http:/ / data. worldbank.org/data-catalog/world-development-indicators.

(2014), Base de datos Global Findex [en línea] http:/ / datatopics.worldbank. org/financialinclusion.

(s /f), Global Financial Development [base de datos en línea] http:/ / databank. worldbank.org/data/reports.aspx?source=global-financial-development [fecha de consulta: 27 de octubre de 2015].

Banerjee, A. y A. Newman (1993), "Occupational choice and the process of development", Journal of Political Economy, vol. 101, N², Chicago, University of Chicago Press.

Banerjee, A. y E. Duflo (2007), "The economic lives of the poor", Journal of Economic Perspectives, vol. 21, N ${ }^{\circ}$, Nashville, Asociación Estadounidense de Economía. (2004), "Do firms want to borrow more? Testing credit constraints using a directed lending program", CEPR Discussion Paper, $\mathrm{N}^{\circ} 4681$, Londres, Centro de investigación sobre políticas económicas.

Bazán Levy, L. y G. A. Saraví (2012), La monetarización de la pobreza: estrategias financieras de los hogares mexicanos, Ciudad de México, Centro de Investigaciones y Estudios Superiores en Antropología Social (CIESAS).

Beck, T. y E. Feyen (2013), “Benchmarking financial systems. Introducing the financial possibility frontier", Policy Research Working Paper, N 6615, Washington, D.C., Banco Mundial.

Beck, T., A. Demirgüç-Kunt y M. Martínez Pería (2007), "Reaching out: access to and use of banking services across countries", Journal of Financial Economics, vol. 85, $\mathrm{N}^{\mathrm{o}} 1$, Amsterdam, Elsevier.

Beck, T., A. Demirgüç-Kunt y R. Levine (2007), "Finance, inequality and the poor", Journal of Economic Growth, vol. 12, N 1, Berlín, Springer.

CAF (Banco de Desarrollo de América Latina) (2011), RED 2011: Servicios financieros para el desarrollo: promoviendo el acceso en América Latina, Caracas [en línea] http:/ / www.caf.com/media/3895/RED2011.pdf.

CFI (Corporación Financiera Internacional) (2011), "Scaling up access to finance for agricultural SMEs. Policy review and recommendations", Washington, D.C.

Claessens, S. (2006), "Access to financial services: a review of the issues and public policy objectives", The World Bank Research Observer, vol. 21, N², Oxford, Banco Mundial/Oxford University Press. 
Cole, S., T. Sampson y B. Zia (2010), "Prices or knowledge? What drives demand for financial services in emerging markets?", Harvard Business School Working Paper, $\mathrm{N}^{\circ}$ 09-117, Cambridge, Universidad de Harvard.

Collins, D. y otros (2009), Portfolios of the Poor: How the World's Poor live on \$2 a Day, Princeton, Princeton University Press.

Cotler, P. (2015) "Crédito de proveedores, tamaño de empresa e informalidad", El Trimestre Económico, vol. 82-3, No 327, Ciudad de México, Fondo de Cultura Económica, julio-septiembre.

Cotler, P. y C. Woodruff (2008), "The impact of short-term credit on microenterprises: Evidence from the Fincomun-Bimbo Program in Mexico", Economic Development and Cultural Change, vol. 56, $\mathrm{N}^{\circ}$ 4, Chicago, University of Chicago Press, julio.

Cotler, P. y E. Rodríguez-Oreggia (2010), “Microfinanzas y la tenencia de activos no financieros en México", Investigación Económica, vol. 69, № 274, Ciudad de México, Universidad Nacional Autónoma de México (UNAM), octubre-diciembre.

Dabla-Norris, E. y otros (2015a), "Financial inclusion: zooming in on Latin America", IMF Working Paper, N ${ }^{\mathrm{o}}$ 15/206, Washington, D.C., Fondo Monetario Internacional (FMI). (2015b), "Identifying constraints to financial inclusion and their impact on GDP and inequality: A structural framework for policy", IMF Working Paper, $N^{o} 15 / 22$, Washington, D.C., Fondo Monetario Internacional (FMI).

Duflo, E. y otros (2013), "The miracle of microfinance? Evidence from a randomized evaluation", NBER Working Paper, No 18950, Cambridge, Oficina Nacional de Investigaciones Económicas.

Dupas, P. y J. Robinson (2013), “Savings constraints and microenterprise development: evidence from a field experiment in Kenya", American Economic Journal: Applied Economics, vol. 5, No 1, Nashville, Asociación Estadounidense de Economía.

Fang, H., R. Ke y L. Zhou (2015), "Rosca meets formal credit market”, NBER Working Paper, $\mathrm{N}^{\mathrm{o}} 21683$, Cambridge, Oficina Nacional de Investigaciones Económicas.

FMI (Fondo Monetario Internacional) (2015), Financial Access Survey [base de datos en línea] http://data.imf.org/?sk=E5DCAB7E-A5CA-4892-A6EA598B5463A34C.

Hermes, N. y R. Lensink (2011), “Microfinance: its impact, outreach, and sustainability”, World Development, Vol. 39, N 6, Amsterdam, Elsevier.

Karlan, D., A. Lakshmi y J. Zinman (2014), "Savings by and for the poor: a research review and agenda", Review of Income and Wealth, vol. 60, N 1, Ottawa, Asociación Internacional de Investigaciones sobre Rentas y Riqueza (IARIW), marzo.

Karlan, D. y M. Valdivia (2011), "Teaching entrepreneurship: impact of business training on microfinance clients and institutions", Review of Economics and Statistics, vol. 93, No 2, Cambridge, MIT Press, mayo.

Karlan, D. y J. Zinman (2010), “Expanding credit access: using randomized supply decisions to estimate the impacts", The Review of Financial Studies, vol. 23, No 1 , Oxford, Oxford University Press, enero.

Khandker, S. y H. Samad (2014), "Dynamic effects of microcredit in Bangladesh", Policy Research Working Paper, No 6821, Washington, D.C., Banco Mundial.

Labie, M, C. Laureti y A. Szafarz (2013), "Flexible products in microfinance: overcoming the demand-supply mismatch", CEB Working Paper, $\mathrm{N}^{\circ} 13 / 044$, Bruselas, Universidad Libre de Bruselas.

Lensink, R., R. Servin y M. Van Den Berg (2015), “Do savings and credit institutions reduce vulnerability? New evidence from Mexico", Review of Income and Wealth. 
Levine, R. (2005), "Finance and growth: theory and evidence", Handbook of Economic Growth, vol. 1, part A, P. Aghion y S. N. Durlauf (eds.), Amsterdam, Elsevier.

López-Moctezuma, C. (2013), “Implementación de canales alternativos para la oferta de servicios financieros en México", Las microfinanzas en México: instrumento de desarrollo e inclusión financiera, P. Cotler y P. López (coords.), Ciudad de México, Instituto Mexicano de Ejecutivos de Finanzas (IMEF).

Mallick, D. (2012), "Microfinance and moneylender interest rate: evidence from Bangladesh", World Development, vol. 40, N 6, Amsterdam, Elsevier.

Martínez Pería, M. (2014), "Financial inclusion in Latin America and the Caribbean", Emerging Issues in Financial Development: Lessons from Latin America, T. Didier y S. Schmukler (eds.), Washington, D.C., Banco Mundial.

Morduch, J. (1998), "Does microfinance really help the poor? New evidence from flagship programs in Bangladesh", Stanford, Universidad de Stanford, inédito.

Pearlman, S. (2012), "Too vulnerable for microfinance? Risk and vulnerability as determinants of microfinance selection in Lima", Journal of Development Studies, vol. 48, N 9, Abingdon, Routledge.

Petersen, M. y R. Rajan (1997), "Trade credit: theories and evidence”, Review of Financial Studies, vol. 10, N 3, Oxford, Oxford University Press.

Pitt, M. y S. Khandker (1998), "The impact of group-based credit programs on poor households in Bangladesh: does the gender of participants matter?", Journal of Political Economy, vol. 106, N 5, Chicago, University of Chicago Press.

Roa, M. (2015), "Financial inclusion in Latin America and the Caribbean: access, usage and quality", Research Papers, No 19, Ciudad de México, Centro de Estudios Monetarios Latinoamericanos (CEMLA).

Rutherford, S. (2000), The Poor and their Money, Oxford, Oxford University Press.

Schneider, F., A. Buehn y C. Montenegro (2010), "Shadow economies all over the world. New estimates for 162 countries from 1999 to 2007", Policy Research Working Paper, N ${ }^{\circ}$ 5356, Washington, D.C., Banco Mundial.

Soto, I. (2015), "Avances en la inclusión financiera en la región centroamericana, Panamá y República Dominicana", Notas Económicas Regionales, Nº 84, San José, Secretaría Ejecutiva del Consejo Monetario Centroamericano.

Stiglitz, J. y A. Weiss (1981), "Credit rationing in markets with imperfect information", American Economic Review, vol. 71, N 3, Nashville, Asociación Estadounidense de Economía.

Uchida, H., G. Udell y W. Watanabe (2006) "Are trade creditors relationship lenders?", RIETI Discussion Paper Series, No 06-E-026, Tokio, Instituto de Investigación de Economía, Comercio e Industria.

Vanroose, A. y B. D’Espallier (2013), “Do microfinance institutions accomplish their mission? Evidence from the relationship between traditional financial sector development and microfinance institutions' outreach and performance", Applied Economics, vol. 45, No 15, Abingdon, Routledge.

Xu, L. y B. Zia (2012), "Financial literacy around the world: an overview of the evidence with practical suggestions for the way forward", Policy Research Working Paper, $\mathrm{N}^{\mathrm{o}}$ 6107, Washington, D.C., Banco Mundial.

Zeller, M. y M. Sharma, (2002), "Access to and demand for financial services by the rural poor: a multicountry synthesis", The Triangle of Microfinance: Financial Sustainability, Outreach and Impact, M. Zeller y R. Meyer (eds.), Baltimore, John Hopkins University Press/Instituto Internacional de Investigación sobre Políticas Alimentarias (IFPRI). 

Capítulo III

\title{
Evolución reciente, situación actual y perspectivas de inclusión financiera de los pequeños productores rurales en Costa Rica
}

\author{
José Antonio Vásquez R. ${ }^{1}$ \\ Melvin Bermúdez ${ }^{2}$ \\ Ronald Rojas ${ }^{3}$ \\ José Antonio Vásquez C. ${ }^{4}$
}

\section{Introducción}

En Costa Rica, los esfuerzos por acercar la oferta de crédito a pequeños productores en zonas rurales históricamente han ido de la mano del desarrollo de la banca pública. Las Juntas Rurales de Crédito, auspiciadas por el Banco Nacional de Costa Rica desde su creación, y la nacionalización bancaria ocurrida a partir de la revolución de 1948 fueron bases fundamentales de la inclusión financiera, que se tradujo en el componente de crédito dirigido a la producción agropecuaria y en la instalación de sucursales bancarias en casi todo el territorio nacional. La transición desde un modelo de desarrollo

Máster en Administración de Empresas de INCAE Business School, con experiencia en áreas de estrategia, finanzas y tecnología.

2 Máster en Gerencia de Proyectos de Desarrollo y Máster en Administración de Empresas del Instituto Tecnológico de Costa Rica, Licenciado en Economía de la Universidad Nacional de Costa Rica, con experiencia en proyectos de desarrollo rural en Costa Rica.

3 Fue Director Nacional de Crédito del Banco Nacional de Costa Rica.

4 Fue Subgerente General del Banco Nacional de Costa Rica. 
agroexportador hacia un modelo de desarrollo basado en las exportaciones de servicios y manufactura resultó en una disminución progresiva del crédito orientado a los pequeños productores rurales y, por ende, del proceso de inclusión financiera del que habían gozado durante muchos años a través de dichos instrumentos.

Los fideicomisos, que aparecieron en la década de 1990 como vehículo para apoyar a los productores agropecuarios, han sido una constante en las estrategias de los gobiernos para atender a los pequeños productores rurales. El Fideicomiso Nacional para el Desarrollo (FINADE), creado a partir de la promulgación de la Ley de Sistema de Banca para el Desarrollo, es la instrumentación más explícita de una política pública orientada a la producción agropecuaria y, por su intermedio, a los pequeños productores rurales de Costa Rica.

En lo que respecta a las herramientas disponibles para promover la inclusión financiera, Costa Rica tiene un amplio marco legal y normativo para las entidades financieras que se encuentran reguladas por la Superintendencia General de Entidades Financieras (SUGEF). Sin embargo, se puede identificar cierta desarticulación institucional en la aplicación de dicha normativa. La ausencia de una política pública integral para el fomento de la inclusión financiera limita la inclusión efectiva de diversos estratos de la población, donde se destaca el caso de los pequeños productores rurales. La apertura del sector de telecomunicaciones a partir de 2009 ha incentivado el aprovechamiento de plataformas de tecnologías de la información y las comunicaciones (TIC) por parte del sector financiero. Las transacciones en línea y los pagos móviles son ejemplos claros de los efectos positivos que ha provocado la apertura del sector.

Con los programas específicos de la Superintendencia de Telecomunicaciones (SUTEL), por medio de los programas del Fondo Nacional de Telecomunicaciones (FONATEL), se busca reducir la brecha digital de las zonas rurales, propiciando una inclusión financiera en servicios complementarios a la oferta crediticia. Por último, resulta importante mencionar que la presencia de la banca estatal, con 531 sucursales y más de 1.400 cajeros automáticos en todas las regiones del país, ofrece una plataforma amplia para la inclusión financiera de los productores rurales, que, sin embargo, carecen de un programa específico de educación financiera.

En el presente capítulo se analizan las estrategias seguidas en Costa Rica para promover la inclusión financiera de pequeños productores rurales a través de instituciones financieras formales. En la sección A se describe la evolución y la situación actual de los servicios financieros existentes en Costa Rica, con énfasis en los que se brindan en el ámbito rural. En la sección $B$ se reseñan las iniciativas que han promovido la inclusión financiera en el país. En la sección C se examina la arquitectura institucional vigente, 
mientras que en la sección D se identifican los instrumentos de política pública disponibles. Por último, en la sección E se concluye con una reflexión sobre los principales retos que enfrenta la inclusión financiera de pequeños productores rurales en Costa Rica.

\section{A. Evolución reciente del acceso y uso de servicios financieros}

Tal como se puede apreciar en el cuadro III.1, Costa Rica es un país pequeño, con un nivel de ingreso por habitante ligeramente por encima del promedio de América Latina, cuya población adulta es relativamente joven y aún vive sobre todo en zonas rurales.

En términos generales, en lo que respecta a los indicadores de acceso y utilización de servicios financieros formales, Costa Rica tiene una posición favorable comparada tanto con América Latina como con el resto del mundo. La proporción de adultos que son cuentahabientes de una institución financiera formal pasó de un 50,4\% en 2011 a un 64,6\% en 2014. Esta cifra supera no solo el promedio regional, sino también el promedio mundial, lo que se ve reflejado en el porcentaje de la población que usa tarjetas de débito y cajeros automáticos. En lo que concierne a la utilización de servicios financieros, la evidencia es más heterogénea. Si bien la posición favorable con respecto a la región y el mundo se mantiene en la utilización de crédito, el uso de instrumentos de ahorro se ubica por debajo del promedio mundial.

Las cifras sobre transferencias, ahorro y crédito indican un rezago en el uso de servicios móviles como medio de pago. Esto se puede explicar por la apertura relativamente tardía del sector de telecomunicaciones en el país. Hasta 2008, existió un modelo caracterizado por la prestación monopólica de servicios de telecomunicaciones por parte del Instituto Costarricense de Electricidad (ICE), situación que generó brechas importantes que aún persisten con respecto a América Latina ${ }^{5}$. Sin embargo, la implementación de sistemas de pagos móviles, donde se destaca el SINPE Móvil, lanzado en 2015, debería incidir positivamente en la distribución de servicios financieros a través de plataformas móviles.

De acuerdo con cifras publicadas por la Asociación Bancaria Costarricense (Camacho y Jiménez, 2010), la población con acceso a servicios financieros pasó de un $46,3 \%$ en 2010 a un 58,2\% en 2015, principalmente por la expansión de la cobertura de parte de la banca. Esta expansión compensó las reducciones en la cobertura de entes financieros no bancarios, que pasó de un $5,3 \%$ a un $3,5 \%$, y en la utilización de servicios financieros informales, que se redujo de un $4,8 \%$ a un $2,1 \%$ durante el mismo período.

El ICE es el monopolio estatal dela generación y distribución de electricidad y telecomunicaciones. 
Cuadro III.1

Costa Rica, América Latina y el Caribe y resto del mundo: indicadores seleccionados de inclusión financiera, 2011-2014

\begin{tabular}{|c|c|c|c|}
\hline Detalle & Mundo & $\begin{array}{c}\text { América Latina } \\
\text { y el Caribe }\end{array}$ & Costa Rica \\
\hline Población de más de 15 años (en millones) & 5231,2 & 428,2 & 3,7 \\
\hline PIB per cápita (en dólares) & 10683,0 & 9542,0 & 9550,0 \\
\hline \multicolumn{4}{|l|}{$\begin{array}{l}\text { Datos generales (población de más de } 15 \text { años) } \\
\text { (en porcentajes) }\end{array}$} \\
\hline Total adultos & 61,5 & 51,4 & 64,6 \\
\hline Mujeres & 58,1 & 48,6 & 60,2 \\
\hline Adultos que pertenecen al $40 \%$ más pobre & 54,0 & 41,2 & 61,3 \\
\hline Adultos jóvenes (de 15 a 24 años) & 46,3 & 37,4 & 61,6 \\
\hline Adultos que viven en zonas rurales & 56,7 & 46,0 & 67,3 \\
\hline \multicolumn{4}{|l|}{$\begin{array}{l}\text { Cuenta en institución financiera (población de más } \\
\text { de } 15 \text { años) (en porcentajes) }\end{array}$} \\
\hline Total adultos, 2014 & 60,7 & 51,1 & 64,6 \\
\hline Total adultos, 2011 & 50,6 & 39,3 & 50,4 \\
\hline \multicolumn{4}{|l|}{$\begin{array}{l}\text { Acceso a una cuenta en instituciones financieras } \\
\text { (población de más de } 15 \text { años) (en porcentajes) }\end{array}$} \\
\hline Cuenta con tarjeta de débito, 2014 & 40,1 & 40,4 & 53,6 \\
\hline Cuenta con tarjeta de débito, 2011 & 30,5 & 28,9 & 43,8 \\
\hline $\begin{array}{l}\text { Cajero automático como principal modo de retiro } \\
\text { (en porcentajes con cuenta), } 2014\end{array}$ & & 71,1 & 83,2 \\
\hline $\begin{array}{l}\text { Cajero automático como principal modo de retiro } \\
\text { (en porcentajes con cuenta), } 2011\end{array}$ & 48,3 & 57,0 & 72,2 \\
\hline \multicolumn{4}{|l|}{$\begin{array}{l}\text { Pagos digitales en el último año (población de más } \\
\text { de } 15 \text { años) (en porcentajes) }\end{array}$} \\
\hline Utiliza una tarjeta de débito para realizar pagos & 23,2 & 27,7 & 35,3 \\
\hline Utiliza una tarjeta de crédito para realizar pagos & 15,1 & 18,0 & 10,8 \\
\hline Utiliza Internet para pagar facturas o hacer compras & 16,6 & 6,9 & 10,4 \\
\hline \multicolumn{4}{|l|}{$\begin{array}{l}\text { Ahorros en el último año (población de más de } \\
15 \text { años) (en porcentajes) }\end{array}$} \\
\hline Ahorros en una institución financiera, 2014 & 27,4 & 13,5 & 24,2 \\
\hline Ahorros en una institución financiera, 2011 & 22,6 & 9,6 & 19,9 \\
\hline \multicolumn{4}{|l|}{$\begin{array}{l}\text { Créditos en el último año (población de más de } \\
15 \text { años) (en porcentajes) }\end{array}$} \\
\hline Préstamos de una institución financiera, 2014 & 10,7 & 11,3 & 12,7 \\
\hline Préstamos de una institución financiera, 2011 & 9,1 & 7,9 & 10,0 \\
\hline
\end{tabular}

Fuente: Elaboración propia, sobre la base de cifras de Banco Mundial, Base de datos Global Findex, 2014.

El principal producto financiero utilizado es la cuenta corriente denominada en colones, utilizada sobre todo por hombres de entre $35 \mathrm{y}$ 44 años, pertenecientes al nivel socioeconómico alto. Es preciso destacar que mientras un $61 \%$ de los encuestados en la gran área metropolitana en torno a San José indican contar con una cuenta de ahorro, la proporción alcanza al $66 \%$ en el resto del país. Entre las principales razones para no disponer de una cuenta de ahorro se mencionan la insuficiencia de ingresos y la preferencia por el uso de efectivo. 
Con respecto a la motivación para contar con una cuenta de ahorro, el 70,7\% de los encuestados indican haberla adquirido en forma voluntaria, mientras que un $23,1 \%$ y un $8,8 \%$, respectivamente, dicen contar con ella por requisito o decisión del patrono, presumiblemente para el pago de nómina, o de una institución, sobre todo para recibir los depósitos de regímenes no contributivos administrados por la Caja Costarricense del Seguro Social.

De acuerdo con el mapeo realizado por el periódico de circulación nacional "El Financiero", el país cuenta con 764 sucursales bancarias y 2.334 cajeros automáticos. Aunque cerca de la mitad de las sucursales y los cajeros se ubican en la zona de San José, se destaca que la mayoría de los cantones del país cuenta con al menos una sucursal bancaria. Aunque la entidad con mayor número de sucursales es el Banco de Costa Rica, el banco con mayor cobertura cantonal es el Banco Nacional de Costa Rica.

\section{B. Las iniciativas de inclusión financiera}

En esta sección se exponen las principales iniciativas de inclusión financiera que el Gobierno de la República ha implementado en los últimos 30 años, resaltando las motivaciones y los objetivos que se persiguieron, así como la institucionalidad por medio de la cual han operado. En la trayectoria reciente, se destaca el papel que ha jugado el acceso a las TIC para expandir la inclusión financiera a zonas rurales. Estas tecnologías han logrado, entre otras cosas, democratizar el acceso a la telefonía y a la conectividad móvil por medio de los proveedores de telecomunicaciones, situación considerada como uno de los puntos de inflexión más importantes en cuanto a los procesos de inclusión financiera en zonas rurales.

La sección inicia con una presentación general de la composición productiva del medio rural en Costa Rica y concluye con un análisis de percepción sobre el alcance que se ha logrado en materia de inclusión financiera, sobre todo dirigida a las zonas rurales.

\section{Composición productiva del medio rural}

Como la mayoría de los países de América Latina, Costa Rica experimentó desde tiempos coloniales un desarrollo productivo eminentemente agrario, basado, a partir de la segunda mitad del siglo XIX, en la producción y exportación de café, así como en productos industriales de la caña de azúcar y banano. Conforme la población fue aumentando y migrando hacia centros urbanos, la producción agropecuaria fue desplazándose cada vez más hacia zonas periféricas. A nivel socioproductivo, se pueden identificar tres hitos que han marcado el desarrollo en las regiones periféricas y rurales en el país.

El primer hito se sitúa en la década de 1830, fecha en que se comenzó a cultivar café, un producto que facilitó la incursión de Costa Rica en el 
mercado internacional. El segundo ocurrió a partir del desarrollo ferroviario en la década de 1880 con la introducción del banano, que fue explotado principalmente por compañías extranjeras y adquirió la forma de un enclave, lo que limitó el desarrollo de las zonas periféricas y rurales del país. El hito más reciente tuvo lugar en la década de 1980, cuando, a raíz de la crisis del modelo agroexportador, la estructura productiva del país tuvo un cambio significativo. La adopción de los programas de ajuste estructural significó el abandono de los subsidios a actividades agrícolas como el cultivo de granos básicos, café y banano, que fueron cediendo terreno a productos no tradicionales como la piña, pero sobre todo a una economía más orientada al comercio y los servicios.

$\mathrm{Al}$ tener las actividades productivas una relación directa con las fuentes de financiamiento, la disponibilidad de financiamiento para los productores rurales se vio afectada como consecuencia de la reducción del aporte agropecuario a la economía costarricense y solo fue posible sostenerla en el tiempo gracias a la estrategia expansiva que utilizó la banca pública.

En el gráfico III.1 se puede observar que durante el período 1950-1984 el aumento en la cantidad de fincas fue sostenido, situación que se revierte a partir de ese año producto de un cambio en la actividad socioproductiva que se realiza en el país y que en los últimos años ha estado orientada a la producción de microprocesadores, turismo y comercio en general.

Gráfico III.1

Costa Rica: cantidad de fincas por censo, 1950-2014

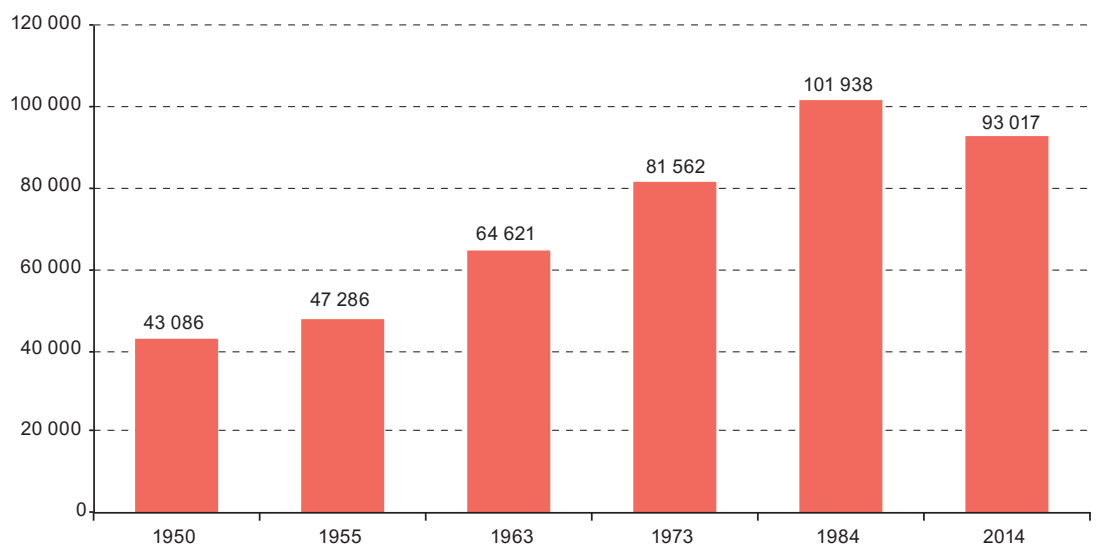

Fuente: Elaboración propia, sobre la base de Instituto Nacional de Estadística y Censos (INEC), "VI Censo Nacional Agropecuario. Características de las fincas y de las personas productoras", San José, 2015.

a Para los censos de 1950, 1955 y 1963, una finca era una extensión de terreno de una manzana o más. Para los censos de 1973, 1984 y 2014 no hubo restricción al respecto. 
De acuerdo con la información censal, el cultivo de café y la explotación pecuaria son las principales actividades en más del $52 \%$ de las fincas y las más tradicionales en la producción agropecuaria de Costa Rica. Por provincia, la mayor cantidad de fincas se registra en la provincia de Alajuela, con 25.176 fincas ( $27 \%$ ), ya que esta provincia tiene cantones eminentemente rurales como los ubicados en la zona norte. Las provincias llamadas periféricas tienen, en conjunto, el $37 \%$ de las fincas registradas en el censo, según el siguiente detalle: Limón tiene un 9,7\%, Guanacaste agrupa el 11,7\% y Puntarenas, la provincia más extensa de Costa Rica, tiene un $15,6 \%$.

Es importante señalar que la reducción de la cantidad de fincas ha sido producto de la urbanización experimentada por el país. Este proceso ha ido acompañado de un aumento en el tamaño medio de las fincas, en especial en la provincia de Guanacaste, donde se ubican grandes haciendas productoras de caña de azúcar, arroz y ganado bovino, y en la provincia de Puntarenas, donde la producción se concentra en palma aceitera, arroz y piña.

\section{La evolución del sistema financiero}

El sistema financiero costarricense tiene algunas particularidades dignas de analizar que han incidido en el grado de inclusión financiera vigente, incluso en ausencia de una política pública integral sobre este tema.

Como se mencionó, la introducción y expansión del cultivo de café produjo importantes cambios en la economía costarricense. Uno de ellos fue la aparición de las primeras entidades bancarias alrededor de 1863 con la creación del Banco Anglo Costarricense, constituido con capital privado. En 1872 apareció el primer proyecto de Banco Rural de Crédito Hipotecario con el fin de promover y ayudar a la agricultura, colaborando con la baja de la tasa de interés. En 1914, el Poder Ejecutivo encargó al Banco Internacional la creación y organización de las Juntas de Crédito Agrícola, manifestando que para la instauración de dichas Juntas se debía dar preferencia a los distritos que contribuyeran en mayor proporción al abastecimiento de la economía ${ }^{6}$. La creación del Banco Internacional tuvo un efecto positivo sobre la colectividad costarricense, especialmente en el campo rural, debido a la ayuda financiera otorgada a la agricultura.

Desde su creación, los bancos públicos han estado ligados al proceso de financiamiento de actividades que se realizan en el ámbito rural. Tanto es así que en la actualidad, 78 de los 81 cantones que tiene Costa Rica poseen al menos una sucursal bancaria de algún banco público.

El Banco Internacional, que en 1933 cambió de nombre a Banco Nacional de Costa Rica, es de propiedad estatal. 
De los tres bancos públicos (Banco Nacional de Costa Rica, Banco de Costa Rica y Banco Crédito Agrícola de Cartago), y tomando en consideración también el Banco Popular, creado mediante una ley específica, el Banco Nacional es el que ha puesto en marcha desde sus orígenes una política de inclusión financiera. La implementación de las Juntas Rurales que se explicarán a continuación representa el ejemplo más explícito de la forma en que este banco logró llegar hasta los sitios más alejados de Costa Rica.

Desde 1914, con la creación de las Cajas Rurales de Crédito en el Banco Internacional de Costa Rica, se puso en evidencia el interés de las autoridades por mejorar el acceso de los productores rurales al crédito. Con las Cajas, se introdujeron dos innovaciones institucionales importantes, que en buena medida explicaron su éxito.

En primer lugar, la asignación de los préstamos se encomendó a una Junta de cinco vecinos que decidían, con considerable autonomía, quiénes eran sujetos de crédito. En segundo término, los integrantes de las Juntas eran responsables de la recuperación de los préstamos (lo que garantizaban con una hipoteca personal) y durante algún tiempo el Banco les pagó una comisión por los préstamos recuperados.

La situación del pequeño productor endeudado empeoró con la Primera Guerra Mundial, cuando muchos no pudieron saldar sus compromisos y perdieron cosechas y propiedades. El Banco Internacional propuso que las Juntas Rurales tuvieran un carácter distrital. En un principio, se establecerían en aquellos distritos conocidos por su contribución al abastecimiento de víveres y capaces de producir mejores resultados, tanto por los recursos a disposición como por el capital humano.

Las Juntas estaban integradas por un mínimo de 3 miembros y un máximo de 5, mayores de 25 años, vecinos del lugar, agricultores y propietarios de bienes sin gravámenes. Los miembros de la Junta eran elegidos por el Banco y entre ellos seleccionarían al presidente, secretario y tesorero de la Junta. Una vez organizada, el Banco destinaría el dinero que considerara conveniente para el desarrollo de la agricultura en el distrito elegido. Las personas interesadas en un crédito debían explicar el destino del dinero, las condiciones de devolución y la garantía ofrecida al Banco. Cada solicitud era examinada por los miembros de la Junta, quienes tenían que velar por que la garantía fuera satisfactoria, la devolución del dinero no demorara más de un año y el dinero se utilizara en labores agrícolas.

En 1938, el Banco Nacional promulgó un nuevo reglamento mediante el cual las Juntas Rurales en adelante dependerían de la Sección de Juntas Rurales de Crédito Agrícola, encargada de dirigir y controlar sus operaciones, organizar el crédito rural en virtud de normas racionales y educar al pequeño 
productor. Las Juntas nombrarían un delegado inspector, quien debía ser ingeniero agrónomo o un buen conocedor de la región y su producción agrícola. Con el nuevo reglamento, las Juntas rurales se organizaron en circuitos. Los primeros cuatro circuitos fueron Puriscal, Orotina, Santa Cruz de Guanacaste y Turrialba. Las actividades que financiaban las Juntas Rurales eran bastante diversas e incluían productos tradicionales de exportación, como café, caña de azúcar y ganadería, y productos de subsistencia, como maíz, arroz y frijoles.

Desde su fundación en 1914, las Juntas Rurales no solo se encargaron de brindar crédito de avío agrícola, de avío ganadero, refaccionario o de fomento rural, sino también de ofrecer asistencia técnica. La asistencia se consideró vital para que los agricultores alcanzaran, en el mediano y largo plazo, el progreso económico y social que desde un principio el Banco Nacional se propuso con su establecimiento. Después de 1950, las Juntas Rurales continuaron asignando crédito para el desarrollo de una agricultura de subsistencia (granos básicos) y una agricultura comercial (café, banano, cacao, caña).

También aumentó el interés por el fomento ganadero, cuando el país se insertó en el mercado internacional con la exportación de carne y el mercado interno se dinamizó, y hubo una clara intención de tecnificar el campo costarricense a partir de la mecanización de la agricultura. En esta labor, las Juntas Rurales trabajaron durante algunos años en conjunto con el Servicio Técnico de Cooperación Agrícola y el Consejo Nacional de Producción.

Todas las provincias del país fueron atendidas por dos o más Juntas y así el Banco Nacional cumplió con el propósito de difundir los servicios de crédito rural en todo el territorio nacional. La expansión de las Juntas rurales y su importancia para el financiamiento rural continuaron durante las décadas de 1950 y 1960, pero a mediados de los años setenta, y en especial con la crisis económica de principios de la década de 1980, la importancia de las Juntas fue disminuyendo. Esta contracción, que se hace patente en el número de operaciones y en los montos prestados, se observó tanto a nivel geográfico como por actividades.

Con el cambio del modelo productivo de Costa Rica y con el proceso de apertura del sector financiero en 1998, las Juntas Rurales del Banco Nacional desaparecieron. Sin embargo, con la creación del Sistema de Banca para el Desarrollo (SBD) y con el afán de cumplir con el objetivo de regionalización, recientemente se ha planteado un proyecto para rescatar la figura de las Juntas Rurales del Banco Nacional, que serían las encargadas de llevar a los productores rurales los recursos del SBD.

El sistema financiero costarricense, establecido mediante la Ley Orgánica del Sistema Bancario Nacional (Ley núm. 1644), promulgada el 
26 de septiembre de 1953, así como la Ley Orgánica del Banco Central de Costa Rica (Ley núm. 1552), del 23 de abril de 1953 y sus reformas posteriores, fija la constitución, naturaleza, operaciones y disposiciones que rigen la actividad bancaria en el país. Estas leyes fueron creadas para dar el debido ordenamiento operativo a las actividades bancarias, autorizando la operación de bancos privados. En esa época solo existía el Banco Lyon y sus funciones estaban limitadas por el decreto de Nacionalización Bancaria (1948), ya que no podía captar del público ahorros a la vista y la principal fuente de recursos eran los depósitos a plazo denominados certificados de inversión.

En los primeros meses de la administración Carazo (1978-1982), se suscitó un amplio debate en torno al sistema bancario nacional. Se llevó a cabo una campaña tendiente a demostrar que la banca nacionalizada estaba expuesta a que primaran más los criterios políticos que los criterios económicos y que estas instituciones eran incapaces de responder a las necesidades del país. Se volvió a mencionar la posibilidad de terminar con el monopolio de los depósitos que tenía el Estado, con el propósito de permitir la competencia de la banca privada. Durante la administración Carazo se aprobaron algunas medidas que, si bien no implicaban un rompimiento del monopolio de los depósitos a la vista, constituían un paso hacia la decisión de dejarlos al libre juego de las fuerzas económicas del mercado.

Estas tesis fueron sustentadas por el Ministerio de Hacienda y la Junta Directiva del Banco Central. La reforma de la Ley de la Moneda, aprobada el 19 de agosto de 1984, permitió un mayor ámbito de acción a la banca privada y le posibilitó el acceso a programas crediticios del Banco Central en los mismos términos en que participan los bancos estatales. En un lapso de 30 años, y bajo estas condiciones, se constituyeron 4 bancos privados: a) Banco Lyon, S.A. (14 de abril de 1947); b) Banco de América Central, S.A., actualmente BAC San José (19 de septiembre de 1968); c) Banco de Santander, posteriormente Banco Fincomer, S.A. (6 de diciembre de 1977), y d) Banco del Comercio, S.A. (5 de febrero de 1979).

En la década de 1980 se verificó un auge en la creación de bancos privados. En 1988, el Banco Central autorizó a dichas entidades a captar recursos por medio de certificados de depósito. En ese mismo año comenzaron a operar el Banco Banex y el Banco Internacional de Exportaciones, S.A. Este último se declaró en quiebra a fines de los años ochenta.

En 1982 se crearon tres nuevas entidades bancarias: el Banco Cooperativo Costarricense, R.L., el Banco Interfin, S.A. y el Banco Weeden Internacional, S.A. (declarado en quiebra en 1989). En 1984 abrieron sus puertas el Banco BCT, S.A. y el Banco de Fomento Agrícola, S.A. En 1985 entraron en operaciones tres bancos más: el Banco de la Industria, S.A., el Banco Metropolitano, S.A. y el Banco Cooperativo de Alajuela, R.L. En 1986 se establecieron el Banco 
Continental y el Banco Cofisa, S.A., y en 1987 se crearon el Banco Mercantil de Costa Rica y el Banco Germano Centroamericano, que se declaró en quiebra en 2000.

A lo largo de los años, se confirmaron algunas ventajas de la banca privada, entre las que se destacan su mayor flexibilidad para contratar bienes y servicios y un régimen de personal mucho más flexible. Aunque la regulación y supervisión prudencial se aplica a bancos públicos y privados por igual, los primeros están sujetos a un mayor escrutinio, en virtud de principios de origen constitucional que rigen en el sector público, como el principio de legalidad, el acceso al expediente administrativo, la fiscalización de la Contraloría y otros.

En la actualidad son muy pocos los bancos privados que tienen presencia en zonas periféricas y que financian a productores rurales, dado que estas entidades atienden el nicho de mercado conformado por las medianas y grandes empresas. De los bancos privados, recientemente solo el BAC San José ha implementado un proyecto de financiamiento a pequeñas empresas, pero no se trata de un programa dirigido a productores rurales, sino a empresas formales en marcha.

Al igual que ocurre en países como la Argentina y México, la utilización de la figura del fideicomiso orientado a productores rurales se constituyó en Costa Rica como un instrumento de política pública que ha permitido crear soluciones a problemas específicos. La proliferación en el país de la figura jurídica del fideicomiso, que permite aislar bienes, flujos de fondos, negocios, derechos y demás en un patrimonio independiente y con finalidades específicas, data de unos 20 años.

En general, estos fidecomisos se han utilizado como la principal herramienta de política pública para encausar acciones gubernamentales hacia el sector agropecuario, sobre todo cuando se reciben fondos de cooperación internacional o cuando, por alguna situación particular, se requiere atender una región o actividad específica.

Quizás el fideicomiso de mayor relevancia para el desarrollo rural sea el Fideicomiso para la protección y el fomento agropecuarios para pequeños y medianos productores (FIDAGRO), creado en 2001 con la finalidad de reactivar unidades productivas?

A los efectos del fideicomiso, por pequeños productores agropecuarios se entienden todos los productores que explotan unidades económicas en las que la participación de la familia es del $75 \%$, que la mayor parte de la producción está destinada a la subsistencia y solo los excedentes se colocan en el mercado nacional, y los ingresos anuales brutos son inferiores a 25.000 dólares anuales (o su equivalente en moneda nacional). 


\section{La apertura de las telecomunicaciones y su papel en la inclusión financiera}

Es indiscutible el papel fundamental que han tenido las TIC en el desarrollo de las actividades cotidianas del mundo moderno. En esta sección se rescata el papel decisivo que ha jugado el acceso a las TIC para expandir la inclusión financiera a zonas rurales. Entre otras cosas, en los últimos años, estas tecnologías han logrado democratizar el acceso a la telefonía y a la conectividad móvil por medio de los proveedores de telecomunicaciones, situación que ha sido considerada como uno de los puntos de inflexión más importantes en cuanto a los procesos de inclusión financiera en zonas rurales.

Al ICE, fundado mediante la Ley de Creación del Instituto Costarricense de Electricidad (Ley núm. 449) del 8 de abril de 1949, le fueron otorgadas las facultades para brindar servicios de telecomunicaciones, con la consecuente asignación de frecuencias del espectro radioeléctrico para su uso. Desde el comienzo, en virtud de la Ley núm. 449, se creó un instituto multisectorial, vinculado particularmente al desarrollo de la producción de la energía eléctrica. Acostumbrado a un escenario monopólico, el ICE y sus empresas constituyen el denominado "operador histórico", por su participación preponderante en el mercado nacional.

La Ley núm. 449 fue modificada mediante la Ley núm. 3226 del 28 de octubre de 1963, que, de manera más específica, brindó al ICE las facultades para la operación de redes y suministro de servicios de telecomunicaciones, estableciendo las condiciones de prestación del servicio bajo un esquema de servicio público.

La reforma planteada en octubre de 1963 asigna competencias específicas a la empresa pública para el desarrollo de la actividad propia del sector de telecomunicaciones. En forma paralela, mediante la Ley núm. 3293 del 18 de junio de 1964, se creó la Radiográfica Costarricense, S.A. (RACSA) por medio del traspaso de la concesión para los servicios de telecomunicaciones antes referidos al ICE, y este, a su vez, se asoció con RACSA, una empresa constituida como sociedad anónima que por mucho tiempo contó con una importante proporción del mercado en lo que respecta a acceso a Internet.

Los antecedentes normativos en materia de telecomunicaciones evidencian una legislación omisa y dispersa. Tanto el ICE como RACSA han gozado de una condición especial y en la práctica han operado bajo lo que se denomina "monopolio de hecho". El ámbito de las atribuciones legales de la autoridad de regulación multisectorial, la Autoridad Reguladora de los Servicios Públicos (ARESEP), se encontraba bastante restringido con respecto al sector de telecomunicaciones, con funciones de regulación relativamente estrechas, según se desprende de la propia Ley de la Autoridad Reguladora de los Servicios Públicos (Ley núm. 7593), del 9 de agosto de 1996. Los servicios 
de telecomunicaciones que presta el ICE eran los únicos que se encontraban sujetos a regulación. Los entes públicos, como RACSA, no estaban sujetos a la regulación de la ARESEP.

Las telecomunicaciones en Costa Rica han permanecido históricamente bajo un esquema de monopolio público. No obstante, debido a la creciente actividad comercial internacional y a distintos aspectos ligados al libre comercio, a partir de 2008 el país inició un proceso de apertura de este mercado. Esto permitió la entrada de nuevas empresas de telecomunicaciones y trajo consigo un mayor avance tecnológico y más facilidad de acceso a estos servicios, lo que, a su vez, provocó una ruptura con los paradigmas del monopolio natural bajo los cuales se fundamentaba el mantenimiento de monopolios públicos.

De acuerdo con los procesos de apertura comercial gestados desde mediados de la década de 1990 y culminados con la firma del Tratado de Libre Comercio entre República Dominicana, Centroamérica y los Estados Unidos, Costa Rica se vio forzada a sumarse a la nueva realidad imperante del sector de telecomunicaciones, situación que se consolidó a partir del rompimiento del monopolio que hasta 2008 había estado en manos del área de telecomunicaciones del ICE.

En general, Costa Rica ha optado por un modelo de apertura regulada y orientada por el Estado. La normativa transformadora del sector plantea la apertura en términos de competencia con una efectiva regulación, con políticas claras en la definición del proceso de desarrollo del sector. Este modelo pretende garantizar la competencia efectiva, privilegiando la transparencia del mercado, lo que se traduce en beneficios para el usuario final de los servicios, además de un flujo continuo de inversión en el sector para su desarrollo.

Asimismo, el modelo pretende ser inclusivo y procura el acceso no discriminatorio de todos los habitantes a los servicios de telecomunicaciones, independientemente de su condición geográfica o socioeconómica. En el entorno del comercio regional, y más allá del compromiso adquirido por el país en el marco del Tratado de Libre Comercio entre República Dominicana, Centroamérica y los Estados Unidos, las iniciativas legales promulgadas recientemente obedecen a ese nuevo orden dinámico de las tecnologías de las telecomunicaciones en el mundo.

Dentro de este nuevo contexto de operación de las telecomunicaciones, en donde la apertura trajo consigo una competencia de los proveedores de telefonía móvil e Internet, se hizo necesaria la creación de un ente de fiscalización especializado en esta temática.

Si bien Costa Rica cuenta con un órgano regulador multisectorial - la ARESEP, a la cual corresponde el desarrollo de un marco reglamentario 
para temas tales como el régimen de competencia, el régimen de acceso e interconexión, el marco de solidaridad y acceso universal, el régimen de protección del usuario y el régimen de fijación tarifaria-, se optó por el establecimiento de un órgano regulador especializado como condición crítica para el éxito de la apertura. La creación de la SUTEL, órgano de desconcentración máxima adscrito a la ARESEP, responde a esta necesidad.

En general, la apertura de las telecomunicaciones marcó un hito en la democratización del acceso a la telefonía móvil e Internet, situación que también ha impactado de forma muy significativa en el proceso de inclusión financiera. Esto se debe a que el desarrollo de plataformas tecnológicas y móviles ha dado un salto cualitativo y cuantitativo, y las instituciones financieras han logrado acercarse aún más a la población urbana y rural.

Con el proceso de apertura de las telecomunicaciones y la creación de la SUTEL, se creó también el FONATEL, que tiene como propósito llevar telefonía e Internet a zonas y comunidades donde aún no hay servicio, promoviendo el acceso universal, el servicio universal y la solidaridad establecidos en la Ley General de Telecomunicaciones (Ley núm. 8642).

Con estas medidas, el FONATEL busca reducir la brecha digital, garantizar mayor igualdad de oportunidades, así como el disfrute de los beneficios de la sociedad de la información y el conocimiento por medio del fomento de la conectividad, el desarrollo de infraestructura y la disponibilidad de dispositivos de acceso y servicios de banda ancha.

Hasta la fecha, el FONATEL ha puestos en marcha cuatro programas que pueden incidir de forma directa en un aumento en el acceso a la conectividad por parte de la población de zonas rurales, lo que llevaría, en principio, a que las instituciones financieras también puedan ofrecer sus productos y servicios a estas zonas. A continuación se hace una breve explicación de los programas creados por el FONATEL.

\section{Programa Comunidades Conectadas}

Este Programa busca ampliar la oferta de servicios de telecomunicaciones a la población y centros de prestación de servicios públicos ubicados en zonas rurales, alejadas y catalogadas en condición de vulnerabilidad social, económica y cultural. Los centros definidos son: escuelas y colegios públicos, sedes de equipos básicos de atención integral en salud, centros de educación y nutrición, y centros infantiles de atención regional, así como centros comunitarios inteligentes.

A través de este Programa, el FONATEL financia el despliegue de infraestructura en las zonas objetivo y la conectividad a los centros de prestación de servicios públicos seleccionados por las instituciones competentes. 
El Programa Comunidades Conectadas es administrado y ejecutado por la SUTEL y forma parte de la Agenda de Solidaridad Digital del Plan Nacional de Desarrollo de las Telecomunicaciones y de la Estrategia Digital de Costa Rica (Costa Rica Digital), con la visión de universalizar el acceso de los servicios de telecomunicaciones en todo el país.

\section{Programa Hogares Conectados}

Este Programa es una iniciativa de la SUTEL, como administradora y ejecutora de los programas y proyectos del FONATEL, para dotar de una conexión de Internet fija a los hogares precalificados en las bases de datos del Instituto Mixto de Ayuda Social (IMAS) y una computadora portátil que genere oportunidades de desarrollo, educación y productividad. El FONATEL paga una parte de la factura de la conexión a Internet y la computadora portátil con recursos que aportan todas las empresas de telefonía, Internet y televisión por cable del país.

\section{Programa Centros Públicos Equipados}

Se trata de una iniciativa de la SUTEL, como responsable de la administración y ejecución del FONATEL, para dotar de dispositivos de acceso a Internet de banda ancha a los centros de prestación de servicios públicos, incluidos los centros educativos del Ministerio de Educación Pública, los Centros Comunitarios Inteligentes, los Centros de Educación y Nutrición, los Centros Infantiles de Atención Integral y los hospitales, las áreas de salud y las clínicas de la Caja Costarricense del Seguro Social, a los que se ha llevado conectividad a Internet en el marco del Programa Comunidades Conectadas. Este Programa tiene previsto entregar un total de 40.000 dispositivos en 2 etapas, durante el bienio 2016-2018. El Programa Centros Púbicos Equipados también forma parte del Programa Costa Rica Digital del Gobierno de la República.

\section{Programa Espacios Públicos Conectados}

Es una iniciativa de la SUTEL, a través del FONATEL, para proveer una red nacional de banda ancha de acceso gratuito a Internet mediante conexiones inalámbricas en espacios públicos de los principales distritos de los cantones seleccionados por medio de instrumentos objetivo provistos por el Estado.

A través de este Programa, el FONATEL financia una red de alta capacidad para la colocación de puntos de acceso a Internet en zonas públicas con el propósito de que los usuarios puedan acceder gratuitamente a Internet con determinadas características, por ejemplo, restricciones de tiempo de uso, identificación de usuario y seguridad adecuada al tipo de servicio, como bloqueo de contenido. El Programa Espacios Públicos Conectados también forma parte del Programa Costa Rica Digital del Gobierno de la República. 


\section{Alcance logrado por las iniciativas públicas para fomentar la inclusión financiera}

A pesar de que en Costa Rica no existe una política pública integral orientada a incentivar y normar la inclusión financiera, la práctica indica que desde el Gobierno se han diseñado programas y herramientas que han incentivado la inclusión financiera a nivel general. Para los productores rurales se pueden identificar algunas iniciativas puntuales, relacionadas directamente con la implementación y puesta en marcha del SBD que se analizará más adelante.

Como ya se indicó, la cobertura de los bancos estatales y del Banco Popular alcanza las 531 sucursales, con 1.402 cajeros automáticos ubicados en todas las cabeceras de los cantones del país, lo que constituye una importante herramienta de inclusión financiera.

Los sistemas de protección social, como las pensiones del régimen no contributivo, los programas de ayuda del IMAS o el Fondo Nacional de Becas (FONABE), han exigido como parte de los requisitos a los beneficiarios la apertura de cuentas de ahorros en algún banco del sistema bancario estatal a fin de transferir a esas cuentas los recursos provenientes de estos programas. Este aspecto ha contribuido a fomentar el acceso a servicios financieros en Costa Rica.

Las cuentas de expediente simplificado comenzaron a operar en el segundo semestre de 2015 y se estima que, producto de su implementación, el 35\% de los ciudadanos mayores de 15 años que actualmente no tienen acceso a servicios financieros formales (1,4 millones de personas) tendrán la opción de abrir una cuenta de fondos en una entidad financiera. De este modo, podrán empezar a construir un historial que los califique para acceder a productos crediticios, de ahorro y de seguros, y usar los diferentes canales disponibles en el sistema financiero nacional para la movilización del dinero por medios electrónicos.

La implementación de este nuevo tipo de cuentas también ofrecerá a las entidades financieras condiciones operativas que les permitirán reducir los costos asociados al cumplimiento de la política "Conozca a su cliente" y concentrar sus actividades de supervisión y seguimiento en los clientes que manifiesten riesgos relevantes para la legitimación de capitales y el financiamiento al terrorismo.

Sumando a ello, con las cuentas de expediente simplificado se busca que los sectores de la población de bajos ingresos dispongan de más oportunidades de acceso a la oferta de servicios de las entidades financieras mediante la eliminación de requisitos documentales y de información que actualmente los descalifican como clientes y les imponen costos altos en relación con sus posibilidades económicas. 
En principio, el proceso de bancarización por medio de las cuentas de expediente simplificado ampliará la base de clientes de las entidades financieras y facilitará la implementación de nuevos servicios en la industria, lo que puede contribuir a mejorar la eficiencia en las decisiones de ahorro, consumo e inversión de los agentes económicos.

El servicio SINPE Móvil es un nuevo mecanismo de pagos, construido con el apoyo de las principales instituciones financieras de Costa Rica y el soporte tecnológico del Sistema Nacional de Pagos Electrónicos (SINPE), puesto en funcionamiento el 7 de mayo de 2015 por parte del Banco Central.

Gracias a este servicio, las personas que posean una cuenta en colones en un banco comercial, mutual de ahorro y préstamo o cooperativa de ahorro y crédito, y que dispongan de una línea de teléfono móvil activa, tienen la opción de ejecutar pagos desde cualquier canal de banca electrónica a una cuenta de fondos asociada a un número de teléfono móvil.

El SBD está constituido por todos los intermediarios financieros públicos, el Instituto Nacional de Fomento Cooperativo (INFOCOOP), las instituciones públicas prestadoras de servicios no financieros y de desarrollo empresarial, y las instituciones u organizaciones estatales y no estatales que canalicen recursos públicos para el financiamiento y la promoción de proyectos productivos. Su objetivo es financiar e impulsar proyectos productivos viables, acordes con el modelo de desarrollo del país en lo referente a la movilidad social de los sujetos beneficiarios:

- Emprendedores: persona o grupo de personas que tienen la motivación y capacidad de detectar oportunidades de negocio, organizar recursos para su aprovechamiento y ejecutar acciones de forma tal que obtienen un beneficio económico o social por ello. Se entiende como una fase previa a la creación de una microempresa.

- Microempresas: unidades empresariales que cuentan con menos de 15 empleados.

- Pequeñas y medianas empresas: unidades empresariales que cuentan con entre 16 y 30 empleados.

- Micro, pequeño y mediano productor agropecuario: unidad de producción que incluye los procesos de transformación, mercadeo y comercialización que agregan valor a los productos agrícolas, pecuarios, acuícolas, forestales, pesqueros y otros productos del mar, así como la producción y comercialización de insumos, bienes y servicios relacionados con estas actividades.

- Modelos asociativos empresariales: mecanismos de cooperación por los cuales se establecen relaciones o articulaciones entre cualquiera de los sujetos beneficiarios del SBD. 
La ley establece como prioritarios los proyectos impulsados por mujeres, adultos mayores, minorías étnicas, personas con discapacidad, jóvenes emprendedores, asociaciones de desarrollo y cooperativas, los microcréditos atendidos por medio de microfinancieras y los proyectos que se ajusten a los parámetros de la ley y sean promovidos en zonas de menor desarrollo relativo, definidas por el índice de desarrollo social calculado por el Ministerio de Planificación Nacional y Política Económica (MIDEPLAN). En principio, estas políticas de financiamiento y apoyo no financiero posibilitarán un acceso equitativo de estos grupos a créditos, avales, garantías, condiciones y servicios no financieros y de desarrollo empresarial.

Asimismo, tendrán tratamiento prioritario los proyectos que incorporen o promuevan el concepto de producción más limpia, entendiéndose como una estrategia preventiva integrada que se aplica a los procesos, productos y servicios a fin de aumentar la eficiencia y reducir los riesgos.

\section{Arquitectura institucional}

A principios de los años ochenta se introdujo un conjunto de reformas orientadas a la modernización del sistema financiero costarricense. Entre ellas se destacan la liberalización de las tasas de interés y del crédito, la apertura de la cuenta de capital, la mayor flexibilidad de los bancos privados para captar recursos y las mejoras al marco regulatorio.

A mediados de la década de 1990, con la aprobación de la nueva Ley Orgánica del Banco Central de Costa Rica (Ley núm. 7558), se eliminó el monopolio estatal de los depósitos en cuenta corriente, lo que incentivó la competencia por la captación de depósitos entre la banca estatal y privada. La ley también permitió que los bancos privados pudieran acceder al redescuento con el Banco Central y recibir depósitos y otras captaciones en moneda extranjera. En materia de supervisión, se fortalecieron las facultades de la SUGEF y se creó el Consejo Nacional de Supervisión del Sistema Financiero (CONASSIF). También se crearon la Superintendencia de Pensiones (SUPEN), la Superintendencia General de Valores (SUGEVAL) y, más recientemente, la Superintendencia General de Seguros (SUGESE).

Los cambios regulatorios transformaron el entorno financiero. Algunas de las tendencias más destacadas son: una mayor participación de la banca privada, de la banca regional y, más recientemente, de la banca internacional; los procesos de fusiones y adquisiciones; el fortalecimiento de la banca corporativa y minorista; y la salida de instituciones que presentaban altos costos operativos y bajo nivel tecnológico. 


\section{Intermediarios financieros}

A mayo de 2016, el sistema financiero costarricense contaba con 53 entidades supervisadas por la SUGEF. En el cuadro III.2 se presenta la evolución del número de intermediarios para el período 2000-2016 y se nota una reducción de 22 entidades como consecuencia, principalmente, de los procesos de fusiones $\mathrm{y}$ adquisiciones que han experimentado algunos de estos intermediarios y de la desaparición de algunas empresas financieras no bancarias.

Cuadro III.2

Costa Rica: entidades financieras supervisadas por la Superintendencia General de Entidades Financieras (SUGEF)/sistema financiero nacional, 2000, 2005, 2009 y 2016 ${ }^{\text {a }}$

\begin{tabular}{lrrrr}
\hline Grupos de entidades & 2000 & 2005 & 2009 & 2016 \\
\hline 1. Sistema bancario nacional ${ }^{\mathrm{b}}$ & 26 & 17 & 16 & 17 \\
\hline 1.1. Bancos comerciales del Estado & 3 & 3 & 3 & 3 \\
\hline 1.2. Bancos creados por leyes especiales & 2 & 2 & 2 & 2 \\
\hline 1.3. Bancos privados y cooperativos & 21 & 12 & 11 & 12 \\
\hline 2. Empresas financieras no bancarias & 13 & 9 & 6 & 5 \\
\hline 3. Cooperativas de ahorro y crédito & 26 & 28 & 31 & 25 \\
\hline 4. Entidades autorizadas para la vivienda & 4 & 3 & 3 & 2 \\
\hline 5. Otras entidades financieras & 1 & 1 & 1 & 1 \\
\hline 6. Entidades del mercado cambiario & 5 & 2 & 3 & 3 \\
\hline Total de entidades del sistema financiero nacional & 75 & 60 & 60 & 53 \\
\hline 7. Conglomerados y grupos financieros & 21 & 22 & 22 & 19 \\
\hline
\end{tabular}

Fuente: Elaboración propia, sobre la base de cifras de la Superintendencia General de Entidades Financieras (SUGEF).

a Las cifras de 2000, 2005 y 2009 corresponden a diciembre, mientras que las de 2016 corresponden a mayo.

b Dos de estas entidades pueden operar en el mercado de derivados cambiarios y también dos pueden realizar operaciones de cobertura con derivados.

También se destaca, a partir de 2000, la incorporación de nuevos participantes sujetos a la supervisión de la SUGEF, como las entidades especializadas en vivienda y las casas de cambio, y, más recientemente, las entidades que pueden participar en mercados de derivados y otras que pueden realizar operaciones de cobertura. Sin embargo, en términos relativos, el sistema bancario nacional aún representa más del $82 \%$ del total de activos del sistema financiero nacional y este es ampliamente dominado por los bancos estatales, con una participación del 40\%. De acuerdo con cifras de la SUGEF, del total de la cartera de crédito del sistema bancario nacional, apenas un 3,4\% se destina a actividades primarias.

A enero de 2016, la Red Costarricense de Organizaciones para la Microempresa (REDCOM) agrupaba a 18 organizaciones de desarrollo orientadas al financiamiento de la micro y pequeña empresa y atendía a 
13.952 clientes, el $41 \%$ de los cuales son mujeres, y la cartera de crédito alcanza la suma de 30,7 millones de cólones costarricenses, el 85\% de los cuales está colocado en el área rural.

Asimismo, existe una amplia red de microfinancieras que atienden sobre todo al sector rural. Una de sus características fundamentales es que son entes no regulados por la SUGEF, que tienen su propia normativa para otorgar los microcréditos y dan crédito a personas que el sistema bancario no podría considerar como sujetos de crédito.

Cabe señalar que el origen del fondeo de las microfinancieras es la cooperación internacional, así como los recursos colocados a través de operaciones de segundo piso del sistema bancario nacional y más recientemente del SBD.

De acuerdo con la Red Centroamericana y del Caribe de Microfinanzas (REDCAMIF, 2015), las instituciones microfinancieras se caracterizan por ser pequeñas y tener pocos incentivos para formalizarse y ampliar sus actividades debido a la importante participación de la banca estatal. En general, el tamaño de la cartera y el número de clientes se consideran pequeños en comparación con las cifras del sector de microfinanzas a nivel regional, y en términos de calidad de la cartera se observa una mejoría asociada con mejores prácticas en la administración del proceso crediticio. Al haber una mayoría de instituciones no reguladas, el grado de calidad y transparencia contable varía y los estándares más altos se observan solo en las instituciones asociadas a las redes de microfinanzas. En la misma publicación se concluye que la transparencia en los precios, el nivel de protección al cliente y la información crediticia suministrada por las centrales de riesgo son adecuados.

Por su parte, los hallazgos del Microscopio global 2016: Análisis del entorno para la inclusión financiera (EIU/BID, 2016) indican que en Costa Rica se ha rezagado la adopción de políticas de inclusión financiera, comenzando con la aplicación de regulaciones específicas y la creación de capacidad especializada y la promoción de aptitudes mediante programas de educación y conocimientos financieros. En el estudio se destaca que los bancos no se han mostrado activos en cuanto a la concesión de préstamos a clientes de bajos recursos, a pesar de que se les exige destinar recursos a productos específicos para la población de bajos ingresos en el marco del SBD.

\section{Servicios financieros y canales de distribución}

Como se detalla en el cuadro III.3, la oferta de servicios financieros se puede agrupar en tres categorías. 


\section{Cuadro III.3}

\section{Costa Rica: oferta de servicios financieros}

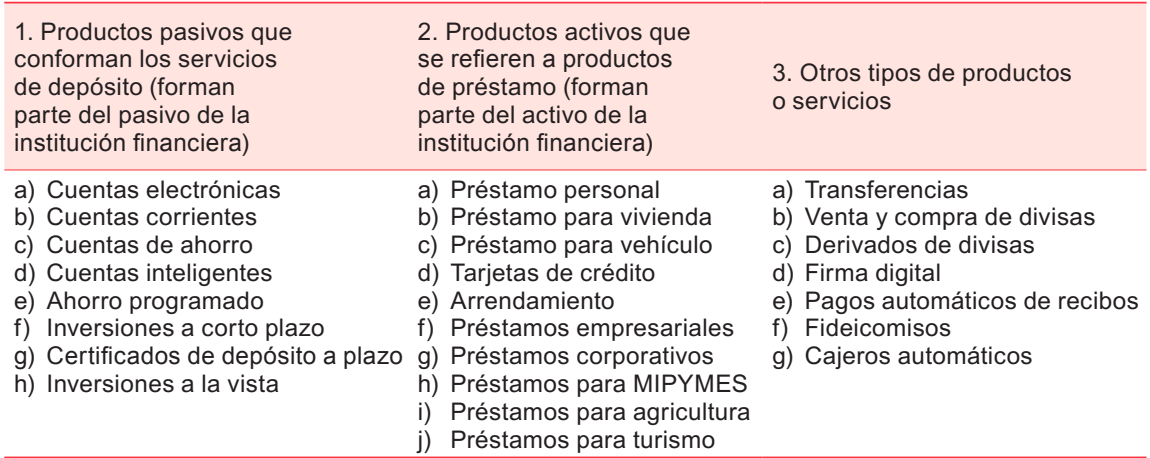

Fuente: Elaboración propia.

Para el primer grupo de servicios, los canales de distribución incluyen sucursales bancarias y corresponsales bancarios, así como banca por Internet y celular. Para este último canal existen opciones para la administración de las inversiones de corto plazo, pero no para la apertura de cuentas. Con la reforma parcial del Reglamento General sobre Legislación Contra el Narcotráfico, Actividades Conexas, Legitimación de Capitales, Financiamiento al Terrorismo y Delincuencia Organizada del Instituto Costarricense sobre Drogas, se pretende que la apertura de cuenta financieras sea de forma más expedita y acelere la bancarización en el país.

Para el segundo grupo de servicios, la administración y el pago de los préstamos otorgados por las entidades financieras se pueden realizar a través de canales electrónicos, como banca por Internet o celular. No obstante, el otorgamiento inicial de cualquiera de estos productos generalmente se debe realizar en una sucursal bancaria o corresponsal.

Para el tercer grupo, a los productos y servicios indicados en los incisos a), b) y e) se puede acceder por medios digitales, mientras que los demás servicios necesitan un apoyo presencial en alguna sucursal bancaria o corresponsal.

El componente tecnológico es esencial en la prestación de servicios financieros y constituye una piedra angular en cualquier programa o estrategia de inclusión financiera. Los programas de gobierno digital y firma digital han sido elementos centrales en el proceso de innovación que emprendió el Gobierno hace ya algunos años, en donde las instituciones financieras públicas y privadas han aprovechado esta base sustantiva para poder realizar transacciones financieras en línea. 


\section{Sistemas de pago}

El principal sistema de pago del país es el SINPE. Esta plataforma tecnológica, desarrollada y administrada por el Banco Central de Costa Rica, conecta a entidades financieras e instituciones públicas del país a través de una red privada de telecomunicaciones que les permite realizar la movilización electrónica de fondos entre cuentas clientes y participar en los mercados de negociación que organiza el Banco Central de Costa Rica. Tanto las entidades que intervienen en el sistema financiero nacional como las instituciones públicas pueden participar en el SINPE como asociadas.

Esta plataforma tecnológica fue puesta en marcha el 17 de abril de 1997 y comenzó a operar con el servicio de compensación y liquidación de cheques. Desde entonces se han agregado otros servicios estatales, como la transferencia de fondos a terceros, así como créditos y débitos directos.

De acuerdo con cifras del Banco Central, a diciembre de 2015, el valor total liquidado en el SINPE representó 9,5 veces el PIB corriente. A nivel de liquidación por servicio, las transferencias a terceros son las que tienen el valor transado más preponderante del total liquidado, seguido de los débitos en tiempo real y los créditos directos.

\section{Mecanismos de protección a usuarios de servicios financieros}

La Ley de Promoción de la Competencia y Defensa Efectiva del Consumidor (Ley núm. 7472) designa a la Comisión Nacional del Consumidor como el ente protector de los derechos de los consumidores, entre los cuales se incluye a los usuarios de servicios financieros. En materia de seguridad informática, las diferentes superintendencias cuentan con una normativa que establece la adecuada gestión de la tecnología de la información por parte de las entidades reguladas. No existe normativa en materia de seguridad informática para entidades que no se encuentran reguladas.

\section{Instrumentos de política pública para fomentar la inclusión financiera de pequeños productores rurales}

\section{La banca de segundo piso}

Una de las motivaciones de la banca de segundo piso es facilitar el acceso a servicios financieros, principalmente a crédito, a sectores no atendidos por la banca tradicional. Los principales oferentes de servicios de segundo piso 
son los bancos estatales, las cooperativas de ahorro y crédito, los bancos privados y, más recientemente, el SBD, que ha puesto énfasis en la colocación de fondos dirigidos al desarrollo agropecuario. Entre las principales entidades que acceden a recursos de segundo piso se encuentran mutuales, sistemas cooperativos, asociaciones solidaristas, microfinancieras, fundaciones, sociedades anónimas, centros agrícolas cantonales e incluso asociaciones de desarrollo. Se financia cualquier tipo de actividad productiva que tenga viabilidad técnica y financiera.

El fondeo al que recurren las organizaciones que realizan operaciones bancarias de segundo piso proviene directamente del sistema financiero nacional, de fondeadores internacionales y, en algunos casos, de recursos de cooperación internacional. En los últimos años, uno de los proveedores de recursos para banca de segundo piso que ha tomado fuerza es el SBD, un mecanismo orientado a financiar e impulsar, de una manera ágil y efectiva, proyectos viables de micro, pequeñas y medianas empresas.

El SBD es un mecanismo que tiene por objeto financiar e impulsar proyectos productivos, viables y factibles desde el punto de vista técnico y económico, acordes con el modelo de desarrollo del país. Dicho mecanismo tiene como fundamento legal la Ley de Sistema de Banca para el Desarrollo (Ley núm. 8634) de 2008 y la reforma integral adoptada en 2014.

El SBD apoya de manera prioritaria proyectos viables promovidos por mujeres, asociaciones de desarrollo indígena, jóvenes emprendedores, cooperativas, pequeños y medianos productores agropecuarios y micro, pequeñas y medianas empresas (MIPYMES) nacientes o en operación.

El sistema de financiamiento opera principalmente con recursos provenientes de tres fuentes: a) fideicomisos agropecuarios (con los que se crea un megafondo conocido como FINADE), b) aporte del 5\% de utilidades de los bancos públicos y c) peaje bancario que aportan los bancos privados por tener derecho a captar depósitos en cuenta corrientes.

La Banca para el Desarrollo es presidida por un Consejo Rector que cuenta con una Secretaría Técnica para la ejecución, articulación e implementación de los alcances de la Ley de Sistema de Banca para el Desarrollo. El Consejo Rector lo componen el Ministro de Agricultura y Ganadería, el Ministro de Economía, Industria y Comercio, un representante del sector industrial y de servicios designado por la Cámara de Industrias de Costa Rica, un representante del sector agropecuario designado por la Cámara Nacional de Agricultura y Agroindustria de Costa Rica y un miembro independiente nombrado por el Consejo Rector mediante una terna enviada por el Colegio de Profesionales en Ciencias Económicas de Costa Rica. 


\section{Garantías de crédito para productores rurales}

El Fondo Especial para el Desarrollo de las Micro, Pequeñas y Medianas Empresas (FODEMIPYME) tiene como principal objetivo fomentar y fortalecer el desarrollo de las micro, pequeñas y medianas empresas y de las empresas de economía social, económicamente viables y generadoras de puestos de trabajo. Sus principales funciones son el otorgamiento de garantías y crédito y el apoyo al desarrollo de proyectos financiados por el Banco Popular y de Desarrollo Comunal, tendientes a fortalecer y desarrollar las micro, pequeñas y medianas empresas en áreas tales como capacitación, asistencia técnica, innovación, investigación y transferencia tecnológica.

El FINADE, por su parte, emite garantías a favor de operadores financieros autorizados ante el SBD para respaldar el financiamiento de hasta el 75\% de los créditos solicitados por micro, pequeñas y medianas empresas.

Como una forma de facilitar el acceso a créditos para aquellas personas o empresas que no tienen bienes inmobiliarios inscritos, en 2014 se promulgó la Ley de Garantías Mobiliarias (Ley núm. 9246) con el propósito de incrementar el acceso al crédito, ampliando las categorías de bienes que pueden ser dados en garantía y el alcance de los derechos sobre estos. En el marco de la mencionada Ley se pueden presentar como garantía: bienes tangibles o intangibles, cuentas por cobrar, cosechas, inventarios, contratos, marcas, propiedad intelectual, ganado, maquinaria y equipo, y otros bienes muebles. De manera complementaria, entró en vigor el Sistema Informático de Inscripción de Garantías Mobiliarias, que funcionará como registro centralizado de estas garantías y cuya operación está a cargo del Registro Nacional.

\section{Instrumentos de fomento productivo al sector rural}

El Ministerio de Economía, Industria y Comercio (MEIC) tiene entre sus funciones la de participar en la formulación de la política económica del Gobierno y en la planificación nacional en los campos de su competencia. Además, es el ente rector de las políticas públicas de Estado en materia de fomento a la iniciativa privada, desarrollo empresarial e incentivo de la cultura empresarial para los sectores de industria, comercio y servicios, así como para el sector de las micro, pequeñas y medianas empresas.

Si bien los procesos de articulación interinstitucional y los proyectos específicos, como el de la simplificación de trámites, se sustentan en decretos gubernamentales, el grado en que son instrumentados en las regiones depende mucho de la voluntad, la disponibilidad y el nivel de compromiso de los funcionarios presentes en las regiones. 
Por su parte, el Ministerio de Agricultura y Ganadería (MAG) de Costa Rica es el responsable de todas las políticas públicas orientadas al sector agropecuario. El MAG dispone de algunas herramientas que contemplan la posibilidad de realizar transferencias de recursos a iniciativas promovidas por cooperativas, asociaciones de desarrollo, asociaciones de productores y asociaciones para la obtención de infraestructura, equipo, maquinaria y herramientas, e incluso la posibilidad de donar a los productores semovientes y animales vivos necesarios para el desarrollo productivo de los productores rurales.

Además, a través de sus direcciones regionales, el MAG cuenta con una red de agencias de extensión agrícola ubicadas principalmente en las cabeceras de los cantones. A pesar de que la arquitectura institucional y normativa es amplia en cuanto a la atención del sector productivo rural, las tendencias de una economía más orientada al sector servicios y al área comercial han mermado el impacto de la producción agropecuaria dentro de la estructura productiva.

\section{E. Principales retos}

Aunque recientemente se anunció la adopción de una estrategia integral de política pública para fomentar la inclusión financiera, en la práctica esta todavía está ausente. Desde la institucionalidad pública, no obstante, se han creado herramientas e instrumentos que han contribuido al fomento de la inclusión financiera por parte de los participantes del sistema financiero nacional. La presencia de la banca estatal, con 531 sucursales y más de 1.400 cajeros automáticos ubicados en todas las regiones del país, ofrece una plataforma amplia para la inclusión financiera de los productores rurales.

En función de los hallazgos expuestos en este capítulo, se considera que tanto los bancos estatales como los bancos privados cuentan con capacidades financieras suficientes para promover la inclusión de los proyectos productivos en el ámbito rural. Ello podría potenciarse mediante la amplia disponibilidad de garantías institucionales que faciliten el acceso a fondos para nuevos proyectos. Esto podría mejorarse si tanto el MEIC como el MAG o las municipalidades locales dispusieran de parte de sus fondos para avalar este tipo de proyectos, como se hace en México a través de los mecanismos de Nacional Financiera.

Se podría utilizar al SBD para promover la inclusión financiera de productores rurales, dado que el espíritu de la Ley de Sistema de Banca para el Desarrollo contempla el financiamiento a las actividades agropecuarias. 
El desarrollo de las telecomunicaciones y el establecimiento del FONATEL han mejorado la conectividad en zonas rurales. Esta particularidad ofrece la posibilidad de democratizar la conectividad y el acceso a las TIC.

Desde el Gobierno, la orientación para que los programas de protección social - como pensiones complementarias, becas de estudiantes, subsidios a familias de escasos recursos y otorgamiento de bonos gratuitos de la vivienda - se tengan que realizar mediante transferencias de fondos a cuenta de los beneficiarios, ha coadyuvado en la inclusión financiera de una parte de la población que de otra forma no podría estar incluida.

La existencia de una institucionalidad financiera y una seguridad jurídica genera una base consistente para programas y proyectos de inclusión financiera, tanto desde la perspectiva privada como pública.

Tanto el MAG como el Instituto de Desarrollo Rural (INDER) cuentan con la infraestructura necesaria para brindar apoyo técnico a los productores rurales y debe existir una articulación y coordinación con los programas de inclusión financiera dirigidos al sector rural.

La información es un activo esencial de las organizaciones, que deben evolucionar en paralelo con la estrategia del negocio de forma integrada y perseguir los objetivos del negocio en el largo plazo. En este sentido, la gestión estratégica de las TIC puede ofrecer un entorno de creación de valor permanente en las entidades y esto resulta indispensable para incrementar la competitividad de los actores del sistema financiero, además de ser necesario para reducir los costos de estos servicios.

Las instituciones financieras están aprovechando la creciente adopción de tecnologías móviles e Internet para entender mejor a los clientes y llevar servicios financieros a la base de la pirámide, donde, por su condición de dispersión, los clientes no cuentan con una infraestructura bancaria cercana o puntos de pagos tradicionales. Ahí es donde la tecnología juega un papel significativo para lograr una bancarización auténtica.

Con la implementación de Cuentas de Expediente Simplificado, se estima que el nivel de bancarización y, por ende, la utilización de servicios financieros se expandirá significativamente en Costa Rica. Aunado a esto, el servicio de SINPE Móvil todavía tiene gran oportunidad de penetración en la base de la pirámide, así como en zonas rurales, por lo que una estrategia de mercadeo conjunta de ambas iniciativas para explotar sus bondades podría contribuir tanto al acceso como al uso de los servicios financieros $y$, por ende, a la inclusión.

También mediante el FONATEL, cuyo principal propósito es llevar telefonía e Internet a zonas y comunidades donde aún no hay servicio (que en su totalidad son zonas rurales), se pretende reducir la brecha digital y 
garantizar mayor igualdad de oportunidades. Por tanto, dotar a esta iniciativa de las herramientas necesarias para garantizar el seguimiento adecuado de los proyectos derivados del Fondo es fundamental para garantizar el éxito.

Las tecnologías se están perfeccionando, pero para tener un impacto positivo se requiere contar con plataformas que sean más intuitivas para el cliente, que dispongan de mejores interfaces y que tengan como principal atributo la comprensión de las necesidades de los usuarios. Esto último está en manos del sistema financiero y los reguladores.

La oferta de servicios financieros formales en Costa Rica es muy amplia, con bastantes facilidades de acceso crediticio para los usuarios finales, pero con trámites engorrosos y lentos. Con el cambio de la Ley de Sistema de Banca para el Desarrollo se incrementaron las facilidades al otorgar créditos a las microfinancieras establecidas y a las cooperativas agroindustriales, que ya eran sujetas de crédito por parte de los bancos estatales que preferían el endoso de garantías reales.

Con la Banca para el Desarrollo se amplió el endoso a la garantía que maneje el operador financiero (pagarés, letras de cambio, avales y prendas sobre cosechas), lo que mejora el tiempo de respuesta para el usuario. La Ley de Garantías Mobiliarias es un instrumento complementario que puede favorecer el acceso al crédito de los productores rurales y con ello mejorar su inclusión financiera.

Los servicios financieros informales (prestamistas) se mantendrán en el negocio, ya que ellos se fijan más en el valor de la garantía real ofrecida que en la valoración financiera del proyecto, por lo que el tiempo de respuesta es de dos a tres días.

$\mathrm{Al}$ ser operadores no regulados, las microfinancieras tienen una mayor flexibilidad en la atención de los créditos a productores rurales y las tasas de interés más altas que cobran estos entes se encuentran asociadas a un nivel de riesgo mayor.

La variable de riesgo en los productores rurales solo se podrá solventar por la aparición en escena de los microseguros. Hasta que esta figura no logre consolidarse, la variable de riesgo llevará a algunos operadores financieros a no considerar el financiamiento a los productores rurales, y las microfinancieras y los prestamistas privados tendrán un mercado donde actuar.

Por último, la inclusión financiera de los productores rurales no debe circunscribirse exclusivamente al acceso al crédito o a la apertura de una cuenta de ahorros. Debe ser un proceso integral donde intervengan servicios complementarios, como microseguros, acompañamiento técnico, educación financiera y acceso a las TIC, que potencien la migración de los productores rurales a sistemas más productivos y con menor riesgo sistemático. 


\section{Bibliografía}

Banco Mundial (2014), Base de datos Global Findex, Washington, D.C. [en línea] http:/ / datatopics.worldbank.org/financialinclusion.

Camacho, E. y R. Jiménez (2010), Acceso a servicios financieros en Costa Rica, San José, Asociación Bancaria Costarricense.

EIU / BID (Economist Intelligence Unit/Banco Interamericano de Desarrollo) (2016), Microscopio global 2016. Análisis del entorno para la inclusión financiera, Nueva York.

REDCAMIF (Red Centroamericana y del Caribe de Microfinanzas) (2015), Boletín Microfinanciero de Centroamérica y del Caribe, $\mathrm{N}^{\circ}$ 6, Managua, diciembre. 
Capítulo IV

\section{La inclusión financiera en El Salvador}

Pedro Argumedo ${ }^{1}$

\section{Introducción}

La inclusión financiera presenta una nueva oportunidad para fomentar un mayor acceso y uso de los diferentes tipos de servicios financieros que permitirán aumentar el bienestar de las personas. El Salvador enfrenta el desafío de impulsar una estrategia nacional basada en una institucionalidad que coordine iniciativas públicas y privadas, combinando innovaciones en la banca tradicional, electrónica y de servicios de telefonía, que contribuirán a reducir los costos de los servicios y ampliarán el acceso a nuevos servicios en zonas desatendidas.

Algunas encuestas internacionales sobre inclusión financiera, como las realizadas por el Banco Mundial (Demirgüç-Kunt y otros, 2015), muestran cómo el desarrollo tecnológico está creando una serie de innovaciones que benefician el acceso y uso de los servicios financieros, en especial en las zonas rurales, donde la distancia a una entidad financiera es una de las principales restricciones. Asimismo, la comparación de resultados entre países revela que está en marcha un proceso de mayor acceso por medio de una combinación de tecnologías, regulaciones y redes bancarias y telefónicas.

Investigador Senior de Estudios Económicos, Fundación Salvadoreña para el Desarrollo Económico y Social. 
Sobre la base de la experiencia de los países que muestran mayores avances en materia de inclusión financiera (Villasenor, West y Lewis, 2016; EIU/BID, 2016), se identifican tres factores que contribuyen a un mayor desarrollo de esta inclusión. En primer lugar, debe existir un vehículo institucional que lidere y coordine las iniciativas públicas y privadas, con el fin de aumentar el acceso y uso de los servicios financieros. Segundo, se debe acordar una estrategia nacional que identifique las fases con sus programas y actores responsables, estableciendo las medidas pertinentes para atender a grupos desatendidos, como ocurre en el ámbito rural. En tercer término, es necesario apoyar la implementación de reformas y políticas públicas que brinden celeridad al proceso, y poder evaluar sus efectos.

Para que la inclusión financiera tenga un mayor impacto en países como El Salvador, caracterizado por una alta informalidad, la agenda debe estar enmarcada en una política pública más amplia de desarrollo inclusivo (Alianza para la Inclusión Financiera, 2012). En El Salvador, solo una de cada cuatro personas pertenecientes a la población económicamente activa (PEA) tiene un empleo formal. Únicamente un 35\% dispone de seguridad social y en la zona rural la situación es más difícil (15,6\%). En tanto, la tasa de pobreza nacional asciende al 31,8\%, pero en el área rural supera el 37,9\% (DIGESTYC, 2015). Esta realidad de muy bajos ingresos pone de relieve la importancia de la creación de oportunidades de empleo, apoyada a través de la inclusión financiera.

De acuerdo con cifras publicadas por el Banco Central de Reserva de El Salvador, el acceso a cuentas financieras de la población salvadoreña fue del 47\% en 2016 (BCR, 2016), una tasa mayor que la de la encuesta del Banco Mundial, del 36,7\% en $2014^{2}$. Los resultados reflejan que la principal vía de acceso corresponde a cuentas de ahorro o corrientes ofrecidas por intermediarios financieros (34,6\%), con una creciente participación de cuentas a través del celular $(4,6 \%)$. Un aspecto clave a destacar es que la disposición de cuentas rurales en instituciones financieras fue de un 28,1\% en 2014, 13 puntos porcentuales por debajo de la disposición de cuentas urbanas. Esta brecha refleja la asimetría de ingresos, así como los problemas de acceso debido a la densidad poblacional relativamente baja que caracteriza al sector rural. Además, los datos muestran que en El Salvador se usa cada vez más la telefonía móvil para hacer transacciones financieras, lo que contribuye a superar el problema de la distancia a sucursales físicas en el área rural.

La encuesta que realizó el BCR en 2016 contenía preguntas similares a las que formuló el Banco Mundial en 2014, pero habían dos diferencias estadísticas importantes: i) el BCR presenta resultados para personas mayores de 18 años y el Banco Mundial para mayores de 15 años, y ii) el BCR entrevistó a 5.211 personas y el Banco Mundial encuestó a 1.000 personas. 
Bajo el liderazgo del BCR, en 2011 se empezó a trabajar en una agenda sobre inclusión financiera. El BCR se integró a la Alianza para la Inclusión Financiera y con el apoyo de la Oficina de Asistencia Técnica del Departamento del Tesoro de Estados Unidos (OTA) creó una instancia institucional especializada llamada Grupo de Apoyo para Temas de Inclusión Financiera (GATIF), que estaba conformado por instituciones como la Superintendencia del Sistema Financiero (SSF), el Banco de Desarrollo de El Salvador (BANDESAL), así como instituciones privadas y de microcrédito.

Se realizaron diagnósticos y encuestas sobre acceso y se determinó crear la Ley para facilitar la inclusión financiera, que fue aprobada por la Asamblea Legislativa el 13 de agosto de 2015 y entró en vigor el 11 de septiembre del mismo año. La Ley establece el procedimiento para autorizar y normar el funcionamiento de las Sociedades Proveedoras de Dinero Electrónico y de pagos móviles, y crea la figura de cuentas de depósitos de ahorro con requisitos simplificados. Esta iniciativa implicó que el BCR y la SSF crearan unidades especializadas sobre inclusión financiera. Por otra parte, más empresas proveedoras de dinero electrónico se han interesado por abrir operaciones en el país y diversas entidades financieras han definido, y se encuentran proponiendo, nuevos programas para promover la inclusión financiera.

No obstante los logros obtenidos, el GATIF dejó de funcionar como entidad coordinadora interinstitucional. Actualmente, el BCR se encuentra realizando varias encuestas a personas y empresas sobre inclusión, que podrán ser el insumo para abrir una segunda fase de una agenda más amplia y mejor articulada de inclusión financiera en el país.

En el presente estudio se sistematizan, de la manera más amplia posible, las diferentes iniciativas que se han puesto en marcha en el país en los últimos años. Sobre esa base, se propone el diseño de una estrategia integral de inclusión financiera y se plantea que las acciones se orienten a enfrentar tres desafíos:

i) El reto de la coordinación entre instituciones financieras públicas y privadas mediante la creación e institucionalización de una Comisión Nacional de Inclusión Financiera, retomando el espíritu del GATIF.

ii) El reto de la transmisión de la información financiera entre oferentes y demandantes, ya que casi todas las instituciones están emprendiendo acciones que los usuarios en general desconocen, $y$ de un mejor enfoque de la educación financiera hacia la inclusión.

iii) El reto de la regulación e interoperabilidad de las redes. El desafío es consolidar la confiabilidad entre las redes financieras y móviles, facilitar la entrada de nuevos operadores y la mayor competencia entre todos, y mantener la seguridad del sistema. 
En la sección A de este capítulo se analiza la evolución reciente del acceso y la utilización de servicios financieros en el país, destacando la situación vigente en el ámbito rural. A continuación, en la sección B se describe el desarrollo de la estrategia de inclusión financiera en El Salvador y en la sección $C$ se revisa la arquitectura institucional con que cuenta el país para instrumentar esta estrategia. En la sección D se analizan los instrumentos de política pública disponibles para apoyar el desarrollo rural, donde se destaca el papel del BANDESAL, los programas del Ministerio de Agricultura y Ganadería (MAG) y las innovaciones de inclusión financiera impulsadas por Tigo Money, el Banco Agrícola, el BCR y la SSF, entre otros. Por último, en la sección E se concluye con una reflexión acerca de los principales retos para aumentar la inclusión financiera y se propone una estrategia en tres áreas fundamentales.

\section{A. Evolución reciente y situación actual del acceso y uso de servicios financieros}

A continuación, se analiza el acceso y uso de los servicios financieros utilizando la definición amplia de inclusión financiera, que contempla una extensa gama de servicios financieros, proveedores de servicios financieros y canales de distribución. La información estadística proviene de encuestas sobre inclusión financiera realizadas por el Banco Mundial (2016a) y el BCR (2016). Si bien los resultados muestran que la inclusión financiera ha venido aumentando, se encuentran por debajo tanto del promedio latinoamericano como de países de ingresos comparables. Los datos de las encuestas se complementan con los registros provenientes del BCR y la SSF. En la medida de lo posible, en el análisis se destaca la situación en el sector rural.

\section{Acceso y uso de servicios financieros}

El uso de servicios financieros en El Salvador sigue siendo muy bajo. De acuerdo con cifras del Banco Mundial (2016a), la proporción de salvadoreños mayores de 15 años que eran cuentahabientes de una institución financiera formal, o que tenían una cuenta a través del celular, era de apenas el 36,7\% en 2014, es decir que más del 63\% registra algún tipo de exclusión (véase el cuadro IV.1). No obstante el desafío pendiente, es preciso destacar el importante aumento en el uso de estos servicios, ya que en 2011 la tasa era del 13,8\%. Como se comenta más adelante, uno de los determinantes del incremento ha sido el mayor uso de celulares para realizar transacciones financieras. 
Cuadro IV.1

El Salvador: inclusión financiera total y rural, 2011, 2014 y 2016

(En porcentajes)

\begin{tabular}{|c|c|c|c|c|c|}
\hline & \multicolumn{4}{|c|}{ Global Findex } & \multirow{3}{*}{$\begin{array}{c}\text { Banco } \\
\text { Central de } \\
\text { Reserva de } \\
\text { El Salvador } \\
2016\end{array}$} \\
\hline & \multicolumn{2}{|c|}{ El Salvador } & \multirow{2}{*}{$\begin{array}{c}\begin{array}{c}\text { América } \\
\text { Latina }\end{array} \\
2014\end{array}$} & \multirow{2}{*}{$\begin{array}{c}\begin{array}{c}\text { Países de } \\
\text { ingresos } \\
\text { medios bajos }\end{array} \\
2014\end{array}$} & \\
\hline & 2011 & 2014 & & & \\
\hline \multicolumn{6}{|c|}{$\begin{array}{l}\text { Cuenta financiera y celular } \\
\text { (en porcentajes de personas mayores de } 15 \text { años) }\end{array}$} \\
\hline \multicolumn{6}{|l|}{ Total } \\
\hline Todos & 13,8 & 36,7 & 51,4 & 42,7 & 47,0 \\
\hline Mujeres & 10,1 & 31,9 & 48,6 & 36,3 & 41,0 \\
\hline Rural & & 31,5 & & & n.d. \\
\hline Instituciones financieras & 13,8 & 34,6 & 51,1 & 41,9 & 39,0 \\
\hline Instituciones financieras, rural & 12,1 & 28,1 & & & n.d. \\
\hline Cuenta celular (Tigo Money) & n.d. & 4,6 & 1,7 & 2,5 & 16,0 \\
\hline Cuenta celular (Tigo Money), rural & & 5,5 & & & \\
\hline \multicolumn{6}{|l|}{ Acceso a cuentas financieras } \\
\hline Tiene tarjeta de débito & 10,9 & 21,8 & 40,4 & 21,2 & \\
\hline Tiene tarjeta de débito, rural & 8,8 & 15,4 & & & \\
\hline Tiene tarjeta de crédito & 5,3 & 8,3 & & & \\
\hline Tiene tarjeta de crédito, rural & 5,1 & 5,8 & & & \\
\hline \multicolumn{6}{|l|}{ Uso de la cuenta financiera } \\
\hline $\begin{array}{l}\text { Uso de la cuenta para } \\
\text { recibir salario }\end{array}$ & & 15,1 & 18,0 & 5,6 & 10,0 \\
\hline $\begin{array}{l}\text { Uso de la cuenta para recibir } \\
\text { transferencias del Gobierno }\end{array}$ & & 4,4 & 9,0 & 3,3 & \\
\hline \multicolumn{6}{|l|}{ Ahorro en el último año } \\
\hline Ahorro en institución financiera & 12,9 & 14,0 & 13,5 & 14,8 & 23,0 \\
\hline \multicolumn{6}{|l|}{ Crédito en el último año } \\
\hline Préstamo de financieras & 3,9 & 17,2 & 11,3 & 7,5 & 12,0 \\
\hline Préstamo de financieras, rural & 3,8 & 16,9 & & & \\
\hline Préstamo de fuentes informales & 2,0 & 6,2 & & & \\
\hline $\begin{array}{l}\text { Préstamo de fuentes } \\
\text { informales, rural }\end{array}$ & 1,9 & 5,1 & & & \\
\hline \multicolumn{6}{|l|}{ Remesas en el último año } \\
\hline Recibió remesas & n.d. & 17,3 & 11,3 & 17,8 & 25,0 \\
\hline Recibió remesas, rural & n.d. & 14,0 & & & \\
\hline
\end{tabular}

Fuente: Elaboración propia, sobre la base de Banco Mundial, Base de datos Global Findex, 2016, y Banco Central de Reserva de El Salvador (BCR), 2016.

Nota: Debido a diferencias metodológicas, los datos de Global Findex no son estrictamente comparables con los del Banco Central de Reserva de El Salvador (BCR).

Como se puede apreciar en el cuadro IV.1, El Salvador muestra un importante rezago tanto con respecto al promedio de América Latina, donde la proporción de mayores de 15 años que contaban con una cuenta 
en 2014 era del 51,4\%, como con respecto al promedio de los países de ingresos medios bajos, donde la proporción de cuentahabientes ascendía al 42,7\%. La comparación con países de similares ingresos indica que una parte de la exclusión observada es de naturaleza involuntaria, asociada a factores relacionados a limitaciones de información, incapacidad de hacer cumplir contratos y otros.

De acuerdo con cifras del BCR (2016), la proporción de adultos con acceso a una cuenta era del $47 \%$ en 2016, una tasa mayor que la de la encuesta del Banco Mundial del 36,7\% en 2014. La principal vía de acceso son los servicios ofrecidos a través de cuentas de proveedores tradicionales de servicios financieros $(34,6 \%)$, con una creciente participación de las cuentas a través de la telefonía móvil $(4,6 \%)$. Sobre esto último se destaca el papel innovador que ha jugado un operador de telefonía, a través de su producto de dinero electrónico Tigo Money.

Por su parte, el acceso a cuentas de ahorro fue del 14\% en 2014, ligeramente por encima del 12,9\% registrado en 2011. La proporción de acceso a cuentas de ahorro fue similar al promedio observado en América Latina $(13,5 \%)$, así como en los países de ingresos medios bajos $(14,8 \%)$.

En lo que respecta a la utilización de servicios financieros, medida por el acceso a crédito proveniente de una institución financiera, de acuerdo con cifras del BCR, la proporción fue de un $12 \%$. Al expandir este último resultado sobre la población total del país mayor de 15 años, que en 2014 ascendía a 4,7 millones de salvadoreños (DIGESTYC, 2015), se obtiene que unas 793.000 personas poseen algún tipo de crédito. Si se consideran los niveles de formalización de la fuerza laboral, medidos como aquellos trabajadores que cotizan al Instituto Salvadoreño del Seguro Social (ISSS) (794.000 personas en 2014), las cifras indican que es muy probable que la mayoría de los trabajadores formales cuenten con algún tipo de crédito. Por su parte, la proporción de acceso al crédito formal en el país (17,2\%) supera a la media de América Latina (11,3\%) y al promedio del grupo de países con ingresos medios bajos (7,5\%) (véase el cuadro IV.1).

En lo que concierne a los medios de pago, El Salvador se encuentra por debajo del promedio de América Latina. El acceso a tarjetas de débito en 2014 era del 21,8\%, inferior al 40,4\% de América Latina, aunque similar al promedio de los países de ingresos medios bajos (21,2\%). Por su parte, el uso de la tarjeta de débito fue menor, con un $12,9 \%$, bastante por debajo del $27,7 \%$ de América Latina. Esto puede ser reflejo de la falta de infraestructura de pagos o la desconfianza para realizar dichos pagos. El acceso a tarjetas de crédito era del 8,3\% en 2014 y el uso apenas llegaba al 6,6\%. No obstante su creciente importancia, los pagos electrónicos vía Internet siguen siendo sumamente bajos, con un $4 \%$, muy por debajo del promedio de América Latina. 
Para analizar la evolución del acceso y uso de los servicios financieros por parte de las empresas se utiliza información del crédito registrado por el BCR, ya que aún no se dispone de una encuesta sobre la inclusión financiera de las empresas. La información se complementa con una encuesta sobre acceso al financiamiento de las empresas desde una óptica de capacidades competitivas.

El crédito ofrecido al sector productivo proviene de fuentes internas y externas, que sumaron 9.283 millones de dólares en 2015, equivalentes al $59 \%$ de todo el crédito ofrecido y a un 35,9\% del PIB. Entre 2003 y 2015, el financiamiento al sector productivo registró un incremento marginal de 2.845 millones de dólares, lo que sería equivalente a un aumento medio anual de 237 millones de dólares, es decir, un 1\% del PIB al año, en promedio.

Las fuentes internas que financiaron el sector productivo, que comprenden las instituciones reguladas, como los bancos, las instituciones financieras no bancarias y las sociedades de ahorro y crédito, otorgaron 5.260 millones de dólares (un 56,7\% del total) 3 . Por su parte, el financiamiento de fuentes externas, que comprende a la banca extraterritorial (off-shore), los préstamos de empresas mediante inversión extranjera directa (IED) y el crédito comercial, ascendió a 4.023 millones de dólares en 2015. Cabe destacar que el financiamiento de fuentes externas ha crecido a una mayor velocidad que el de fuentes internas, ya que en 2003 representaba el 39,3\% del total y en 2015 su participación alcanzó un 43,3\% del total.

Para analizar el otorgamiento de crédito por sectores se utiliza la información disponible de las instituciones reguladas (bancos, instituciones financieras no bancarias, y sociedades de ahorro y crédito), ya que para las fuentes externas no se cuenta con la clasificación sectorial. Se destaca que cuatro actividades económicas concentraron el 75\% del total (véase el gráfico IV.1). Por orden de importancia, estas son: i) consumo, que llegó a 3.121 millones de dólares en 2015 y tuvo una expansión explosiva si esta cifra se compara con los 711 millones de dólares de 2002; ii) adquisición de vivienda, que alcanzó los 2.522 millones de dólares y registra el segundo mayor incremento, al compararlo con los 1.099 millones dólares de 2002; iii) servicios, que recibieron 1.840 millones de dólares en 2015, con el mayor incremento en el sector empresarial (573 millones de dólares adicionales con respecto a 2002); y iv) comercio, que registró un aumento marginal de 493 millones de dólares. El sector agropecuario fue el que menos aumentó en 13 años, ya que registraba 264 millones de dólares en 2002 y apenas subió a 383 millones de dólares en 2015, lo que refleja su limitado desempeño en la economía.

Las instituciones financieras no bancarias son cooperativas y federaciones de cooperativas. 


\section{Gráfico IV.1}

El Salvador: crédito a sectores productivos de fuentes internas (bancos, instituciones financieras no bancarias y sociedades de ahorro y crédito), 2002-2015

(En millones de dólares)

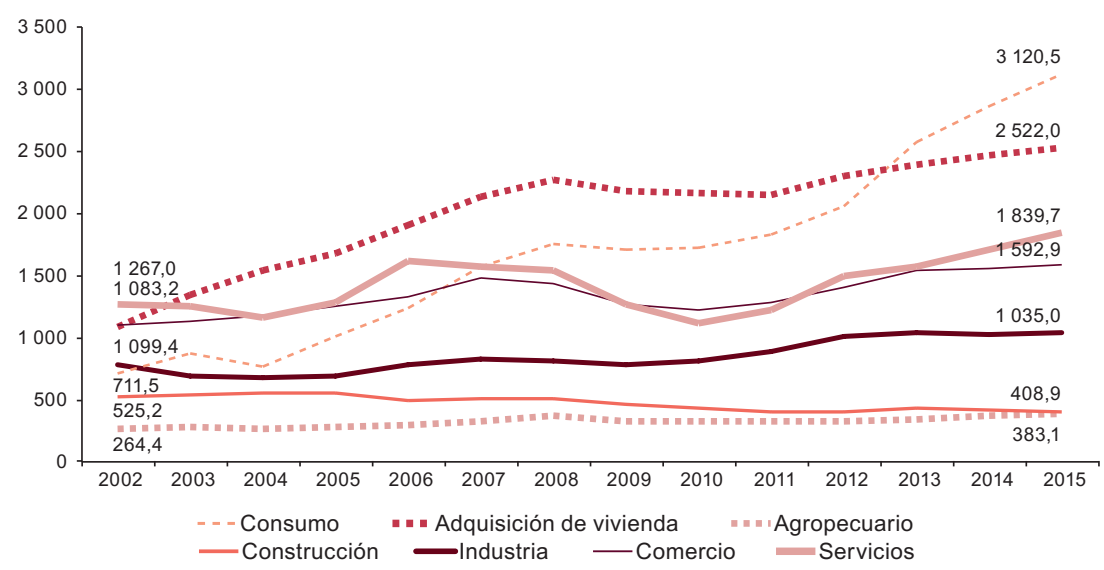

Fuente: Banco Central de Reserva de El Salvador (BCR).

De acuerdo con los resultados de la encuesta de competitividad empresarial realizada por la Fundación Salvadoreña para el Desarrollo Económico y Social (FUSADES, 2015), en la que se incluye un módulo sobre el acceso a financiamiento de las empresas, en 2014 , un $38,4 \%$ de las empresas encuestadas habían solicitado crédito ${ }^{4}$. Las principales fuentes de crédito fueron la banca comercial (92\%), los proveedores $(15 \%)$, los bancos extraterritoriales $(4 \%)$ y las instituciones financieras no bancarias $(2 \%)$. Solo un $7 \%$ de las empresas recurrieron a familiares y prestamistas no formales. Es importante destacar que al 5,3\% de las empresas encuestadas se les negó el crédito. Las principales razones para la negativa fueron: la situación económica del país (52\%), el riesgo representado por la empresa $(16 \%)$ y los cambios en las políticas de crédito de las instituciones financieras $(8 \%)$.

\section{Desempeño del sector rural}

De acuerdo con la Dirección General de Estadística y Censos (DIGESTYC, 2015), en 2014, la población rural representaba el 37,7\% de un total de 6,4 millones de habitantes, una importante reducción con respecto al 52,2\% registrado en 1992 (Angel, 2011). Este fenómeno de urbanización se ve impulsado por el diferencial de pobreza y oportunidades entre los entornos urbano y rural. En 1992 la pobreza rural representaba el 65,1\%, mientras que la urbana era

La encuesta se aplica a más de 430 empresas de tamaño micro, pequeño, mediano y grande, y cubre todo el país (FUSADES, 2015). 
del 52,9\%, lo que creó incentivos para migrar del campo a la ciudad. Este fenómeno se mantiene en 2014, ya que la tasa de pobreza rural es del 37,9\% y la urbana asciende al 28,5\% (DIGESTYC, 2015). De manera paralela, la participación del sector agropecuario se redujo de un 16,5\% del PIB en 1992 a un 12,2\% del PIB en 2014.

Uno de los desafíos en el análisis del ámbito rural es lo difuso de su definición, situación que se agrava por el enfoque sectorial de buena parte de las estadísticas económicas, lo que obliga a aproximar el desempeño rural haciendo referencia a las actividades agropecuarias. En la Encuesta de Hogares de Propósitos Múltiples, la DIGESTYC define lo urbano utilizando criterios de densidad poblacional y lo rural como el residuo ${ }^{5}$.

Como se puede apreciar en el diagrama IV.1, de acuerdo con cifras del Banco Mundial (2016a), el porcentaje de la población rural mayor de 15 años con algún tipo de cuenta ascendía al 31,5\% en 2014, 5 puntos porcentuales por debajo del promedio del país. Si bien el acceso a cuentas a través de instituciones financieras fue menor al promedio del país (un $28,1 \%$ frente a un $34,6 \%$ ), es importante destacar que un 5,5\% de las cuentas en el ámbito rural se manejan a través de celulares, cifra que se ubica por encima del promedio nacional. Esto ilustra el potencial de las nuevas tecnologías para superar los retos de cobertura geográfica.

\section{Diagrama IV.1 \\ El Salvador: inclusión financiera rural de personas mayores de 15 años, 2014 (En porcentajes)}

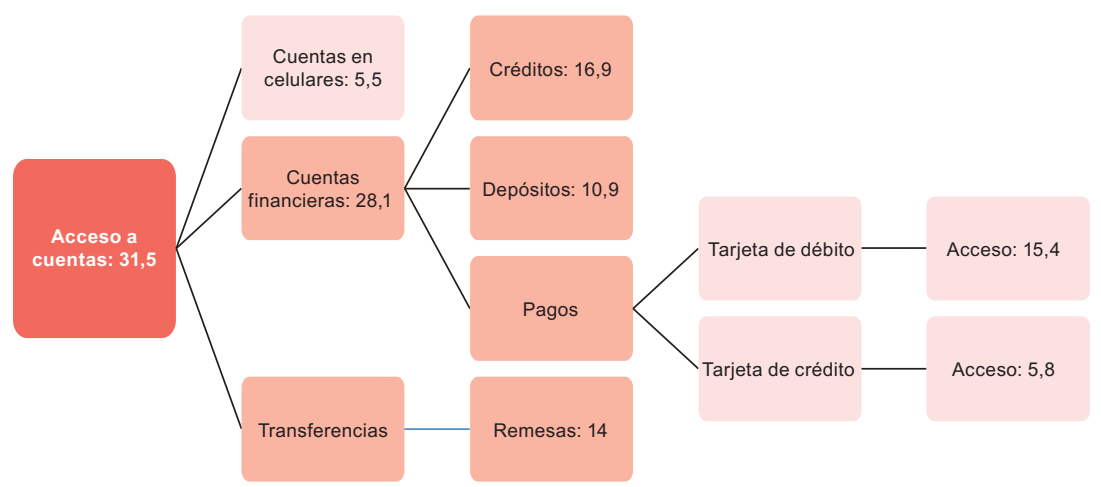

Fuente: Elaboración propia, sobre la base de Banco Mundial, Doing Business 2016: Measuring Regulatory Quality and Efficiency, Washington, D. C., 2016.

La DIGESTYC define como urbanos los segmentos censales que cumplen con alguno de los siguientes requisitos: i) la alcaldía municipal se ubica en el segmento censal; ii) conglomerados de segmentos censales con una población mayor a 1.000 habitantes por $\mathrm{km}^{2}$; iii) segmentos censales con una superficie superior a $0,6 \mathrm{~km}^{2}$; iv) viviendas agrupadas en manzanas con una superficie menor a $20.000 \mathrm{~m}^{2}$. 
Por otra parte, aunque la utilización de crédito en el ámbito rural $(16,9 \%)$ es muy similar al promedio nacional $(17,2 \%)$, el ahorro rural es casi 4 puntos porcentuales inferior al ahorro a nivel nacional (14\%). En reflejo de ello, aunque el uso de tarjetas de débito en el ámbito rural pasó de un $8,8 \%$ en 2011 a un $15,4 \%$ en 2014 , este se mantiene por debajo del $21,8 \%$ registrado a nivel nacional.

La proporción relativamente alta de receptores de remesas en zonas rurales $(14 \%)$ refleja el origen rural de una buena parte de la migración hacia los Estados Unidos. Es importante destacar que el flujo mensual de remesas ha incentivado el desarrollo de servicios financieros complementarios a la recepción de remesas.

De acuerdo con el BCR, el crédito otorgado al sector agropecuario ascendió a 365 millones de dólares en 2016, equivalente a un 3,1\% del total otorgado por bancos, instituciones financieras no bancarias y sociedades de ahorro y crédito. Se destaca que los bancos son los que más aportan al crédito agropecuario, con el $95 \%$ del total de recursos otorgados. Al analizar el desempeño desde 2002, se observa que el crédito agropecuario creció a una menor velocidad que todo el crédito otorgado a la economía, ya que en 2002 representaba el 4,1\% del total y descendió al 3,1\%.

Los resultados del módulo sobre actividades agropecuarias de la Encuesta de Hogares de Propósitos Múltiples muestran que en 2014 la principal actividad primaria fue la agricultura, con un $76,8 \%$ del total, seguida de la combinación de agricultura y ganadería con un $17,7 \%$, y un $5 \%$ dedicado exclusivamente a actividades pecuarias (véase el cuadro IV.2).

Con respecto a la inclusión financiera de los productores, el 12,1\% solicitó un crédito durante 2014. Del total de solicitudes de crédito, el 98\% lo obtuvo, lo que muestra un alto grado de autoexclusión financiera. Sin embargo, si se analiza el origen de los créditos, las cifras indican que una cuarta parte del crédito proviene de familiares o amigos. Se destaca que el Banco de Fomento Agropecuario (BFA) ocupa el primer lugar con un 28,6\% en 2014, lo que da cuenta de un marcado incremento con respecto al 17,1\% observado en 2010. Dicho incremento parece haber compensado el descenso del crédito otorgado por la banca privada, que pasó del $25,4 \%$ del total en 2010 al 16,5\% en 2014. De manera similar, durante el mismo período, las cooperativas y las Cajas de Crédito Rural redujeron su participación en el financiamiento al sector agropecuario de un $20 \%$ a un $8,3 \%$.

En resumen, no obstante los avances observados desde 2011, aún persisten brechas en materia de inclusión financiera con respecto a la región y los países con un nivel de ingreso similar. Cabe señalar que hasta 2016 se verificó un gran incremento de las transacciones financieras a través de servicios de telefonía, por arriba de lo observado por las fuentes tradicionales 
de las entidades bancarias, y muy por encima del promedio regional o de los países de ingresos medios bajos. Otra actividad que utiliza intensivamente los servicios financieros es la transferencia de remesas familiares, que se asocia a la enorme cantidad de salvadoreños que viven principalmente en los Estados Unidos.

\section{Cuadro IV.2}

El Salvador: financiamiento a las actividades agropecuarias, 2010 y 2014 (En porcentajes)

\begin{tabular}{|c|c|c|}
\hline & 2010 & 2014 \\
\hline \multicolumn{3}{|l|}{ 1. ¿A qué actividad agropecuaria se dedica? } \\
\hline Agricultura & 66,8 & 76,8 \\
\hline Agricultura y pecuaria & 25,6 & 17,7 \\
\hline Pecuaria & 7,4 & 5,0 \\
\hline Otros & 0,2 & 0,5 \\
\hline \multicolumn{3}{|l|}{ 2. ¿Solicitó crédito? } \\
\hline Sí & 10,1 & 12,1 \\
\hline No & 89,9 & 87,9 \\
\hline \multicolumn{3}{|l|}{ 3. ¿Obtuvo el crédito que solicitó? } \\
\hline Sí & 98,0 & 97,9 \\
\hline No & 2,0 & 2,1 \\
\hline \multicolumn{3}{|l|}{ 4. ¿Quién lo financió? } \\
\hline Banco de Fomento Agropecuario (BFA) & 17,1 & 28,6 \\
\hline Familiares o amigos & 25,4 & 25,4 \\
\hline Banco privado & 25,4 & 16,5 \\
\hline Otros & 1,6 & 13,0 \\
\hline Cooperativa & 9,7 & 5,0 \\
\hline Caja de crédito rural & 10,3 & 3,3 \\
\hline Organismo no gubernamental & 3,8 & 3,2 \\
\hline Agroservicio & 2,0 & 2,5 \\
\hline Prestamista & 1,9 & 1,7 \\
\hline Compradores de cosecha & 0,9 & 0,7 \\
\hline Banco hipotecario & 1,0 & 0,1 \\
\hline Intermediario & 0,7 & 0,1 \\
\hline
\end{tabular}

Fuente: Elaboración propia, sobre la base de Dirección General de Estadística y Censos (DYGESTIC), Encuestas de Hogares de Propósitos Múltiples, San Salvador, 2011 y 2015.

Las estadísticas oficiales sobre el sector rural son limitadas o inexistentes, y la mayoría se divulgan en términos de lo que comprenden las actividades agropecuarias, que son muy limitadas en comparación con el concepto de lo rural. Esto reduce el análisis del desempeño de los servicios financieros, ya que en el sector rural se realizan actividades de comercio o de turismo que no se diferencian para el ámbito urbano y rural. Los datos disponibles indican que las brechas de inclusión financiera se acentúan en el ámbito rural. 


\section{B. La estrategia de inclusión financiera}

Desde su gestación, el desarrollo de la estrategia de inclusión financiera ha sido liderado por el BCR, con el apoyo tanto del Departamento del Tesoro de los Estados Unidos como de la Alianza para la Inclusión Financiera. La primera fase del proceso culminó en agosto de 2015 con la aprobación de la Ley para facilitar la inclusión financiera. A continuación, se detallan los hitos del proceso, los cuales se resumen en el diagrama IV.2.

\section{Diagrama IV.2}

El Salvador: estrategia de inclusión financiera, 2008-2015

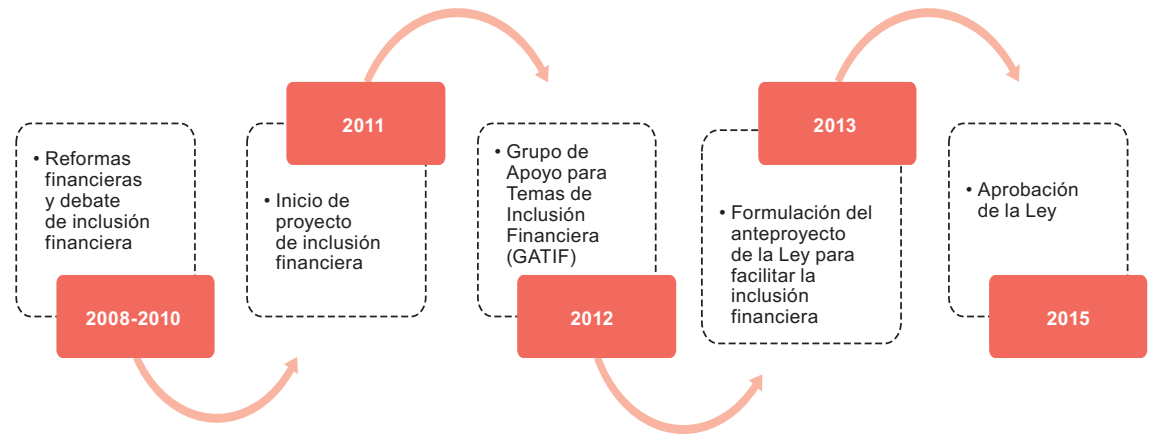

Fuente: Elaboración propia.

Durante el período 2008-2010, las políticas públicas financieras del país se orientaron a la creación del Programa de Educación Financiera (BCR, 2009), con la finalidad de fortalecer las capacidades de la población respecto de la utilización de servicios financieros. En el marco del Plan Quinquenal de Desarrollo 2010-2014 (Gobierno de El Salvador, 2010), se planteó una reforma del sistema financiero, en donde el BCR asumió la responsabilidad de regulación del sistema, mientras que la responsabilidad de la supervisión se asignó a la SSF. Además, se transformó el Banco Multisectorial de Inversiones (BMI) para crear el BANDESAL. Se destaca que en 2009, el BCR recibió del Banco Mundial la consultoría "Informe de diagnóstico sobre el marco jurídico y normativo de la banca sin sucursales en El Salvador", en la que se proponía la creación de corresponsales no bancarios (BCR, 2010). Asimismo, comenzaron los trabajos para plantear un nuevo esquema de fondo de garantías (BCR, 2010), para lo cual en 2010 se recibió asistencia técnica del Banco Interamericano de Desarrollo (BID) para el diseño y la implementación de un Fondo Salvadoreño de Garantías para MIPYME (BCR, 2011a). 
En 2011, la presidencia del BCR y funcionarios de la Gerencia de Desarrollo Financiero participaron en foros internacionales sobre inclusión financiera. Bajo ese contexto, con el apoyo técnico de la Oficina de Asistencia Técnica del Departamento del Tesoro de los Estados Unidos (OTA), se diseñó el "Programa de Inclusión Financiera OTA-BCR" (BCR, 2011b), que contemplaba la realización de un diagnóstico de la situación de la inclusión financiera en el país, la implementación de programas de educación financiera, el fortalecimiento institucional de entidades no reguladas, el desarrollo de la normativa necesaria para la operación de pagos móviles, la revisión de regulaciones para adecuarlas al riesgo de operaciones de bajo monto, el reforzamiento del régimen de garantías mobiliarias, el establecimiento de la normativa necesaria para la operación de microseguros y micropensiones, y el apalancamiento del microcrédito orientado al sector productivo.

Con apoyo de la OTA, en 2012 el BCR creó el GATIF, donde participaron la SSF, el BANDESAL, el Ministerio de Economía, la Secretaría Técnica y de Planificación de la Presidencia de la República de El Salvador e instituciones privadas y de microcrédito (BCR, 2013). Paralelamente, ese mismo año, El Salvador se suscribió a la Alianza para la Inclusión Financiera.

En julio de 2013, el BCR elaboró el anteproyecto de la Ley para facilitar la inclusión financiera, que enfatizaba el aprovechamiento de nuevas tecnologías y la diversificación de la oferta de transacciones a lugares donde no hay presencia física de instituciones, a través de la regulación de las transacciones de dinero electrónico y la creación de cuentas de ahorro con requisitos simplificados (BCR, 2014).

El BCR aprobó, también en julio de 2013, la normativa técnica para prestar servicios por medio de corresponsales financieros. La normativa faculta a las instituciones reguladas (bancos, instituciones financieras no bancarias y sociedades de ahorro y crédito) a brindar servicios por medio de un contrato con corresponsales no bancarios, tales como tiendas, pequeños comercios y personas naturales. Esta figura facilita el acceso a los servicios en lugares remotos, con horarios ampliados. Los servicios que se pueden prestar son los pagos de créditos, el abono y la recepción de depósitos, así como la recepción y el pago de remesas (BCR, 2014).

En mayo de 2014, el BCR remitió la propuesta de anteproyecto de ley, que pasó por el proceso de discusión y debate entre instituciones financieras reguladas y empresas de telefonía que realizan transacciones monetarias vía móvil. La Ley fue aprobada en agosto de 2015 (Asamblea Legislativa, 2015) y a fines de agosto de 2016 el BCR aprobó las normas técnicas.

El GATIF fue un vehículo institucional que permitió que instituciones con funciones muy distintas adoptaran una agenda conceptual común y empezaran a definir, dentro de sus ámbitos de responsabilidad, acciones que 
podrían favorecer la inclusión financiera. El GATIF planteó la realización de una encuesta y sobre la base de sus hallazgos propuso una agenda para crear una ley de inclusión financiera que buscaba abaratar el costo de la utilización de servicios financieros, facilitando el acceso a familias de muy bajos ingresos, y aprovechar las nuevas tecnologías usando el dinero electrónico vía móvil.

\section{Rasgos de la arquitectura institucional}

En esta sección se analiza la arquitectura institucional disponible para promover la inclusión financiera. Primero se describe el marco legal que sustenta la estructura institucional del sistema financiero y posteriormente se identifican las instituciones financieras reguladas que apoyan al sector rural. A continuación, se analiza la evolución de los medios de pagos, donde sobresale el rápido crecimiento de los medios electrónicos, se identifican los servicios y canales financieros que ofrecen las principales instituciones de apoyo en el área rural y se detallan las innovaciones recientes que favorecen la inclusión financiera. Después se revisan los mecanismos de protección de los usuarios, donde se destaca el papel de la Defensoría del Consumidor en términos de las atribuciones que le confiere la ley para resguardar la protección de los usuarios del sistema y la devolución de recursos ante la resolución favorable de denuncias. Por último, se realiza un análisis de las condiciones legales para el cumplimiento de contratos.

\section{Política regulatoria y de supervisión}

La estructura del sistema financiero formal está definida en la Ley de supervisión y regulación del sistema financiero (Asamblea Legislativa, 2011b) ${ }^{6}$. En la Ley se establece que el BCR será responsable de la aprobación del marco de normas técnicas que regulan el sistema, mientras que la SSF deberá supervisar el cumplimiento de las normas que rigen el sistema.

Las entidades sujetas a regulación son los bancos comerciales, las instituciones financieras no bancarias, las entidades previsionales, las empresas de seguros y fianzas, las empresas bursátiles y las instituciones públicas de crédito. Existen otras entidades financieras que no son reguladas, como las que conforman la Federación de Cajas de Crédito y de Bancos de los Trabajadores (FEDECRÉDITO), que son fiscalizadas por el Instituto Salvadoreño de Fomento Cooperativo (INSAFOCOP) ${ }^{7}$.

$6 \quad$ Esta Ley consolidó la regulación y la supervisión. Antes, las normas eran emitidas por la SSF y la supervisión estaba segmentada por entidades especializadas separadas.

7 El BCR y la SSF presentaron en septiembre de 2016 una iniciativa para reformar la Ley de bancos cooperativos y sociedades de ahorro y crédito, en la que se busca ampliar el universo regulatorio para incluir las Cajas de Crédito. 
La SSF establece la normativa para autorizar la operación de bancos, instituciones financieras no bancarias y sociedades de ahorro y crédito. En el caso de los bancos, los procedimientos se detallan en la Ley de bancos (Asamblea Legislativa, 2011c), mientras que para las instituciones financieras no bancarias y las sociedades de ahorro y crédito estos se establecen en la Ley de bancos cooperativos y sociedades de ahorro y crédito (SSF, 2008). Los principales requisitos son: presentación de un proyecto de creación de la entidad financiera a la SSF, constitución de un capital mínimo (dependiendo del tipo de institución) y cumplimiento con ciertas condiciones con respecto al número y la naturaleza de los accionistas. Además, la SSF también define normas prudenciales que las instituciones reguladas deben cumplir con el fin de garantizar la liquidez, solidez y estabilidad del sistema financiero

Los usuarios del sistema financiero regulado cuentan con la garantía de depósitos a través del Instituto de Garantía de Depósitos (IGD), que se financia con aportes de las entidades financieras reguladas. Actualmente ofrece una cobertura de hasta 10.171 dólares por ahorros que se encuentren en cuentas de ahorro, corrientes y a plazo.

\section{Intermediarios financieros}

Como se puede observar en el cuadro IV.3, el 92\% del total de crédito otorgado por entidades financieras formales fue originado por 14 bancos en 2015, seguido por 7 instituciones financieras no bancarias que otorgaron el $6,7 \%$ del crédito y 4 sociedades de ahorro y crédito que brindaron el 1,4\%. El crédito a actividades agropecuarias ascendió a 383,1 millones de dólares y representó apenas el 3,2\% de todo el financiamiento otorgado en $2015^{8}$.

Al analizar el crédito agropecuario otorgado por segmento, se observa que los bancos aportaron el $96 \%$ del crédito, seguidos de las sociedades de ahorro y crédito (3\%) y de los bancos cooperativos (1\%). Es importante destacar que los dos bancos del Estado (el BFA y el Banco Hipotecario) prestaron el 60\% de los recursos al sector agropecuario en 2015. El BFA brindó 125 millones de dólares (un 32,7\% del total), mientras que el Banco Hipotecario otorgó 102 millones de dólares (un 26,7\% del total). Entre los bancos privados se observa una especialización del crédito para empresas y agricultores medianos y grandes, salvo en el caso del Banco ProCredit, que desde el comienzo ha atendido a micro y pequeños empresarios.

De acuerdo con los resultados de la Encuesta de Hogares de Propósitos Múltiples, entre un 10\% y un $20 \%$ del financiamiento a actividades agropecuarias proviene de instituciones financieras no formales, sobre las cuales no se cuenta con información sistematizada. 
Cuadro IV.3

EI Salvador: crédito otorgado por intermediarios financieros formales, 2015

\begin{tabular}{|c|c|c|c|}
\hline & $\begin{array}{l}\text { En miles de } \\
\text { dólares }\end{array}$ & $\begin{array}{c}\text { En } \\
\text { porcentajes } \\
\text { del total }\end{array}$ & $\begin{array}{c}\text { En } \\
\text { porcentajes } \\
\text { de la cartera } \\
\text { agropecuaria }\end{array}$ \\
\hline Banco de Fomento Agropecuario (BFA) & 125092 & 32,7 & 56,1 \\
\hline Banco Hipotecario ${ }^{a}$ & 102223 & 26,7 & 16,1 \\
\hline Banco Agrícola $^{a}$ & 56558 & 14,8 & 1,9 \\
\hline Banco Davivienda $^{a}$ & 29847 & 7,8 & 1,9 \\
\hline Banco ProCredita ${ }^{a}$ & 21408 & 5,6 & 9,4 \\
\hline Banco Promerica $^{a}$ & 12981 & 3,4 & 1,8 \\
\hline Integral $^{\mathrm{c}}$ & 11388 & 3,0 & 14,6 \\
\hline Banco G\&T Continental $^{a}$ & 10013 & 2,6 & 2,8 \\
\hline BAC Credomatic $^{a}$ & 4861 & 1,3 & 0,4 \\
\hline Banco Citibank $^{a}$ & 2903 & 0,8 & 0,3 \\
\hline $\begin{array}{l}\text { Federación de Cajas de Crédito y de Bancos } \\
\text { de los Trabajadores (FEDECRÉDITO) }\end{array}$ & 1599 & 0,4 & 0,6 \\
\hline $\begin{array}{l}\text { Asociación Cooperativa de Ahorro y Crédito } \\
\text { Vicentina (ACCOVI) }\end{array}$ & 1371 & 0,4 & 1,2 \\
\hline Banco Scotiabank $^{a}$ & 1190 & 0,3 & 0,1 \\
\hline Primer Banco de los Trabajadores ${ }^{b}$ & 482 & 0,1 & 0,6 \\
\hline Banco Azula & 448 & 0,1 & 0,6 \\
\hline Constelación $^{c}$ & 350 & 0,1 & 5,1 \\
\hline Corporación Multi Inversiones $(\mathrm{CMI})^{\mathrm{b}}$ & 137 & 0,0 & 0,2 \\
\hline Credicomer $^{\mathrm{C}}$ & 91 & 0,0 & 0,2 \\
\hline Banco de los Trabajadores Salvadoreños (BTS) ${ }^{b}$ & 77 & 0,0 & 0,2 \\
\hline Banco Industrial $^{a}$ & 66 & 0,0 & 0,0 \\
\hline Banco Izalqueño de los Trabajadores ${ }^{b}$ & 1 & 0,0 & 0,0 \\
\hline Banco Azteca ${ }^{a}$ & - & 0,0 & 0,0 \\
\hline COMEDICA $^{\mathrm{b}}$ & - & 0,0 & 0,0 \\
\hline Multivalores $^{\mathrm{c}}$ & - & 0,0 & 0,0 \\
\hline
\end{tabular}

Fuente: Superintendencia del Sistema Financiero (SSF).

a Bancos.

b Instituciones financieras no bancarias (cooperativas).

c Sociedades de ahorro y crédito.

La baja participación de la banca comercial y cooperativa en el crédito a actividades agropecuarias puede deberse a tres factores vinculados a temas de riesgo y costos:

i) La gran mayoría de los productores agrícolas o pecuarios se caracterizan por realizar su actividad en microparcelas para autoconsumo y con baja productividad, lo que implica mayores costos administrativos y mayor riesgo.

ii) En los últimos años se han registrado fuertes sequías que han provocado millonarias pérdidas en cultivos. Esto aumenta el riesgo 
de impago, ya que las actividades de los pequeños productores se basan en el régimen de lluvias y muy pocas operan bajo sistemas técnicos de regadío. Además, las organizaciones de productores agropecuarios han promovido el impago de los adeudos vía decretos, lo que desincentiva la canalización de recursos hacia el sector.

iii) La incidencia de la delincuencia también desincentiva la oferta de servicios financieros en ciertas zonas del país.

La combinación de los tres factores mencionados genera incentivos perversos y lleva a las entidades financieras privadas a reducir la exposición del riesgo en actividades productivas agrícolas.

\section{Sistemas de pago}

El Banco Central es el responsable del funcionamiento de los sistemas de pago, cuyos instrumentos, procedimientos y normas se utilizan para la transferencia de recursos financieros entre sus participantes. El Salvador cuenta con cuatro sistemas de pago. El sistema de liquidación bruta en tiempo real es un sistema de operaciones de alto valor, como las transferencias interbancarias. Los otros tres sistemas son la Cámara de Compensación Electrónica de Cheques (CCECH), los sistemas de pagos masivos y los sistemas de títulos valores, que se consideran de bajo valor y se usan para procesar operaciones como compensación de cheques y pagos con tarjetas de crédito y débito, y operaciones de crédito y débito. Los medios utilizados para acceder a los sistemas de bajo valor incluyen cajeros automáticos, puntos de venta, Internet y celulares.

En un estudio sobre las condiciones de competencia en el mercado de tarjetas de crédito elaborado por la Superintendencia de Competencia se documentó que entre 2004 y 2009 el número de tarjetas de crédito y débito se expandió significativamente debido a la disponibilidad de dispositivos electrónicos en puntos de venta. Hasta 2012, las redes que prestaban los servicios de pagos electrónicos eran cinco y tenían una amplia cobertura. Por su parte, el número de dispositivos para tarjetas de crédito llegó a 735.919 en junio de 2012 (último dato disponible por el BCR), lo que supone un aumento de 15.221 puntos con respecto a diciembre de 2011. Este comportamiento refleja el dinamismo del crédito de consumo (véase el gráfico IV.2).

Además de las redes de cajeros de los principales bancos, en el país existen empresas que brindan servicios de pagos electrónicos y gozan de una amplia cobertura geográfica. Estas redes son Puntoxpress y Red Multiservicios AKÍ, cuyo detalle se puede consultar en el cuadro IV.4. 


\section{Gráfico IV.2}

El Salvador: dispositivos electrónicos en puntos de venta de tarjetas de crédito y débito, 2003-junio de 2012

(En número de dispositivos)

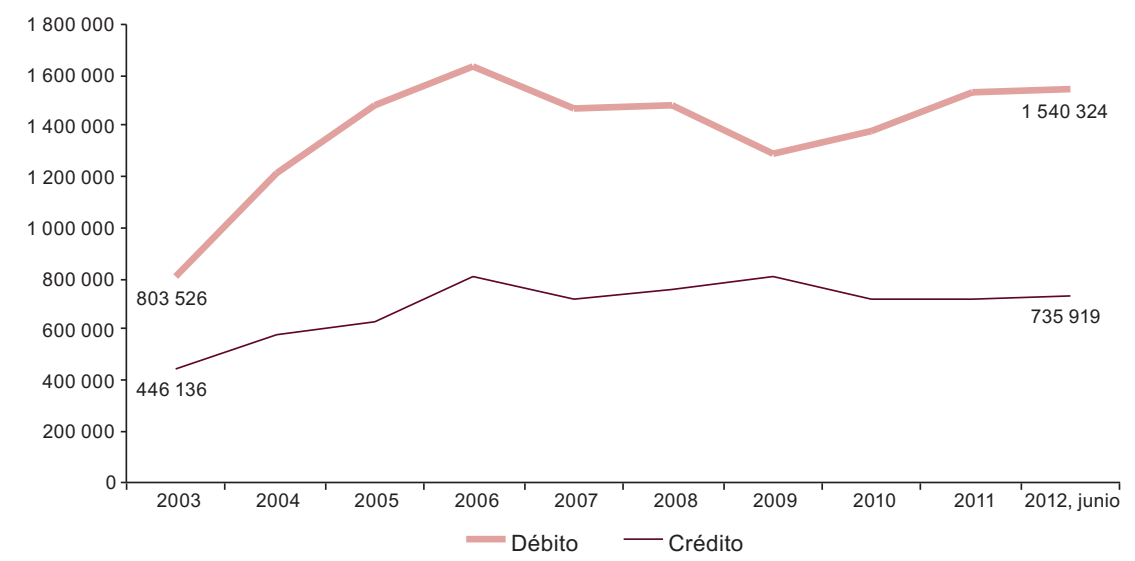

Fuente: Banco Central de Reserva de El Salvador (BCR).

\section{El Salvador: agencias y puntos de pago}

\begin{tabular}{ll}
\hline Empresa & Cantidad de puntos de pago \\
\hline Puntoxpress & 91 Salas de Súper Selectos, \\
cobertura nacional \\
& 28 Restaurantes Biggest \\
& 71 Farmacias Económicas \\
& 2 Salas de Walmart \\
& 2 Salas de Despensa Familiar \\
& 6 Almacenes El Gallo más gallo \\
& 49 Almacenes Prado \\
& 29 Farmacias La Buena (Oriente) \\
& 5 Tiendas Galo (Oriente) \\
& 1 Gasolinera Puma (American Park) \\
& Total: 285
\end{tabular}

Tipo de transacción

Pago de préstamos: Integral Sociedad de Ahorro y Crédito, Credi Q, FINCA, Presta Fácil, Lotificaciones Diversas S.A. (LOTIVERSA), Óptima Servicios Financieros, Fundación para el Autodesarrollo de la Micro y Pequeña Empresa (FADEMYPE)

Pago de colectores: electricidad, telefonía fija y celular, cable, aseguradoras

Pago de tarjetas de crédito: Banco Agrícola, Citibank, Almacenes Simán, Prisma Moda, Primer Banco de los Trabajadores

Cobro de remesas de diversas empresas

Cobro de subsidio de gas

Pago de universidades

Suscripción a periódicos

Pago de ventas por catálogo

\begin{tabular}{|c|c|}
\hline Red & 20 Farmacias Virgen de Guadalupe \\
\hline Multiservicios & \\
\hline & $\begin{array}{l}4 \text { Agencias propias en el Área } \\
\text { Metropolitana de San Salvador }\end{array}$ \\
\hline de Servicio & 6 Almacenes El Baratillo \\
\hline $\begin{array}{l}\text { Salvadoreño de } \\
\text { Protección S.A. }\end{array}$ & 25 Súper tiendas locales en ciudades \\
\hline
\end{tabular}

12 Farmacias locales en ciudades del interior

20 Comercios como librerías, kioscos

Pago de colectores: electricidad, telefonía fija, móvil, Internet, cable (todas las compañías)

Pago de colegios y universidades Pago de primas de aseguradoras Pago de ventas por catálogo

Próximamente pagos a tarjetas de crédito, préstamos y remesas de instituciones que se asociarán

Total: 105

Fuente: Elaboración propia. 


\section{Servicios financieros y canales de distribución}

Debido a la amplia variedad de instituciones que ofrecen servicios financieros al sector rural en el país, y ante la falta de sistematización de esos datos, en este apartado se identifican las tres principales instituciones que brindan apoyo al sector para posteriormente analizar los servicios financieros que ofrecen y sus respectivos canales de distribución.

De acuerdo con cifras de la SSF, en 2015, el BFA disponía de una cartera de crédito por 222,8 millones de dólares, de los cuales un 34\% fueron recibidos por mujeres. Los principales segmentos de crédito se concentran en el sector agropecuario, sobre todo granos básicos, y las actividades de micro y pequeños productores. La composición de la cartera de crédito implica un perfil de riesgo mayor que el de un banco comercial, por lo que la gestión y el conocimiento del mercado han sido clave para mantener una cartera sana.

En 2015 el BFA ofreció a sus clientes depósitos que ascendieron a 236 millones de dólares. El 88,5\% de los depositantes tienen un saldo menor a 1.000 dólares. La mitad de las cuentas son de ahorro a plazo fijo, un 38,8\% son cuentas de ahorro y el resto son productos a la vista. Asimismo, se ofrecen servicios de microseguros por un monto de 1,1 millones de dólares.

El BFA cuenta con 28 agencias, 4 serviagencias y 9 cajas exprés situadas en puntos estratégicos, como Ciudad Mujer ${ }^{9}$. En 2015 lanzó un plan piloto con la instalación de tres cajeros propios. Además, ofrece algunos de sus servicios a través de Internet y por teléfono.

El Banco Hipotecario es un banco estatal enfocado en apoyar a la micro y pequeña empresa, y ocupa el segundo lugar en la asignación de recursos al sector agropecuario, con 102,2 millones de dólares. A diferencia del BFA, su cartera se concentra $(75,3 \%)$ en atender la demanda de los agroexportadores. Se destaca su financiamiento para renovar el parque cafetalero del país, que en los últimos años sufrió un severo ataque de roya y otras enfermedades que provocaron graves daños al bosque cafetero. También ofrece un gran apoyo a los cultivadores de caña en el país, ya sean productores individuales, cooperativas o ingenios.

El Banco Hipotecario tiene 28 agencias físicas en 12 departamentos del país, cuenta con 59 cajeros propios y dispone de servicio de banca telefónica y banca por Internet.

El Sistema FEDECRÉDITO consolida las operaciones de una amplia red de bancos cooperativos distribuidos en todo el país. En 2015, el monto

El programa Ciudad Mujer es una iniciativa del Gobierno a través de la cual en una oficina de atención a las mujeres se integran diversos servicios que brinda el Estado, como salud, formación, acceso a financiamiento, asesoría legal, seguridad y otros. 
de créditos ascendió a 266,8 millones de dólares. Se destaca el marcado incremento que han registrado sus operaciones en los últimos años, ya que en 2010 el monto otorgado fue de 141,8 millones de dólares. El crédito que otorgó al sector agropecuario fue de apenas un 0,6\% del total, equivalente a 1,7 millones de dólares, de los cuales cerca de 0,9 millones de dólares corresponde a un convenio con el MAG para otorgar microcréditos a pequeños productores (162 préstamos) del nororiente del país a través del Proyecto de Desarrollo y Modernización Rural para la Región Oriental (PRODEMORO) (FEDECRÉDITO, 2016). FEDECRÉDITO se ha consolidado como un operador de segundo piso para sus entidades socias, por lo que en 2015 proporcionó cerca de 201,4 millones de dólares.

La institución ha impulsado una estrategia agresiva para consolidar su presencia en los 14 departamentos y en la mayoría de los 260 municipios del país. Actualmente impulsa el programa "a la vuelta de tus sueños", con el que pretende disponer de puntos de acceso a los servicios financieros en el interior en el país. El Sistema FEDECRÉDITO cuenta con 57 instituciones socias: 7 bancos de los trabajadores y 50 cajas de crédito ubicadas en los municipios. Además de las sucursales de sus socios, ofrece servicios a través de una red de 160 cajeros automáticos (FEDE red 365), 229 corresponsales financieros no bancarios (FEDE punto vecino), banca por celular (Fede Móvil) y banca por teléfono.

\section{Innovaciones}

Varias entidades del sistema financiero se encuentran implementando una serie de iniciativas innovadoras, y algunas están realizando cambios en la estructura organizacional para adecuar mejor sus programas de inclusión financiera. Cabe señalar que, debido a su carácter innovador y de reciente implementación, la información documental es muy limitada, por lo que buena parte de los datos sobre estas acciones se obtuvieron por medio de entrevistas directas con actores clave del sistema. A continuación se describen algunas iniciativas, pero hay que tener presente que pueden existir más y que es necesario lograr una mejor sistematización.

Se estima que la tasa de penetración de móviles alcanza un $148 \%$ en El Salvador. De acuerdo con la encuesta de inclusión financiera (BCR, 2016), pese a cierta desconfianza, el $27 \%$ de la población indica haber usado el servicio de transferencias y pagos vía celulares. El principal producto para realizar dichas transacciones es Tigo Money, ofrecido por la empresa de telecomunicaciones Tigo. La empresa ha facilitado una serie de transacciones a través de su red, como la compra de gas subsidiado, los pagos de la factura eléctrica, el pago de nómina vía celular, los pagos del programa Adulto Mayor y la digitalización de pagos de diversas empresas. 
A la fecha de la realización del estudio, existían otras cuatro empresas interesadas en obtener la autorización para brindar servicios de dinero electrónico. Uno de los principales obstáculos que presentan los servicios financieros móviles es la limitada interoperabilidad entre proveedores de servicios de telecomunicaciones y entidades financieras.

El Banco Agrícola ocupa el primer lugar en créditos y activos en El Salvador. En 2016 creó la gerencia de inclusión financiera con el fin de adecuar los diferentes productos existentes a las necesidades de la población que no tiene acceso a servicios financieros formales.

Entre los innovadores programas que impulsa, ha optado por aprovechar su condición de primer pagador de remesas del país, lo que le permite acceder a personas que no tienen cuentas en el sistema bancario formal. Mediante la aplicación de una metodología basada en riesgos, determina la frecuencia de flujos de remesas por mes y ofrece a los usuarios con disponibilidad de recepción de recursos estables productos financieros que les permiten aprovechar una amplia gama de servicios, como los adelantos de pago de remesas, los créditos educativos y de vivienda, los microseguros y la capacitación en educación financiera.

El Banco Agrícola cuenta con una red propia de más de 1.000 puntos de acceso a los servicios financieros en todo el país y, para seguir apoyando la inclusión financiera, recientemente promovió e impulsó la normativa de inclusión financiera. Logró ampliar su cobertura bajo esta modalidad y agregó más de 100 corresponsales.

Es importante señalar que algunas instituciones maduras, con una larga tradición de servicios financieros, están invirtiendo recursos para definir su estrategia de inclusión financiera, que comprende tareas básicas como la definición y el alcance de la inclusión financiera, y la definición de las acciones que impulsarán para cerrar la brecha de las personas excluidas. Al respecto, la Asociación Bancaria Salvadoreña (ABANSA) podría jugar un destacado papel al apoyar a diferentes entidades financieras y al Gobierno en el diseño de acciones que promuevan las mejores prácticas viables, factibles y de mayor impacto para la inclusión financiera.

Ante la entrada en vigor de la Ley para facilitar la inclusión financiera, en 2016 la SSF creó la Intendencia de Inclusión Financiera, con la finalidad de supervisar las nuevas entidades habilitadas por la Ley. La entidad también es responsable de la supervisión de otras actividades reguladas, como los burós de créditos, las sociedades de garantía recíproca, los agentes financieros receptores de remesas y las casas de cambio.

Por su parte, con el apoyo de la Alianza para la Inclusión Financiera, el BCR está implementando el "Proyecto de Inclusión Financiera de El Salvador", que contempla la realización de mesas de trabajo con agentes de la industria 
para discutir el acceso al crédito para las micros y pequeñas empresas, la capacitación a formadores del Programa de Educación Financiera, los eventos de divulgación y la realización de tres encuestas: la Encuesta Nacional de Acceso a Servicios Financieros de El Salvador, la Encuesta Nacional de Capacidades Financieras y la Encuesta Nacional de Acceso al Crédito para la Micro y Pequeña Empresa.

\section{Mecanismos de protección a usuarios}

La Defensoría del Consumidor es la institución facultada para defender los derechos de los consumidores. En particular, de acuerdo con la Ley de protección al consumidor (Asamblea Legislativa, 2005) y su respectivo reglamento, en referencia a transacciones financieras, se establece el mecanismo de cálculo de intereses, las condiciones para el cobro de comisiones y recargos, y la prohibición de condicionar el acceso a servicios financieros.

La Defensoría puede recibir la denuncia de cobro de una tasa de interés superior a la que se establece en la Ley contra la usura, en cuyo caso procederá a la sanción respectiva y comunicará al BCR, la SSF y los juzgados correspondientes el incumplimiento de la entidad financiera en cuestión.

\section{Estado de derecho y administración de justicia}

El Banco Mundial elabora el indicador de Doing Business, en el cual el país se ubicó en la posición 86 de un total de 189 naciones evaluadas en 2016 (Banco Mundial, 2016a). Este indicador se construye a partir de 10 componentes y el que ocupa el quinto lugar en términos de desventajas es el componente "Cumplimiento de contratos", donde el país se ubica en la posición 109. En promedio, hacer cumplir un contrato significa esperar 786 días, lo que lleva a las instituciones financieras a ser muy cautelosas, en particular en operaciones de crédito de bajo monto.

Desde 2002, El Salvador cuenta con la Ley de mediación, conciliación y arbitraje, como una herramienta alterna para la solución de conflictos. En el marco de esta Ley, la Cámara de Comercio e Industria de El Salvador es la única autorizada por gobernación para realizar arbitrajes, a través del Centro de Mediación y Arbitraje.

En oposición, el de "Obtención de crédito" es el componente donde el país se encuentra mejor calificado; en 2016 alcanzó la posición 15 y experimentó una mejora de 56 posiciones con respecto al año previo. Esta importante mejora está relacionada a la aprobación de la Ley de garantías mobiliarias (Asamblea Legislativa, 2013a) y su reglamento.

Con la Ley de garantías mobiliarias (Asamblea Legislativa, 2013a) se sustituyeron varias normas que se encontraban dispersas en la legislación civil y mercantil. La Ley amplía lo que se puede considerar como garantía, incluidos 
bienes corporales, bienes incorporales, derechos sobre bienes futuros que el deudor garante adquiera con posterioridad a la constitución de la garantía, bienes fungibles, derechos de propiedad intelectual, elementos aislados de la empresa mercantil, acciones y participaciones sociales, así como todo bien, derecho, contrato o acción al que las partes atribuyan valor económico.

También se establece la creación de un registro de garantías administrado por el Centro Nacional de Registros (CNR) e inaugurado en octubre de 2014. El registro se realiza a través de una plataforma electrónica, lo que brinda una gran agilidad a los usuarios para registrar bienes o confirmarlos, y facilita que las instituciones financieras puedan disponer de información clave sobre el estatus de la garantía del solicitante de financiamiento. También se permite que los usuarios recuperen con mayor facilidad la garantía una vez finalizados sus compromisos.

El Salvador cuenta desde hace muchos años con empresas que brindan servicios sobre historial de créditos. Debido al creciente número de quejas ante la Defensoría del Consumidor, ya sea por problemas que enfrentan personas con una inadecuada calificación de su historial crediticio o por la venta de las bases de datos, en 2011 se aprobó la Ley de regulación de los servicios de información sobre el historial de crédito de las personas (Asamblea Legislativa, 2011b). Esta Ley facultó a la SSF para aprobar y revocar el funcionamiento de cualquier empresa que presta los servicios de historial y estableció que la Defensoría del Consumidor será la receptora de quejas de los usuarios y podrá establecer sanciones por faltas cometidas por las empresas que manejan el historial.

Además, la Ley exige que las empresas de historial crediticio suministren la información que los consumidores requieran, que actualicen mensualmente el estatus de los créditos, que proporcionen información gratuita a los clientes, que permitan la realización de auditorías informáticas de la SSF, que dispongan de un centro de atención regional para facilitar el acceso en el interior del país, que a los tres años se elimine cualquier dato negativo sobre los clientes desde su clasificación y que, una vez que el cliente pague la deuda, se elimine dicha información negativa de su historial en el término de un año. La Ley estableció prohibiciones para los burós de crédito, como incluir el historial de pagos de los servicios sociales básicos sin consentimiento del usuario, publicar en cualquier medio de comunicación el nombre de personas (naturales o jurídicas) por incumplimiento de créditos y comercializar las bases de datos ${ }^{10}$.

10 En 2013, la Sala de lo Constitucional declaró inconstitucional el artículo 30 de la Ley de regulación de los servicios de información sobre el historial de crédito de las personas, por lo que en julio de 2016 se aprobaron nuevas reformas a la Ley. Por una parte, con esto se buscaba cumplir la sentencia de la Sala reformando el artículo 30. Por la otra, a fines de 2015 la Asamblea Legislativa aprobó 32 reformas a la Ley, y una de las principales fue reducir el tiempo por el cual una persona natural o jurídica permanece en el registro con historial negativo, y si la mora es menor a la mitad de un salario mínimo, el historial negativo se borra automáticamente. 


\section{Identificación y análisis de los instrumentos de política pública}

La política pública de apoyo al financiamiento para el desarrollo productivo está concentrada en el BANDESAL. Otros recursos financieros para apoyar la productividad y la innovación se proporcionan a través del Fondo de Desarrollo Productivo (FONDEPRO) por medio del Ministerio de Economía. Por su parte, el MAG cuenta con un amplio programa de entrega de semillas para cultivo de granos básicos, otorga asistencia técnica a pequeños productores y lleva adelante programas para compensar los efectos de las sequías.

A nivel nacional existe una iniciativa dirigida a apoyar la educación financiera, y en las encuestas del BCR se destaca el amplio reconocimiento de los usuarios al identificar a los bancos como principal fuente de educación financiera. También existen programas en instituciones públicas y bancos cooperativos.

\section{Banca de desarrollo}

En 2011, con la aprobación de la Ley del sistema financiero para fomento al desarrollo (Asamblea Legislativa, 2011a), se transformó el antiguo BMI para crear el BANDESAL. La Ley faculta al BANDESAL a realizar actividades de banca de segundo piso, otorgar préstamos directos y administrar fideicomisos. Además, es responsable de la gestión del Fondo de Desarrollo Económico (FDE) y del Fondo Salvadoreño de Garantías (FSG). Dicha institucionalidad está enfocada hacia el segmento de MIPYMES, para lo cual coordina las acciones con el BFA, el Banco Hipotecario, el Fondo Social para la Vivienda (FSV) y el Fondo Nacional de Vivienda Popular (FONAVIPO).

El financiamiento indirecto a través de operaciones de segundo piso sigue siendo el principal mecanismo de apoyo al desarrollo productivo. Las líneas de financiamiento se otorgan a través de 42 instituciones financieras a las siguientes actividades: i) agricultura intensiva, ii) fomento agropecuario, iii) inversión en fincas cafeteras, iv) fomento a la agricultura familiar, v) rehabilitación de la agricultura, vi) avío para seguridad alimentaria, vii) avío para cultivos tradicionales y viii) control de enfermedades del café (BANDESAL, 2016). El BANDESAL también está facultado para otorgar financiamiento directo por hasta un $50 \%$ del valor de los proyectos productivos, siempre y cuando el monto solicitado sea menor al $10 \%$ del patrimonio neto de las reservas del solicitante.

Con los recursos del FDE se busca incrementar la producción y la exportación, apoyar las cadenas productivas, promover la competitividad empresarial y respaldar a las micro y pequeñas empresas. El FDE puede otorgar recursos de manera directa a personas naturales o jurídicas y brindar 
recursos a instituciones financieras elegibles para apoyar determinadas líneas productivas. Se prohíbe que el FDE pueda utilizarse para financiar al Estado y a instituciones o empresas sin calificación de riesgo de la SSF, para invertir en acciones o para apoyar créditos de consumo.

El BANDESAL es responsable de la operación de diversos fideicomisos, entre los que se destacan el Fideicomiso Especial de Desarrollo Agropecuario, el Fideicomiso de Apoyo a la Producción de Café, el Fideicomiso de Apoyo a la Inversión en la Zona Norte y el Fideicomiso Ambiental para la Conservación del Bosque Cafetalero (FICAFE).

Desde 2015, el BANDESAL impulsa un programa orientado a promover la inclusión financiera de la mujer, ofreciendo créditos, garantías y capacitaciones. Otro programa de apoyo inclusivo es Banca Emprendes, a través del cual se apoyan iniciativas emprendedoras de micro, pequeñas y medianas empresas.

\section{Política de fomento}

El Ministerio de Economía, a través del FONDEPRO, apoya a la micro, pequeña y mediana empresa mediante cofinanciamientos no reembolsables, a fin de fortalecer su competitividad y generar un impacto económico en términos de empleo, ventas, nuevos productos o mercados. El cofinanciamiento cubre un 60\% del proyecto para las MIPYMES dentro del Área Metropolitana de San Salvador (AMSS), un 75\% para las empresas ubicadas fuera del AMSS y un $50 \%$ para la adquisición de maquinaria, equipo, software especializado e infraestructura para el cumplimiento de normativas de calidad.

A través del MAG, se impulsa el Plan de Agricultura Familiar y Emprendedurismo Rural para la Seguridad Alimentaria Nutricional, donde sobresale el Programa de Entrega de Paquetes Agrícolas (semillas y fertilizantes) para maíz y frijol. Cabe destacar que existen muy pocos datos sobre la rendición de cuentas de los programas o proyectos, lo que hace difícil la evaluación del impacto de los programas de fomento.

\section{Garantía de crédito}

El BANDESAL es la institución que administra los diferentes fondos de garantía, entre los que se destacan el FSG creado en 2011 (Asamblea Legislativa, 2011a) y el Programa de Garantía Agropecuaria (PROGARA). El FSG se enfoca en apoyar a las MIPYMES en diferentes sectores productivos, para lo cual dispone de 13 líneas. Por su parte, el PROGARA se concentra en el crédito otorgado a pequeños productores vinculados a cultivos para la seguridad alimentaria, así como el avío para cosecha de café. 


\section{Fortalecimiento de capacidades}

Desde 2012, el BANDESAL dispone de un Centro de Formación. En 2015, el Centro de Formación brindó capacitación especializada al sector agropecuario a través de un acuerdo con el Consejo Salvadoreño del Café y el Centro Nacional de Tecnología Agropecuaria y Forestal "Enrique Álvarez Córdova", en el cual se brindó apoyo a 343 MIPYMES productoras de café. Además, el BANDESAL implementa programas estratégicos que contemplan la capacitación de recursos humanos como una actividad clave para el desarrollo de los productores.

El BCR realizó la encuesta de inclusión financiera 2016 y encontró que solo el $4 \%$ de los entrevistados había recibido educación financiera. Esto da cuenta de que aún queda por delante la gran tarea de profundizar la educación financiera a fin de comprender y mejorar el uso de los servicios financieros. Al preguntar de qué institución había recibido educación, sobresalieron los bancos $(28 \%)$, seguidos de las organizaciones no gubernamentales $(17 \%)$, las cooperativas (14\%) y, por último, con tasas muy bajas, el BCR $(6 \%)$ y la SSF $(2 \%)$. Estos resultados plantean dos grandes tareas: incrementar de manera generalizada la educación y realizar una mejor coordinación entre los diferentes actores para dar a conocer las innovaciones financieras.

\section{E. Principales retos para la inclusión financiera de pequeños productores rurales}

La inclusión financiera en El Salvador es un tema relativamente nuevo y los resultados de la última encuesta sobre el tema indican que apenas un $12 \%$ de los entrevistados dispone de un crédito formal, un $16 \%$ realiza transacciones financieras por celulares, solo un $20 \%$ ahorra en el sistema de pensiones y un $23 \%$ tiene cuenta de ahorro en una institución financiera formal. Sobre estos resultados, se destaca el crecimiento acelerado de las operaciones financieras por medio de celulares.

La limitada formalización de la PEA plantea un desafío para crear políticas públicas inclusivas que, por el lado del sector financiero, involucren el diseño de instrumentos a un costo menor, la promoción de innovaciones financieras que faciliten el acceso a los segmentos de menor ingreso y el desarrollo de programas que se adecuen a sus necesidades para apoyar su desarrollo. Simultáneamente, se necesita una política nacional inclusiva que apoye con el aumento de la cobertura de acceso a educación, salud, seguridad, servicios sociales básicos y desarrollo productivo. Combinadas, estas áreas generan oportunidades inclusivas para que todas las personas puedan desarrollar su potencial y encuentren apoyo para alcanzar su bienestar. 
De acuerdo con los resultados del estudio realizado por Villasenor, West y Lewis (2016), El Salvador enfrenta rezagos en diferentes ámbitos de la inclusión financiera, como la falta de una institucionalidad públicoprivada de coordinación para definir, impulsar e implementar una estrategia coordinada con todos los actores nacionales. Esta situación se agudiza a nivel rural.

En este contexto, el BFA y el MAG tienen la oportunidad de liderar una iniciativa de inclusión rural aprovechando la experiencia de otros países. Colombia tiene una experiencia interesante, ya que la Comisión Intersectorial de Inclusión Financiera (2016) contempla al sector rural entre sus cuatro prioridades y ha propuesto un conjunto de líneas de acción específicas para el área rural: i) facilitar el uso del redescuento de las instituciones que financian al sector agropecuario, ii) fortalecer el esquema de garantías rurales, iii) diseñar productos y canales para el sector y iv) fortalecer la política de manejo de riesgo rurales.

En virtud de la elevada informalidad de la economía y los problemas nacionales y del sector rural, se propone avanzar en la creación de un vehículo institucional público-privado que lidere y coordine la inclusión financiera nacional y que incorpore entre sus prioridades al sector rural. Para ello se propone la creación de un Consejo Nacional de Inclusión Financiera (CNIF) que deberá enfocarse en abordar tres retos estratégicos: i) las fallas de coordinación entre entidades públicas y privadas, ii) las fallas de información entre los que ofrecen y los que demandan los servicios y iii) las fallas de regulación/competencia, en términos de la interoperabilidad de las redes tradicionales bancarias y las redes de servicios móviles para operaciones financieras.

\section{El reto de la coordinación entre instituciones financieras públicas y privadas}

La presente investigación permitió constatar la existencia de diversas iniciativas de inclusión financiera, dispersas en distintas instituciones públicas y privadas. Tomando como referencia las experiencias de algunos países de la región, como Colombia, México y el Perú, que se han beneficiado de la existencia de una entidad que coordina la iniciativa de inclusión financiera, define la política nacional, identifica prioridades, establece programas, asigna recursos y promueve acciones conjuntas, se considera pertinente la creación de un CNIF que, bajo el liderazgo del BCR, convoque a la SSF, la Secretaría Técnica y de Planificación de la Presidencia de la República de El Salvador, el Ministerio de Economía, el MAG, el BANDESAL, el BFA y representantes del sector privado. 
En principio, las funciones del CNIF serían las siguientes:

- Proponer al Gobierno la Política Nacional de Inclusión Financiera (PNIF), en la cual se establezcan las recomendaciones sobre normas o iniciativas legislativas, proponiendo las actividades de la PNIF que las entidades deberán implementar y ejecutar.

- Coordinar los lineamientos que impulsarán las instituciones públicas y privadas, con el fin de incrementar la inclusión financiera.

- Recomendar la implementación de medidas para gestionar el financiamiento de la ejecución de la PNIF, entre los sectores público y privado.

- Crear un grupo técnico especializado en temas rurales para que diseñe una estrategia de inclusión financiera rural, integrando las entidades reguladas y no reguladas, y que considere la dispersión de sus actores y las limitaciones de infraestructura, alta informalidad y pobreza.

\section{El reto de la información financiera entre oferentes y demandantes}

Los usuarios de los productos financieros enfrentan la dificultad de poder acceder con facilidad a la variedad de servicios financieros disponibles en las diferentes instituciones. El sector rural sufre una sustancial deficiencia de información, ya que la difusión está estructurada bajo el ámbito de actividades agropecuarias, lo que deja fuera a otras actividades que son relevantes en el medio rural. Se recomienda que el CNIF realicé las siguientes tareas:

- Coordinar la realización de actividades, programas publicitarios o capacitaciones en inclusión financiera en el país; se sugiere coordinar entre Gobierno y la ABANSA un evento ancla, "la semana de la educación financiera", que permita mostrar todos los programas que se impulsan en el país y que un día sea dedicado al sector rural para difundir lo que hacen las entidades públicas y privadas (reguladas y no reguladas).

- Diseñar programas de desarrollo de la infraestructura financiera, con énfasis en el área rural, debido a que varios municipios no cuentan con cobertura, y aumentar la oferta de servicios financieros en municipios que experimentan una elevada exclusión financiera. La cobertura de las encuestas del BCR puede brindar una base de información para este diseño.

- Continuar ampliando los programas de apoyo rural ante los efectos negativos del cambio climático, evaluar la cobertura del microseguro y su eficiencia, y revisar la experiencia internacional (como el caso de Colombia). 
- Diseñar un portal sobre servicios financieros bancarios y móviles para facilitar que el usuario disponga de todos los servicios y los conozca.

- Elaborar y publicar informes semestrales sobre la oferta de servicios financieros en el sistema financiero formal e informal, con un área dedicada a los servicios rurales y las innovaciones financieras (móviles y en línea). En estos informes también se podrá brindar una evaluación del avance de la estrategia de inclusión financiera.

\section{El reto de la regulación y la interoperabilidad de las nuevas tecnologías}

La aprobación de la Ley para facilitar la inclusión financiera en 2015 incrementa las oportunidades para ampliar los servicios financieros a través de celulares y facilita el acceso a más segmentos a un menor costo. Un desafío será lograr una interoperabilidad de las redes de telefonía móvil y de la industria bancaria que permita crear un ecosistema de transacciones que facilite una mayor inclusión.

El Salvador se puede beneficiar de los avances que ha logrado el Perú mediante la creación del "Modelo Perú", en virtud del cual se ha formado un canal digital a través de celulares. Por medio de este canal participan en una red interoperable, para hacer transacciones, 34 emisores financieros y 3 de las 4 compañías telefónicas. Esto ha sido posible gracias al establecimiento de normativas entre el regulador y el supervisor bancario y el regulador de telecomunicaciones. En este proceso ha sido clave la disposición de las entidades financieras y de telecomunicaciones para unirse en un objetivo nacional y lograr una mayor inclusión financiera (BBVA Research, 2016).

La interoperabilidad es fundamental para reducir los costos y aumentar la cobertura, propiciando más competencia entre los actores. La interoperabilidad financiera presenta dificultades técnicas, de seguridad y confiabilidad en el sistema. Los bancos tradicionales, que han invertido años en consolidar su credibilidad, podrán tener más temor de participar por los riesgos que ello implica, mientras que los nuevos operadores no tienen una reputación que perder, sino que más bien se enfrentan al desafío de ganar con calidad y eficiencia. Dirimir estas dos realidades y apostar a ser catalizadores que generen confianza serán tareas clave a las que deberán abocarse los entes reguladores (la SSF, el BCR y la Superintendencia General de Electricidad y Telecomunicaciones).

La población rural, los productores agropecuarios y las MIPYMES rurales percibirán gran parte de los beneficios de la interoperabilidad, ya que se encuentran muy dispersos en todo el territorio y enfrentan costos de transacción más altos para llegar a una entidad financiera, un corresponsal 
o un cajero automático. El canal digital a través de celulares podrá tener un impacto mayor a la hora de proveer conectividad e inclusión a dichos segmentos del país.

La reciente Ley para facilitar la inclusión financiera genera las condiciones para autorizar y regular la participación de operadores móviles que brinden servicios de transacciones electrónicas. Un primer reto será que la normativa cree las condiciones que faciliten el ingreso de nuevos operadores. Tigo Money tiene una ventaja en su posicionamiento y liderazgo en el mercado, pero también hay otras empresas, como Mobile Money (MoMo), que se encuentran brindando servicios en el país. MoMo ha firmado un convenio con el BFA para apoyar la estrategia de inclusión financiera móvil del banco (BFA, 2015) y se ha convertido en la primera iniciativa que aprovecha el marco de la nueva Ley.

Existen, sin embargo, ciertos riesgos en materia de barreras a la competencia. La Superintendencia de Competencia también deberá controlar que los operadores ya establecidos no pongan barreras a los nuevos ingresos y promover y apoyar una mayor competencia mediante una interoperabilidad de redes que cumpla con las condiciones de seguridad y confiabilidad del sistema financiero y móvil.

Se sugiere que el BCR, la SSF, la ABANSA y la Asociación Interamericana de Empresas de Telecomunicaciones (ASIET) realicen visitas técnicas para conocer el "Modelo Perú" y efectuar gestiones de cooperación interinstitucional a fin de que los expertos que gestionaron el proyecto en el Perú compartan el modelo y la estrategia que siguieron. 


\section{Bibliografía}

Alianza para la Inclusión Financiera (2012), "Informe acerca del Foro Mundial sobre Políticas de Inclusión Financiera 2012 de la AFI: haciendo que la inclusión financiera sea una realidad", Bangkok, diciembre.

Angel, A, (2011), "Panorama productivo e infraestructura para el desarrollo rural en El Salvador", documento preparado para el proyecto "Determinantes de la pobreza rural en Centroamérica: desafíos y oportunidades para la acción", Estado de la Región, marzo.

Asamblea Legislativa (2015), "Ley para facilitar la inclusión financiera", Diario Oficial de la República de El Salvador, vol. 408, N 160, San Salvador, septiembre.

(2013a), "Ley de garantías mobiliarias", Diario Oficial de la República de El Salvador, vol. 401, N 190, San Salvador, septiembre.

(2011a), "Ley del sistema financiero para fomento al desarrollo", Diario Oficial de la República de El Salvador, vol. 393, N 197, San Salvador, octubre.

(2011b), "Ley de regulación de los servicios de información sobre el historial de crédito de las personas", Diario Oficial de la República de El Salvador, vol. 392, $N^{\mathrm{o}} 141$, San Salvador, julio.

(2011c), “Decreto No 595. Reformas a la Ley orgánica del Banco Central de Reserva de El Salvador", Diario Oficial de la República de El Salvador, vol. 390, $\mathrm{N}^{\circ} 28$, San Salvador, febrero.

(2005), "Ley de protección al consumidor", Diario Oficial de la República de El Salvador, vol. 368, No 166, San Salvador, septiembre.

Banco Mundial (2016a), Doing Business 2016: Measuring Regulatory Quality and Efficiency, Washington, D. C.

(2016b), Base de datos Global Findex [en línea] http:/ / datatopics.worldbank. org/financialinclusion.

BANDESAL (Banco de Desarrollo de El Salvador) (2016), "Memoria de Labores 2015". BBVA Research (2016), "BIM: el billetero móvil peruano para los no bancarizados", Situación de la Economía Digital, marzo.

BCR (Banco Central de Reserva de El Salvador) (2016), “Demanda nacional de servicios financieros", San Salvador, julio.

(2015), “Memoria de Labores 2014", San Salvador, mayo.

(2014), "Memoria de Labores 2013", San Salvador, abril.

(2013), "Memoria de Labores 2012", San Salvador, abril.

(2012), "Memoria de Labores 2011", San Salvador, mayo.

(2011a), "Programa de Inclusión Financiera OTA-BCR" [en línea] http:/ / www. bcr.gob.sv / bcrsite/uploaded/content/category /694410629.pdf. (2011b), "Memoria de Labores 2010", San Salvador, abril.

(2010), "Memoria de Labores 2009", San Salvador, abril.

(2009), "Memoria de Labores 2008", San Salvador, abril.

BFA (Banco de Fomento Agropecuario) (2015), "Alianza estratégica entre BFA y Mobile Money", diciembre.

Comisión Intersectorial de Inclusión Financiera (2016), “Estrategia Nacional de Inclusión Financiera en Colombia", mayo.

Demirgüç-Kunt, A. y otros (2015), "The Global Findex Database 2014: Measuring Financial Inclusion around the World", Policy Research Working Paper, No 7255, Washington, D.C., Banco Mundial. 
DIGESTYC (Dirección General de Estadística y Censos) (2015), Encuesta de Hogares de Propósitos Múltiples 2014, San Salvador.

(2011), Encuesta de Hogares de Propósitos Múltiples 2010, San Salvador.

EIU / BID (Economist Intelligence Unit/Banco Interamericano de Desarrollo) (2016), Microscopio global 2016. Análisis del entorno para la inclusión financiera, Nueva York.

FEDECRÉDITO (Federación de Cajas de Crédito y de Bancos de los Trabajadores) (2016), "Memoria de Labores 2016", San Salvador.

FUSADES (Fundación Salvadoreña para el Desarrollo Económico y Social) (2015), “Encuesta de competitividad empresarial: inversión, competitividad e incertidumbre", San Salvador.

Gobierno de El Salvador (2010), Plan Quinquenal de Desarrollo 2010-2014, San Salvador.

SSF (Superintendencia del Sistema Financiero) (2008), Ley de Bancos Cooperativos y Sociedades de Ahorro y Crédito, San Salvador.

Villasenor, J., D. West y R. Lewis (2016), The 2016 Brookings Financial and Digital Inclusion Project Report: Advancing Equitable Financial Ecosystems, Washington, D. C., Brookings Institution, agosto. 
Capítulo V

\title{
La inclusión financiera de pequeños productores rurales en Honduras ${ }^{1}$
}

\author{
Daniela $\mathrm{Cruz}^{2}$ \\ Jesús López $z^{3}$ \\ César Valenzuela ${ }^{4}$
}

\section{Introducción}

Los pequeños productores rurales en Honduras, y en América Latina y el Caribe en general, enfrentan múltiples obstáculos para realizar su actividad productiva y comercializar sus excedentes de producción en el mercado. Entre estos obstáculos se identifican: los altos costos de transacción, la escasa inversión en activos productivos e infraestructura, la insuficiencia de recursos y la falta de acceso y uso de servicios financieros acordes a sus necesidades (Sievers y Saarelainen, 2011).

En principio, la inclusión financiera incrementa la resiliencia de los productores rurales ante eventualidades como las condiciones climáticas adversas, frecuentes en su proceso de producción. También contribuye a disminuir el impacto negativo de dichas adversidades al evitar la liquidación de sus activos productivos, disminuir la probabilidad de caer en trampas de

Este capítulo está basado en el estudio de caso realizado por Valenzuela y Cruz (2017).

Investigadora Senior de Espirálica Research and Consulting.

Economista de la Unidad de Desarrollo Económico de la sede subregional de la Comisión Económica para América Latina y el Caribe (CEPAL) en México.

4 Director de Espirálica Research and Consulting. 
pobreza y, por lo tanto, poder recuperarse económicamente por sí mismos (Carter y otros, 2007). Además, la inclusión financiera incrementa la capacidad de los pequeños productores rurales de generar ahorro (Karlan, Ratan y Zinman, 2014; Efobi, Beecroft y Osabuohien, 2014).

El presente capítulo tiene por objeto identificar los elementos del sector financiero, la arquitectura institucional y los instrumentos de política pública que favorecen la inclusión financiera de los pequeños productores rurales, así como las características de la demanda que actúan como barrera para dicha inclusión en Honduras.

En la sección A se presenta una radiografía de la situación actual de la inclusión financiera y el sector financiero en Honduras. Los datos muestran diferencias en los niveles de inclusión financiera entre las distintas áreas geográficas del país y en la comparación internacional. También revelan que las instituciones financieras que concentran el mayor tamaño por el valor de sus activos son los bancos $(90,1 \%)$, las cooperativas $(4,1 \%)$ y las aseguradoras $(2,8 \%)$. Los principales productos y servicios financieros ofertados por el sistema financiero a la población hondureña son los productos tradicionales de ahorro y crédito, seguidos por los seguros, el envío y pago de remesas y las pensiones. A nivel nacional, el sector tiene presencia en los 18 departamentos y cubre el $67,1 \%$ de los municipios. Uno de los determinantes de la poca cobertura de intermediarios financieros en el resto de los municipios del país es la escasa población residente, ya que el 93\% de estos municipios tienen menos de 20.000 habitantes.

Los resultados del diagnóstico realizado como parte de la Estrategia Nacional de Inclusión Financiera (ENIF) en Honduras indican que los micro y pequeños productores agrícolas son el grupo que sufre mayor exclusión financiera debido a su ubicación en zonas rurales de baja densidad poblacional. Aunado a ello, la inestabilidad en el flujo de ingresos y el riesgo de perder esos ingresos disminuyen la probabilidad de acceso al sistema.

En reconocimiento a la sustancial brecha de inclusión financiera prevaleciente en el país, en 2015 el Gobierno de Honduras presentó la ENIF, cuyos detalles se abordan en la sección $B^{5}$. Los principales retos identificados por el lado de la oferta son: escasez de financiamiento focalizado en el sector, limitaciones regulatorias en lo referente a requisitos de acceso y cálculo de reservas, insuficientes capacidades para ampliar la cobertura e incremento de la inseguridad ciudadana. Por el lado de la demanda, las principales restricciones se originan en la falta de información financiera y fiscal del sector, la baja titulación de tierras y la consecuente falta de garantías, los ingresos bajos e inestables, la alta dispersión rural, la limitada vinculación

Según datos de Global Findex (Demirgüç-Kunt y otros, 2015), el 30,0\% de la población hondureña tenía una cuenta abierta en instituciones financieras formales en 2014, mientras que en la región de América Latina y el Caribe el promedio era del 51,1\% 
a cadenas productivas, la pobre articulación de acciones que impulsen el sector y la falta de servicios de asistencia técnica.

En la sección C se expone la arquitectura institucional que acompaña la oferta de los intermediarios financieros. Esta arquitectura provee las condiciones que favorecen o limitan la inclusión financiera de pequeños productores rurales. La arquitectura institucional en Honduras está constituida por la política prudencial y de supervisión, los sistemas de pago, los mecanismos de protección a los usuarios de los productos y servicios financieros, y la infraestructura y regulación complementarias que contribuyen a la inclusión financiera. En la sección D se identifican los instrumentos de política pública que, si bien trascienden el ámbito financiero, inciden en la inclusión financiera de los pequeños productores pertenecientes al ámbito rural a través de la promoción de su inserción productiva. Por último, en la sección E se plantea una reflexión sobre los principales desafíos.

De este estudio se desprende que existe una oferta importante del sector financiero para atender a la población hondureña, con la regulación y supervisión de entidades gubernamentales constituidas hace un tiempo. También se entiende que las instituciones financieras cuentan con una gran capacidad económica para atender la demanda de los productos y servicios financieros.

Sin embargo, existen profundas brechas en el acceso y uso de productos y servicios financieros, que se agudizan en el ámbito rural. Aunque las telecomunicaciones ofrecen una vía para incrementar la inclusión financiera en áreas rurales, también existen otros elementos de la arquitectura institucional que podrían ayudar a este fin. En este sentido, la arquitectura institucional disponible ofrece un buen espacio para favorecer el incremento de la inclusión financiera de los pequeños productores rurales en Honduras. Contar con una infraestructura complementaria que disminuya los riesgos que enfrentan los productores rurales, con una regulación prudencial más flexible y acorde a la realidad nacional, con una supervisión oportuna y con las mejoras tecnológicas necesarias para optimizar los sistemas de pagos supondría un incentivo para los intermediarios financieros. El fortalecimiento de las instituciones de defensa al usuario de los servicios financieros, la educación financiera y la supervisión de los intermediarios financieros crearán incentivos para incrementar la demanda de productos y servicios financieros.

\section{A. Situación actual del sector financiero y la inclusión financiera en Honduras}

En esta sección se analiza la posición de la inclusión financiera en Honduras en el contexto mundial a partir de datos comparativos internacionales de Global Findex (Demirgüç-Kunt y otros, 2015) y el informe sobre inclusión 
financiera mundial publicado por The Economist Intelligence Unit y el Banco Interamericano de Desarrollo (EIU/BID, 2016). En primera instancia se contrasta la situación de la inclusión financiera del país con la de América Latina y el Caribe, para después examinar las características del sistema financiero en Honduras, destacando las brechas de inclusión financiera que persisten en el ámbito rural.

\section{Posición de la inclusión financiera en Honduras en el contexto internacional}

En comparación con otras naciones y regiones del mundo, Honduras presenta un notorio rezago en términos de inclusión a nivel nacional y por área rural. De acuerdo con los datos de Global Findex (Demirgüç-Kunt y otros, 2015), en 2014, un 30\% de los adultos mayores de 15 años tenía una cuenta en el sistema financiero formal. En contraste, el porcentaje era de apenas un $24,9 \%$ en el ámbito rural (véase el gráfico V.1). En lo que respecta a otros productos básicos que ofrecen las instituciones financieras, solo el 14,5\% de los adultos mayores de 15 años de Honduras ahorraban en instituciones financieras, mientras que el porcentaje de sus pares en el área rural era del 11,3\%. Por otra parte, solo el 9,7\% de los adultos mayores de 15 años había recibido algún tipo de crédito de las instituciones financieras, en tanto que el porcentaje de sus pares en el área rural era del 7,8\%.

\section{Gráfico V.1}

Honduras, América Latina y el Caribe y el mundo: adultos mayores de 15 años con servicios o productos financieros básicos a nivel nacional y en áreas rurales, 2014 (En porcentajes)

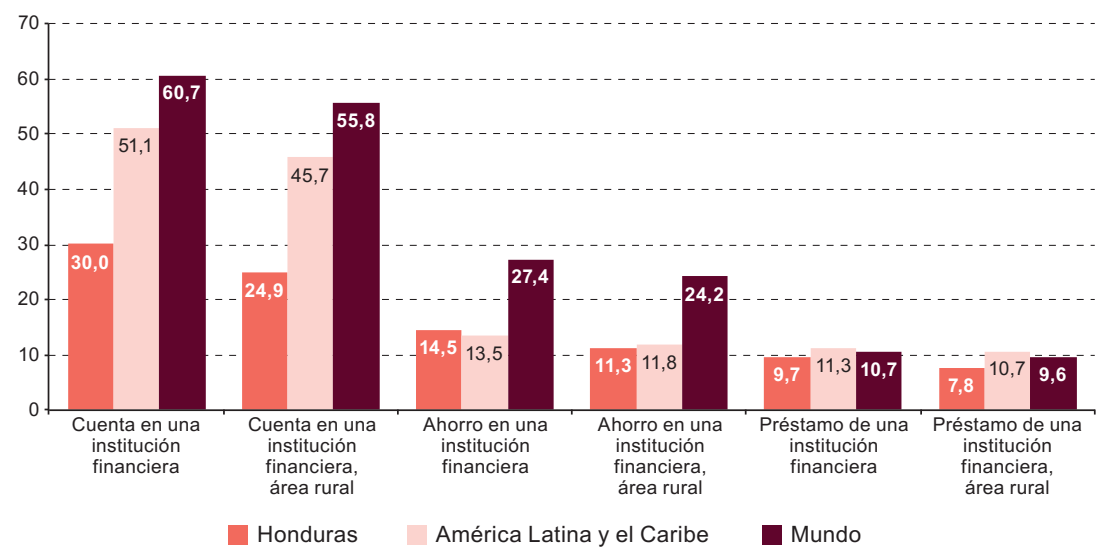

Fuente: Elaboración propia, sobre las base de A. Demirgüç-Kunt y otros, "The Global Findex Database 2014: Measuring Financial Inclusion around the World”, Policy Research Working Paper, № 7255 , Washington, D.C., Banco Mundial, 2015. 
Al comparar los datos de los productos y servicios mencionados con el promedio en América Latina y el Caribe y el mundo, en Honduras se observa un rezago en la mayoría de los productos tradicionales que ofrece el sistema financiero, excepto en el porcentaje de ahorro de la población mayor de 15 años en una institución financiera. El rango de la diferencia porcentual entre el ahorro y el crédito en Honduras con respecto al promedio de América Latina y el Caribe va del 1\% (ahorro en una institución financiera, porcentaje favorable a Honduras) al 2,9\% (préstamo de una institución financiera en el área rural, porcentaje desfavorable a Honduras). Con respecto al promedio mundial, Honduras se encuentra rezagada en todos los productos.

Honduras también exhibe cierto rezago en el contraste con los países de Centroamérica y la República Dominicana. En el gráfico V.2 se muestra una evaluación en las tres variables tradicionales de productos y servicios financieros a nivel nacional y rural en los países de Centroamérica y la República Dominicana. A partir de ellas se calcula un índice simple de inclusión financiera. Cuanto más grande sea el área, mayor será el índice de inclusión. Se observa claramente que el área más amplia pertenece a Costa Rica, seguida de la República Dominicana, Panamá, Guatemala, El Salvador, Honduras y, finalmente, Nicaragua. También resulta evidente que la mayoría de los países muestran un porcentaje menor del lado del crédito que respecto de los productos y servicios de cuenta corriente y ahorro. Esto se puede interpretar como retos y oportunidades de mejora para el sistema financiero de Honduras.

\section{Gráfico V.2}

Centroamérica y la República Dominicana: adultos mayores de 15 años con servicios o productos financieros básicos a nivel nacional y en áreas rurales, 2014

(En porcentajes)

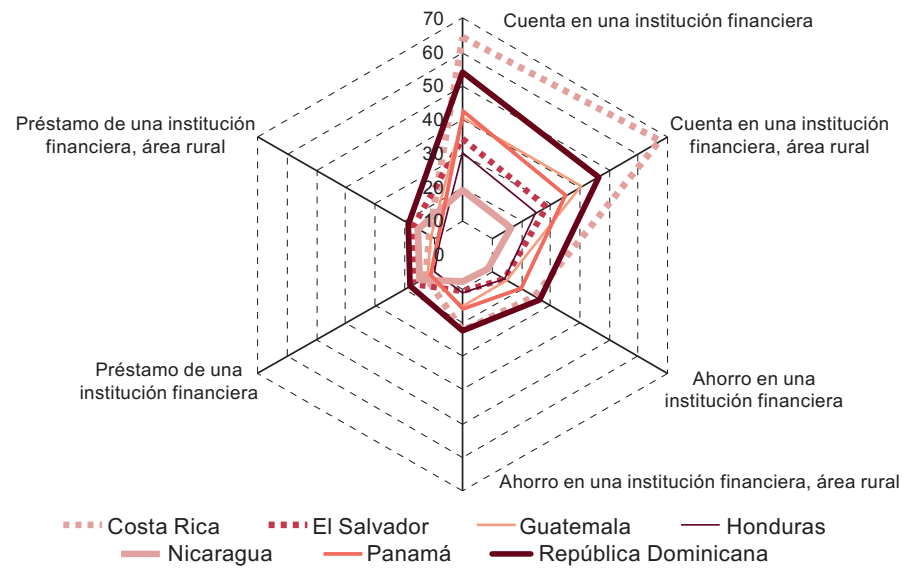

Fuente: Elaboración propia, sobre la base de A. Demirgüç-Kunt y otros, "The Global Findex Database 2014: Measuring Financial Inclusion around the World", Policy Research Working Paper, N 7255 , Washington, D.C., Banco Mundial, 2015. 
En el informe más reciente sobre inclusión financiera de The Economist Intelligence Unit y el Banco Interamericano de Desarrollo (EIU/BID, 2016), Honduras se encuentra clasificado en el tercer grupo de países, en la categoría de 30 a 55 puntos de un máximo de 100, y se muestra que ha avanzado 6 posiciones para situarse por encima de países como China y la Argentina. En el informe se atribuye este reposicionamiento al compromiso de sus instituciones con la inclusión financiera y al lanzamiento de la ENIF en 2015.

\section{Situación actual del sistema financiero en Honduras}

En esta sección se examina en detalle la situación actual del sistema financiero en Honduras. En los siguientes párrafos se describe la oferta del sistema financiero, es decir, el mapa general de los proveedores de productos y servicios financieros, así como el tamaño y las instituciones que integran la oferta financiera del país. Además, se revisa el nivel de acceso a los servicios $y$ productos tradicionales que ofrece el sistema financiero.

El sistema financiero hondureño se encuentra conformado por 6.872 proveedores formales e informales de servicios y productos financieros (CNBS, 2014a y 2015a; REDMICROH, 2015a; CONSUCOOP, 2015; SAG, 2015). Se consideran proveedores formales los intermediarios financieros que se encuentran regulados y supervisados por el Banco Central de Honduras (BCH), la Comisión Nacional de Bancos y Seguros (CNBS) o el Consejo Nacional Supervisor de Cooperativas (CONSUCOOP). Por su parte, se considera informales a aquellas instituciones supervisadas por la Secretaría de Estado en los Despachos del Interior y Población (SEIP), mediante su Unidad de Registro y Seguimiento de Asociaciones Civiles (URSAC). En el cuadro V.1 se presenta la oferta total del sistema financiero de acuerdo con esta clasificación y el carácter legal del proveedor (público o privado).

En el cuadro V.2 se muestran las cifras de activos, pasivos y patrimonio de las principales instituciones financieras privadas formales y no formales de Honduras. Los números indican que, si bien la figura jurídica e institucional que presenta la mayor cantidad de instituciones es la Caja Rural, los bancos son las entidades de mayor tamaño en el sistema financiero hondureño, ya que concentran el $90,1 \%$ de los activos, el $95,4 \%$ de los pasivos y el $66,1 \%$ del patrimonio. 


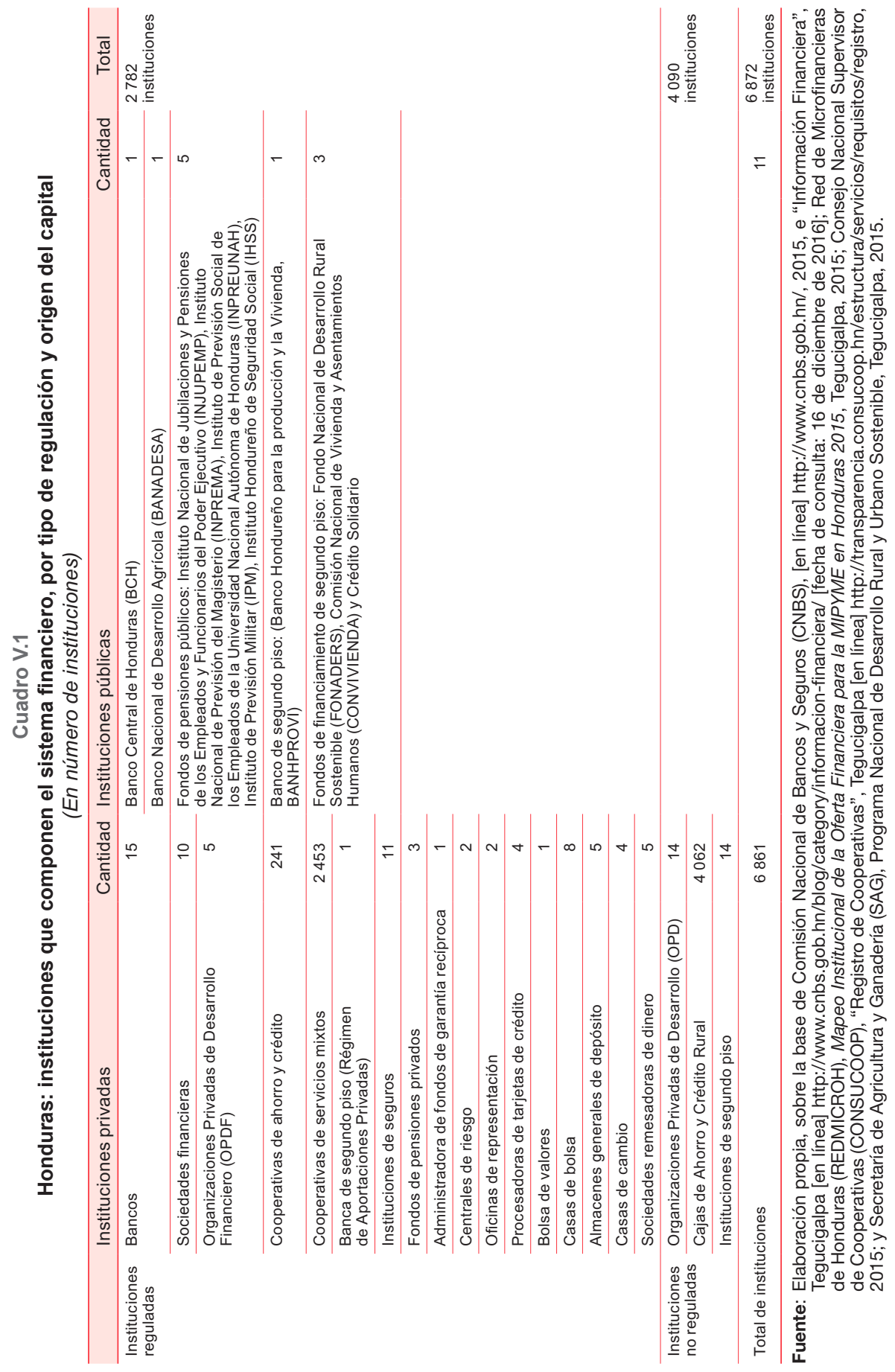




\section{Cuadro V.2}

Honduras: activos, pasivos y patrimonio de las principales instituciones

financieras, diciembre de 2015

(En millones de dólares y porcentajes)

\begin{tabular}{|c|c|c|c|c|c|c|c|}
\hline Tipo & Número & Activos & Porcentajes & Pasivos & Porcentajes & Patrimonio & Porcentajes \\
\hline Bancos ${ }^{\mathrm{a}}$ & 16 & 19449,5 & 90,1 & 17819,8 & 95,4 & 1629,7 & 66,1 \\
\hline Financieras & 10 & 426,4 & 2,0 & 334,0 & 1,8 & 92,3 & 3,7 \\
\hline $\begin{array}{l}\text { Organizaciones } \\
\text { Privadas de } \\
\text { Desarrollo } \\
\text { Financiero } \\
\text { (OPDF) }\end{array}$ & 5 & 80,1 & 0,4 & 54,8 & 0,3 & 25,3 & 1,0 \\
\hline Cooperativas $^{b}$ & 90 & 881,1 & 4,1 & 438,6 & 2,3 & 442,5 & 17,9 \\
\hline $\begin{array}{l}\text { Organizaciones } \\
\text { Privadas de } \\
\text { Desarrollo } \\
(\text { OPD)c }\end{array}$ & 12 & 150,9 & 0,7 & 24,1 & 0,1 & 126,7 & 5,1 \\
\hline Aseguradoras & 11 & 596,9 & 2,8 & N.D. & 0,0 & 149,4 & 6,1 \\
\hline Total & 144 & 21584,9 & 100 & 18671,4 & 100 & 2465,9 & 100 \\
\hline
\end{tabular}

Fuente: Elaboración propia, sobre la base de la Comisión Nacional de Bancos y Seguros (CNBS) "Memoria 2015", Tegucigalpa, 2015 [en línea] http://www.cnbs.gob.hn/files/memoria/MEMORIA\%20 2015.pdf; Federación de Cooperativas de Ahorro y Crédito de Honduras (FACACH), "Mapeo del Sistema Federado de Ahorro y Crédito de Honduras 2008-2009. Actualizado a 2014", Tegucigalpa, 2014; MIX Market, "Honduras Market Overview", Washington, D.C. [en línea] https://www.themix.org/mixmarket/countries-regions/honduras, s/f; y Red de Microfinancieras de Honduras (REDMICROH), 2015.

a Las cifras incluyen información de 15 bancos comerciales y 1 banco público (Banco Nacional de Desarrollo Agrícola, BANADESA).

b Solo se incluyen las cifras de las cooperativas afiliadas a la Federación de Cooperativas de Ahorro y Crédito de Honduras (FACACH) que estaban disponibles.

c Solo se incluyen las cifras de las OPD afiliadas de la Red de Microfinancieras de Honduras (REDMICROH) que estaban disponibles.

Las instituciones que se detallan a continuación se encuentran clasificadas conforme a las funciones que cumplen en el sistema financiero. Esta clasificación las agrupa en: instituciones reguladoras y supervisoras del sistema financiero, instituciones financieras y otras instituciones relacionadas al sistema financiero.

Los entes reguladores y supervisores del sistema financiero formal de Honduras son el BCH, la CNBS y el CONSUCOOP.

El BCH es la entidad encargada de formular, desarrollar y ejecutar la política monetaria, crediticia y cambiaria de Honduras, así como de cuidar el buen funcionamiento y la estabilidad del sistema financiero y de pagos del país. Por tal motivo, la máxima autoridad en el sistema financiero y económico hondureño en lo que refiere a regulaciones prudenciales compete al $\mathrm{BCH}$. Por su parte, la CNBS es la entidad encargada específicamente del control, la vigilancia y la fiscalización del sistema financiero regulado y demás entidades 
supervisadas que realicen funciones análogas ${ }^{6}$. Por último, el CONSUCOOP tiene la responsabilidad de supervisar y regular a las cooperativas ${ }^{7}$.

Es preciso destacar que la evolución histórica de los intermediarios no bancarios o cooperativas, las características intrínsecas de su operación financiera y las características propias de sus clientes han hecho que la supervisión de las cooperativas esté a cargo de una institución especializada en un marco normativo diferenciado en el que no existe regulación prudencial (Arzbach, Durán y Japp, 2012).

La regulación y supervisión del sistema financiero no formal está a cargo de la SEIP, que autoriza y supervisa la operación de las Organizaciones Privadas de Desarrollo (OPD) a través de la URSAC, y de la Comisión Reguladora del Sistema Privado de Cajas de Ahorro y Crédito Rural, que, sin embargo, no se encuentra en operación.

Los bancos, según la Ley del Sistema Financiero, son los que cuentan con mayor flexibilidad para brindar servicios y productos financieros al público en general, ya que están autorizados por ley para realizar hasta 26 tipos de operaciones, entre ellas recibir depósitos a la vista y a plazo, conceder todo tipo de préstamos en moneda nacional o extranjera, emitir bonos generales, comerciales, hipotecarios y cédulas hipotecarias, y aceptar y administrar fideicomisos ${ }^{8}$.

Como se detalla en el cuadro V.1, el sistema financiero formal en Honduras cuenta con 15 bancos privados, 2 bancos de desarrollo, 1 banco central y 10 sociedades financieras. De estos, siete se encuentran especializados en la atención de las micro, pequeñas y medianas empresas (MIPYME) o en microfinanzas. Dichas instituciones especializadas operan a través de 164 oficinas en el territorio nacional y cuentan con una cartera que asciende a aproximadamente 88,2 millones de dólares 9 .

Las cooperativas en Honduras pueden ser de producción, de servicios, de consumo o mixtas, y pueden ofrecer servicios financieros tanto de primer como de segundo piso, siempre y cuando cumplan con los principios del cooperativismo establecidos en la Ley de Cooperativas de Honduras. Según esta Ley, la intermediación financiera de las cooperativas de ahorro y crédito

La CNBS cuenta con tres superintendencias en su organigrama a fin de poder cumplir con sus atribuciones: superintendencia de bancos y otras instituciones financieras, superintendencia de seguros y superintendencia de pensiones y valores.

7 El CONSUCOOP regula cooperativas dedicadas a diversas actividades, como agroforestal, agropecuaria, de ahorro y crédito, mixta, cafetalera, de vivienda, de transporte, industrial, de consumo, estudiantil, de pesca y agroindustrial.

8 Los bancos y demás instituciones reguladas por la CNBS pueden brindar seguros, pero bajo la figura de intermediarios financieros de las instituciones de seguros y reaseguros conforme a lo descrito en la Resolución 1001/19-08-2003 emitida por la CNBS.

9 Al tipo de cambio de 22,94 lempiras por dólar (tipo de cambio medio anual hasta noviembre de 2016, hecho público por el BCH). 
comprende la realización de cualquier acto de captación de dinero de sus propios afiliados con el propósito de destinar esos recursos al otorgamiento de crédito a sus afiliados o a la inversión en el mercado financiero, cualquiera sea el documento en que se formalice la operación ${ }^{10}$. De igual manera, conforme a las reformas realizadas a la Ley y al Reglamento de la Ley de Cooperativas de Honduras en febrero de 2014, las cooperativas pasaron a ser entidades reguladas y supervisadas por un organismo propio (el CONSUCOOP).

De las 2.694 cooperativas distribuidas en todos los sectores económicos y los departamentos, 241 se dedican a la actividad de ahorro y crédito, y de estas, 92 pertenecen a la Federación de Cooperativas de Ahorro y Crédito de Honduras (FACACH), que maneja activos por alrededor de 1.862,3 millones de dólares y atiende a más de 823.000 asociados.

Las OPD surgen a mediados de la década de 1980 como instituciones dedicadas a la promoción del desarrollo local y nacional a partir de iniciativas de la sociedad civil organizada y de programas de desarrollo que mayoritariamente brindaban donaciones en efectivo y asistencia técnica para la implementación de metodologías de grupos solidarios y bancos comunales. En 2001 se emite la Ley Reguladora de las Organizaciones Privadas de Desarrollo que se Dedican a Actividades Financieras, mediante el Decreto núm. 229-2000, que regula a las OPD cuya actividad principal sea el financiamiento de la micro y pequeña empresa (MYPE).

En virtud de esta Ley, las Organizaciones Privadas de Desarrollo Financiero (OPDF) están autorizadas a realizar hasta nueve tipos de operaciones financieras. Las principales operaciones que pueden llevar a cabo estas organizaciones son: conceder todo tipo de préstamos en moneda nacional o extranjera, recibir depósitos a la vista y a plazo (únicamente de sus prestatarios), obtener préstamos de instituciones públicas y privadas, y administrar fondos especiales de programas para apoyo a las MYPE.

La figura jurídica de las cajas rurales tiene su fundamento legal inicial en la Ley para la Modernización y Desarrollo del Sector Agrícola promulgada en 1992. En 1993 se emite una Ley específica a través del Decreto núm. 201-93 para la creación de Cajas de Ahorro y Crédito Rural. Dichas figuras surgieron por la promoción de proyectos gubernamentales o de cooperación internacional, generalmente canalizados a través de organizaciones no gubernamentales de desarrollo y de las municipalidades. El sistema de cajas rurales está integrado por una comisión reguladora, la caja central, las cajas rurales y una unidad de asesoría y promoción. En 2015 existían 4.062 cajas en Honduras, con una membresía de 84.789 socios directos.

Las cajas rurales son sumamente importantes para la población rural, ya que muchas instituciones financieras no llegan hasta estas zonas

10 La Ley de Cooperativas de Honduras se reformó mediante el Decreto núm. 174-2013. 
(Marulanda, Paredes, y Fajury, 2011). Cabe mencionar que la oportuna labor y el desempeño de las cajas rurales dependen, en gran medida, de la buena administración y asistencia técnica a las que sus miembros están sujetos. Los principales problemas que enfrentan las cajas rurales son la insuficiencia de fondos en condiciones crediticias favorables, el escaso acompañamiento de programas de asistencia técnica para su funcionamiento y las limitadas políticas públicas nacionales que las respaldan, más allá del otorgamiento de fondos públicos (CNBS/BID, 2015).

En la actualidad, el sistema financiero cuenta con 11 instituciones de seguros y reaseguros, cuyos activos a diciembre de 2015 rondaban los 596,9 millones de dólares. Para la suscripción de pólizas, las instituciones de seguros pueden utilizar la intermediación directa o a través de agentes de seguros dependientes, independientes o sociedades de corretaje que se encuentren inscritos en el registro de agentes y corredores que lleva la CNBS.

Existen otras instituciones que complementan la oferta de productos y servicios financieros, entre las que se encuentran las centrales de riesgo, la banca de desarrollo, la administradora de fondos de garantía recíproca y las administradoras de fondos de pensiones.

Existen dos centrales de riesgo (burós de crédito) privadas y una pública que reciben datos tanto del sector financiero como de los prestadores de servicios públicos y del comercio. La información que proveen las centrales de riesgo está disponible para todas las instituciones que les proporcionan datos. El deudor y aval de un crédito también tienen acceso al historial crediticio y pueden rectificar su información personal.

Las centrales manejan información de los perfiles crediticios de los usuarios de los servicios financieros, lo que les ha permitido diseñar modelos parametrizados de comportamiento crediticio. La situación en Honduras ha sido calificada como favorable en este aspecto. El Banco Mundial otorgó a Honduras la puntuación máxima en el índice de alcance de la información crediticia (Banco Mundial, 2014).

Existen dos instituciones consideradas banca de desarrollo en el sistema financiero de Honduras: el Banco Nacional de Desarrollo Agrícola (BANADESA) y el Banco Hondureño para la Producción y la Vivienda (BANHPROVI).

El objetivo principal del BANADESA es canalizar recursos financieros para el desarrollo de la producción y la productividad en las áreas de agricultura, ganadería, pesca, avicultura, apicultura, silvicultura y demás actividades relacionadas con el procesamiento primario de esa producción (incluida la comercialización). También realiza toda clase de operaciones bancarias en general, coordinando sus actividades con la política de desarrollo del Estado para el sector. 
El BANHPROVI es el único banco público de segundo piso de Honduras $^{11}$. El banco fue creado en 2005 con la finalidad de promover el crecimiento y desarrollo de los sectores productivos mediante el otorgamiento de crédito de mediano y largo plazo a las instituciones financieras de primer piso. Para ello, el BANHPROVI fue capitalizado por el BCH y se fondea, en gran medida, con recursos propios.

Confianza SA-FGR es la administradora de fondos de garantía recíproca. Se trata de una sociedad anónima, creada con el apoyo e impulso del Gobierno de Honduras, que tiene por objeto facilitar el acceso de las MIPYME al financiamiento y apoyar al sector agrícola, las viviendas de tipo social y el sector educativo en el país.

El fondo de garantía tiene cuatro productos que contribuyen al incremento de la inclusión financiera: i) Fondo de Garantía para la Micro, Pequeña y Mediana Empresa (FOGMIPYME), que funge como garante de las MIPYME en procesos de licitación; ii) Fondo de Garantía para la Agricultura (FAGRE), que está dirigido a los micro, pequeños y medianos productores agrícolas y actúa como garante de crédito ante instituciones financieras; iii) Fondo de Garantía para la Vivienda Social (FOGAVIS), que funge como garante de crédito para viviendas de interés social, y iv) Fondo de Garantía de Depósitos (FOGADE), un fondo de garantía para préstamos educativos de alumnos de escasos recursos económicos.

El sistema de previsión en Honduras lo integran ocho fondos de pensiones: cinco públicos y tres que pertenecen a empresas privadas. Los fondos se encuentran bajo la supervisión y regulación de la CNBS. Las administradoras de fondos privados de pensiones son reguladas por la Ley del Régimen Opcional Complementario para la Administración de Fondos Privados de Pensiones, mientras que las instituciones de previsión públicas se rigen por sus propias leyes de creación y las normativas prudenciales emitidas por la CNBS.

Los institutos de previsión públicos acumulaban activos por 102.083,5 millones de lempiras al cierre de 2015, equivalentes a un 22,9\% del PIB del mismo año, y una concentración del $81,9 \%$ del total de activos en tres institutos de previsión. En 2015 operaban dos institutos de previsión privados con activos por 552,2 millones de lempiras.

Tal como se detalla en el cuadro V.3, los productos financieros tradicionales ofertados por las instituciones financieras son cuentas corrientes y productos de ahorro, préstamos y crédito. Además, se ofrecen seguros, servicios de envío y pago de remesas y pensiones.

11 A fines de 2016, el BANHPROVI fue autorizado a realizar operaciones de primer piso. 


\section{Cuadro V.3}

Honduras: productos y servicios financieros ofertados, por tipo de institución y nivel de acceso

\begin{tabular}{|c|c|c|c|c|c|}
\hline \multirow[b]{2}{*}{ Tipo de institución } & \multicolumn{5}{|c|}{ Principales productos ofertados } \\
\hline & $\begin{array}{c}\text { Cuentas corrientes } \\
\text { y de ahorro }\end{array}$ & $\begin{array}{l}\text { Préstamos } \\
\text { y crédito }\end{array}$ & Seguros & Remesas & Pensiones \\
\hline Bancos & 1 & 1 & & 1 & \\
\hline Financieras & 1 & 1 & & 1 & \\
\hline $\begin{array}{l}\text { Organizaciones } \\
\text { Privadas de Desarrollo } \\
\text { Financiero (OPDF) }\end{array}$ & 2 & 1 & & 1 & \\
\hline Cooperativas & 3 & 3 & & 1 & \\
\hline $\begin{array}{l}\text { Organizaciones } \\
\text { Privadas de Desarrollo } \\
\text { (OPD) }\end{array}$ & & 1 & & 1 & \\
\hline $\begin{array}{l}\text { Administradoras } \\
\text { de fondos privados } \\
\text { de pensiones (AFP } \\
\text { privadas) }\end{array}$ & & & & & 1 \\
\hline Aseguradoras & & & 1 & & \\
\hline
\end{tabular}

Fuente: Elaboración propia, sobre la base de datos de las instituciones financieras y la Comisión Nacional de Bancos y Seguros (CNBS).

Nota: 1: Abiertos a todo público. 2: Solo para clientes. 3: Mixtos (productos abiertos u orientados a algún sector de la población, según el giro de la institución).

\section{Cobertura geográfica de los oferentes de servicios financieros}

La cobertura de los servicios financieros de las instituciones financieras que atienden directamente a la población se conforma por una red de más de 3.566 puntos de servicio, que cubre los 18 departamentos del país ${ }^{12}$. Los puntos de servicio que utilizan las instituciones financieras para ofrecer sus productos y servicios financieros son: oficinas principales, sucursales, agencias, ventanillas, agentes corresponsales, autobancos, cajeros automáticos y otras oficinas de atención al público.

Con esta oferta de puntos de servicio, la cobertura geográfica de Honduras llega al 67\% del total de los 298 municipios del país. Si se excluye a los agentes corresponsales, la cobertura disminuye a un 39\% del total de municipios.

En el mapa V.1 se muestra la distribución de los puntos de servicio a nivel departamental (la intensidad del color denota el grado de cobertura disponible en cada departamento). Como se puede apreciar, los departamentos que han mejorado bastante su posición desde 2011 son los ubicados en el oeste, como Lempira, Intibucá y La Paz, que han pasado del primer grupo al segundo, mientras que Santa Bárbara pasó del segundo al tercer grupo, y los

12 Los 3.566 puntos de servicio están conformados por la red de bancos, financieras y OPDF (2.303 agencias y sucursales), Agentes Atlántida (870), puntos se servicio de la FACACH (310) y puntos de servicio de la REDMICROH (83). 
de la región centro-este (Colón y Olancho) pasaron del tercer al último grupo. Es importante mencionar que la oferta de servicios y productos financieros es crítica en el departamento de Gracias a Dios, donde la presencia de puntos de servicio, incluidos los agentes corresponsales, es escasa a nivel municipal.

Mapa V.1

\section{Honduras: distribución de los puntos de servicio, 2011 y 2015}

A. 2011

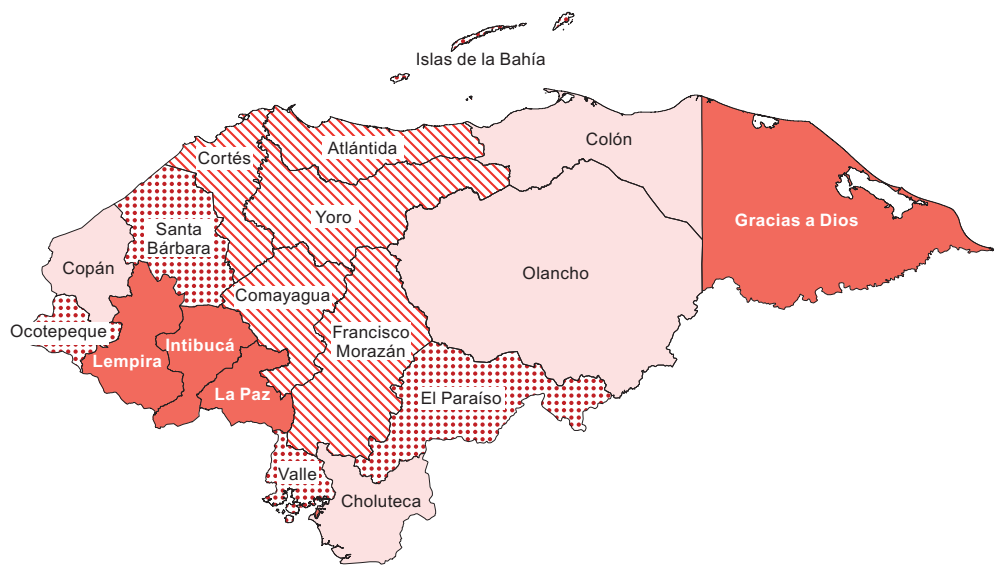

B. 2015

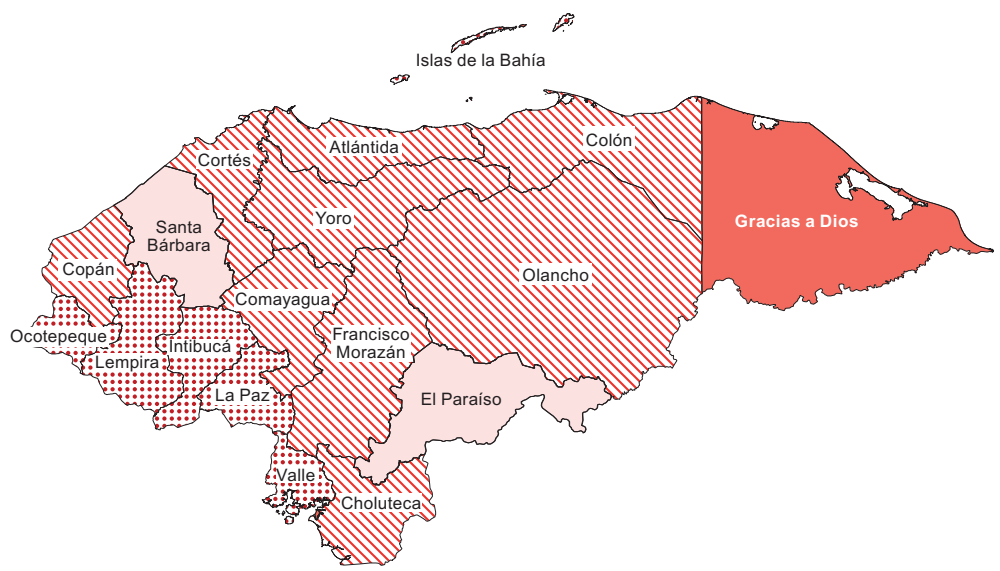

Fuente: Elaboración propia, sobre la base de datos de la Comisión Nacional de Bancos y Seguros (CNBS), Tegucigalpa [en línea] http://www.cnbs.gob.hn, 2015; Federación de Cooperativas de Ahorro y Créditos de Honduras (FACACH), "Mapeo del Sistema Federado de Ahorro y Crédito de Honduras 2008-2009. Actualizado a 2014", Tegucigalpa, 2014; Red de Microfinancieras de Honduras (REDMICROH), Mapeo Institucional de la Oferta Financiera para la MIPYME en Honduras 2015, Tegucigalpa, 2015.

Nota: La distribución por departamentos corresponde a la oferta financiera de 2011 y 2015. Para 2011, los departamentos que se muestran en trama punteada son los que se encontraban en el primery segundo cuartil de la distribución, mientras que los que se muestran en trama de línea identifican los correspondientes al tercer y cuarto cuartil. En el mapa de 2015, los departamentos que se muestran en trama punteada son los que se mantuvieron dentro del rango del primer y segundo cuartil de la distribución de 2011, mientras que los que se muestran en trama de línea son los que se encontraron dentro del rango del tercer y cuarto grupo. 


\section{Brechas de inclusión financiera en el ámbito rural}

A pesar de los avances logrados en los últimos años, aún persisten grandes brechas en materia de inclusión financiera. Entre los segmentos que sufren un mayor grado de exclusión financiera se encuentran los micro y pequeños productores agrícolas, los micro y pequeños comerciantes y emprendedores, los asalariados que perciben un salario mínimo o menos, los receptores de remesas y los beneficiarios de transferencias monetarias condicionadas (bonos) y no condicionadas.

En el marco de la ENIF se realizó una encuesta en la que se preguntaba por las razones por las que estos segmentos sufren de exclusión financiera (CNBS/BID, 2015), las que se pueden clasificar en virtud de si afectan a la oferta o a la demanda.

Entre los factores que inhiben la oferta se identifican: la ausencia de información financiera y fiscal sobre los segmentos excluidos (lo que también afecta la identificación y caracterización de potenciales clientes pertenecientes a segmentos vulnerables), la limitada articulación de acciones encaminadas a fomentar el crecimiento económico de los individuos de los segmentos vulnerables y la falta de servicios de asistencia técnica y de desarrollo empresarial.

Los factores que limitan la demanda, por su parte, incluyen: la baja titulación de tierras (lo que restringe las garantías reales que se pueden ofrecer), los ingresos bajos e inestables de las personas de los segmentos vulnerables, la dispersión territorial en el área rural de las personas de los segmentos vulnerables (lo que incrementa los costos de distribución, promoción y recuperación de la cartera), la delincuencia y su incidencia en la inversión y el emprendimiento, y la limitada vinculación a cadenas productivas del sector agrícola.

De acuerdo con los resultados de una investigación realizada en el sector rural (BID/REDMICROH/Espirálica, 2011), las MYPE agrícolas habían tenido acceso a 1,5 créditos, en promedio, de instituciones financieras. Una de las características mencionadas por las MYPE agrícolas era que estos créditos habían sido cancelados puntualmente o con pequeños atrasos de menos de dos meses. Las principales garantías que las MYPE agrícolas habían brindado para obtener un crédito habían sido bienes inmuebles y avales. De igual manera, solo el 40\% de todas las MYPE agrícolas recibieron préstamos para sus cultivos en 2010. En contraste, y como se indica más adelante, un $49 \%$ de las microempresas y un $65 \%$ de las pequeñas empresas no agrícolas, en promedio, han obtenido créditos (SIC/BID/Espirálica, 2013). En el caso de las MYPE agrícolas, las principales fuentes de financiamiento fueron las cooperativas y asociaciones (25\%), los parientes o amigos (18\%) y los bancos privados (15\%). 
De los segmentos mencionados, las MYPE agrícolas presentan la mayor brecha de inclusión financiera. Esto se debe a las características intrínsecas de la actividad productiva que realizan y a que la mayoría de las personas de este segmento poblacional viven en el área rural.

Los resultados del mismo estudio también indican que la proporción de MYPE no agrícolas que han tenido acceso a créditos de una institución financiera fue equivalente a un $49 \%$ y a un $65 \%$ de las MYPE, respectivamente, sin importar la zona geográfica en que se encuentren. Asimismo, las MYPE no agrícolas indicaron que, en promedio, en los últimos 12 meses previos a 2012, al menos 3 instituciones financieras les habían realizado un ofrecimiento formal de crédito. Si bien esto evidencia que las MYPE no agrícolas disponen de una oferta dinámica que les brinda acceso a financiamiento, no significa que encuentren las condiciones crediticias adecuadas a sus necesidades.

La mayoría de las MYPE que han obtenido crédito indicaron que tienen sus ahorros en los bancos y solo el 19\% de las microempresas tienen sus ahorros en otro tipo de instituciones financieras (como las cooperativas, las financieras y las OPDF) $)^{13}$.

Las MYPE que han obtenido crédito señalaron que el uso de seguros de vida o seguros médicos privados para los empleados es bajo y que la utilización de otros productos financieros (como factoraje, arrendamiento y fondos de pensiones) es minoritaria. Pese al escaso uso de estos productos, se denotaba una leve tendencia en su empleo relacionada con el tamaño de la empresa, es decir, a mayor tamaño, mayor uso de estos productos.

La exclusión financiera de las MYPE comerciales tiende a ser más una exclusión parcial relacionada al acceso a otros productos financieros, que no sean créditos para capital de trabajo o ahorro, o a una oferta de productos financieros en condiciones poco apropiadas. El estudio sectorial no identifica diferencias significativas en el acceso de servicios financieros de las MYPE entre la zona rural y urbana.

Los asalariados que reciben hasta un salario mínimo tienen acceso a ciertos productos y servicios que ofrece el sistema financiero hondureño (Valenzuela, 2014) ${ }^{14}$. Se observa que estos trabajadores tienen una mayor facilidad para la apertura de cuentas, ya que pueden demostrar que disponen de ingresos regulares. Sin embargo, estos asalariados también enfrentan restricciones al acceso y uso de otros productos y servicios financieros, sobre todo relacionadas con los montos y tipos de crédito a los que tienen acceso,

13 Según el Diagnóstico Sectorial de la MIPYME No Agrícola en Honduras, el $81 \%$ de las microempresas y el $95 \%$ de las pequeñas empresas indicaron que tenían la mayoría de sus ahorros en bancos (SIC/BID/Espirálica, 2013).

14 El salario mínimo en Honduras en 2014 era de 7.419 lempiras mensuales (aproximadamente 353 dólares) (La Prensa, 2013). 
debido a su bajo nivel de ingresos. También se observó que enfrentan una oferta menos diversificada de productos de ahorro (Valenzuela, 2014).

Los asalariados que reciben hasta un salario mínimo tienen acceso regular a créditos de consumo, pero se enfrentan a restricciones en el acceso a créditos de vivienda, ya que no logran satisfacer todos los requisitos para obtener estos créditos. Entre estos requisitos se destacan: contar con un nivel de ingreso mínimo, disponer de garantías hipotecarias (solo disponen de garantías mobiliarias que no son aceptadas) y tener una vivienda ubicada en una zona no residencial (CNBS/BID, 2015) ${ }^{15}$.

Además, según cifras del Instituto Nacional de Estadística de Honduras (INE), el porcentaje de la población asalariada que cotizaba a los sistemas de pensiones públicos en 2012 era solo de un 8,7\% y el de la población que cotizaba a los sistemas de pensiones privados era aún más bajo (1,2\%). De estas estadísticas se deduce que tanto la población trabajadora del sector formal como los trabajadores que forman parte del sector informal en Honduras continúan teniendo un acceso limitado a los servicios de previsión y pensión. Se ha argumentado lo poco atractivo que resultan los productos de pensiones y seguros asociados a la oferta de los fondos privados en comparación con los fondos públicos existentes.

Los receptores de remesas suelen mantener contacto con el sistema financiero exclusivamente para la recepción del dinero y para el pago de algunos servicios públicos (energía eléctrica, agua y otros), sin tener una relación estable con ninguna institución financiera especial, ya que es habitual que recurran a diferentes instituciones para recibir las remesas. Del mismo modo, de acuerdo con un estudio de Valenzuela y Puerta (2007) y cifras del INE, se destaca que la mayoría de los hogares receptores de remesas hacían uso de recursos propios o familiares $(77 \%)$ para financiar la adquisición de una vivienda.

De manera similar a lo que ocurre con los receptores de remesas, los receptores de transferencias suelen mantener contacto con el sistema financiero exclusivamente para el pago de servicios públicos (energía eléctrica, agua y demás). Conforme a lo descrito y a los datos disponibles, se puede deducir que los receptores de transferencias condicionadas conforman una población que no se encuentra bancarizada y que habitualmente conserva sus ahorros en el hogar.

A través de la Secretaría de Desarrollo e Inclusión Social (SEDIS), desde 2015, el Gobierno de Honduras se encuentra en un proceso de bancarización de los receptores de bonos mediante la apertura de cuentas básicas a dicha población. Este proceso tiene como finalidad realizar la acreditación del bono

15 La Ley de Garantías Mobiliarias del 28 de enero de 2010, que se describe más adelante, fue emitida para apoyar el crédito a las MIPYME, no para personas físicas como los asalariados. 
a las cuentas de ahorro de los receptores y con ello promover su vinculación al sistema financiero.

\section{B. Estrategia Nacional de Inclusión Financiera (ENIF)}

Hasta 2015, Honduras contaba con diversas iniciativas de instituciones públicas y privadas que buscaban promover la inclusión financiera, pero estas no se encontraban coordinadas. Entre ellas había actividades de educación financiera promovidas y realizadas por la Red de Microfinancieras de Honduras (REDMICROH) y las cooperativas de ahorro y crédito, propuestas de políticas públicas y canalización de fondos para el sector agrícola. Muchas de las iniciativas se emplearon como insumos durante la elaboración de la ENIF, creada por iniciativa del Gobierno de Honduras y concebida como una estrategia integral que incluyera y contara con la participación de diversos sectores económicos de la sociedad.

El objetivo explícito de la ENIF es lograr que las personas excluidas tengan acceso a una amplia gama de servicios financieros brindados en condiciones favorables y adecuadas a sus características y necesidades. Ello plantea la necesidad de que estas personas cuenten con la educación financiera y las capacidades técnicas suficientes para optimizar el acceso y uso de los servicios financieros con el propósito de reducir la pobreza.

La estructura organizacional que fue aprobada por el Gobierno de Honduras para ser la entidad coordinadora de la ENIF fue la de un "comisionado presidencial de inclusión financiera", con su respectivo órgano ejecutor. A la fecha de la elaboración del estudio, la entidad coordinadora se encontraba en un proceso de establecimiento de su estructura y designación de personal. En el diagrama V.1 se muestra de forma resumida la estructura organizacional, con las principales funciones y los integrantes que fueron planteados en el diseño de la ENIF.

Para la implementación de sus acciones, la ENIF contempla la articulación de diferentes actores públicos y privados, cuyas acciones se interrelacionan y son necesarias para fomentar la inclusión financiera en Honduras. Para ello, clasifica a los diferentes actores conforme a los mecanismos y componentes de intervención en los que desempeñan un papel activo, los que, a su vez, están clasificados desde la perspectiva de la oferta y la demanda. Es importante mencionar que la ENIF detalla el papel que cada actor debe desempeñar según su componente y los mecanismos de intervención, identificando las principales limitaciones que enfrenta para lograrlo. 


\section{Diagrama V.1 \\ Honduras: estructura organizacional para la implementación de la Estrategia Nacional de Inclusión Financiera (ENIF)}

\begin{tabular}{|c|c|c|}
\hline Estructura organizacional & Principales funciones & Integrantes \\
\hline $\begin{array}{c}\text { Presidencia de la República o } \\
\text { Secretario Coordinador } \\
\text { General de Gobierno }\end{array}$ & $\begin{array}{l}\text { 1. Tomar decisiones en torno a propuestas de } \\
\text { políticas o estrategias de inclusión, reformas } \\
\text { regulatorias y demás } \\
\text { 2. Definir politicas o estrategias de inclusión } \\
\text { 3. Supervisar las acciones de la comisión } \\
\text { especial de regulación financiera }\end{array}$ & $\begin{array}{l}\text { Presidencia de } \\
\text { la República } \\
\text { o Secretario } \\
\text { Coordinador } \\
\text { General de } \\
\text { Gobierno }\end{array}$ \\
\hline $\begin{array}{l}\text { Comisionado presidencial } \\
\text { de inclusión financiera }\end{array}$ & $\begin{array}{l}\text { 1. Coordinar las acciones interinstitucionales } \\
\text { 2. Integrar y representar al consejo interno } \\
\text { del órgano ejecutor } \\
\text { 3. Supervisar la labor del órgano ejecutor y } \\
\text { solicitar correcciones en dicha labor en caso } \\
\text { de que se esté desviando de su objetivo } \\
\text { 4. Contratar al personal del órgano ejecutor } \\
\text { 5. Informar sobre el avance de la ENIF y } \\
\text { presentar políticas y estrategias de inclusión } \\
\text { financiera al Presidente o } \\
\text { Coordinador General }\end{array}$ & $\begin{array}{c}\text { Comisionado } \\
\text { presidencial } \\
\text { de inclusión } \\
\text { financiera }\end{array}$ \\
\hline Órgano ejecutor & $\begin{array}{l}\text { 1. Ejecutar las acciones de la ENIF e } \\
\text { implementar y dar seguimiento a su sistema } \\
\text { de monitoreo } \\
\text { 2. Ejecutar programas en el marco de una } \\
\text { política de inclusión financiera y canalizar } \\
\text { fondos para asistencia técnica } \\
\text { y financiamiento } \\
\text { 3. Formular y proponer políticas o estrategias } \\
\text { de inclusión financiera } \\
\text { 4. Proponer reformas regulatorias } \\
\text { 5. Generar y utilizar información de encuestas } \\
\text { del Instituto Nacional de Estadística (INE) } \\
\text { y otras bases de datos }\end{array}$ & $\begin{array}{c}\text { Personal } \\
\text { específico y } \\
\text { especializado } \\
\text { que se encargue } \\
\text { de impulsar cada } \\
\text { línea estratégica } \\
\text { de la ENIF }\end{array}$ \\
\hline
\end{tabular}

Fuente: Comisión Nacional de Bancos y Seguros/Banco Interamericano de Desarrollo (CNBS/BID), Estrategia Nacional de Inclusión Financiera (ENIF) 2015-2020, Tegucigalpa, 2015.

En el cuadro V.4 se presentan de forma resumida los actores del sector público y privado requeridos para articular la ENIF y agrupados por componentes para atender las causas de exclusión financiera. Los componentes permiten evidenciar que la oferta (instituciones financieras) y la demanda (población excluida) requieren la intervención de diferentes actores en un determinado orden o momento, que es flexible. 


\section{Cuadro V.4}

Honduras: componentes y actores clave del sector público y privado en la Estrategia Nacional de Inclusión Financiera (ENIF)

\begin{tabular}{|c|c|c|c|c|c|}
\hline & $\begin{array}{l}\text { Componente } \\
\text { del mecanismo }\end{array}$ & \multicolumn{4}{|c|}{ Actores del componente } \\
\hline \multirow[t]{7}{*}{ Oferta } & Componente regulador & \multicolumn{4}{|c|}{$\begin{array}{l}\text { - Comisión Nacional de Bancos y Seguros (CNBS) } \\
\text { - Consejo Nacional Supervisor de Cooperativas } \\
\text { (CONSUCOOP) }\end{array}$} \\
\hline & $\begin{array}{l}\text { Componente } \\
\text { gubernamental } \\
\text { (Gobierno) }\end{array}$ & \multicolumn{3}{|c|}{$\begin{array}{ll}\text { - Secretaría de } & \text { - Secretaría de } \\
\text { Finanzas (SEFIN) } & \text { Agricultura y } \\
\text { - Secretaría de } & \text { Ganadería (SAG) } \\
\text { Desarrollo e } & \text { - Dirección } \\
\text { Inclusión Social } & \text { Ejecutiva de } \\
\text { (SEDIS) } & \text { Ingresos (DEI) } \\
\text { - Secretaría } & \text { Secretaría de } \\
\text { de Industria y } & \text { Relaciones } \\
\text { Comercio (SIC) } & \text { Exteriores de } \\
& \text { Honduras (SRE) }\end{array}$} & $\begin{array}{l}\text { - Secretaría de } \\
\text { Seguridad } \\
\text { - Instituto Nacional } \\
\text { de Estadística } \\
\text { (INE) } \\
\text { - Programa } \\
\text { Nacional de } \\
\text { Desarrollo } \\
\text { Rural y Urbano } \\
\text { Sostenible } \\
\text { (PRONADERS) }\end{array}$ \\
\hline & $\begin{array}{l}\text { Componente de } \\
\text { asistencia técnica }\end{array}$ & \multicolumn{2}{|c|}{$\begin{array}{l}\text { - Organizaciones no } \\
\text { gubernamentales (ONG) } \\
\text { - Empresas de tecnología } \\
\text { - Burós de crédito }\end{array}$} & \multicolumn{2}{|c|}{$\begin{array}{l}\text { - Cooperación internacional } \\
\text { - Empresas privadas } \\
\text { relacionadas a la asistencia } \\
\text { técnica o servicios de } \\
\text { desarrollo empresarial }\end{array}$} \\
\hline & Componente financiero & \multicolumn{4}{|c|}{$\begin{array}{l}\text { - Instituciones de segundo piso } \\
\text { - Cooperación internacional interesada en promover la } \\
\text { inclusión financiera } \\
\text { - Fondos de garantía recíproca } \\
\text { - Fondos de pensiones públicos }\end{array}$} \\
\hline & $\begin{array}{l}\text { Componente de } \\
\text { distribución de servicios } \\
\text { y productos financieros }\end{array}$ & \multicolumn{2}{|c|}{$\begin{array}{l}\text { - Telefonía móvil (Tigo) } \\
\text { - Agentes corresponsales } \\
\text { - Comercios }\end{array}$} & & \\
\hline & $\begin{array}{l}\text { Mecanismo de } \\
\text { intervención interno } \\
\text { de las instituciones }\end{array}$ & \multicolumn{2}{|c|}{$\begin{array}{l}\text { - Instituciones bancarias } \\
\text { - Cooperativas de ahorro } \\
\text { y crédito }\end{array}$} & \multicolumn{2}{|c|}{$\begin{array}{l}\text { - Aseguradoras } \\
\text { - Fondos de pensiones } \\
\text { privados }\end{array}$} \\
\hline & & \multicolumn{4}{|c|}{$\begin{array}{l}\text { - Instituciones microfinancieras y financieras (incluye } \\
\text { Organizaciones Privadas de Desarrollo Financiero (OPDF) } \\
\text { y Organizaciones Privadas de Desarrollo (OPD)) }\end{array}$} \\
\hline \multirow[t]{2}{*}{ Demanda } & $\begin{array}{l}\text { Componente de } \\
\text { educación financiera y } \\
\text { protección del usuario } \\
\text { financiero }\end{array}$ & \multicolumn{2}{|c|}{$\begin{array}{l}\text { - Comisión Nacional de } \\
\text { Bancos y Seguros (CNBS) } \\
\text { - Consejo Nacional } \\
\text { Supervisor de Cooperativas } \\
\text { (CONSUCOOP) } \\
\text { - Dirección de Protección } \\
\text { al Consumidor } \\
\text { - Fiscalía de Protección } \\
\text { al Consumidor } \\
\text { - Juzgados }\end{array}$} & \multicolumn{2}{|c|}{$\begin{array}{l}\text { - Secretaría de Educación } \\
\text { - Consejo de Educación } \\
\text { Superior } \\
\text { - Instituciones financieras } \\
\text { - Fundación Capital }\end{array}$} \\
\hline & $\begin{array}{l}\text { Componente de } \\
\text { asistencia técnica }\end{array}$ & \multicolumn{4}{|c|}{$\begin{array}{l}\text { - Centro de desarrollo empresarial } \\
\text { - Organizaciones no gubernamentales (ONG) } \\
\text { - Entidades públicas o privadas relacionadas } \\
\text { a la asistencia técnica } \\
\text { - Cooperación internacional } \\
\text { - Instituciones financieras }\end{array}$} \\
\hline
\end{tabular}

Fuente: Comisión Nacional de Bancos y Seguros/Banco Interamericano de Desarrollo (CNBS/BID), Estrategia Nacional de Inclusión Financiera (ENIF) 2015-2020, Tegucigalpa, 2015. 
En este contexto, los distintos componentes tienen distintas responsabilidades: i) el componente regulador es el responsable de adecuar la regulación y normar las acciones financieras, ii) el componente gubernamental facilita el acercamiento entre las instituciones financieras y los segmentos excluidos, iii) el componente de asistencia técnica fortalece las capacidades de las instituciones financieras para atender a los segmentos excluidos, iv) el componente financiero facilita la canalización de fondos dirigidos a las poblaciones excluidas, v) el componente de distribución permite la generación de alianzas y la inversión en infraestructura para canalizar los nuevos productos, y vi) el componente de educación financiera y protección al usuario dota a los segmentos excluidos y no excluidos del conocimiento adecuado sobre temas financieros y su protección como usuarios.

La ENIF plantea una matriz de implementación general y una matriz de responsabilidades a nivel de los actores que están organizadas en torno a cuatro líneas estratégicas: reducir el riesgo, aumentar la rentabilidad, incrementar la educación financiera y la protección del usuario financiero, y mejorar las capacidades económicas y de inversión. El diseño de la ENIF cuenta con un sistema que permite mantener un monitoreo ordenado e integral del avance de sus acciones mediante el seguimiento de los 57 indicadores y las 15 metas de impacto conforme a la frecuencia de evaluación establecida en la matrices de evaluación.

Los instrumentos o medios de verificación planteados por la ENIF incluyen las encuestas de hogares del INE, a las que se deberá incorporar preguntas específicas que permitan medir determinados indicadores de inclusión financiera, información provista tanto por las entidades financieras como por el propio Gobierno, informes de avance de las instituciones encargadas de llevar a cabo la asistencia técnica, tanto a la oferta como a la demanda de servicios financieros, datos proporcionados por las empresas de telefonía móvil y el instrumento general de monitoreo y seguimiento de la estrategia.

Por último, la ENIF también plantea metas que se espera poder alcanzar en un horizonte de tiempo de cinco años y que servirán para una evaluación de mediano plazo. Los valores de base asociados a las metas de mediano plazo se establecieron sobre la base de una combinación de indicadores que tomaban, por una parte, los valores medios de inclusión financiera a nivel de América Latina y el Caribe, publicados por el Banco Mundial y la Federación Latinoamericana de Bancos (FELABAN), y, por la otra, las cifras y proyecciones particulares relacionadas al contexto de Honduras. En el cuadro V.5 se presentan las metas de los indicadores de impacto de la ENIF. En un término de 5 años, se espera que más del $50 \%$ de los adultos mayores de 15 años tengan cuentas abiertas en instituciones financieras. También se espera incrementar el crédito, al elevar del 7,1\% al 12,0\% el porcentaje de adultos mayores de 15 años que se financia con instituciones formales. 


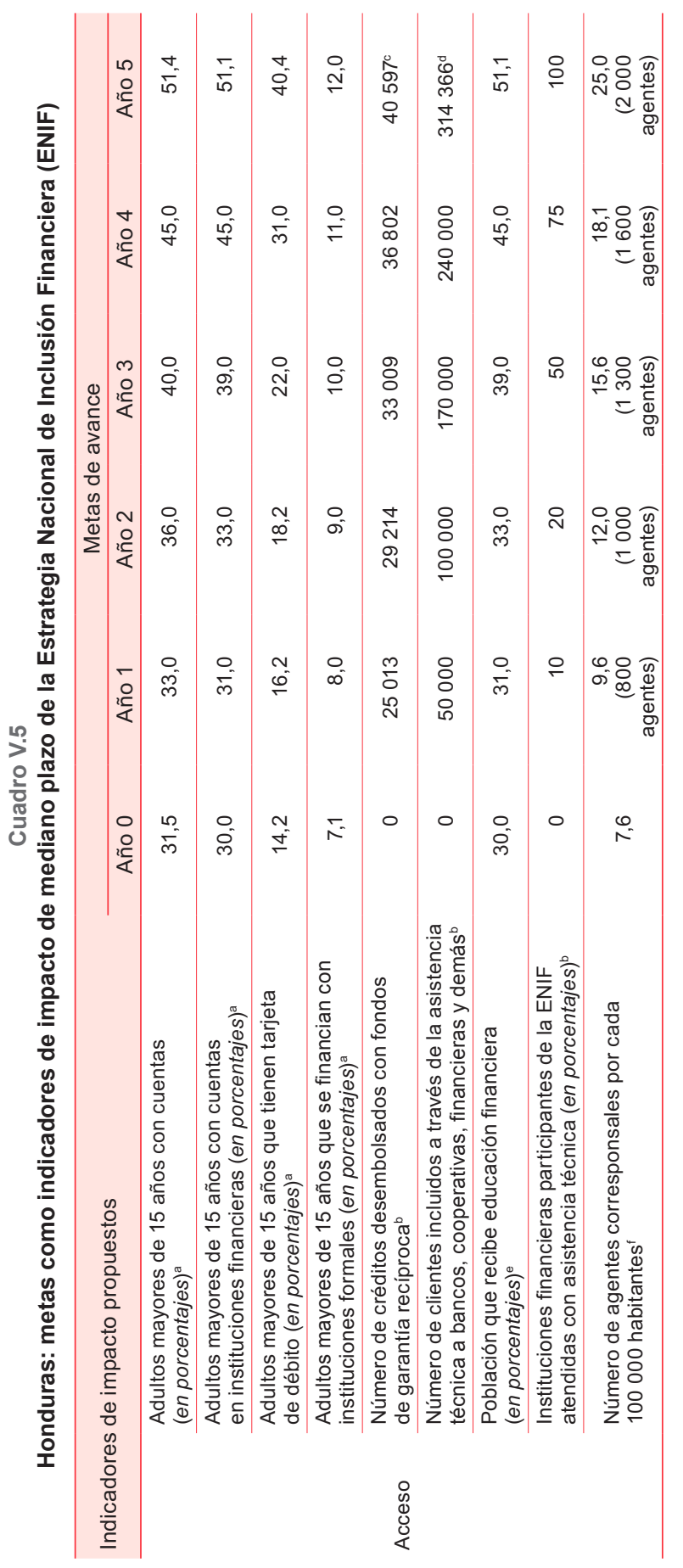




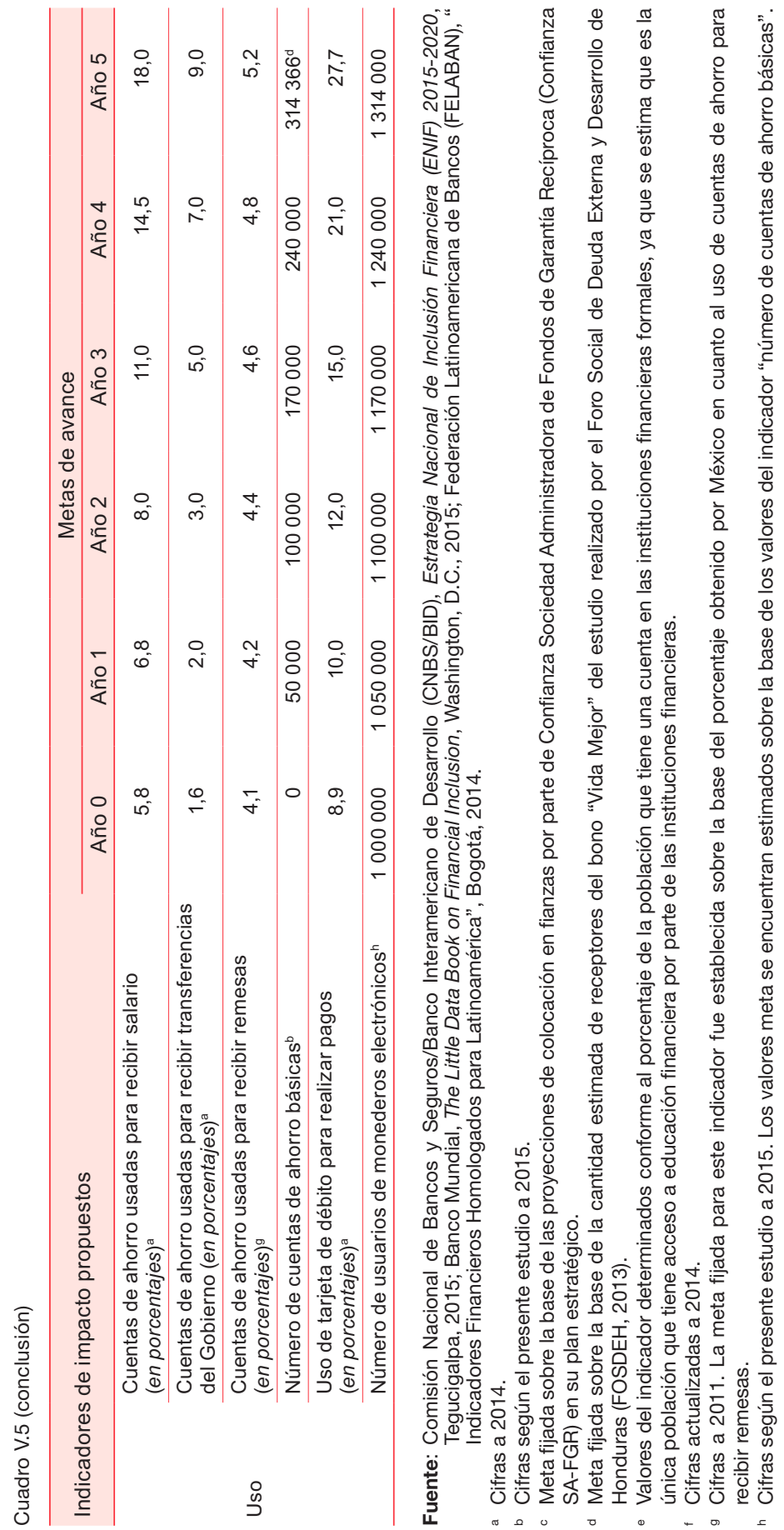




\section{Arquitectura institucional}

En esta sección se detalla la arquitectura institucional disponible en Honduras para el logro de los objetivos de la ENIF.

\section{Política regulatoria y de supervisión}

La política regulatoria y de supervisión del sistema financiero en Honduras norma el ingreso y la operación de los proveedores de productos y servicios financieros de acuerdo con el esquema descrito en el diagrama V.2. Los requerimientos de ingreso al sistema financiero regulado son definidos por la CNBS y el CONSUCOOP, mientras que los requerimientos de ingreso al sistema financiero no regulado los definen la URSAC de la SEIP y la Comisión Reguladora del Sistema Privado de Cajas de Ahorro y Crédito Rural.

\section{Diagrama V.2 \\ Honduras: entorno regulatorio y de supervisión de los proveedores de productos y servicios financieros}

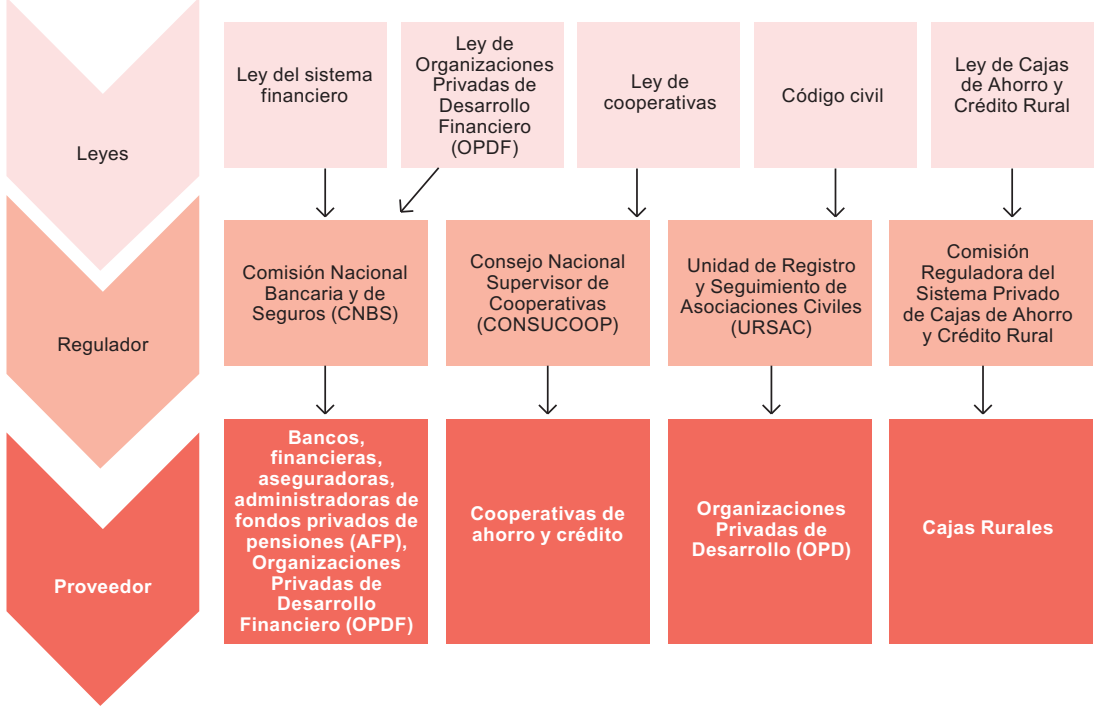

Fuente: Elaboración propia, sobre la base de información del Decreto núm.129-2004, Decreto núm.1742013, Decreto núm. 229-2000, Acuerdo Ejecutivo núm.65-2013, Decreto núm. 110-2004 y Decreto núm. 201-93.

El Programa Nacional de Desarrollo Rural y Urbano Sostenible (PRONADERS) maneja la organización de las Cajas de Ahorro y Crédito Rural a nivel nacional, amparado en el Plan Nacional de Cajas Rurales dirigido por el Gobierno ${ }^{16}$. No obstante, la finalidad del PRONADERS es canalizar

Véase Programa Nacional de Desarrollo Rural y Urbano Sostenible (PRONADERS), 2016 [en línea] http://www.pronaders.hn/. 
recursos financieros hacia las comunidades y, de esa forma, contribuir a la reducción de la pobreza en Honduras. Por ello, a fin de lograr su cometido y brindar servicios, establece las condiciones que las cajas rurales deben cumplir para ser inscritas en su directorio.

Es importante destacar que la normatividad respecto de la información requerida a los clientes de los productos y servicios financieros no hace distinciones por tipo de intermediario ni por tipo de producto. En algunas ocasiones, sin embargo, la CNBS ha emitido normativas específicas con respecto a determinados productos financieros.

Como forma de complementar la oferta de productos y servicios financieros descrita, existen proveedores de productos y servicios financieros que los ofrecen en nombre de una institución financiera regulada o no regulada. Entre estos se encuentran los agentes corresponsales y las instituciones no bancarias que brindan servicios de pago utilizando dinero electrónico (INDEL). Los agentes corresponsales son las personas naturales o jurídicas legalmente constituidas para ejercer actos de comercio, con las que una institución financiera supervisada suscribe un contrato para que puedan ofrecer algunos productos o servicios financieros específicos a los clientes de dicha institución ${ }^{17}$.

Las INDEL deben ser autorizadas por el $\mathrm{BCH}$ para operar conforme a la normativa emitida para tal efecto (Acta de la Sesión núm. 1054 de 2016). Es importante mencionar que en Honduras estas instituciones venían funcionando desde 2011, aunque de forma no regulada. A fin de promover la inclusión financiera en el país, el $\mathrm{BCH}$, junto con la CNBS, estableció la regulación y supervisión oportuna de estas entidades. Las INDEL ofrecen servicios como la activación de billeteras electrónicas, la conversión de dinero físico en dinero electrónico y viceversa, la consulta de saldos, el envío y la recepción de dinero electrónico, las transferencias y los pagos.

\section{Los sistemas de pago}

El sistema de pago es el conjunto de normas, acuerdos, instrumentos y procedimientos que tienen por objeto la ejecución de órdenes de transferencia de fondos aceptados entre las entidades participantes (Ley de Sistemas de Pago y Liquidación de Valores del Decreto núm. 46-2015). El funcionamiento de un sistema de pago requiere la autorización previa del Directorio del $\mathrm{BCH}$ y una vez autorizado queda sujeto a la supervisión de la CNBS y a la vigilancia del $\mathrm{BCH}$.

Los sistemas de pago en Honduras están regulados por la Ley de Sistemas de Pago y Liquidación de Valores. Se clasifican en sistemas de

Véase Comisión Nacional de Bancos y Seguros (CNBS), “Circular CNBS núm. 251/2013", Tegucigalpa, 2013. 
alto valor y de bajo valor: los primeros son los que se utilizan para realizar transferencias entre instituciones financieras, así como con entidades del Gobierno, en tanto que los segundos son los que suelen utilizar los usuarios para efectuar transferencias entre ellos a través del sistema financiero.

Es importante mencionar que el dinero electrónico y los monederos electrónicos son productos de reciente regulación que son ofrecidos por empresas proveedoras de servicios de telecomunicaciones.

\section{Los mecanismos de protección a los usuarios de los productos y servicios financieros}

La CNBS emitió una normativa denominada "Normas para el Fortalecimiento de la Transparencia, la Cultura Financiera y Atención al Usuario Financiero en las Instituciones Supervisadas" (Circular CNBS núm. 140/2012). En dicha normativa se detallan los lineamientos generales que las instituciones supervisadas del sistema financiero deben seguir a fin de establecer políticas y procedimientos de transparencia financiera, promoción de la cultura financiera y atención eficiente y eficaz de las reclamaciones, quejas o consultas que realicen los usuarios financieros. Por tal motivo, la institución que vela por la defensa de los derechos y deberes de los usuarios financieros es la CNBS mediante su Dirección de Protección al Usuario Financiero (DPUF).

La CNBS establece que cada institución supervisada debe contar con áreas u oficiales de atención al usuario financiero, debidamente identificados, a fin de atender sus reclamos o consultas ${ }^{18}$. Las normativas y circulares emitidas por la CNBS indican que las instituciones supervisadas tienen obligación de dar a conocer a los usuarios financieros todos los aspectos relativos a sus productos financieros, tales como las condiciones, tasas de interés y comisiones. De igual manera, la CNBS recopila información relacionada con los productos financieros ofertados por el sistema financiero y la pone a disposición de los usuarios en su página web.

\section{Infraestructura coadyuvante para la inclusión financiera de los productores rurales}

En principio, la infraestructura coadyuvante fortalece la rentabilidad y disminuye la vulnerabilidad de los ingresos provenientes de las actividades productivas rurales. Los almacenes de granos básicos, por ejemplo, permiten almacenar los excedentes de producción. Además, brindan la posibilidad de utilizar los acervos almacenados como garantías mobiliarias. En este caso, los almacenes de granos básicos sirven como organizaciones auxiliares del crédito.

18 Se incluye a las cooperativas de ahorro y crédito conforme a la Circular CONSUCOOP núm. 03-2014. 
La infraestructura de almacenamiento público en Honduras está a cargo del Instituto Hondureño de Mercadeo Agrícola (IHMA), una institución técnica y normativa de las políticas adoptadas por el Estado sobre la comercialización de productos agrícolas para el pequeño agricultor. El IHMA cuenta con una capacidad de almacenamiento de 1.231.200 quintales y también es responsable de contribuir a generar seguridad alimentaria.

La infraestructura de almacenamiento privado en Honduras está a cargo de instituciones privadas denominadas "almacenes generales de depósito". Actualmente existen cinco instituciones que están registradas y autorizadas por la CNBS para operar como almacenes. Los almacenes generales de depósito tienen la función de almacenar, manejar, guardar, conservar, trasladar y despachar bienes o mercancías. Además, expiden certificados de depósito y bonos de prenda para ser utilizados como garantía de crédito.

\section{Instrumentos de política pública}

\section{La política de fomento}

Entre los instrumentos identificados que tienen como una de sus metas incrementar la inclusión financiera de pequeños productores rurales en Honduras se destacan los programas de la Secretaría de Agricultura y Ganadería (SAG) y el PRONADERS.

La SAG tiene como finalidad lograr que la producción agrícola nacional sea competitiva y sostenible y tenga la capacidad de insertarse en la economía internacional ${ }^{19}$. También tiene la responsabilidad de responder a las necesidades del mercado interno e integrar en un esquema de desarrollo humano, social, ambiental y basado en la autogestión, la participación comunitaria, el enfoque de equidad de género y el manejo sostenible de los recursos naturales.

La SAG es responsable de la Política de Estado para el Sector Agroalimentario y el Medio Rural de Honduras 2004-2021, que incluye en su diseño el financiamiento $\mathrm{rural}^{20}$. La política de financiamiento agrícola se concentra en ampliar y tecnificar el acceso al crédito para sustentar la modernización productiva del sector con la diversificación de fuentes financieras y la mejora de las condiciones de acceso. La política busca el fortalecimiento de mecanismos tales como el seguro agrícola y los fondos de garantías para disminuir los riesgos del sistema financiero y de los productores.

Véase [en línea] http://www.sag.gob.hn/.

Información tomada y adaptada de la SAG "Política de Estado para el Sector Agroalimentario y el Medio Rural de Honduras 2004-2021", Tegucigalpa, 2004. 
El PRONADERS, que comenzó a funcionar en 2000, lleva a cabo políticas específicas para el sector rural21. En 2014, el PRONADERS se fusionó con el Fondo Hondureño de Inversión Social y el Servicio Autónomo Nacional de Acueductos y Alcantarillados para dar paso al Instituto de Desarrollo Comunitario, Agua y Saneamiento, que aún mantiene los objetivos de las tres instituciones originales.

Dentro del PRONADERS existe el Fondo Nacional de Desarrollo Rural Sostenible (FONADERS), una instancia que atiende las demandas de las comunidades rurales mediante proyectos de desarrollo rural sostenible (sociales, productivos, ambientales, educativos e institucionales, entre otros). De igual manera, el FONADERS lleva a cabo políticas de desarrollo rural enfocadas en el sector agrícola junto con otras instituciones, aunque su vinculación con otros sectores del medio rural no siempre es constante. Además, ejecuta programas de desarrollo rural financiados por la cooperación internacional.

\section{Las garantías de crédito mobiliarias y recíprocas para incrementar el acceso al crédito}

La Ley de Garantías Mobiliarias está diseñada para incrementar la inclusión financiera de las MYPE mediante la ampliación de los bienes, derechos o acciones que pueden ser objeto de garantía, simplificando su constitución, publicidad y ejecución (Decreto núm. 182-2009). Dicha Ley estipula que las garantías mobiliarias podrán ser sobre bienes corporales, bienes incorporales, cosas mercantiles, derechos o acciones, $\mathrm{u}$ obligaciones de otra naturaleza sobre bienes muebles o cosas mercantiles.

De manera complementaria, la Ley de Garantías Mobiliarias también crea un registro especial para estas garantías. La operación está diseñada para ser más simple y eficaz que los registros de propiedad inmueble, y funciona mediante formularios y acceso electrónico. Dicho registro permite una ejecución pactada entre particulares y, por lo tanto, de forma expedita sin recurrir a instancias judiciales. El registro de garantías mobiliarias es administrado por el Registro Mercantil de Francisco Morazán, que, a su vez, es administrado por la Cámara de Comercio e Industria de Tegucigalpa como un centro asociado al Instituto de la Propiedad ${ }^{22}$.

Por otra parte, la Ley del Sistema de Fondos de Garantía Recíproca para la Promoción de las MIPYMES, Vivienda Social y Educación TécnicaProfesional tiene por objeto crear la figura de sociedades administradoras de fondos de garantías recíprocas y regular su operación (Decreto núm. 205-2011). Dicha Ley regula la constitución, organización, dirección y actividades de

Véase [en línea] http://www.pronaders.hn/.

22 Véase [en línea] http://www.garantiasmobiliarias.hn/. 
las sociedades de garantías recíprocas, que brindan apoyo financiero a otras instituciones, avalando o garantizando sus obligaciones financieras para que estas puedan mejorar los términos y condiciones en la contratación de financiamiento. La operación de estas sociedades es beneficiosa para las MIPYME, ya que provee un respaldo financiero a empresas de poco capital o limitado respaldo financiero para que puedan obtener mejores condiciones de financiamiento o inversión.

\section{El desarrollo de las capacidades de los micro y pequeños empresarios}

El Instituto Nacional de Formación Profesional (INFOP) es una institución que funciona con fondos del Gobierno mediante una oferta de servicios abierta y gratuita que cuenta con una unidad especializada de servicios de desarrollo empresarial. La actual oferta de servicios de desarrollo empresarial del INFOP es variada y enfocada en capacitaciones, entre las que se encuentra desarrollar las capacidades de administración y manejo de las finanzas de las empresas.

Las instituciones privadas dedicadas a brindar los servicios de desarrollo empresarial que atienden al sector de las PYME en Honduras actualmente solo funcionan conforme a la disponibilidad de recursos económicos. De igual manera, la decisión de atender o no al sector de las PYME depende estrictamente de lo dispuesto por el donante que provee los fondos, ya que este es quien decide cuáles son las categorías de empresas que desea impulsar.

El Centro Asesor para el Desarrollo de los Recursos Humanos (CADERH) es de las pocas entidades privadas que cuentan con una infraestructura a nivel nacional, con recursos y con 25 centros afiliados a su red de proveedores. Es una institución que canaliza fondos provenientes de cooperantes internacionales para el desarrollo de jóvenes y adultos, servicios que ejecuta a través de su red de centros identificados por niveles. El propósito es identificar el nivel de capacidades de ejecución de cada uno y las áreas que se deba mejorar. Las instituciones privadas atienden principalmente a emprendedores, asalariados y grandes empresas.

Además, existen redes gremiales vinculadas a las MIPYME y relacionadas con la oferta de productos y servicios financieros y la prestación de servicios de desarrollo empresarial. Entre las principales se encuentra la REDMICROH, la Red Katalysis, la FACACH y la Federación Hondureña de Cooperativas de Ahorro y Crédito Limitada (FEHCACREL).

La REDMICROH y la Red Katalysis son redes gremiales de apoyo al sector microfinanciero, que aglutina instituciones financieras reguladas y no reguladas, mientras que la FACACH y la FEHCACREL son redes gremiales 
de apoyo al sector cooperativo. La REDMICROH y la FACACH reúnen la mayor cantidad de afiliados y ofrecen servicios especializados.

La red gremial que ha evidenciado un mayor enfoque hacia el área rural es la REDMICROH. En virtud de su marco estratégico, entre otros, ha dirigido estudios para el desarrollo de productos financieros y la caracterización del área rural. Dichos estudios los ha realizado con el apoyo de fondos de cooperantes internacionales a fin de brindar a sus afiliados los insumos necesarios para que pudieran canalizar un financiamiento oportuno a esos sectores. La Red Katalysis tiene una función similar, aunque en menor medida, al dirigir estudios relacionados a la movilización de ahorros, la red de agentes corresponsales y el desarrollo de productos financieros para productores rurales.

En virtud de lo expuesto, se considera que en Honduras existen entidades que podrían brindar servicios de apoyo para fortalecer el diseño y la gestión de productos financieros para productores rurales o dirigir estudios sectorizados.

\section{E. Conclusiones}

El interés en fomentar la inclusión financiera desde las instituciones públicas en Honduras ha ido quedando de manifiesto con el paso de los años mediante la creación de leyes y normativas, el direccionamiento de las políticas públicas y la implementación de proyectos o programas de gobierno. De este estudio también se desprende que existe una oferta importante del sector financiero para atender a la población hondureña, con la regulación y supervisión de entidades gubernamentales constituidas tiempo atrás. Asimismo, se identifica una gran capacidad económica de parte de las instituciones financieras para atender la demanda de productos y servicios financieros.

No obstante el interés del sector público, la oferta del sector financiero y la capacidad de ambos, aún persisten profundas brechas en el acceso y uso de productos y servicios financieros, que la institucionalidad y los instrumentos disponibles no han lograron atenuar. Como se ha mostrado, en 2014, el 30\% de los adultos mayores de 15 años contaba con una cuenta, mientras que el promedio en América Latina y el Caribe era del 51,1\%. La brecha se agranda si se compara el área urbana con la rural.

La ENIF tiene carácter integral y busca dar solución a esta problemática. Sin embargo, los retos y soluciones para fomentar la inclusión financiera de pequeños productores rurales no se encuentran focalizados hacia dichos productores en el marco de la ENIF, sino que más bien forman parte de la estrategia general. Además, hay que agregar que aún no se ha creado el órgano ejecutor que implementaría la ENIF. 
En estudios previos y en el diagnóstico de la ENIF se mencionan algunos retos para la inclusión financiera de pequeños productores rurales que es importante destacar. Los retos se pueden dividir en dos: i) los que inciden sobre la oferta de productos y servicios financieros y ii) los que inciden sobre la demanda. Desde la perspectiva de la oferta destacan la escasez de financiamiento a los pequeños productores rurales, las limitaciones regulatorias en lo referente a requisitos de acceso y cálculo de reservas, el escaso acceso a tecnologías especializadas para atender al sector rural, la falta de recursos humanos especializados, las pocas herramientas para la mitigación de riesgo asociada al sector, la mala apreciación del sector por experiencia o desconocimiento, y el incremento de la inseguridad ciudadana. En este sentido, una regulación diferenciada y flexible entre los distintos intermediarios financieros podría ayudar a incrementar la inclusión financiera de los pequeños productores rurales.

Desde la demanda se identifican la falta de información financiera y fiscal del sector, la baja titulación de tierras y la falta de garantías reales, los ingresos limitados e inestables, la alta dispersión de las personas en el área rural, la exigua vinculación de los pequeños productores a las cadenas productivas, la poca articulación de acciones que impulsen el sector y la falta de servicios de asistencia técnica que fortalezcan el sector. Por ello, una política pública que apunte a fomentar o modernizar los registros públicos de la propiedad, a promover las cadenas productivas, a lograr una coordinación efectiva y eficiente de las políticas intersectoriales, y a apoyar los servicios de extensión agrícola podría ayudar a incrementar la inclusión financiera de los pequeños productores rurales.

Aunque las telecomunicaciones ofrecen una vía para incrementar la inclusión financiera en áreas rurales, en la arquitectura institucional existen otros elementos de menor costo que podrían ayudar a este fin. En este sentido, la arquitectura institucional ofrece un buen espacio para favorecer el crecimiento de la inclusión financiera de los pequeños productores rurales en Honduras. No hay duda de que una infraestructura complementaria que disminuya los riesgos que enfrentan los productores rurales, una regulación prudencial acorde a la realidad nacional, una supervisión oportuna y la disponibilidad de las mejores tecnologías para optimizar los sistemas de pagos ofrecerán incentivos a los intermediarios financieros. En este mismo sentido, el impulso de esquemas de riesgo compartido, como el fondo de garantías recíprocas, y los esquemas de garantías mobiliarias podrían incrementar de manera significativa la oferta de crédito al sector.

Por último, el reforzamiento de las instituciones de defensa al usuario de los servicios financieros, la educación financiera y la oportuna supervisión de los intermediarios financieros fortalecerán la confianza y los incentivos para incrementar la demanda de productos y servicios financieros formales. 


\section{Bibliografía}

Arzbach, M., Á. Durán y C. Japp (2012), “Regulación y Supervisión de Cooperativas de Ahorro y Crédito en América Latina y el Caribe", Documentos de la DGRV, $\mathrm{N}^{\mathrm{o}}$ 3, San José, Confederación Alemana de Cooperativas (DGRV).

Banco Mundial (2014), Doing Business 2015: Going Beyond Efficiency, Washington, D.C. BANHPROVI (Banco Hondureño para la Producción y la Vivienda) (2016), “Bienes inmuebles fondos propios", Tegucigalpa [en línea] http://www.banhprovi. org / DOCUMENTOS /VIVIENDA / BIENES\%20INMUEBLES/BIENES\%20 INMUEBLES/Proyecto\%20Bienes \%20Inmuebles /CONDICIONES\%20DE $\% 20$ BIENES\%20INMUEBLES\%20FONDOS\%20PROPIOS\%20PARA\%20COMITE\%20 DE\%20CREDITO\%20.htm [fecha de consulta: 16 de diciembre de 2016].

(2014), “Informe de Gestión Anual 2014", Tegucigalpa [en línea] http:/ / www. banhprovi.org/transparencia/sitio/finanzas /PRESUPUESTO/inf-anuales / informes-gestion/informe_Anual_2014/INF_GES_2014\%20web.pdf [fecha de consulta: 16 de diciembre de 2016].

BID/REDMICROH/Espirálica (Banco Interamericano de Desarrollo/Red de Microfinancieras de Honduras/Espirálica Research \& Consulting) (2011), "Investigación de Mercados para el Diseño de Nuevos Productos en el Sector Rural de Honduras. Proyecto Mejoramiento de la Calidad de los Servicios Financieros para la Microempresa Rural de Honduras", Tegucigalpa, mayo.

Carter, M. y otros (2007), "Poverty Traps and Natural Disasters in Ethiopia and Honduras", World Development, vol. 35, N 5, Amsterdam, Elsevier, mayo.

CNBS (Comisión Nacional de Bancos y Seguros) (2015a), "Instituciones supervisadas por la Comisión Nacional de Bancos y Seguros" [en línea] http:/ / www.cnbs.gob. hn/files/boletines/listainst.pdf [fecha de consulta: 16 de diciembre de 2016]. (2015b), “Memoria 2015”, Tegucigalpa [en línea] http:/ / www.cnbs.gob.hn/files / memoria/MEMORIA\%202015.pdf [fecha de consulta: 16 de diciembre de 2016]. (2014a), "Información Financiera", Tegucigalpa [en línea] http:/ /www.cnbs. gob.hn/blog/category/informacion-financiera/ [fecha de consulta: 16 de diciembre de 2016].

(2014b), "Manual Reporte de Datos de Crédito", Tegucigalpa, mayo [en línea] http:/ / www.cnbs.gob.hn/files/capturadores/Datoscredito/MRDC\%20 Capturador\%20SL_Version\%20public\%2030May2014.pdf [fecha de consulta: 16 de diciembre de 2016].

(2014c), "Memoria 2014", Tegucigalpa [en línea] http:/ /www.cnbs.gob.hn/ files/memoria/Memoria_2014.pdf [fecha de consulta: 16 de diciembre de 2016]. (2013), "Normas para la Gestión de Información Crediticia”, Tegucigalpa, junio [en línea] http:/ / www.cnbs.gob.hn/files/GE/Compendio/2013/155-2013.pdf [fecha de consulta: 16 de diciembre de 2016].

CNBS/BID (Comisión Nacional de Bancos y Seguros/Banco Interamericano de Desarrollo) (2015), Estrategia Nacional de Inclusión Financiera (ENIF) 2015-2020, Tegucigalpa.

Confianza SA-FGR (Confianza Sociedad Administradora de Fondos de Garantía Recíproca) (2015), “Memoria Anual 2015”, Tegucigalpa [en línea] http:/ / www. confianza.hn/wp-content/uploads/2016/04/Memoria.pdf [fecha de consulta: 16 de diciembre de 2016].

CONSUCOOP (Consejo Nacional Supervisor de Cooperativas) (2015), "Registro de Cooperativas", Tegucigalpa [en línea] http:/ /transparencia.consucoop.hn/ estructura/servicios/requisitos/registro [fecha de consulta: 16 de diciembre de 2016]. 
Demirgüç-Kunt, A. y otros (2015), “The Global Findex Database 2014: Measuring Financial Inclusion around the World", Policy Research Working Paper, N 7255, Washington, D.C., Banco Mundial.

Efobi, U., I. Beecroft y E. Osabuohien (2014), “Access to and use of bank services in Nigeria: micro-econometric evidence", Review of Development Finance, vol. 4, No 2, Ciudad del Cabo, Africagrowth Institute, diciembre.

EIU/BID (The Economist Intelligence Unit/Banco Interamericano de Desarrollo) (2016), Microscopio global 2016. Análisis del entorno para la inclusión financiera, Nueva York.

FACACH (Federación de Cooperativas de Ahorro y Crédito de Honduras) (2014), "Mapeo del Sistema Federado de Ahorro y Crédito de Honduras 2008-2009. Actualizado a 2014", Tegucigalpa.

FOSDEH (Foro Social de Deuda Externa y Desarrollo de Honduras) (2013), “Análisis de la pobreza en Honduras: caracterización y análisis de determinantes, 20132014", R. Perdomo y M. Díaz (coords.), Tegucigalpa.

Karlan, D., A. L. Ratan, y J. Zinman (2014), "Savings by and for the Poor: A Research Review and Agenda", Review of Income and Wealth, vol. 60, N 1, Ottawa, Asociación Internacional de Investigaciones sobre Rentas y Riquezas (IARIW), marzo.

La Prensa (2013), "Honduras: Pactan aumento del 7.5\% al salario mínimo para 2014", Tegucigalpa, 20 de diciembre.

Marulanda, B., M. Paredes, y L. Fajury (2011), “Diagnóstico sobre el acceso a servicios financieros en Honduras", Banco Interamericano de Desarrollo (BID).

MIX Market (s/f), "Honduras market overview", Washington, D.C. [en línea] https: / / www.themix.org/mixmarket/countries-regions/honduras [fecha de consulta: 16 de diciembre de 2016].

REDMICROH (Red de Microfinancieras de Honduras) (2015a), "Estadísticas", Tegucigalpa [en línea] http://www.redmicroh.org/estadisticas / [fecha de consulta: 16 de diciembre de 2016].

(2015b), Mapeo Institucional de la Oferta Financiera para la MIPYME en Honduras 2015, Tegucigalpa.

SAG (Secretaría de Agricultura y Ganadería) (2015), Programa Nacional de Desarrollo Rural y Urbano Sostenible, Tegucigalpa.

SIC/BID/Espirálica (Secretaría de Industria y Comercio/Banco Interamericano de Desarrollo/Espirálica Research \& Consulting) (2013), “Diagnóstico Sectorial de la MIPYME No Agrícola en Honduras", Tegucigalpa, enero.

Sievers, M. y E. Saarelainen (2011), "Value chains for rural development", Ginebra, Organización Internacional del Trabajo (OIT) [en línea] http://www.ilo.org/ wcmsp5/groups/public/---ed_emp/---emp_ent/---ifp_seed/documents / publication/wcms_161156.pdf [fecha de consulta: 3 de junio de 2016].

Valenzuela, C. (2014), Investigación sobre las estrategias preferidas por los hogares hondureños para enfrentar fluctuaciones negativas en el ingreso del hogar, Banco Interamericano de Desarrollo (BID).

Valenzuela, C. y D. Cruz (2017), “Estudio de caso sobre estrategias para promover la inclusión financiera de pequeños productores rurales en Honduras" (LC/MEX/W.22), Documentos de Proyectos, Ciudad de México, Comisión Económica para América Latina y el Caribe (CEPAL).

Valenzuela, C. y R. Puerta (2007), “Remesas, Economía y Estrategia para la Reducción de la Pobreza", Tegucigalpa, Foro Nacional para las Migraciones en Honduras (FONAMIH) / Pastoral de Movilidad Humana (PMH), enero. 



\title{
Capítulo VI \\ Panorama y perspectivas de la inclusión financiera en la República Dominicana
}

\author{
Rolando Reyes ${ }^{1}$ \\ Cameron Daneshvar ${ }^{2}$
}

\section{Introducción}

A pesar de la existencia de normas y reglamentos orientados a facilitar el acceso a productos y servicios financieros, hasta la fecha no ha existido en la República Dominicana una estrategia explícita de inclusión financiera destinada a facilitar de forma sistemática el acceso de las poblaciones pobres y rurales a los productos de crédito o de ahorro y a los medios de pagos electrónicos.

Durante el período 2007-2015, la utilización de los servicios financieros creció alrededor de siete puntos porcentuales del PIB en la República Dominicana. Asimismo, se observa que el grado de utilización se ha acelerado a partir de 2009, año en el que se inician las operaciones del Sistema de Pagos y Liquidación de Valores de la República Dominicana (SIPARD). De acuerdo con los resultados de la primera Encuesta de Cultura Económica y Financiera del Banco Central de la República Dominicana (BCRD, 2014a),

Socio Fundador de Rolando Reyes y Asociados.

Oficial Asociado de Asuntos Económicos de la Unidad de Desarrollo Económico de la sede subregional de la CEPAL en México. 
el 61,2\% de la población nacional estaba bancarizada a inicios de $2014^{3}$. En términos de los productos de crédito, se concluye que el $40 \%$ del total de la población recibe algún tipo de financiamiento del sistema financiero o de instituciones de intermediación financiera. Estas cifras ubican a la República Dominicana por encima del promedio regional.

No obstante, en el país persisten brechas profundas y se observa que el uso de los distintos tipos de productos y servicios en casi todos los casos es significativamente mayor entre la población urbana que entre la rural.

En respuesta a esta situación, durante los últimos años se ha puesto en marcha una serie de acciones con respecto al marco legal y regulatorio del sistema financiero que han facilitado e impulsado el acceso a los servicios financieros y su utilización. La aprobación y la puesta en vigencia del Reglamento de Microcréditos en 2014, y posteriormente del Reglamento de Protección a los Usuarios de Servicios y Productos Financieros en 2015, y de sus modificaciones, propiciaron la profundización de la inclusión financiera. Asimismo, las flexibilizaciones del Reglamento de Evaluación de Activos (REA) aprobadas a partir de 2005 también sirvieron para impulsar una cobertura más amplia de los productos de crédito.

En este mismo sentido, la modernización del Sistema de Pagos, la facilitación y regulación de los procedimientos de emisión de tarjetas de crédito y de débito, la emisión de las tarjetas de pago de subsidios gubernamentales y el surgimiento de las cuentas de usuarios de pagos móviles han impulsado la inclusión financiera de manera directa e indirecta. Además, como parte de los esfuerzos para promover el uso de los servicios financieros, en 2014 se realizó la primera Encuesta Nacional de Educación y Cultura Financiera (BCRD, 2014a), con la que por primera vez se midió a nivel nacional el grado de inclusión y se obtuvo una radiografía completa del acceso a los servicios financieros de toda la población y de su grado de utilización.

En este documento se argumenta que, con el objetivo de disminuir las brechas existentes en el acceso a los servicios financieros de pago, ahorro, crédito y aseguramiento, así como las brechas en su utilización, tanto entre los grupos poblacionales de los entornos urbano y rural como entre los grupos de alto, mediano y bajo nivel de ingreso, es necesario formular e implementar una estrategia integral y explícita de inclusión financiera en torno a los siguientes objetivos específicos:

- fortalecer las capacidades tanto de los usuarios tradicionalmente excluidos del acceso a los servicios financieros y de su utilización, como de los proveedores de servicios financieros, en particular de las cooperativas, en lo atinente al diseño de los productos;

El término "bancarizado" es el utilizado en la encuesta para referirse a aquellos individuos que cuentan con algún tipo de instrumento bancario, como cuentas, préstamos o instrumentos de inversión. 
- consolidar el liderazgo de la banca de desarrollo en el desarrollo rural del país por medio de la canalización de recursos mediante operaciones de segundo piso;

- adecuar la regulación vigente para lograr un balance apropiado entre inclusión y estabilidad del sistema financiero;

- promover el acceso de proveedores de servicios financieros, en particular de aquellos que dan servicios a usuarios en el ámbito rural, a infraestructura clave, por ejemplo, el Sistema de Pagos, y

- fortalecer los mecanismos de protección de usuarios y solución de controversias, y ampliar su cobertura.

Además de esta introducción, el capítulo se divide en cinco secciones. En la sección A se describe la situación actual de la inclusión financiera en la República Dominicana. En la sección B se analizan los esfuerzos realizados hasta la fecha por las autoridades con el objeto de incrementar la inclusión financiera. En la sección C se detallan los componentes de la arquitectura institucional que rige actualmente en el país, mientras que en la sección D se identifican los instrumentos de política pública disponibles para fomentar la inclusión financiera. Por último, en la sección E se presentan las conclusiones y recomendaciones, que se centran en el diseño e implementación de una estrategia integral y coordinada de inclusión financiera dentro del marco de la Estrategia Nacional de Desarrollo (END) vigente.

\section{A. Situación de la inclusión financiera}

\section{Situación con respecto al contexto internacional}

La base de datos Global Findex del Banco Mundial (Demirguc-Kunt y otros, 2015) reúne datos sobre inclusión financiera a nivel mundial. A los fines de este informe, se han procesado los datos de dicha base para extraer información básica sobre la inclusión financiera en la República Dominicana e información agregada acerca de América Latina y el Caribe.

Aunque no existen otros datos históricos que sirvan de comparación, es preciso resaltar que, como se puede verificar en el cuadro VI.1, en solo tres años la proporción de la población general con una cuenta en instituciones financieras formales aumentó más de 15 puntos porcentuales. Es posible que este significativo crecimiento sea explicado en gran parte por el resultado de la expansión del Sistema de Pagos, sobre todo en lo que tiene que ver con los instrumentos de tarjeta de débito para el pago de la nómina y los pagos móviles por medio de teléfonos celulares. 
Cuadro VI.1

República Dominicana y América Latina y el Caribe: población con cuentas en instituciones financieras, 2011 y 2014

(En porcentajes)

\begin{tabular}{lcccccc}
\hline \multirow{2}{*}{} & \multicolumn{2}{c}{$\begin{array}{c}\text { República } \\
\text { Dominicana }\end{array}$} & & \multicolumn{2}{c}{$\begin{array}{c}\text { América Latina } \\
\text { y el Caribe }\end{array}$} \\
\cline { 2 - 3 } \cline { 6 - 7 } & 2011 & 2014 & & 2011 & 2014 \\
\hline Población general & 38,2 & 54,0 & & 39,3 & 51,1 \\
\hline Población femenina & 37,4 & 55,8 & & 34,8 & 48,5 \\
\hline El 40\% más pobre de la población & 22,8 & 41,8 & & 24,1 & 40,9 \\
\hline El 60\% más rico de la población & 48,6 & 62,6 & & 49,5 & 58,1 \\
\hline Población con educación primaria o menos & 25,3 & 41,1 & & 30,0 & 42,9 \\
\hline Población rural & 29,6 & 46,5 & & 35,0 & 45,7 \\
\hline
\end{tabular}

Fuente: Elaboración propia, sobre la base de Banco Mundial, The Global Findex Database, 2016 [en línea] http://datatopics.worldbank.org/financialinclusion/.

El mayor crecimiento se produjo en el grupo correspondiente al 40\% más pobre, muy cercano al experimentado por la población femenina. Esto refleja en cierta medida un punto de partida relativamente bajo. La población rural con cuentas en instituciones financieras aumentó casi 17 puntos porcentuales, lo que quizá también se deba al crecimiento de los medios de pagos.

Si se comparan los resultados de la República Dominicana con los del promedio de América Latina y el Caribe, lo primero que llama la atención es que, aunque en 2011 el promedio regional fue similar o incluso superior al de la República Dominicana, en 2014 la única variable en la que la República Dominicana se ubica por debajo del promedio regional es en la proporción de la población con educación primaria o menos que tiene una cuenta en instituciones financieras.

Una de las diferencias más significativas es la del grupo perteneciente a la población rural, que en el caso dominicano superó a la región por 6,1 puntos porcentuales. En el caso de la población general con cuentas en instituciones financieras, la República Dominicana superó a la región por 3,4 puntos porcentuales. Como se mencionó, es probable que el mayor avance del país con relación al resto de la región se explique por el hecho de que también la modernización del Sistema de Pagos fue más acelerada que en los demás países, lo que se ve reflejado en la disminución en el uso de efectivo, así como en el incremento del número de cuentas y el mayor nivel de transaccionalidad.

\section{Situación a nivel nacional}

En el cuadro VI.2 se presenta la evolución de la participación del ahorro y los créditos de las instituciones financieras en el PIB durante los últimos diez años, y se observa que la intermediación financiera creció alrededor de siete puntos del PIB. 


\section{Cuadro VI.2}

República Dominicana: relación entre PIB, préstamos y depósitos, 2007-2015 (En millones de pesos dominicanos)

\begin{tabular}{lccccc}
\hline Años & PIB & $\begin{array}{c}\text { Total de } \\
\text { préstamos }\end{array}$ & $\begin{array}{c}\text { Total de depósitos } \\
\text { yalores (excluidas } \\
\text { las acciones) }\end{array}$ & $\begin{array}{c}\text { Préstamos como } \\
\text { proporción } \\
\text { del PIB }\end{array}$ & $\begin{array}{c}\text { Depósitos como } \\
\text { proporción } \\
\text { del PIB }\end{array}$ \\
\hline Dic 2007 & 1455253,30 & 314243,00 & 452468,80 & 0,22 & 0,31 \\
\hline Dic 2008 & 1656961,70 & 370043,30 & 497243,70 & 0,22 & 0,30 \\
\hline Dic 2009 & 1729468,40 & 411726,90 & 575598,80 & 0,24 & 0,33 \\
\hline Dic 2010 & 1978851,90 & 469018,20 & 657021,10 & 0,24 & 0,33 \\
\hline Dic 2011 & 2218428,80 & 517806,30 & 744942,50 & 0,23 & 0,34 \\
\hline Dic 2012 & 2377503,70 & 578096,20 & 808673,70 & 0,24 & 0,34 \\
\hline Dic 2013 & 2558585,60 & 677212,20 & 906585,60 & 0,26 & 0,35 \\
\hline Dic 2014 & 2786229,70 & 751852,80 & 992686,50 & 0,27 & 0,36 \\
\hline Dic 2015 & 3023116,10 & 872426,20 & 1109688,20 & 0,29 & 0,37
\end{tabular}

Fuente: Elaboración propia, sobre la base de cifras del Banco Central de la República Dominicana.

Se destaca que el grado de intermediación se acelera a partir de 2009, año en el que se inician las operaciones del Sistema de Pagos y Liquidación de Valores de la República Dominicana (SIPARD), que administra el Banco Central de la República Dominicana. Al cierre de 2015, la participación de los créditos en el PIB alcanzó un 29\%, cifra que es significativamente superior al promedio histórico de América Latina y el Caribe ${ }^{4}$.

Aunque no se pueda demostrar estadísticamente, la profundización de la intermediación financiera a partir de 2007 debe tener una relación positiva con los esfuerzos de inclusión financiera representada por los reglamentos puestos en vigencia antes de la aprobación del Reglamento del Subagente Bancario (véanse las próximas secciones). En este tenor, debería esperarse que las flexibilizaciones del Reglamento de Evaluación de Activos aprobadas a partir de 2005 y las acciones orientadas a expandir el microcrédito tengan un efecto positivo en la participación de los préstamos en el PIB. En ese mismo sentido, la modernización del Sistema de Pagos — mediante la adopción de métodos de pagos electrónicos con tarjetas y otros medios- así como la facilitación y regulación de los procedimientos de emisión de tarjetas de crédito y de débito también deberían traer aparejado un efecto positivo en la participación de los ahorros como proporción del PIB, pues la apertura de cuentas o el depósito previo es un prerrequisito para recibir o efectuar pagos electrónicos.

4 Cálculo del autor sobre la base de cifras oficiales del Banco Central de la República Dominicana. 
No obstante, cabe precisar que a la luz de las brechas existentes, un aumento de la cantidad de transacciones de usuarios con cuentas no es un indicador de un mayor grado de inclusión, pues para que se produzca tal condición es necesario que se registre un incremento del número de usuarios, asunto que se analizará en las próximas secciones.

Según la primera Encuesta de Cultura Económica y Financiera (BCRD, 2014a) realizada por el Banco Central de la República Dominicana en 2014, a inicios de dicho año el 61,2\% de la población dominicana estaba bancarizada, denominación que hace referencia al uso de por lo menos un producto financiero, incluidos los seguros de vida y de salud. Si se limita la definición a la cantidad de personas que posee un producto de ahorro o de crédito, este porcentaje se reduce al $43 \%$.

\section{Brechas en el ámbito rural}

Si bien a nivel nacional se observa que la inclusión financiera en la República Dominicana está bastante avanzada respecto de América Latina y el Caribe, hay brechas pronunciadas dentro del país, sobre todo entre los ámbitos rural y urbano.

En el cuadro VI.3 se presenta el porcentaje de la población, clasificada en urbana o rural, que utiliza los distintos tipos de servicios y productos financieros ofrecidos por las entidades de intermediación financiera reguladas y por otras instituciones no reguladas y de servicios relacionados con el sistema financiero general.

La cuenta de nómina — producto que no siempre depende de la libre elección del usuario - es utilizada por la población urbana en una proporción que supera en diez puntos porcentuales a la rural, lo que probablemente responde a la mayor incidencia de la informalidad en el ámbito rural. En el caso de las tarjetas de crédito, que sí son de libre elección y fundamentales para un buen manejo financiero-, la diferencia entre el uso urbano y rural es igual que en la cuenta de nómina. El hecho de que la diferencia entre el uso de la cuenta de nómina y de la tarjeta de crédito sea igual entre la población urbana y la rural refleja los aspectos estructurales del sistema y la arquitectura financiera que limitan la inclusión financiera, independientemente del tipo específico de producto financiero.

La diferencia se amplía en el caso de la cuenta de ahorro, aunque cabe resaltar que en el caso de los productos de crédito o préstamos, dicha diferencia se torna mucho menos significativa, sobre todo en el caso de los préstamos personales o de consumo, donde la diferencia resulta insignificante. Esto podría deberse a que muy probablemente las condiciones y las razones que llevan a las personas a contratar préstamos personales y de consumo no se ven influenciadas por el territorio donde residen. Asimismo, el resultado podría estar vinculado con la oferta de este tipo de producto por parte de las entidades microfinancieras que atienden a los usuarios rurales. 
Cuadro VI.3

República Dominicana: tipo de producto o servicio financiero utilizado, por zona geográfica, 2014

(En porcentajes)

\begin{tabular}{lrc}
\hline Tipo de producto o servicio financiero & Zona rural & Zona urbana \\
\hline Cuenta de nómina & 18,5 & 28,8 \\
\hline Cuenta de ahorro & 31,6 & 44,2 \\
\hline Cuenta corriente/chequera & 2,8 & 5,0 \\
\hline Cuenta de ahorro en cooperativa & 9,8 & 12,5 \\
\hline Depósito a plazo fijo o certificado financiero & 2,2 & 3,0 \\
\hline Cuenta de ahorro o depósito a plazo fijo en moneda extranjera & 0,6 & 1,5 \\
\hline Tarjeta de crédito & 13,2 & 23,4 \\
\hline Tarjeta prepagada & 5,7 & 7,5 \\
\hline Préstamo de nómina & 3,5 & 4,8 \\
\hline Préstamo/crédito vehicular & 1,2 & 2,7 \\
\hline Préstamo o línea de crédito/crédito diferido & 2,1 & 2,7 \\
\hline Préstamo para compra de electrodomésticos, equipos o activos fijos & 2,0 & 3,9 \\
\hline Otro préstamo personal o de consumo & 11,1 & 11,8 \\
\hline Préstamo de cooperativa & 7,5 & 7,1 \\
\hline Préstamo o crédito hipotecario para adquisición y/o remodelación & 1,2 & 2,5 \\
\hline Préstamo pyme de Banca Solidaria o PROMIPYME & 1,2 & 2,8 \\
\hline Préstamo pyme de ONG o microfinanciera & 1,0 & 0,8 \\
\hline Préstamo pyme de banca privada & 1,9 & 2,0 \\
\hline Fondo de pensiones administrado por institución privada (AFP) & 16,4 & 25,7 \\
\hline Fondo de pensiones administrado por empleador & 7,2 & 7,7 \\
\hline Seguro de salud & 61,7 & 62,0 \\
\hline Seguro de vida & 9,2 & 13,5 \\
\hline Seguro de accidentes personales & 4,8 & 6,3 \\
\hline Seguro vehicular de ley & 14,6 & 14,1 \\
\hline Servicio de banca electrónica por Internet & 2,6 & 5,0 \\
\hline
\end{tabular}

Fuente: Elaboración propia, sobre la base de cifras del Banco Central de la República Dominicana (BCRD), primera Encuesta de Cultura Económica y Financiera de la República Dominicana 2014, Santo Domingo, 2014.

Como era de esperarse, la participación de la población urbana en los distintos tipos de productos y servicios es significativamente mayor que la rural en casi todos los casos; sin embargo, llaman la atención los préstamos de cooperativas, pues presentan la situación inversa, lo que refleja la vocación rural de las cooperativas en lo concerniente a los préstamos.

\section{B. Iniciativas de inclusión financiera}

Como se indicó, pese a la existencia de normas y reglamentos orientados a facilitar el acceso a productos y servicios financieros, hasta la fecha no ha existido en el país una estrategia explícita y coordinada de inclusión financiera destinada a facilitar de forma sistemática el acceso de las poblaciones pobres y rurales a los productos de crédito y de ahorro, o a los medios de pagos electrónicos. 
No obstante, el acceso de las pequeñas y medianas empresas (pymes) urbanas y de los pequeños productores rurales al crédito bancario ha sido una preocupación permanente de la política pública. En ese sentido, se podría decir que la primera acción de la política pública a favor del acceso al crédito fue la creación del Banco Agrícola en 1947, que tuvo como objeto brindar financiamiento a la actividad agropecuaria en general ${ }^{5}$.

Muchas de las iniciativas o programas han surgido como acciones propias de gobiernos y de instituciones públicas sin un marco institucional explícitamente orientado a promover la inclusión financiera. De hecho, hasta el inicio de la reforma financiera que condujo a la aprobación de la Ley Monetaria y Financiera en 2001, y sus reglamentos posteriores, los pequeños créditos y el financiamiento de la microempresa no estaban separados de los de gran envergadura, y no existía diferencia en cuanto a los criterios de evaluación del riesgo crediticio. En el mismo sentido, las modificaciones al Reglamento de Evaluación de Activos (REA) (BCRD, 2004) significó un avance considerable para facilitar el acceso al crédito de las microempresas y las pymes, pues la división entre pequeños y grandes deudores marcó una diferencia sustancial en cuanto a los criterios de historial y capacidad de pago, y a su preponderancia para la evaluación del riesgo crediticio de los deudores en el sistema bancario regulado.

El año 2013 marca un punto de inflexión en la inclusión financiera con la entrada en vigencia del Reglamento del Subagente Bancario (RSB) (BCRD, 2013), que permite que los servicios financieros básicos sean prestados por diferentes tipos de establecimientos comerciales. Asimismo, la inclusión financiera se vio favorecida con la aprobación y la entrada en vigencia del Reglamento de Microcréditos el 14 de agosto de 2014 (BCRD, 2014b) y posteriormente con el Reglamento de Protección a los Usuarios de Servicios y Productos Financieros del 30 de septiembre de 2015, y sus modificaciones (BCRD, 2015).

Aunque no existe una estrategia integral de inclusión financiera, las autoridades dominicanas han avanzado en la formulación de una estrategia de educación financiera, lo que constituye un elemento fundamental de una eventual estrategia más amplia de inclusión financiera. En 2014, se formó una mesa de trabajo para la elaboración de la Estrategia Nacional de Educación Económica y Financiera, que fue coordinada por el Banco Central de la República Dominicana y contó con la colaboración de la Superintendencia de Bancos, Pensiones y Valores; la Asociación de Bancos Comerciales; la Asociación de Bancos de Ahorro y Crédito; la Liga de Asociaciones de Ahorros y Préstamos; así como con la colaboración del Ministerio de la Presidencia; el Ministerio de Economía, Planificación y Desarrollo; el Ministerio de

Consúltese la historia de las operaciones y transformaciones de dicha institución desde su creación hasta 2015 en Banco Agrícola (2015). 
Industria, Comercio y MiPymes; el Ministerio de Educación; y el Ministerio de Hacienda.

Con el fin de fortalecer el diseño de la estrategia de educación financiera, en 2014 se realizó la primera Encuesta de Cultura Económica y Financiera (BCRD, 2014a), con la que por primera vez se obtuvo una radiografía completa del acceso a los servicios financieros y su utilización a nivel nacional. Asimismo, como parte de los esfuerzos en aras de la educación financiera, las autoridades lanzaron un programa para capacitar en esta materia a 1.800 docentes (600 en 2014 y 1.200 en 2015) en el ámbito nacional con miras a lograr una mayor diseminación de los conocimientos financieros en todo el país.

\section{Arquitectura institucional}

\section{Regulación y supervisión del sistema financiero}

La Constitución de la República Dominicana y la Ley Monetaria y Financiera facultan a la Junta Monetaria y al Banco Central de la República Dominicana a dictar los reglamentos necesarios para la adecuada regulación del sistema monetario y financiero, así como para introducir los cambios e innovaciones necesarios para una mayor eficiencia de los servicios financieros. La Ley Monetaria y Financiera rige para todos los intermediarios bancarios e intermediarios cambiarios, con excepción de las cooperativas, cuya reglamentación se aborda más adelante.

El marco legal para el sistema monetario y financiero establece lineamientos relativos al capital mínimo, la solvencia regulatoria, la liquidez y la gestión con el fin de garantizar la estabilidad del sistema en un entorno competitivo. Además, se exige una estructura eficiente de gobierno corporativo y de gestión de riesgos en función de la naturaleza, el tamaño y el perfil de riesgo de las entidades.

En el caso de los servicios bancarios, las entidades responsables de la regulación y la supervisión de los proveedores de servicios financieros son la Junta Monetaria y la Superintendencia de Bancos, respectivamente. En el caso del mercado de valores y los servicios fiduciarios, son el Consejo Nacional de Valores (regulador) y la Superintendencia de Valores (supervisor). En cuanto a las pensiones, son el Consejo Nacional de Seguridad Social (regulador) y la Superintendencia de Pensiones (supervisor), mientras que para los seguros, son el Ministerio de Hacienda (regulador) y la Superintendencia de Seguros (supervisor). Finalmente, si bien las cooperativas de ahorro y crédito no están reguladas y supervisadas como entidades de intermediación financiera, existe una regulación y supervisión de estas entidades de forma general, cuya responsabilidad recae en el Instituto de Desarrollo y Crédito Cooperativo (IDECOOP). 
Entre los cambios que han afectado al sector financiero en los últimos años y, por ende, las necesidades desde la perspectiva de la regulación y supervisión, destacan la entrada de bancos extranjeros al mercado bancario, el desarrollo del Sistema de Pagos, la ampliación de la cobertura geográfica de los servicios financieros, una mayor oferta de productos y servicios financieros así como de canales de distribución, el creciente uso de servicios de pagos electrónicos, las innovaciones tecnológicas en servicios de pagos puestas a disposición del público, el surgimiento de nuevos actores (no financieros) proveedores de servicios de pago, la adopción de nuevos instrumentos de pago y el establecimiento de subagentes bancarios.

En cuanto a este último cambio, cabe resaltar que fue el impulso por el lado de la regulación lo que dio lugar al surgimiento de los subagentes bancarios como un nuevo canal de distribución de los servicios financieros. En su sesión del 14 de febrero de 2013, la Junta Monetaria aprobó el Reglamento del Subagente Bancario (RSB) con la finalidad de incrementar la inclusión financiera, facilitando el acceso a servicios financieros de la población más empobrecida que no participa en el sistema financiero formal. Los objetivos citados indican claramente que se considera que el RSB tiene la categoría de una reforma reglamentaria con un potencial de alto impacto en la inclusión financiera. Se trata de una innovación en cuanto al canal de distribución de los servicios financieros, que facilita de manera significativa el acceso a los servicios financieros básicos sin disminuir su calidad y sin aumentar el riesgo operativo de las instituciones financieras.

\section{Intermediarios financieros}

A nivel nacional, los principales oferentes de servicios financieros incluyen bancos múltiples, asociaciones de ahorros y préstamos, bancos de ahorro y crédito, corporaciones de crédito, el Banco Agrícola, cooperativas de ahorro y crédito, y entidades microfinancieras. Las cooperativas de ahorro y crédito ocupan un rol dominante en la provisión de servicios financieros al segmento rural de la población. Además, cabe reconocer el papel destacado de los proveedores informales de servicios financieros, sobre todo en las zonas rurales. En este sentido, prevalecen las limitaciones para el acceso a los servicios de ahorro y crédito del sistema financiero formal, según lo muestra la Encuesta de Cultura Económica y Financiera (BCRD, 2014a), que reveló que el $13,5 \%$ de la población obtiene créditos por medio de prestamistas informales.

Dada la vocación eminentemente rural de las cooperativas de ahorro y crédito, debería esperarse que sus oficinas estén concentradas en los distritos municipales, secciones y parajes rurales. Es por eso que llama la atención el hecho de que el porcentaje de la población que tiene cuentas de ahorro en cooperativas sea significativamente mayor en el caso urbano que en el 
rural. Sin embargo, el porcentaje de la población rural con préstamos de cooperativas es muy similar al de la población urbana que tiene préstamos de dichas instituciones. Ello sugiere que algunos de los factores que constriñen el acceso a estos proveedores de servicios financieros se originan en los insuficientes ingresos de la población rural, en el desconocimiento o la desconfianza de los usuarios rurales con respecto a los proveedores formales de servicios financieros, así como en una oferta de productos inadecuados para el ámbito rural.

A pesar del papel destacado de las cooperativas de ahorro y crédito en la ampliación de los servicios financieros, en la actualidad estas entidades no están reguladas y supervisadas, tal como ocurre con los demás intermediarios financieros que operan en el país. Debido a esta situación, las cooperativas están excluidas del Sistema de Pagos y de los instrumentos de pagos electrónicos con tarjetas y dispositivos móviles, lo que se convierte de hecho en una restricción al acceso de parte de las poblaciones rurales que geográficamente dependen de ellas para obtener servicios financieros.

El hecho de que no exista un ente regulador de las cooperativas de ahorro y crédito que realizan intermediación financiera determina la inexistencia de estadísticas consolidadas relativas a este tipo de entidades. En 2014 los activos totales y la cartera de préstamos de los miembros de la Asociación de Instituciones Rurales de Ahorro y Crédito (AIRAC), entidad que agrupa a las principales cooperativas de ahorro y crédito, ascendían a $33.465,1$ millones y a 23.850,3 millones de pesos, respectivamente. Al cierre de dicho año, la cartera de créditos del sistema financiero consolidado totalizaba $725.586,3$ millones de pesos, lo que significa que la cartera de créditos de las cooperativas miembros de AIRAC representaba el 3,3\% de la cartera total de todo el sistema financiero. Si se toman en cuenta todas las cooperativas de ahorro y crédito, es probable que la cartera de préstamos de estas instituciones sea muy cercana al 5\% de la cartera del sistema financiero, lo que también podría considerarse una cifra que amerita un mayor esfuerzo de supervisión y regulación de parte de las autoridades de este importante segmento del sistema y de la propia intermediación financiera.

Si se toma en cuenta que en 2014 el Banco Agrícola desembolsó préstamos por un monto de $14.765,3$ millones de pesos y que su cartera de crédito alcanzó los 11.561,4 millones, se concluye que las cooperativas agrupadas en AIRAC prestaban 2,1 pesos por cada peso prestado por el Banco Agrícola, monto que podría llegar a 3 pesos si se incluyeran las cooperativas no agrupadas en AIRAC. El hecho de que las cooperativas no reguladas y supervisadas administren una cartera de crédito tres veces superior a la de la principal institución pública de financiamiento de la agricultura y el desarrollo rural subraya la importancia y la urgencia que revisten la supervisión y la regulación de estas instituciones. 
Las entidades microfinancieras también juegan un rol preponderante a la hora de llevar los productos y servicios de crédito a la población rural. Entre ellas, destacan la Asociación para el Desarrollo de Microempresas (ADEMI) y el Banco de la Mujer, conocido como Banco ADOPEM.

\section{Principales productos y canales de distribución}

En el cuadro VI.4 se presenta el porcentaje de la población que utiliza los distintos tipos de servicios y productos financieros ofrecidos por las entidades de intermediación financiera reguladas y por otras instituciones no reguladas $\mathrm{y}$ de servicios relacionados con el sistema financiero general.

\section{Cuadro VI.4 \\ República Dominicana: población que posee actualmente distintos tipos de productos financieros, 2014}

(En porcentajes)

\begin{tabular}{lc}
\hline Tipo de producto o servicio & $\begin{array}{c}\text { Porcentaje } \\
\text { de la población }\end{array}$ \\
\hline Seguro de salud & 61,9 \\
\hline Cuenta de ahorro & 43,0 \\
\hline Cuenta de nómina & 27,8 \\
\hline Fondo de pensiones administrado por institución privada (AFP) & 24,8 \\
\hline Tarjeta de crédito & 22,5 \\
\hline Seguro vehicular de ley & 14,1 \\
\hline Seguro de vida & 13,1 \\
\hline Cuenta de ahorro en cooperativa & 12,2 \\
\hline Otro préstamo personal o de consumo & 11,7 \\
\hline Fondo de pensiones administrado por empleador & 7,7 \\
\hline Tarjeta prepagada & 7,4 \\
\hline Préstamo de cooperativa & 7,1 \\
\hline Seguro de accidentes personales & 6,1 \\
\hline Cuenta corriente/chequera & 4,8 \\
\hline Servicio de banca electrónica por Internet & 4,7 \\
\hline Préstamo de nómina & 4,6 \\
\hline Préstamo para la compra de electrodomésticos, equipos o activos fijos & 3,8 \\
\hline Depósito a plazo fijo o certificado financiero & 2,9 \\
\hline Préstamo pyme de Banca Solidaria o PROMIPYME & 2,6 \\
\hline Préstamo o línea de crédito/crédito diferido & 2,6 \\
\hline Préstamo o crédito vehicular & 2,5 \\
\hline Préstamo o crédito hipotecario para adquisición y/o remodelación & 2,3 \\
\hline Préstamo pyme de banca privada & 2,0 \\
\hline Cuenta de ahorro o depósito a plazo fijo en moneda extranjera & 1,4 \\
\hline Préstamo pyme de ONG o microfinanciera & 0,8 \\
\hline Fuente: Elara & \\
\hline
\end{tabular}

Fuente: Elaboración propia, sobre la base de cifras del Banco Central de la República Dominicana (BCRD), Encuesta de Cultura Económica y Financiera de la República Dominicana 2015, Santo Domingo, 2014. 
Entre los productos de ahorro, destacan las cuentas de ahorro (43\% de los hogares optan por este producto), las cuentas de nómina (27,8\%), las cuentas de ahorro en cooperativas (12,2\%), los certificados de depósito y a plazos $(2,9 \%)$ y las inversiones en el mercado de valores $(0,4 \%)$. Con respecto a los productos de crédito, existen los préstamos hipotecarios $(1,0 \%)$ y de consumo $(11,7 \%)$, y los préstamos de cooperativas $(4,0 \%)$. Por su parte, los servicios de pago incluyen servicios de banca electrónica $(1,0 \%)$, tarjetas de crédito $(22,5 \%)$, y servicios de subsidios gubernamentales, canales y dispositivos electrónicos. Por último, los productos de seguro incluyen el seguro de salud (61,9\%), el seguro de vida $(13,1 \%)$ y el seguro vehicular de ley $(14,1 \%)$.

Si se suman todos los productos de crédito, se concluye que el $40 \%$ de la población recibe algún tipo de financiamiento de parte de instituciones de intermediación financiera. Esta cifra resulta ser muy superior al porcentaje de la población que tiene tarjeta de crédito $(22,5 \%)$ y muy similar a la que tiene cuenta de ahorro ( $43 \%$ ).

Por último, hay que resaltar dos resultados significativos. En primer lugar, la población que mantiene cuentas de ahorro en cooperativas es muy superior a la que contrata préstamos en este tipo de entidades. Dado que la cuenta de ahorro puede servir de punto de entrada y eje para otros productos financieros más sofisticados, este dato apunta a una oportunidad para lograr un mayor uso de diversos productos que en la actualidad están desaprovechados. En segundo lugar, la población con préstamos de la banca pública de microcréditos (Banca Solidaria) o de instituciones sin fines de lucro, y microcréditos de la banca privada es muy similar al porcentaje de la población con préstamos de consumo de la banca privada formal, lo que indica el grado de penetración o utilización de esta clase de financiamiento.

En el cuadro VI.5 se presenta desagregada la información relativa a la utilización de servicios financieros según el nivel de ingreso de los usuarios. Como puede observarse y cabía esperar, el porcentaje de utilización de los principales productos y servicios financieros aumenta con el nivel de ingreso.

Sobresalen los casos de las cuentas de nómina, de chequeras y de ahorro; las tarjetas de crédito y los préstamos de toda clase, en los que la participación de las poblaciones de ingreso mediano, mediano bajo y bajo cae de manera significativa con relación a la de los grupos de ingreso alto y mediano alto. El producto de mayor participación en el estrato de ingreso mediano bajo y bajo, excluido el seguro de salud, es la cuenta de ahorro, lo que destaca el potencial de apalancar el uso de este instrumento como punto de entrada a otros productos financieros. El nivel de uso relativamente elevado de las cuentas de nóminas por parte de los estratos de ingreso mediano bajo y bajo sugiere que existe una estrecha relación entre el empleo formal y la inclusión financiera. 


\section{Cuadro VI.5 \\ República Dominicana: productos y servicios financieros utilizados, por nivel de ingreso, 2014}

(En porcentajes)

\begin{tabular}{|c|c|c|c|c|}
\hline $\begin{array}{l}\text { Tipo de producto } \\
\text { o servicio financiero }\end{array}$ & $\begin{array}{l}\text { Ingreso alto y } \\
\text { mediano alto }\end{array}$ & $\begin{array}{l}\text { Ingreso } \\
\text { mediano }\end{array}$ & $\begin{array}{l}\text { Ingreso } \\
\text { mediano bajo } \\
\text { y bajo }\end{array}$ & $\begin{array}{c}\text { No sabe } \\
\text { o no contesta }\end{array}$ \\
\hline Cuenta de nómina & 50,6 & 36,0 & 21,4 & 8,4 \\
\hline Cuenta de ahorro & 73,5 & 61,6 & 30,1 & 34,9 \\
\hline Cuenta corriente/chequera & 19,5 & 6,4 & 1,8 & 0,0 \\
\hline Cuenta de ahorro en cooperativa & 29,7 & 15,4 & 8,3 & 2,7 \\
\hline $\begin{array}{l}\text { Depósito a plazo fijo } \\
\text { o certificado financiero }\end{array}$ & 12,1 & 3,5 & 1,2 & 0,7 \\
\hline $\begin{array}{l}\text { Cuenta de ahorro o depósito } \\
\text { a plazo fijo en moneda extranjera }\end{array}$ & 3,4 & 1,7 & 1,1 & 0,0 \\
\hline Tarjeta de crédito & 56,5 & 37,4 & 10,8 & 8,4 \\
\hline Tarjeta prepagada & 23,6 & 11,5 & 3,1 & 0,4 \\
\hline Préstamo de nómina & 12,5 & 6,7 & 2,7 & 0,0 \\
\hline Préstamo o crédito vehicular & 13,3 & 3,3 & 0,5 & 0,0 \\
\hline $\begin{array}{l}\text { Préstamo o línea de crédito/ } \\
\text { crédito diferido }\end{array}$ & 6,4 & 5,7 & 0,6 & 2,7 \\
\hline $\begin{array}{l}\text { Préstamo para compra de } \\
\text { electrodomésticos, equipos } \\
\text { o activos fijos }\end{array}$ & 8,5 & 6,5 & 1,8 & 2,7 \\
\hline $\begin{array}{l}\text { Otro préstamo personal } \\
\text { o de consumo }\end{array}$ & 22,3 & 17,6 & 7,8 & 3,6 \\
\hline Préstamo de cooperativa & 14,7 & 8,7 & 5,6 & 0,0 \\
\hline $\begin{array}{l}\text { Préstamo o crédito hipotecario } \\
\text { para adquisición y/o } \\
\text { remodelación }\end{array}$ & 7,4 & 3,7 & 0,8 & 2,7 \\
\hline $\begin{array}{l}\text { Préstamo pyme de Banca } \\
\text { Solidaria o PROMIPYME }\end{array}$ & 5,3 & 3,5 & 1,6 & 5,4 \\
\hline $\begin{array}{l}\text { Préstamo pyme de ONG } \\
\text { o microfinanciera }\end{array}$ & 0,2 & 2,1 & 0,5 & 0,0 \\
\hline Préstamo pyme de banca privada & 2,3 & 3,1 & 1,5 & 0,5 \\
\hline $\begin{array}{l}\text { Fondo de pensiones administrado } \\
\text { por institución privada (AFP) }\end{array}$ & 54,3 & 31,2 & 18,1 & 4,8 \\
\hline $\begin{array}{l}\text { Fondo de pensiones administrado } \\
\text { por empleador }\end{array}$ & 15,2 & 10,5 & 5,6 & 0,9 \\
\hline Seguro de salud & 81,1 & 70,2 & 56,0 & 46,3 \\
\hline Seguro de vida & 32,0 & 18,7 & 8,1 & 2,6 \\
\hline Seguro de accidentes personales & 20,1 & 7,4 & 3,4 & 1,2 \\
\hline Seguro vehicular de ley & 45,2 & 21,9 & 5,9 & 4,6 \\
\hline $\begin{array}{l}\text { Servicio de banca electrónica } \\
\text { por Internet }\end{array}$ & 20,9 & 7,0 & 1,2 & 0,0 \\
\hline
\end{tabular}

Fuente: Elaboración propia, sobre la base de cifras del Banco Central de la República Dominicana (BCRD), Encuesta de Cultura Económica y Financiera de la República Dominicana 2015, Santo Domingo, 2014. 
Con respecto a los principales canales por los cuales se ofrecen los servicios financieros, en las zonas urbanas son las oficinas principales, las sucursales, los canales electrónicos, los subagentes bancarios y las estafetas (puntos de pago). Por su parte, en las zonas rurales los canales de distribución están representados por las sucursales, los canales electrónicos y los subagentes bancarios. Existen marcadas diferencias en la manera en que se ofrecen los servicios financieros entre los ámbitos rural y urbano.

Como se indicó anteriormente, la introducción de la figura del subagente bancario representa un canal de distribución nuevo y potencialmente de gran importancia, sobre todo para los segmentos que sufren graves restricciones para acceder a los productos y servicios financieros por la falta de presencia física de los intermediarios financieros en sus localidades. Los intermediarios financieros que pueden ofrecer sus productos por medio de los subagentes son los bancos múltiples, las asociaciones de ahorro y préstamo, y los bancos de ahorro y crédito. Como subagentes pueden actuar farmacias, hoteles, centros de servicios de telecomunicaciones, supermercados, minimercados, colmados, ferreterías y otras tiendas que se consideren convenientes.

El recibimiento de todo tipo de pagos, depósitos, retiros, tramitaciones y solicitudes de crédito, y de otros tipos de productos y servicios es lo que transforma al subagente bancario en una cuasisucursal bancaria que está presente en poblaciones rurales pobres y aisladas de los grandes centros urbanos para que los usuarios que ya han abierto cuentas hagan todas las transacciones relacionadas con las operaciones bancarias. Sin embargo, el hecho de que no se incluya la apertura de cuentas entre sus servicios limita el efecto en la inclusión financiera a una mayor intensidad en el uso de los servicios financieros de parte de quienes previamente ya han tenido acceso a algún producto financiero.

De acuerdo con Piña (2016), en enero de 2016 existían en total 3.106 subagentes, utilizados por nueve instituciones financieras, que a su vez representaban cerca del $80 \%$ de todos los activos del sistema de intermediación financiera.

\section{Sistemas de pagos}

El acceso a los medios de pago es una condición necesaria para que exista una inclusión financiera efectiva, ya que el uso de cualquier otro medio diferente al efectivo requiere utilizar una cuenta de débito o de depósito, o algún producto de crédito. En la República Dominicana, la expansión de los medios de pago ha tenido un efecto significativo en la inclusión financiera. A continuación, se presenta un análisis descriptivo del Sistema de Pagos y Liquidación de Valores de la República Dominicana y de su modernización a fin de ampliar el acceso a servicios de pagos y así aumentar la inclusión financiera. 
En los sistemas de pagos minoristas de la República Dominicana, actúan tres figuras: las entidades de intermediación financiera, los clientes o usuarios, y los administradores de sistemas de pago o de liquidación de valores. En cuanto a la forma en que cada uno de estos accede a los sistemas de pagos minoristas, las entidades de intermediación financiera firman acuerdos con los administradores de sistemas de pagos que operan los sistemas de pagos minoristas. En el caso de los clientes, solo deben contar con uno de los instrumentos de pago definidos en la reglamentación — provisto por su propia entidad de intermediación financiera-, que puede ser utilizado en cualquiera de los sistemas de pago minoristas existentes. Los administradores de sistemas de pago deben cumplir con los requisitos establecidos en el Reglamento del Sistema de Pagos y sus instructivos de aplicación para ser autorizados a operar un sistema de pagos minorista.

Es importante mencionar que la reglamentación y el funcionamiento del Sistema de Pagos y Liquidación de Valores de la República Dominicana (SIPARD) es responsabilidad de la Junta Monetaria y que todas las entidades de intermediación financiera están obligatoriamente adscritas al sistema; además, no pueden organizarse sistemas multilaterales de compensación y liquidación de medios de pago fuera de dicho sistema.

En el cuadro VI.6 se resume la evolución reciente de la utilización de medios de pago, donde puede observarse que la tarjeta de débito es por mucho el instrumento electrónico de pago más utilizado: supera a la tarjeta de crédito por más de un millón de unidades. Sin embargo, cabe tomar en cuenta que, si bien ello entraña un aumento de la cantidad de personas bancarizadas, la intensidad en el uso de los servicios financieros no aumenta de la misma forma, ya que una parte de los usuarios de cuenta de nómina se limita a recibir su pago mediante este mecanismo y luego retira el efectivo para realizar pagos en dinero contante.

Al analizar los datos del cuadro VI.6, también se debe tomar en consideración el pago de la nómina pública y de los subsidios gubernamentales. Según la encuesta laboral del Banco Central de la República Dominicana, la fuerza laboral empleada en el sector público al inicio de 2016 era de 603.919 personas y las tarjetas para pagos de subsidios gubernamentales llegaban a las 986.224 unidades. Por ende, si se tienen en cuenta estos datos y si del número de tarjetas de débito vigentes en dicha fecha se resta la suma de ambas cifras, entonces se concluye que la cantidad de tarjetas de débito obtenidas por individuos que no son empleados públicos y que no reciben subsidios gubernamentales pero que sí obtuvieron dicho instrumento para pagos privados asciende a 1.718.940, cifra significativamente menor al número de tarjetas de crédito. 


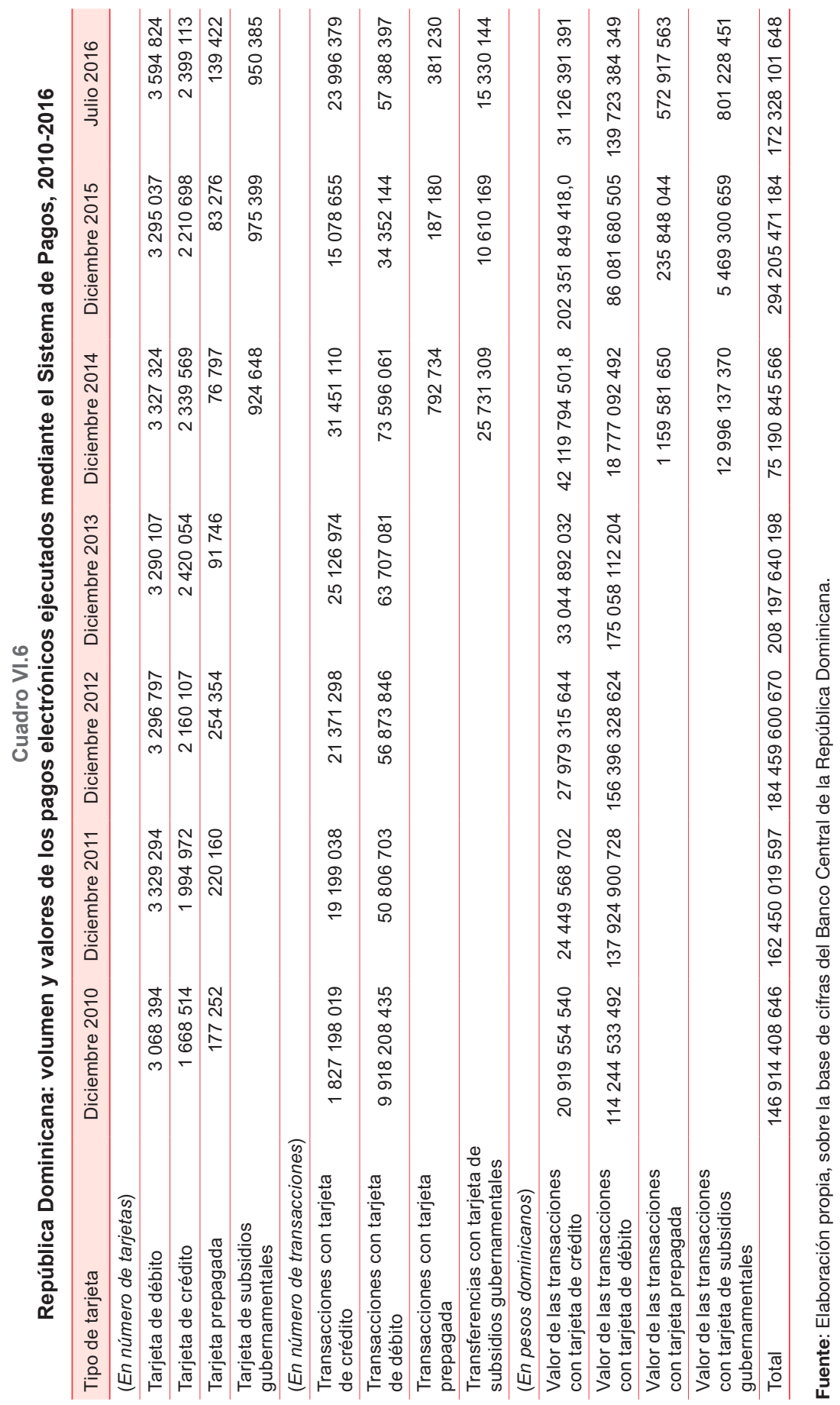


En cuanto al acceso general a los medios de pagos - un prerrequisito para la inclusión financiera, al igual que el acceso a productos de ahorro y de crédito-, la masificación y la cobertura de pagos y compensaciones electrónicos entre entidades registraron una significativa aceleración, como ya se explicó, con la entrada en vigor del Sistema de Liquidación Bruta en Tiempo Real en 2008. También experimentó un crecimiento pronunciado la disponibilidad de medios de pagos, ahorros y créditos electrónicos, que repercutió en la inclusión financiera.

\section{Mecanismos de protección de usuarios}

La protección de los usuarios es un factor fundamental en la inclusión financiera. Al incrementar la confianza de los consumidores, las reglamentaciones tendientes a intensificar la protección de los usuarios de productos financieros deberían también aumentar la inclusión financiera, pues más personas se incorporarán al sistema como usuarios habituales.

El Reglamento de Protección a los Usuarios de Servicios y Productos Financieros (RPUPSF) fue aprobado en enero de 2006, pero fue modificado en septiembre de 2015 para incluir un mayor número de mecanismos de protección e intensificar los existentes. En este sentido, las modificaciones introdujeron procedimientos de quejas internas y requisitos sobre la revelación adecuada de los costos de los servicios financieros, los derechos de los consumidores y las obligaciones de los proveedores de servicios financieros, así como la prohibición de prácticas abusivas y ventas agresivas, y el fortalecimiento de la Comisión Nacional de Defensa de la Competencia (ProCompetencia).

\section{Infraestructura complementaria}

En la República Dominicana los sistemas de información de crédito operan por conducto de las sociedades de información crediticia. Estos sistemas recopilan información de todos los deudores del sistema financiero, así como acerca de los servicios que tienen contratados con diversas compañías. Esta información es confidencial y a ella solo pueden acceder sus propios titulares y entidades de información para fines de manejo de portafolio y evaluación de expedientes.

Dada la preponderancia de la producción agrícola en las zonas rurales y el posible uso de esta producción como garantía, un tema de particular importancia en términos de la infraestructura complementaria para el sector rural es la existencia de una infraestructura de almacenamiento de productos básicos. Así, existen los llamados centros de acopios en sectores como el lechero y de algunos productos agrícolas, en su mayoría formados por fuerzas del sector privado y, en algunos casos, por alianzas públicoprivadas con apoyo de algunas entidades gubernamentales. 
En cuanto a la conectividad, las principales problemáticas, sobre todo para las poblaciones rurales, radican en la limitada accesibilidad a las carreteras dadas las condiciones de los caminos vecinales. Otro de los problemas que pueden enfrentar los habitantes de las zonas rurales está ligado al acceso a servicios básicos, como el agua y la energía eléctrica.

En el caso de controversias, en la República Dominicana existen tres mecanismos de resolución de orden administrativo: la liquidación forzosa, el Mecanismo Subsidiario de Liquidación Administrativa y el Mecanismo Subsidiario de Liquidación Voluntaria. Por su parte, los criterios de priorización de acreedores se encuentran consignados en la Ley Monetaria y Financiera, que coloca en primer lugar los recursos depositados provenientes del sector privado.

Los tipos de activos que pueden ser utilizados como garantía son los activos financieros, los bienes raíces, los bienes de capital, los inventarios, los medios de transporte y las garantías fiduciarias. Los principales retos para utilizar bienes como garantía son su registro, seguimiento, custodia y valorización.

\section{Instrumentos de política pública}

\section{Banca de desarrollo}

El principal banco de desarrollo enfocado en el ámbito rural dominicano es el Banco Agrícola de la República Dominicana, que fue creado para financiar la actividad agropecuaria en general y, aunque ha otorgado y otorga crédito a los medianos y grandes productores, su segmento de mercado incluye a los pequeños agricultores.

Además, existen iniciativas del sector público que incluyen el otorgamiento de financiamiento a microempresas y pymes mediante una institución llamada Banca Solidaria, que fue creada en 2012. Dicha institución gestiona un programa especializado en microfinanzas, cuya meta es facilitar el financiamiento y proveer servicios de educación financiera a los microempresarios con el fin de apoyar su desarrollo e inclusión financiera.

Del mismo modo, existe el Fondo Especial para el Desarrollo Agropecuario (FEDA), que fue fundado en 1972 y ejecuta acciones de política para promover el desarrollo rural sostenible, entre las que puede mencionarse el apoyo mediante el financiamiento de las pequeñas empresas y las microempresas agropecuarias. El FEDA ha diseñado una política de crédito que proporciona financiamiento a una baja tasa de interés ( $5 \%$ anual) y sin ningún tipo de garantía, con un fondo disponible de 125 millones de pesos para financiar actividades que benefician a pequeños productores asociados. 


\section{Política regulatoria y de supervisión}

Al analizar el caso de la República Dominicana, se pueden destacar varias áreas específicas donde la política pública ha podido incidir de manera significativa sobre la inclusión financiera. Entre ellas sobresale la promulgación y aplicación de algunos reglamentos financieros que tienen una relación positiva con la inclusión financiera. El Reglamento de Evaluación de Activos, el Reglamento de Protección a los Usuarios de Productos y Servicios Financieros, y el Reglamento de Microcréditos son los tres con el mayor efecto directo en la inclusión financiera.

El Reglamento de Evaluación de Activos de 2004 ha tenido dos grandes modificaciones, con profundas implicaciones para la inclusión financiera de las microempresas y los pequeños empresarios mediante el acceso al crédito de las instituciones financieras. La primera modificación, efectuada en julio de 2009, llevó el límite de crédito para la clasificación de los pequeños deudores comerciales a los 15,0 millones de pesos. A partir de esta enmienda, el riesgo crediticio de todos los que adeudaban hasta dicho monto pasó a ser evaluado sobre la base de la morosidad de sus compromisos de pago. La principal consecuencia de esta modificación en el aumento de la inclusión financiera a través de los productos de crédito se produjo mediante las instituciones crediticias especializadas. En 2010 la cartera de crédito de las microfinancieras privadas ADEMI y ADOPEM aumentó un 19,5\%.

La segunda modificación se llevó a cabo en marzo de 2013: se aumentó a 25,0 millones de pesos el límite de crédito para la clasificación del riesgo crediticio de los pequeños deudores comerciales sobre la base de la morosidad de sus compromisos de pagos. En esta modificación se toma en cuenta por primera vez el debido equilibrio entre la promoción y el fomento de las pymes, y el riesgo de las entidades de intermediación.

Por su parte, las modificaciones al Reglamento de Protección a los Usuarios de Productos y Servicios Financieros de septiembre 2015 introdujeron procedimientos de quejas internas y requisitos sobre la revelación adecuada de los costos de los servicios financieros, los derechos de los consumidores y las obligaciones de los proveedores de servicios financieros, así como la prohibición de prácticas abusivas y ventas agresivas, y el fortalecimiento de la Comisión ProCompetencia.

El tercer reglamento con un impacto directo en la inclusión financiera es el Reglamento de Microcréditos, aprobado en 2014, cuyo principal efecto es una flexibilización que permite que los microcréditos sean evaluados sobre la base de su morosidad y la exención de la documentación formal para determinar el riesgo crediticio. 
Las acciones reglamentarias tendientes a facilitar y promover el financiamiento otorgado a las microempresas y las pequeñas empresas han tenido un impacto fundamental en el acceso a productos de créditos. Las flexibilizaciones del REA y las acciones del Banco de Reservas (por conducto de su programa Banca Solidaria) en materia de financiamiento a la microempresa han sido un factor determinante de la duplicación del microcrédito entre 2009 y 2015, tal como puede observarse en el cuadro VI.7.

\section{Cuadro VI.7}

\section{República Dominicana: evaluación de la cartera de instituciones especializadas en microcréditos, 2009-2015 \\ (En millones de pesos dominicanos)}

\begin{tabular}{lccccccc}
\hline $\begin{array}{l}\text { Entidades } \\
\text { especializadas }\end{array}$ & $\begin{array}{c}\text { Diciembre } \\
2009\end{array}$ & $\begin{array}{c}\text { Diciembre } \\
2010\end{array}$ & $\begin{array}{c}\text { Diciembre } \\
2011\end{array}$ & $\begin{array}{c}\text { Diciembre } \\
2012\end{array}$ & $\begin{array}{c}\text { Diciembre } \\
2013\end{array}$ & $\begin{array}{c}\text { Diciembre } \\
2014\end{array}$ & $\begin{array}{c}\text { Diciembre } \\
2015\end{array}$ \\
\hline ADEMI & 6127,13 & 7319,57 & 8574,86 & 9574,66 & 10910,38 & 12157,78 & 13260,84 \\
\hline ADOPEM & 1777,84 & 2131,24 & 2598,37 & 2994,28 & 3603,69 & 4335,44 & 5164,05 \\
\hline $\begin{array}{l}\text { Total de } \\
\text { instituciones } \\
\text { privadas }\end{array}$ & 7904,97 & 9450,82 & 11173,23 & 12568,93 & 14514,07 & 16493,22 & 18424,89 \\
\hline $\begin{array}{l}\text { Total de } \\
\text { microcréditos }\end{array}$ & 11422,20 & 10252,20 & 11842,20 & 11598,40 & 13075,60 & 16972,80 & 22701,10 \\
\hline
\end{tabular}

Fuente: Elaboración propia, sobre la base de datos de estadísticas financieras de las instituciones.

\section{Desarrollo de capacidades}

La educación financiera y el desarrollo de capacidades para diseñar una estrategia de inclusión financiera son dos metas transversales y necesarias para garantizar su éxito. Tal como se indicó anteriormente, las autoridades dominicanas ya han avanzado en la formulación de una estrategia de educación financiera. El objetivo de dicha iniciativa es lograr un mayor nivel de conciencia entre la población dominicana en cuanto a sus derechos y oportunidades relacionados con el uso del sistema financiero, de manera que se sienta incluida y se creen las bases para un mayor nivel de desarrollo económico.

En lo que se refiere a las capacidades necesarias para administrar una estrategia de inclusión, hay que destacar que en la introducción al informe de la primera Encuesta de Cultura Económica y Financiera (BCRD, 2014a), se establece que en el ámbito de planificación, las autoridades del Banco Central de la República Dominicana, con el apoyo del Banco Interamericano de Desarrollo y del Departamento del Tesoro de los Estados Unidos, convocaron a finales de 2013 a otras entidades públicas y privadas para conformar la Mesa de Trabajo para la Elaboración de una Estrategia Nacional de Cultura Económica y Financiera (ENCEF). El liderazgo del Banco Central de la República Dominicana en la ejecución de la ENCEF representa un factor que aumenta su posibilidad de éxito. 
En cuanto a la educación financiera como condición necesaria para garantizar el éxito de una estrategia de inclusión, cabe señalar que el uso (demanda de los servicios financieros) correcto, la intensidad y la cantidad de los productos financieros son factores que dependen esencialmente de los conocimientos y la cultura que los nuevos usuarios incorporados al sistema tengan sobre dichos productos y servicios. Al respecto, hay que señalar como primer elemento la campaña masiva de la Superintendencia de Bancos de la República Dominicana en cuanto a la utilización correcta de las tarjetas de crédito y los préstamos personales.

Aunque la campaña dirigida a educar la población en el mejor uso de los productos financieros es ejecutada por la Superintendencia de Bancos, es menester resaltar que el proceso de educación formal de los docentes que deben transmitir los conocimientos básicos de la cultura financiera estuvo y está encabezado por el Banco Central.

Mediante alianzas público-privadas y alianzas académicas con seis universidades del país, el Ministerio de Industria, Comercio y MiPymes ha formulado, por su parte, una estrategia para dar servicios de desarrollo empresarial por medio de los Centros PYMES, con las siguientes ubicaciones estratégicas: tres centros en la ciudad de Santo Domingo - Universidad Nacional Pedro Henríquez Ureña (UNPHU), Universidad Iberoamericana (UNIBE) y Universidad Autónoma de Santo Domingo (UASD)—, uno en la región del Cibao - Instituto Superior de Agricultura (ISA) - , uno en el este del país -UASD-Hato Mayor-y, por último, uno en el sur - Universidad Católica Tecnológica de Barahona (UCATEBA)—. Por medio de los Centros PYMES se brindan servicios de capacitación, asistencia técnica, asesoría empresarial y vinculación. Con esta estrategia se pretende incentivar y promover las buenas prácticas de producción y otras herramientas necesarias entre los empresarios rurales ubicados en la cercanía de estas universidades.

\section{E. Conclusiones y recomendaciones}

Aunque en la República Dominicana aún no existe una estrategia integral de inclusión financiera, tal como se ha reiterado a lo largo del documento, algunos elementos están implícitos en los objetivos específicos y en las líneas de acción de la Estrategia Nacional de Desarrollo (END) 2030. Por tanto, la formulación de una estrategia de inclusión financiera debería tomar en cuenta lo establecido en la END y aprovechar los instrumentos disponibles que promueven dicha inclusión. En opinión del autor, el objetivo de la estrategia general de inclusión financiera debería apuntar, en particular, a disminuir la brecha entre los grupos poblacionales rurales y urbanos, y entre los grupos de altos ingresos y de ingresos medianos y bajos, en lo atinente al acceso a los servicios financieros de crédito, ahorro y pagos, y 
su utilización. La estrategia también debería estar orientada a proteger el acceso de estos grupos vulnerables a dichos servicios sin aumentar el riesgo de los proveedores que los prestan. Para ello, es necesario cumplir con los siguientes objetivos específicos:

- aumentar la participación de la población rural en una amplia gama de servicios financieros ofrecidos por el sistema financiero formal y reducir la brecha existente en 2014 con respecto a la población urbana;

- incrementar la participación de las cooperativas de ahorro y crédito en el crédito total del sistema financiero formal y reducir sus riesgos mediante una reforma que permita su regulación y supervisión como entidades de intermediación financiera;

- impulsar la participación del Banco Agrícola en el crédito rural total mediante una transformación y una nueva arquitectura institucional que le permite actuar como banca de segundo piso, y fomentar una mayor especialización en los microcréditos rurales;

- fomentar la participación de los microcréditos en los créditos totales del sistema financiero formal mediante una reforma de las normas y reglamentos vigentes, sin aumentar el riesgo de las entidades proveedoras de microcréditos y otros servicios financieros;

- ampliar el acceso a los medios de pago electrónico y brindar protección a quienes estén en una situación de vulnerabilidad que les dificulte acceder a los servicios, y

- mejorar el grado de conocimiento de la población sobre los servicios financieros mediante acciones explicitas de educación financiera.

La viabilidad de la consecución del objetivo dirigido a aumentar la inclusión financiera de la población rural exige crear un marco legal para regular y supervisar las cooperativas, y una nueva arquitectura del Banco Agrícola y del FEDA, así como adecuar las normas y los reglamentos relativos a la inclusión financiera, incluida la formulación de un programa de actividades de educación financiera.

\section{Reforma para la regulación y supervisión de las cooperativas de ahorro y crédito}

Como se planteó, las cooperativas de ahorro y crédito son demasiado importantes como para no tenerlas en cuenta en una estrategia nacional de inclusión financiera. Aunque dichas entidades realizan actividades de intermediación financiera, no son reguladas ni supervisadas por la Autoridad Monetaria y Financiera, pese a que muchas tienen dos y hasta tres veces más activos que las entidades de intermediación financiera debidamente reguladas. 
Si se toma en cuenta su alto grado de penetración en las poblaciones rurales y su gran participación en la totalidad del mercado financiero, y si se parte de la hipótesis de que la debida regulación y supervisión aumenta la confianza y la demanda pública de los servicios y productos de las cooperativas, tal vez se necesite una reforma orientada al logro de tales condiciones para garantizar el éxito de una estrategia de inclusión financiera. La exclusión que permite el marco regulatorio y de supervisión vigente limita el papel que pueden desempeñar en el fomento de la inclusión financiera, ya que limita la oferta de productos disponibles. Al no contar con una cuenta de compensación del Banco Central de la República Dominicana, no pueden participar en el Sistema de Pagos, lo que a su vez les impide ofrecer medios electrónicos de pago. Finalmente, al no existir información sistematizada acerca de su desempeño, los socios tienen pocos elementos para evaluar la solidez de las instituciones.

Del análisis del marco nacional y de las experiencias internacionales surgen dos alternativas. La primera es incluir las cooperativas en el ámbito de aplicación de la Ley Monetaria y Financiera, con lo cual estarían en las mismas condiciones que las demás entidades de intermediación financiera. La segunda es ubicar a las cooperativas bajo la regulación y supervisión de la Autoridad Monetaria y Financiera, pero con una ley especial que tome en cuenta el carácter diferenciado del énfasis en el ahorro y el crédito rural, y que permita su conexión al Sistema de Pagos con cuentas de compensación real y para productos electrónicos.

\section{Nueva arquitectura del Banco Agrícola y del FEDA}

El Banco Agrícola y el Fondo Especial para el Desarrollo Agropecuario (FEDA) son dos instituciones con alto impacto en la inclusión financiera de la población rural, por lo que una reforma orientada a mejorar la focalización de ambas instituciones en los grupos rurales pobres y excluidos del crédito bancario sería también una condición necesaria para lograr el éxito e instrumentar una verdadera estrategia de inclusión financiera realmente eficaz.

Un primer paso consiste en formular una política de financiamiento del FEDA mediante las visitas sorpresa ${ }^{6}$, cuyos objetivos deben estar alineados con la política de desarrollo rural del Gobierno y el resto de las políticas públicas. Una primera condición necesaria para alcanzar ese objetivo es que los grupos que son objeto de estas visitas y sus proyectos financiables sean coherentes con la política de financiamiento del Banco Agrícola, pues al final de cuentas quien mantiene y administra una cartera de préstamos para los pequeños productores rurales es esta entidad. Una vez que exista una política de ejecución de las visitas sorpresa y de la consiguiente política

Las visitas sorpresa se refieren a visitas realizadas por el Presidente de la República a las diferentes regiones para iniciar diálogos con diversos actores. 
de financiamiento del FEDA, será menester realizar una transformación del Banco Agrícola orientada a convertirlo en un banco de segundo piso, de modo que mantenga en cartera solo los financiamientos de profundo impacto social y de alto riesgo, como lo son efectivamente los financiamientos del FEDA y las visitas sorpresa.

La reforma tendiente a crear un marco para la regulación y la supervisión de las cooperativas, y la transformación del Banco Agrícola en un banco de segundo piso que prioriza los financiamientos de profundo impacto social y de alto riesgo representan dos reformas que deberían complementarse con una revisión de los reglamentos financieros que afectan la inclusión financiera: el Reglamento de Evaluación de Activos (REA), el Reglamento del Subagente Bancario (RSB), el Reglamento de Microcréditos (RM) y el Reglamento de Protección al Usuario de Productos y Servicios Financieros (RPUPSF).

\section{Bibliografía}

Banco Agrícola (2015), Evolución histórica del Banco Agrícola, 1945-2015, Santo Domingo. (2008), Propuesta para la creación de un sistema que garantice el fomento y el financiamiento de la producción agropecuaria y forestal en la República Dominicana, Comisión de Reforma.

Banco Mundial (2016), The Global Findex Database [en línea] http://datatopics. worldbank.org/financialinclusion/.

BCRD (Banco Central de la República Dominicana) (2015), “Reglamento de Protección al Usuario de los Productos y Servicios Financieros", Aviso. (2014a), 1ra. Encuesta de Cultura Económica y Financiera de la República Dominicana 2014, Santo Domingo. (2014b), "Reglamento de Microcréditos", Aviso. (2013), "Reglamento de Subagente Bancario", Aviso. (2004), "Reglamento de Evaluación de Activos", Aviso.

Demirguc-Kunt, A. y otros (2015), "The Global Findex Database 2014: measuring financial inclusion around the World", Policy Research Working Paper, $\mathrm{N}^{\circ}$ 7255, Washington, D.C., Banco Mundial.

Piña, L. (2016), “Subagentes: los colmados y pequeños negocios convertidos en brazos de la banca", Argentarium tu portal financiero, 1 de febrero [en línea] https:/ / www. argentarium.com/veedor/reportajes/14271-los-colmados-y-pequenos-negociosconvertidos-en-brazos-de-la-banca/. 

Capítulo VII

\section{Arquitectura de la inclusión financiera rural en México}

Pilar Campos ${ }^{1}$

\section{Introducción}

A partir de 2001 aparecen, por primera vez en México, una serie de cambios institucionales orientados a incorporar a segmentos amplios de la población al sistema financiero formal. No obstante, la inclusión financiera, en general, y la rural, en particular, muestran todavía marcados rezagos pese a los profundos cambios experimentados por el sistema financiero durante el presente siglo y la transformación del andamiaje institucional que culmina con la promulgación de la reforma financiera de 2014, en la que se destacan la formalización de un gran número de intermediarios financieros y la reorientación de la banca de desarrollo, así como el fortalecimiento institucional para la regulación y la supervisión financieras.

En México se comienza a hablar de inclusión financiera como concepto de política pública en 2009 y se define oficialmente en 2011 como "el acceso y uso de servicios financieros bajo una regulación apropiada que garantice esquemas de protección al consumidor y promueva la educación financiera para mejorar las capacidades financieras de todos los segmentos de la población"

Investigadora independiente graduada del Instituto Tecnológico Autónomo de México y de la London School of Economics and Political Science. 
(México, Presidencia de la República, 2011). No obstante la definición formal, aún existe confusión por parte de algunos tomadores de decisiones tanto en el ámbito público como en el privado respecto al carácter integral del concepto de inclusión financiera.

En lo que concierne a indicadores de oferta, de acuerdo con cifras del Fondo Monetario Internacional (FMI, 2015), México muestra un marcado rezago no solo respecto a países con un nivel de desarrollo comparable, sino también respecto a otros con niveles más bajos. Así, en 2014 México se ubicó por debajo del promedio de América Latina y el Caribe en cuanto al número de sucursales de entidades financieras: 1,5 por cada 10.000 adultos frente a un promedio regional de 2,6. Lo mismo ocurría con la disponibilidad de cajeros automáticos, ya que había 4,9 cajeros por cada 10.000 adultos, por debajo de los 5,2 disponibles a nivel regional. En el ámbito rural, se acentuaba el rezago, ya que en el mismo año el número de sucursales y de cajeros fueron de apenas 0,9 y 0,7 , respectivamente, por cada 10.000 adultos en municipios con menos de 50.000 habitantes.

Los retos que enfrentan tanto la población rural como las instituciones financieras que buscan atenderla son diversos. Entre ellos sobresale una actividad económica con una marcada estacionalidad, así como una creciente incertidumbre asociada al impacto del cambio climático; una baja densidad poblacional que implica significativos costos de transacción para los usuarios y las instituciones; una creciente, pero aún escasa, conectividad; problemas graves de inseguridad; deterioro y pulverización de la tierra; desplazamientos y migración; limitados encadenamientos productivos que limitan el acceso a mercados clave; una alta volatilidad de los precios de los insumos, que genera incertidumbre en la capacidad de pago y la planeación de las empresas. Aunada a estos factores, la escasa penetración del sector financiero, incluso en núcleos urbanos, provoca que las instituciones financieras continúen teniendo ventajas al expandir sus servicios a sectores urbanos de ingresos medios y bajos (Trivelli y Venero, 2007).

En México es necesario hablar de bancas de desarrollo cuando se hace referencia a dicha figura. Tan solo en el sector rural, operan la Financiera Nacional de Desarrollo Agropecuario, Rural, Forestal y Pesquero (FND) y el Banco del Ahorro Nacional y Servicios Financieros (BANSEFI), los que ofrecen programas de crédito, ahorro, garantías, asistencia técnica y educación financiera, entre otros servicios ${ }^{2}$. Además, existen los Fideicomisos Instituidos en Relación con la Agricultura (FIRA), que llevan adelante algunos programas

En México hay un total de seis instituciones de banca de desarrollo y una financiera rural: el Banco Nacional de Obras y Servicios Públicos (BANOBRAS), Nacional Financiera (NAFIN), el Banco Nacional de Comercio Exterior (BANCOMEXT), el Banco Nacional del Ejército, Fuerza Aérea y Armada (BANJÉRCITO), el Banco del Ahorro Nacional y Servicios Financieros (BANSEFI), la Sociedad Hipotecaria Federal (SHF) y la Financiera Nacional de Desarrollo Agropecuario, Rural, Forestal y Pesquero (FND). 
que fomentan el crédito rural mediante diferentes apoyos. Asimismo, otros fondos públicos, principalmente de la Secretaría de Economía y de la Secretaría de Agricultura, Ganadería, Desarrollo Rural, Pesca y Alimentación (SAGARPA), mantienen como fiduciario a la banca de desarrollo y brindan apoyos en el sector rural.

Reconociendo los rezagos en esta materia, el Gobierno de Enrique Peña Nieto envió en 2013 la reforma financiera al Congreso de la Unión, que fue promulgada en enero de 2014. Con ella, se buscó impulsar la inclusión financiera a partir de cinco acciones: la ampliación de productos y canales de distribución disponibles para las Entidades de Ahorro y Crédito Popular, el fortalecimiento de la transparencia y protección al consumidor, una mayor competencia en las redes de medios de disposición, la redefinición del mandato de la banca de desarrollo para fortalecer su enfoque hacia la atención de grupos prioritarios y la modificación del marco legal para que las instituciones privadas ofrezcan mayor crédito, especialmente a las microempresas y las pymes $^{3} 45$.

Posteriormente, en junio de 2016 se presentó la Política Nacional de Inclusión Financiera (PNIF) emitida por el Consejo Nacional de Inclusión Financiera (CONAIF), que está articulada en torno a seis ejes: el fortalecimiento de capacidades de los usuarios de servicios financieros, el aprovechamiento de innovaciones tecnológicas para la inclusión financiera, el desarrollo de infraestructura financiera en zonas desatendidas, el fomento de la oferta y uso de servicios financieros formales para la población subatendida y excluida, el fortalecimiento de la confianza en el sector financiero formal, y la generación de datos y mediciones para evaluar los esfuerzos de inclusión financiera.

A continuación, se realiza un diagnóstico de la arquitectura de la inclusión financiera en México, comenzando, en la sección A, con una descripción crítica de las leyes y figuras existentes, y sus ventajas y contradicciones en términos de la inclusión financiera rural. Posteriormente, en la sección B se analiza el papel de la banca de desarrollo en la inclusión financiera rural, mientras que en la sección $C$ se abordan los retos que enfrentan tanto los usuarios como los proveedores de servicios financieros en el ámbito rural. Finalmente, la sección D concluye con algunas reflexiones de política pública.

Las Sociedades Cooperativas de Ahorro y Préstamo (SOCAP), las Sociedades Financieras Populares (SOFIPO) y las Sociedades Financieras Comunitarias (SOFINCO) constituyen lo que se conoce como Entidades de Ahorro y Crédito Popular.

4 Los corresponsales fueron autorizados en 2010 solo para la banca comercial. A partir de la reciente reforma financiera, las Entidades de Ahorro y Crédito Popular también pueden expandir sus servicios a través de esta modalidad.

5 Desde el gobierno de Felipe Calderón (2006-2012) se definen los grupos prioritarios como aquellos que no cuentan con ingresos suficientes para enfrentar su condición de vulnerabilidad y que tienen características y necesidades específicas. Entre ellos, destacan los pueblos y comunidades indígenas, los jornaleros agrícolas, las mujeres y los adultos mayores, así como los niños, niñas y jóvenes en riesgo de calle. 


\section{A. La arquitectura institucional de la inclusión financiera rural}

En México los cambios más significativos para llevar los servicios financieros a la población típicamente excluida de los oferentes tradicionales - banca comercial y de desarrollo- inician en los primeros años del siglo XXI. En 2001 y 2002, en coincidencia con el cambio de gobierno y de régimen político en el país, sucedieron dos procesos significativos. El primero fue la aprobación de la Ley de Ahorro y Crédito Popular para la formalización de entidades no bancarias que ofrecían servicios financieros a población de ingresos medios y bajos. El segundo consistió en concebir un papel diferente para la banca de desarrollo y su transformación hacia el segundo piso. De este modo, el Patronato del Ahorro Nacional (PAHNAL) se transformó en el BANSEFI y el Banco Nacional de Crédito Rural (BANRURAL) se convirtió en la Financiera Rural (posteriormente Financiera Nacional de Desarrollo Agropecuario, Rural, Forestal y Pesquero (FND)).

Desde el inicio de las discusiones que dieron origen a la Ley de Ahorro y Crédito Popular, la preocupación por el ámbito rural fue crucial. El principal interés radicaba en proteger el ahorro y expandir los servicios financieros regulados a las localidades rurales y marginadas del país a la luz de los fraudes y quiebras de algunas sociedades de ahorro y préstamo en la década de 1990. Asimismo, se privilegiaba el ahorro como vehículo de inclusión, lo que permitiría atender a las poblaciones de mayor pobreza, acumular y movilizar ahorro local para el desarrollo de las comunidades y que el ahorro fuera la base para generar hábitos y disciplinas financieros para el uso prudente del crédito formal. Para ello, era fundamental contar con entidades autorizadas para captar ahorro.

El argumento de regular y fortalecer a los intermediarios financieros no bancarios se justificaba, entre otros, por la falta de interés que hasta ese momento había mostrado la banca comercial por atender a poblaciones marginadas, incluso en áreas urbanas. En el país, además, había instituciones no bancarias que llevaban décadas ofreciendo servicios financieros, como las cajas de ahorro y, más recientemente, organizaciones que en esos años difundían las innovaciones del microcrédito.

Hacia mediados de la década de 2000, con la reorientación de la banca de desarrollo hacia servicios de segundo piso, la Secretaría de Hacienda y Crédito Público (SHCP) consideró necesario contar con más entidades dispersoras de crédito. Para ello, se creó la figura jurídica de Sociedad Financiera de Objeto Múltiple, Entidad No Regulada (SOFOM E.N.R.), que, además de no estar limitada a un producto específico de crédito, tampoco requería estar 
asociada a grupos financieros ni estaría regulada por la Comisión Nacional Bancaria y de Valores (CNBV) ${ }^{6}$.

En el cuadro VII.1 se resumen las figuras jurídicas que, además de la banca múltiple, son relevantes en México para la inclusión financiera, así como las leyes que las rigen, cuándo tuvieron inicio o fueron modificadas, si son reguladas y si están bajo una supervisión directa o una supervisión auxiliar ejercida por la autoridad ${ }^{7}$.

Cuadro VII.1

\section{Resumen de la arquitectura de leyes y oferentes financieros relacionados} con la inclusión financiera ${ }^{a}$

\begin{tabular}{|c|c|c|c|c|c|}
\hline Leyes o normas & Figuras & $\begin{array}{l}\text { Inicio de la Ley } \\
\text { o las figuras }\end{array}$ & $\begin{array}{l}\text { Captan } \\
\text { depósitos }\end{array}$ & $\begin{array}{l}\text { Tipo de } \\
\text { supervisión } \\
\text { de la } \\
\text { Comisión } \\
\text { Nacional } \\
\text { Bancaria } \\
\text { y de Valores }\end{array}$ & Reguladas \\
\hline $\begin{array}{l}\text { Ley de Ahorro y } \\
\text { Crédito Popular }\end{array}$ & $\begin{array}{l}\text { SOFIPO y } \\
\text { SOFINCO }\end{array}$ & $\begin{array}{l}2001 \text { y } \\
\text { modificada } \\
\text { en } 2009\end{array}$ & Sí & Auxiliar & Sí \\
\hline $\begin{array}{l}\text { Ley para Regular } \\
\text { las Actividades de } \\
\text { las Sociedades } \\
\text { Cooperativas de } \\
\text { Ahorro y Préstamo }\end{array}$ & $\begin{array}{l}\text { Sociedades } \\
\text { Cooperativas } \\
\text { de Ahorro } \\
\text { y Préstamo } \\
(\text { SOCAP) }\end{array}$ & 2009 & Sí & Auxiliar & Sí \\
\hline $\begin{array}{l}\text { Ley General de } \\
\text { Organizaciones } \\
\text { y Actividades } \\
\text { Auxiliares del } \\
\text { Crédito }\end{array}$ & $\begin{array}{l}\text { Sociedades } \\
\text { Financieras de } \\
\text { Objeto Múltiple, } \\
\text { Entidad No } \\
\text { Regulada } \\
\text { (SOFOM E.N.R.) }^{\text {b }}\end{array}$ & 2006 & No & $\mathrm{N} / \mathrm{A}$ & No \\
\hline $\begin{array}{l}\text { Ley de Instituciones } \\
\text { de Crédito }\end{array}$ & Bancos de nicho & $\begin{array}{l}2008 \\
\text { (modificada) }\end{array}$ & Sí & Directa & Sí \\
\hline $\begin{array}{l}\text { Ley de Instituciones } \\
\text { de Crédito }\end{array}$ & $\begin{array}{l}\text { Corresponsales } \\
\text { bancarios }\end{array}$ & $\begin{array}{l}2009 \\
\text { (modificada) }\end{array}$ & Sí & Directa & Sí \\
\hline
\end{tabular}

Fuente: Elaboración propia.

a Todas las instituciones están sujetas a la supervisión de la Comisión Nacional para la Protección y Defensa de los Usuarios de Servicios Financieros (CONDUSEF).

b La SOFOM Entidad No Regulada (E.N.R.) está sujeta a ciertas disposiciones de la Ley General de Organizaciones y Actividades Auxiliares del Crédito y a las que el Banco de México emita al respecto.

Además, las cooperativas financieras se rigen por la Ley General de Sociedades Cooperativas.

d La Ley de Instituciones de Crédito, equivalente a las leyes de bancos de otros países, tiene como objeto legislar sobre instituciones de banca múltiple, banca de desarrollo y bancos de nicho.

6 Anteriormente se contó, primero, con Sociedades Financieras de Objeto Limitado (SOFOL) y, luego, para poder dispersar créditos para diferentes propósitos, se creó la SOFOM Entidad Regulada (SOFOM E.R.), asociada a grupos financieros.

7 La CNBV está facultada para someter a las entidades financieras a ambos tipos de supervisión. En el caso de la supervisión indirecta, esta se realiza por conducto de organismos auxiliares autorizados, conocidos en México como federaciones, que realizan la supervisión e informan a la autoridad sobre la situación financiera de las Entidades de Ahorro y Crédito Popular. 


\section{Entidades de Ahorro y Crédito Popular}

Con la Ley de Ahorro y Crédito Popular y la creación del BANSEFI en 2001 se procuró organizar y formalizar un sector compuesto por diferentes figuras jurídicas que captaban depósitos - cooperativas, sociedades de ahorro y préstamo, organizaciones no gubernamentales (ONG) de microfinanzas y cajas solidarias- con el fin de proteger el ahorro de los socios y clientes de estas instituciones. Para ello, la Ley priorizó la eliminación del problema del arbitraje regulatorio que ocasionaban distintas leyes para intermediarios financieros no bancarios que realizaban la misma actividad, lo que dio inicio a una nueva generación de reglas prudenciales para las finanzas populares ${ }^{8}$. De este modo, con la primera versión de la Ley de Ahorro y Crédito Popular se otorgaron facultades a la CNBV para la autorización, supervisión, regulación y sanción de intermediarios no bancarios de distinta naturaleza.

En 2001, las instituciones que atendían a pequeños productores del sector rural eran básicamente 42 uniones de crédito que daban servicios a un total de 38.000 socios; 211 cajas solidarias que atendían a 200.000 clientes; un número desconocido de cooperativas, cajas de ahorro y ONG, con baja presencia en el campo, así como algunas sociedades de ahorro y préstamo predominantemente urbanas, que tímidamente se acercaban al sector rural (Campos, 2005) .

Hasta 2009, la Ley de Ahorro y Crédito Popular reconoció dos figuras jurídicas: las cooperativas y las SOFIPO. Mientras que las cooperativas están conformadas por socios y son asociaciones sin fines de lucro, las SOFIPO atienden a clientes y son instituciones de microfinanzas constituidas como sociedades anónimas de capital variable, por lo que deben cumplir también con la Ley General de Sociedades Mercantiles. De conformidad con la primera versión de la Ley de Ahorro y Crédito Popular, ambos tipos de entidades estaban sometidas a una misma regulación basada en la supervisión auxiliar. Durante casi toda la primera década de este siglo, las Entidades de Ahorro y Crédito Popular y sus federaciones, con el apoyo de consultores contratados por el BANSEFI, se dedicaron a la construcción y profesionalización del andamiaje institucional previsto por la Ley.

La Ley de Ahorro y Crédito Popular fue concebida como una ley funcional que regularía la actividad del ahorro no bancario, independientemente de la entidad. En el texto de esta norma se incluyeron cuatro niveles de operación

\footnotetext{
8 Las cooperativas financieras tenían la opción de operar sujetas a los lineamientos establecidos en la Ley General de Sociedades Cooperativas o en la Ley General de Organizaciones y Actividades Auxiliares del Crédito si se convertían en sociedades de ahorro y préstamo. La principal diferencia es que en el primer caso no estaban sujetas a la regulación de la autoridad financiera, mientras que en el segundo, sí.

9 Solo unas pocas uniones de crédito, como la Asociación Mexicana de Uniones de Crédito del Sector Social A.C. (AMUCSS), prestaban servicios de crédito y ahorro a campesinos de muy bajos ingresos.
} 
para entidades con diferentes grados de desarrollo, ya fueran cooperativas o SOFIPO, que iban del nivel I para las entidades más simples — generalmente rurales-al nivel IV para los organismos de mayor sofisticación. Conforme se subía de nivel, la Ley permitía realizar operaciones más sofisticadas con una consecuente carga regulatoria mayor. Las críticas a la Ley de Ahorro y Crédito Popular se centraron en las implicaciones de la carga regulatoria que la Ley planteaba para las instituciones que atendían a la población rural. En consecuencia, el sector experimentó un marcado proceso de consolidación donde, si bien el número de socios de cajas solidarias es prácticamente el mismo de hace 15 años, el número de entidades que los atienden se redujo a un $10 \%$ del existente en 2001.

Con la finalidad de incorporar a otras entidades rurales que querían ser reguladas y supervisadas pero que no cumplían con los requisitos establecidos en la Ley de Ahorro y Crédito Popular, en 2009 esta sufrió profundas modificaciones al tiempo que se aprobó la Ley para Regular las Actividades de las Sociedades Cooperativas de Ahorro y Préstamo. El resultado fue una dualidad regulatoria: una ley específica para las cooperativas y otra, para las instituciones de microfinanzas comerciales que captan depósitos (SOFIPO) con una figura específica para el sector rural (SOFINCO).

Las SOFINCO fueron incorporadas en la Ley de Ahorro y Crédito Popular, en la reforma de 2009, como una solución para atender al sector rural marginado. La Ley tiene como objeto que estas entidades estén afiliadas a Organismos de Integración Financiera Rural (OIFR), que constituyen personas morales autorizadas por la CNBV para promover la integración operativa de las SOFINCO.

Tanto la Ley de Ahorro y Crédito Popular como la Ley para Regular las Actividades de las Sociedades Cooperativas de Ahorro y Préstamo cuentan con los cuatro niveles de operación creados con la promulgación de la primera ley en 2001. Las actividades financieras autorizadas en los primeros tres niveles de operación de ambas leyes son prácticamente las mismas. En contraste, además de poder realizar las operaciones de las Sociedades Cooperativas de Ahorro y Préstamo (SOCAP), en el nivel IV las SOFIPO están autorizadas a emitir títulos de crédito para su colocación entre el público inversionista en general y a emitir obligaciones subordinadas, entre otras facultades.

Respecto a la supervisión, la Ley de Ahorro y Crédito Popular mantiene el esquema de supervisión auxiliar para las SOFIPO y SOFINCO por medio de las federaciones. La Ley para Regular las Actividades de las Sociedades Cooperativas de Ahorro y Préstamo, por su parte, también ejerce supervisión auxiliar, pero lo hace a través del Comité de Supervisión Auxiliar del Comité Técnico del Fondo de Protección, cuyos miembros son representantes del sector cooperativo. Las críticas a este diseño parten de que los miembros sean juez y parte de la operación y la supervisión de las SOCAP. 
Tanto la Ley de Ahorro y Crédito Popular como la Ley para Regular las Actividades de las Sociedades Cooperativas de Ahorro y Préstamo permiten a las SOFINCO y a las SOCAP, respectivamente, mantener un nivel básico para aquellas sociedades que cuenten con activos equivalentes a menos de 2,5 millones de UDI, lo que reviste particular relevancia para el sector rural $^{10}$. En este nivel no requieren de la autorización de la CNBV, aunque sí de su registro. Tienen permitido realizar operaciones limitadas de ahorro y préstamo, y no cuentan con el beneficio del seguro de depósito. En el caso de las SOFINCO, en el nivel básico solo pueden operar con socios como una pequeña cooperativa.

Hasta junio de 2016, existían 146 SOCAP autorizadas y supervisadas por la CNBV a nivel nacional de aproximadamente las 400 sociedades que iniciaron el proceso de transformación en 2002. Estas atendieron en ese año, con un total de 1.747 sucursales, a más de 5,2 millones de socios en el país y administraron activos por más de 89.000 millones de pesos, que representan aproximadamente el $85 \%$ de la totalidad de los activos del sector de ahorro y crédito popular.

Respecto a la presencia rural de las SOCAP, en los municipios menores a los 50.000 habitantes había en marzo de 2016 un total de 670 sucursales (una tercera parte del total), es decir que representaban los segundos oferentes después de la banca comercial. A partir de los municipios con menos de 15.000 habitantes, la presencia institucional que sobresale es la de las SOCAP, que supera a la de los bancos y de cualquier otra figura institucional. En ese mismo año se contaba con 218 sucursales en estos municipios. Cabe destacar que en 111 municipios, las SOCAP son la única alternativa disponible como intermediario financiero regulado. Esto representa casi una cuarta parte de los municipios donde están presentes las cooperativas.

Además de las SOCAP autorizadas, existen las cooperativas de nivel básico, entre las que se encuentran principalmente cooperativas rurales. En agosto de 2016, existía un total de 444 cooperativas en el nivel básico, 9 de las cuales eran cajas solidarias. Del total, 32 fueron clasificadas por el Fideicomiso Fondo de Supervisión Auxiliar de Sociedades Cooperativas de Ahorro y Préstamo y de Protección a sus Ahorradores (FOCOOP) en la categoría D, por lo que la CONDUSEF recomendaba no ahorrar en esas cajas ${ }^{11}$.

10 Las unidades de inversión (UDI) son unidades de valor que se basan en el incremento de los precios y son usadas para solventar las obligaciones de créditos hipotecarios o cualquier acto mercantil. El Banco de México publica en el Diario Oficial de la Federación el valor de la unidad de inversión en moneda nacional para cada día del mes. En octubre de 2016, una UDI equivalía a 5,47 pesos mexicanos y a 29 centavos de dólar (ese mes el tipo de cambio era de 19 pesos mexicanos por dólar).

11 Las Entidades de Ahorro y Crédito Popular deben llevar su contabilidad de acuerdo a criterios de solvencia y estabilidad que indican las disposiciones de carácter general. Los criterios van de la categoría A — que representa una buena situación financiera de la entidad-a la categoría D, con la que están calificadas las instituciones insolventes y de mayor riesgo. 
Respecto a las figuras jurídicas contempladas en la Ley de Ahorro y Crédito Popular, en 2016 había 44 SOFIPO autorizadas a nivel nacional, que atendían a 3.057.140 clientes por medio de 1.043 sucursales en 1.199 municipios, en su mayoría de baja marginación. En el sector rural, las SOFIPO o microfinancieras autorizadas juegan un papel menos importante que las SOCAP. En marzo de 2016, los municipios con menos de 50.000 habitantes contaban con 143 sucursales de SOFIPO, mientras que aquellos con menos de 15.000 solo contaban con 16 sucursales, y los menores a 5.000, únicamente con 2.

Respecto a las SOFINCO, hasta septiembre de 2016 solo había sido autorizada una institución, que cuenta con 30 sucursales en localidades marginadas del país y atiende a 60.000 clientes, principalmente población indígena. En la misma fecha se encontraban con expediente en la CNBV y en proceso de ser autorizadas 8 SOFINCO y 12 SOFIPO. En total, las SOFINCO acumulan 110.000 clientes. Por lo tanto, las dificultades de atender al sector rural no se solucionaron con las nuevas figuras. A siete años de reformada la Ley, ningún OIFR había sido autorizado.

El BANSEFI calculaba que en total, incluidas las Entidades de Ahorro y Crédito Popular autorizadas con expediente en la CNBV y en el nivel básico, en julio de 2016 estas atendían a 10,4 millones de usuarios en el país y contaban con 140.000 millones de pesos en activos y 110.000 millones de pesos en captación. Las Entidades de Ahorro y Crédito Popular autorizadas atendían al $86 \%$ de los usuarios y mantenían el $88 \%$ de los activos del sector de ahorro y crédito popular (BANSEFI, 2016).

La reforma financiera de 2014 requirió de modificaciones a la Ley de Ahorro y Crédito Popular y a la Ley para Regular las Actividades de las Sociedades Cooperativas de Ahorro y Préstamo. Respecto a la expansión de puntos de acceso, la reforma permite la participación de las SOFIPO y SOCAP en la oferta de productos y servicios de banca móvil y, al igual que la banca, abre la posibilidad de contar con corresponsales y con cuentas de expediente simplificado.

\section{Instituciones de crédito no reguladas}

Las SOFOM no reguladas surgieron en 2006 como agentes activos dispersores de crédito. Aunque se encuentran fuera del ámbito regulatorio, estas entidades deben sujetarse a las disposiciones de la Ley General de Organizaciones y Actividades Auxiliares de Crédito, así como a las que emitan en los términos de dicha Ley la CNBV y la SHCP. Además, deben cumplir con la Ley de Protección y Defensa al Usuario de Servicios Financieros y la Ley para la Transparencia y Ordenamiento de los Servicios Financieros. En 2012 el Sistema de Registro de Prestadores de Servicios Financieros (SIPRES) comprendía 2.755 SOFOM, y se tenía conocimiento de que otras 921 entidades 
no se habían registrado, por lo que se encontraban en una situación de grave incumplimiento ${ }^{12}$.

La figura jurídica de las SOFOM abarca el mayor número de microfinancieras (ProDesarrollo, 2015). La gran mayoría se encuentra en el sector urbano, donde ofrecen microcréditos a la población de ingresos medios y bajos de barrios conurbados. En 2012, el Registro de Contratos de Adhesión (RECA) de la CONDUSEF contabilizaba al menos 250 SOFOM en el sector primario y un total de 342 productos de crédito de habilitación y avío. De igual modo, cerca de 200 SOFOM ofrecían 225 productos de crédito refaccionario.

La reforma financiera de 2014 creó el Buró de Entidades Financieras, que tiene como objetivo informar sobre el desempeño de todas las entidades financieras del país, incluidas las SOFOM, que representan el $85 \%$ del total de las entidades financieras de México, con el fin de que los usuarios tengan elementos para la toma de decisiones.

Las SOFOM deben registrarse ante la CONDUSEF y presentar ante la CNBV informes en materia de prevención del lavado de dinero. Además, a raíz de la reforma financiera, deben consultar y notificar a alguna de las sociedades de información crediticia y solicitar el alta ante la CONDUSEF antes de constituir una SOFOM, así como notificar cualquier modificación en sus estatutos.

\section{La banca comercial}

La incursión de la banca comercial en el sector microfinanciero es un indicador importante de la expansión de servicios financieros a la población típicamente excluida. El interés de la banca comercial en atender a sectores populares se inicia en 2002 con el Banco Azteca y se refuerza en 2005 con Compartamos Banco. En los años siguientes entraron al mercado otras entidades, la mayoría vinculadas a cadenas de supermercados. Aquellos que se han focalizado en el sector de las microfinanzas son Compartamos Banco, Banco Azteca y Banco Wal-Mart. Estos bancos atienden a población de ingresos medios bajos y bajos de los barrios populares de las ciudades y zonas conurbadas. Su presencia en el sector rural es escasa. El caso de Compartamos Banco reviste particular relevancia por el número de clientes que atiende, su modelo de negocio y su rápida expansión urbana y semiurbana, basada por muchos años casi exclusivamente en el microcrédito grupal y sin ofrecer servicios de ahorro. A diferencia de sus competidores bancarios, Compartamos Banco proviene de una SOFOL.

12 Entrevista con la Vicepresidencia Técnica de la Comisión Nacional para la Protección y Defensa de los Usuarios de Servicios Financieros (CONDUSEF), 17 de julio de 2012. 
Como se muestra en el gráfico VII.1, la presencia de sucursales bancarias en el sector rural es sumamente baja. En los municipios por debajo de los 15.000 habitantes ha habido una tendencia de la banca a retirarse de estas zonas desde 2010. En 2016 estos municipios contaban solo con 142 sucursales. Las sucursales no han sido sustituidas por corresponsales; de hecho, este canal de acceso también ha tendido a retirarse de las zonas rurales.

\section{Gráfico VII.1}

México: sucursales bancarias en municipios rurales, 2010-2016

(En número de sucursales)

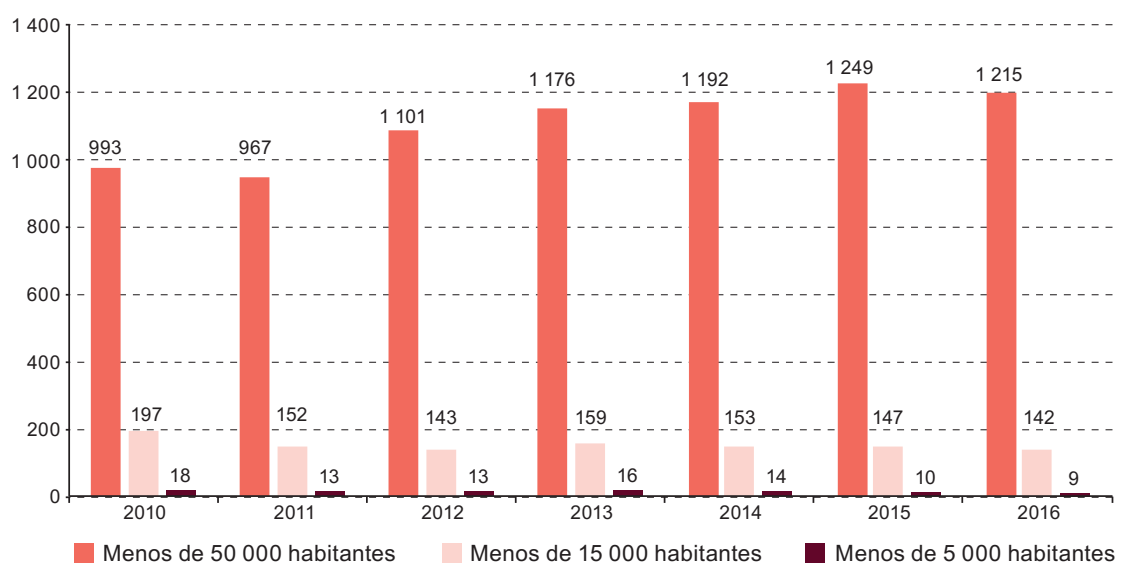

Fuente: Elaboración propia, sobre la base de cifras del Consejo Nacional de Inclusión Financiera (CONAIF).

En 2008 se aprobaron las reformas para autorizar bancos de nicho o de objeto social acotado. Los requisitos para su autorización son los mismos de la banca múltiple. Sin embargo, como su nombre lo indica, los bancos de nicho son bancos especializados en un producto, región o sector de la población autorizados a realizar operaciones financieras básicas y cuyos requerimientos de capital son inferiores a los exigidos a la banca múltiple. Entre 2012 y 2016, la CNBV autorizó siete bancos de nicho. Respecto a esta figura hay que destacar que tanto el Banco de México (Román, 2014) como Moody's Investor Service (2014) han cuestionado la viabilidad de este tipo de instituciones. En particular, se considera que el modelo de negocios de los bancos de nicho implica poca diversificación y dificultades para cumplir con la regulación prudencial.

La reforma financiera autorizó a la banca comercial, al igual que a las Entidades de Ahorro y Crédito Popular, a ofrecer cuentas de expediente simplificado. La innovación fue la incorporación de cuatro niveles con requerimientos específicos para su apertura y con límites de transaccionalidad: tres de bajo riesgo y la cuenta tradicional. Los tres niveles de bajo riesgo pueden contratarse por medio de canales alternos, como los corresponsales 
bancarios o medios electrónicos, mientras que la cuenta tradicional solo puede contratarse en una sucursal. El informe de la PNIF sostiene que las cuentas de nivel 2 han sido un producto de captación apropiado para desarrollar modelos de negocio enfocados en la población de bajos ingresos, clientes no bancarizados e, incluso, población con residencia en zonas donde el único acceso al sistema financiero es a través de corresponsales bancarios.

La reforma financiera prohibió las ventas vinculadas, una práctica relativamente común que afectaba, sobre todo, a los clientes bancarios de menores ingresos y desmotivaba la inclusión financiera. Por otra parte, la reforma faculta al Instituto para la Protección al Ahorro Bancario (IPAB) con poderes de intervención para proteger a los depositantes que reúnen los requisitos exigidos, lo que permitirá dar soluciones más ordenadas y expeditas que beneficien a los acreedores con garantías.

\section{Los corresponsales bancarios, los cajeros automáticos y las terminales punto de venta}

El esquema de corresponsales bancarios entró en vigor a principios de 2010 como un complemento de las sucursales bancarias, con la finalidad de llegar a lugares que no contaban con ellas y brindar un punto de acceso al sistema financiero a un menor costo. Según información de la CNBV, de marzo de 2010 a mayo de 2012 la tasa media de crecimiento mensual del número de corresponsales bancarios autorizados fue de un 7,9\%. En 2012, 15 bancos contaban con comisionistas que representaban 21.161 puntos de atención a nivel nacional. En 2016, 18 bancos contaban con comisionistas. En 2015 los corresponsales bancarios alcanzaron su punto más alto a nivel nacional. Sin embargo, de marzo de 2015 a marzo de 2016 se registró la desaparición de 1.671 puntos de servicio en el ámbito nacional, que equivale al $6 \%$ del total.

De acuerdo con la normativa, los comisionistas pueden ser tiendas, gasolineras, farmacias, oficinas de telégrafos y otros establecimientos. En 2016 solo CitiBanamex y Compartamos Banco tenían como comisionistas a pequeños negocios, por ejemplo, tiendas de abarrotes, que podían llegar al sector rural. Sin embargo, se trata de pocos puntos de atención, excepto por "Yastás", la red de corresponsales de Compartamos Banco, que en agosto de 2016 sumaba cerca de 3.000 puntos de atención.

Los corresponsales realizan operaciones limitadas: el tipo y número depende del banco y del comisionista. El énfasis está puesto en la cobranza de créditos del banco acreedor más que en cualquier otro servicio financiero. Prácticamente en los puntos de atención de casi todos los comisionistas se pueden pagar créditos, pero solo del banco del que es corresponsal (únicamente Afirme Grupo Financiero acepta pagos de otros bancos). En 
un número considerablemente menor y en orden decreciente, se pueden realizar en las corresponsalías depósitos, pagos de servicios y retiros. Muy pocos comisionistas ofrecen consulta de saldos.

Con el fin de bancarizar a la población de menores ingresos que habita principalmente en el sector rural, en 2010 se autorizó la red de tiendas abastecidas por el Sistema de Distribuidoras Conasupo, S.A. de C.V. (DICONSA) como comisionistas del BANSEFI ${ }^{13}$. Las tiendas son propiedad de la comunidad, que se organiza para solicitar su apertura, proveer un espacio para la tienda y nombrar a un encargado para que la opere. En marzo de 2016, de un total de 20.101 tiendas DICONSA, el BANSEFI mantenía a 258 como corresponsales en operación. En principio, este total está ubicado en localidades con conectividad celular.

En 2016, los municipios que no alcanzaban los 50.000 habitantes contaban con menos del $10 \%$ del total de puntos de atención de corresponsales bancarios en el país, es decir, con 2.429 puntos de atención. Los municipios con menos de 15.000 habitantes contaban únicamente con 571 puntos de atención y los municipios con menos de 5.000 habitantes contaban solo con 91 (CONAIF, 2016b).

Los cajeros automáticos han experimentado una tendencia creciente en el país. A nivel nacional, hasta marzo de 2016 se contaba con un total de 47.043 cajeros. A pesar de los avances, su presencia sigue siendo escasa, sobre todo en el sector rural. En los municipios con menos de 50.000 habitantes se encuentra apenas el 7\% de los cajeros automáticos, a pesar de que en estos municipios habita el $22 \%$ de la población adulta del país. En su mayoría, los cajeros son de la banca comercial, pero también algunas SOFIPO, SOCAP e, incluso, el BANSEFI cuentan con ellos, aunque con muy poca presencia.

Las terminales punto de venta (TPV) son fundamentales para los corresponsales bancarios y son consideradas esenciales como complemento del ecosistema financiero, ya que permiten el uso de medios electrónicos para realizar compras y otros pagos, lo que reduce la necesidad de tener efectivo. En el informe de la PNIF se reconoce la escasa terminalización de los comercios que aún persiste en México, pues solo el 10\% a nivel nacional (574.000 de un total de más de 5,6 millones) cuenta con una TPV. En marzo de 2016 se tenía registro de 874.419 TPV en el país. Si bien el incremento se ha dado en todos los sectores, persiste un pronunciado rezago en el ámbito rural.

${ }_{13}$ DICONSA es la entidad pública responsable del programa de abasto social en el ámbito rural por medio de una red de tiendas fijas y móviles. 


\section{B. La banca de desarrollo en la arquitectura financiera rural}

No se puede entender la arquitectura de la inclusión financiera en México, principalmente la rural, sin analizar la profusa actividad y los tipos de intervención de la banca de desarrollo, tanto en actividades de primero como de segundo piso. A pesar de esta importante intervención pública, aún no existe un modelo claro sobre el tipo de relación que debe establecerse entre las distintas bancas de desarrollo y las instituciones financieras privadas, los usuarios y otros organismos de desarrollo para potenciar la inclusión financiera rural.

\section{Breves antecedentes}

A lo largo de los últimos 15 años, se pueden identificar tres períodos por los que ha transitado la banca de desarrollo. El primero, de 2001 a 2006, fue un período de estabilización y modernización orientado a lograr la sostenibilidad financiera, mejorar los lineamientos operativos y el gobierno corporativo. El segundo período va de 2006 a 2012 y se caracteriza por una expansión del crédito que, sin embargo, fue condicionada por las restricciones impuestas para su saneamiento. De acuerdo a sus estatutos, la banca de desarrollo debía cumplir su misión utilizando su propio patrimonio y, aunque podía recibir recursos adicionales del sector público, estas restricciones la limitaban.

El tercer período - que comienza con la promulgación de la reforma financiera de 2013 y su consecuente implementación en 2014— trae consigo un nuevo mandato para la banca de desarrollo: el fomento de la economía mediante la atención de sectores estratégicos que enfrentan limitantes para tener acceso a alternativas de financiamiento. La reforma financiera flexibilizó el marco normativo que rige a la banca de desarrollo a fin de agilizar los procesos de crédito, y así le permitió allegarse y gestionar los recursos indispensables, sobre todo de capital humano, para el cumplimiento de su mandato.

En las siguientes secciones se presentan los detalles de los programas de la banca de desarrollo relacionados específicamente con la inclusión financiera rural.

\section{Financiera Nacional de Desarrollo Agropecuario, Rural, Forestal y Pesquero}

La Financiera Nacional de Desarrollo Agropecuario, Rural, Forestal y Pesquero (FND) realiza operaciones directamente con usuarios mediante una red de 95 agencias, y canaliza recursos por medio de entidades financieras no bancarias. De acuerdo con estimaciones de la otrora Financiera Rural, por 
cada intermediario financiero que recibía crédito, en 2010 se atendieron de manera indirecta a 700 acreditados (Merino, 2011). Sin embargo, en la misma fecha la mitad de los recursos de la institución se seguían colocando a través de operaciones de primer piso.

La FND canaliza recursos orientados a todas las actividades vinculadas al sector rural y privilegia aquellos destinados a las localidades con menos de 50.000 habitantes. Los productos de crédito que otorga son el crédito simple, de habilitación y avío, prendario, refaccionario, cuenta corriente y avío agrícola múltiple. En agosto de 2016 contaba con ocho programas eje de financiamiento para diferentes fines, entre los que destaca el Programa de Financiamiento para Pequeños Productores, que ha sido considerado por el Gobierno la principal estrategia de inclusión financiera rural de la FND (CONAIF, 2016a).

El Programa de Financiamiento para Pequeños Productores surge en 2014 al cambiar la norma de la FND. Anteriormente, el acceso de pequeños productores se limitaba al crédito refaccionario debido a los niveles de garantía exigidos. Con el cambio, entra en vigor la garantía natural de avío, es decir, la cosecha, lo que abrió la posibilidad de que un pequeño productor propietario de media hectárea en el sureste del país, por ejemplo, accediera a créditos destinados a los insumos de la producción agrícola. Los créditos del programa se otorgan en el primer piso a través de las agencias de la FND y, en el segundo, mediante líneas de crédito a entidades financieras o dispersoras de crédito. En 2016 el programa atendía a 40.000 productores: un $90 \%$ en el primer piso y un $10 \%$ en el segundo ${ }^{14}$.

El programa establece topes a las tasas de los créditos, que incluyen un margen de tres puntos porcentuales para gastos operativos de las entidades dispersoras de recursos. Los topes a las tasas de interés buscan subsidiar al productor y no al intermediario. Sin embargo, el establecimiento de tasas máximas ha desmotivado la entrada de intermediarios financieros al programa. Si se toma en cuenta que en 2016 este crédito representaba la primera experiencia de financiamiento formal para el $80 \%$ de los productores beneficiarios del Programa, la falta de participación de intermediarios financieros limita su posibilidad de ser clientes permanentes de una institución financiera con acceso a una amplia gama de productos.

Otro de los problemas que enfrenta el programa en términos de la inclusión financiera es la imposibilidad de verificar si los nuevos acreditados del programa son familiares del dueño o ejidatario del terreno cuya producción está en garantía. Esto puede ocasionar que el crédito se concentre en beneficiarios o coproductores que ponen en garantía la cosecha del mismo

14 Entrevista con funcionarios de la FND de la Dirección General Adjunta de Crédito, 29 de octubre de 2016. 
terreno. El problema radica en que en el país no existen registros que cuenten con información desagregada sobre las tierras, por lo que la FND no tiene la posibilidad de identificar esta situación. Por último, es importante mencionar que una proporción significativa de los productores invitados a conocer el Programa de Financiamiento para Pequeños Productores no quisieron el crédito, a pesar de las condiciones favorables. Esto pone de relieve que el elemento principal de la inclusión financiera no siempre es el crédito, sino el conjunto de los productos y servicios complementarios.

No obstante los límites con que se topa el programa para la inclusión financiera rural, en términos de ampliar la base social beneficiaria de los créditos productivos en condiciones preferenciales, ha logrado incluir a productores que tradicionalmente no accedían a la banca de desarrollo.

\section{Banco del Ahorro Nacional y Servicios Financieros}

El Banco del Ahorro Nacional y Servicios Financieros (BANSEFI), creado en 2002, ofrece productos de ahorro, de envío y pago de remesas y de microseguros de vida. Además, distribuye diversos apoyos gubernamentales. Cuenta con una red de 428 sucursales, principalmente en zonas urbanas. De acuerdo a información del BANSEFI, en junio de 2016 la institución manejaba más de 13 millones de cuentas, 6,5 millones de las cuales correspondían a beneficiarias del programa de transferencias monetarias condicionadas PROSPERA. Sin embargo, no se dispone de información sobre el número de clientes ni sobre la transaccionalidad o intensidad de uso de las cuentas.

El BANSEFI ha contribuido a la inclusión financiera en el país sobre todo mediante su programa de fortalecimiento institucional. Durante casi 15 años, este programa ha ayudado a la mayoría de las Entidades de Ahorro y Crédito Popular a formalizar y ofrecer a usuarios tradicionalmente excluidos de la banca comercial servicios financieros más sólidos y regulados por la autoridad. Entre sus diferentes programas, el BANSEFI cuenta con tres estrategias que se vinculan, total o parcialmente, con el sector rural: L@ Red de la Gente, el Programa de Asistencia Técnica a las Microfinanzas Rurales (PATMIR) y el Programa Integral de Inclusión Financiera (PROIIF).

L@ Red de la Gente, una alianza comercial creada por el BANSEFI en 2002, está conformada por Entidades de Ahorro y Crédito Popular y las sucursales del banco. Se trata de una asociación voluntaria de intermediarios que buscan promover el ahorro, y ofrecer productos y servicios financieros en condiciones competitivas para reducir los costos, compartir los riesgos y aumentar sus operaciones. En agosto de 2016 participaban en el programa 189 Entidades de Ahorro y Crédito Popular, que acumulaban un total de 2.298 sucursales en 938 municipios del país y atendían a 4 millones de socios o clientes. 
Además de ahorro, crédito, remesas, transferencias entre cuentas y microseguros, 58 entidades de L@ Red de la Gente dispersan los apoyos del programa de transferencias condicionadas PROSPERA a alrededor de 100.000 beneficiarias en 19 estados del país. Es preciso destacar que dichas prestaciones se realizan a través de lo que se conoce como canal cerrado, donde la transferencia se paga en efectivo y no por depósito en cuenta, debido a que las cuentas de ahorro de las beneficiarias de PROSPERA están constituidas en el BANSEFI y no en la caja que entrega los recursos. En consecuencia, pocas cajas de ahorro han logrado asociar a las beneficiarias de PROSPERA, lo que limita su inclusión plena al sistema financiero.

El Programa de Asistencia Técnica a las Microfinanzas Rurales (PATMIR) inicia en 2002 dentro de la Secretaría de Agricultura, Ganadería, Desarrollo Rural, Pesca y Alimentación (SAGARPA) y en 2010 es transferido al BANSEFI. Es posible decir que, en términos de inclusión financiera rural, es el programa público más importante del país, pues ha logrado incorporar al sector financiero formal a un número considerable de clientes rurales marginados. A grandes rasgos, en los 14 años de existencia del programa, este ha procurado que las cooperativas, y más recientemente también las SOFIPO, atiendan a población rural marginada mediante la promoción de una inclusión financiera basada en el ahorro. De este modo, ha transferido recursos para que las entidades integren como nuevos socios o clientes a miembros de la población rural de zonas de muy alta, alta y media marginación (según los índices del Consejo Nacional de Población, que en general no ha tenido acceso a servicios financieros formales ${ }^{15}$.

La tercera estrategia de inclusión financiera del BANSEFI relacionada con el sector rural es el PROIIF, que fue creado en 2015 en respuesta al mandato de reforma financiera que enfatiza el papel de la banca de desarrollo en la promoción del acceso al crédito de grupos prioritarios. El PROIIF está orientado a las beneficiarias de PROSPERA y consta de una cuenta de ahorro programado, una cuenta de ahorro a la vista, y dos productos de crédito. Debido a las complejidades de operación del sistema, hay un desfase entre el contrato o la solicitud y la ejecución de las transacciones. Con el tiempo, el sistema tendrá que ajustarse, pues una de las características de un buen producto de crédito y ahorro es precisamente la oportunidad. La mayoría de las veces, esta condición es más valorada que una mejor tasa de interés, sobre

15 El Consejo Nacional de Población estratifica los estados, municipios, localidades y áreas geoestadísticas básicas en cinco grados de marginación que responden a un índice creado con indicadores básicos de desarrollo: niveles de escolaridad, calidad de las viviendas, drenaje, uso de aparatos electrodomésticos, entre otros. La marginalidad se divide en alta, muy alta, media, baja y muy baja. 
todo a causa de la marcada estacionalidad de las actividades económicas rurales y de la vulnerabilidad ante las emergencias a las que está expuesta esta población, que hacen que la disponibilidad inmediata de los ahorros o de créditos constituya un recurso indispensable.

\section{Fideicomisos Instituidos en Relación con la Agricultura}

FIRA $^{16}$ facilita el acceso al crédito por medio de operaciones de crédito y descuento, así como mediante el otorgamiento de garantías a proyectos relacionados con la agricultura, la ganadería, la avicultura, la agroindustria, la pesca y otras actividades relacionadas con el medio rural.

En la década pasada, FIRA empezó a trabajar con intermediarios no bancarios y entidades financieras no reguladas. Las entidades financieras con las que actualmente trabaja FIRA, además de la banca comercial, son SOFOM, SOFIPO, SOCAP, uniones de crédito y almacenes generales de depósito. Estas entidades pueden otorgar créditos a personas físicas y morales cuya actividad sea la producción, acopio y distribución de bienes, y servicios relacionados con los sectores agropecuario, forestal y pesquero, y otras actividades llevadas a cabo en el sector rural.

FIRA también facilita el crédito para actividades no tradicionales del sector rural, por medio de los esquemas de financiamiento rural y microcréditos. El primero busca financiar cualquier actividad económica que se desarrolle en el medio rural, diferente de las que efectúan las empresas de los sectores agropecuario, forestal y pesquero. Son elegibles los proyectos que se lleven a cabo en localidades con menos de 50.000 habitantes. El segundo es el más significativo en términos de inclusión: busca específicamente incrementar la penetración y cobertura de los mercados financieros rurales para dar acceso al crédito a pequeños productores cuyo ingreso neto anual sea menor a 3.000 veces el salario mínimo diario de la zona donde se realizarán las inversiones.

El programa autoriza líneas de crédito a los intermediarios financieros de acuerdo a su plan de negocios, para que otorguen microcréditos productivos a personas físicas. Los montos y plazos otorgados a los solicitantes deben

16 Los fideicomisos que integran FIRA son el Fondo de Garantía y Fomento para la Agricultura, Ganadería y Avicultura; el Fondo Especial para Financiamientos Agropecuarios; el Fondo Especial de Asistencia Técnica y Garantía para Créditos Agropecuarios; y el Fondo de Garantía y Fomento para las Actividades Pesqueras. 
estar alineados con la actividad que financian, el tipo y recurrencia de sus ingresos, y su capacidad de pago (se excluyen los créditos al consumo). Los microcréditos están sujetos a un tope máximo de 33.000 UDI y tienen plazos de hasta tres años.

Los intereses que FIRA cobra a los intermediarios deben ser cubiertos de conformidad con el esquema de tasas de interés vigente en la fecha en que se realice la disposición de los recursos. FIRA ofrece a los intermediarios esquemas de tasas de interés variable y esquemas de cobertura de riesgos con tasas fijas. Los intermediarios acreditados suscriben pagarés a favor del fiduciario.

La tasa de interés que pagan los productores es la que cobran las microfinancieras por este producto. A diferencia del Programa de Financiamiento para Pequeños Productores de la FND o del PROIIF del BANSEFI, las tasas no tienen límites máximos, por lo que los productores acreditados por el esquema de microcréditos de FIRA pagan una tasa mayor que la de los acreditados de los otros dos programas. No obstante, este último tiene una cobertura considerablemente mayor: en 2014 el programa llegaba a 724.977 acreditados.

FIRA también otorga apoyos para actividades de capacitación de intermediarios financieros, al igual que el BANSEFI y la FND. En ningún caso hay coordinación entre los programas de asistencia técnica y las tres bancas de desarrollo.

En el cuadro VII.2 se comparan los tres programas de las tres bancas de desarrollo analizadas en este capítulo que ofrecen crédito a población rural no bancarizada. Como puede verse, existe una relación entre la tasa de interés, el canal de distribución y la cobertura del programa. Los programas de crédito con tasas de interés sin subsidio, distribuidos a través del segundo piso, alcanzan una mayor cobertura que los programas subsidiados y distribuidos a través de operaciones de primer piso. El PROIIF está entre los dos extremos, pero, a diferencia de sus contrapartes, es un crédito muy pequeño y tiene como garantía asegurada las transferencias monetarias condicionadas. Teniendo en cuenta que en los tres casos se trata de programas públicos de inclusión financiera, cabe preguntarse cuál debe ser el equilibrio entre la tasa de interés, la cobertura y sostenibilidad del programa, la seguridad para el usuario y la eficiencia del servicio. 


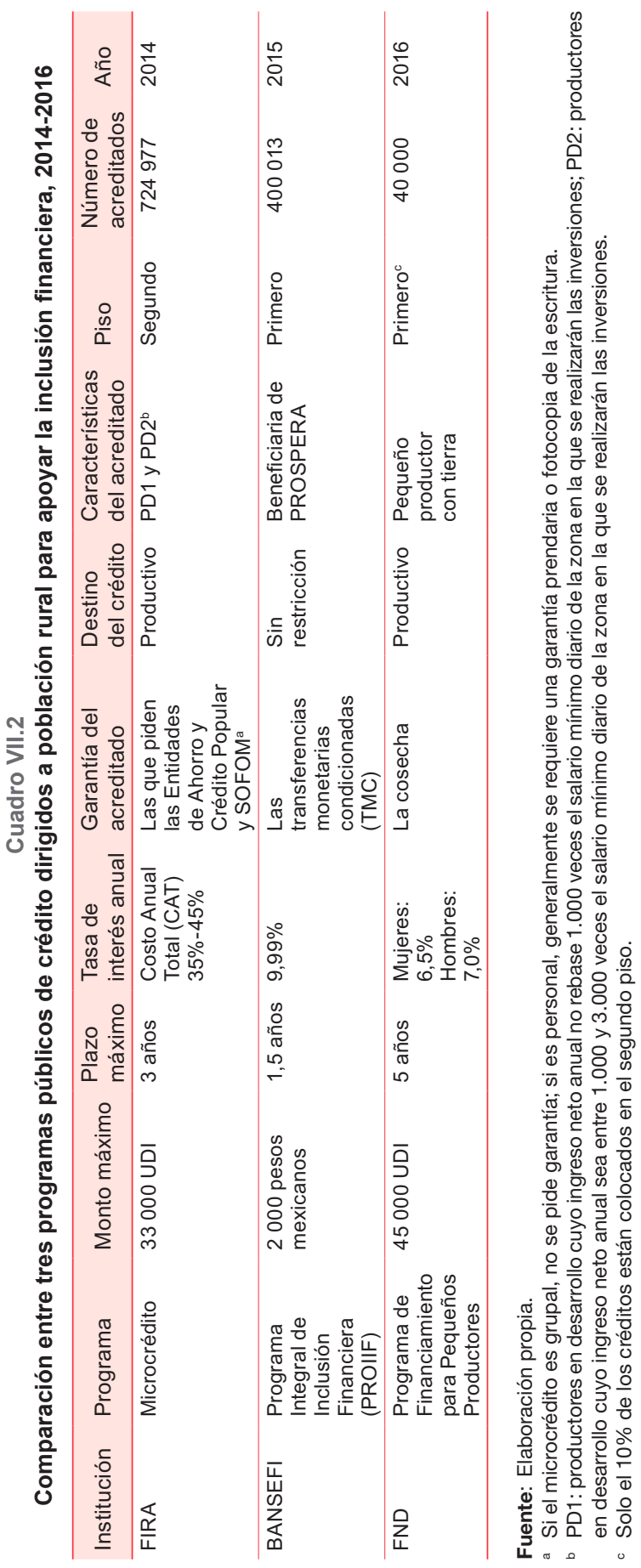




\section{Retos que enfrentan los usuarios y las entidades financieras en el ámbito rural}

\section{Evolución de los puntos de acceso en el sector rural}

Como puede apreciarse en el gráfico VII.2, pese a los avances registrados entre 2011 y 2014, a partir de 2015 se observa una reducción en el número de sucursales de las entidades reguladas (bancos, bancos de desarrollo, SOCAP y SOFIPO), que se acentúa en el ámbito rural, donde la caída comienza en 2014. Esta disminución afecta la ya exigua presencia de entidades financieras en el campo. De 2014 a 2016, el número de sucursales por cada 10.000 adultos pasó de 0,68 a 0,58 en los municipios con menos de 5.000 habitantes; se mantuvo en 0,80 en los municipios con menos de 15.000 habitantes y bajó de 1,20 a 1,16 en los que tenían menos de 50.000 .

\section{Gráfico VII.2}

México: sucursales de entidades reguladas en municipios con menos de 15.000 habitantes, $\mathbf{2 0 1 0 - 2 0 1 6}$

(En número de sucursales)

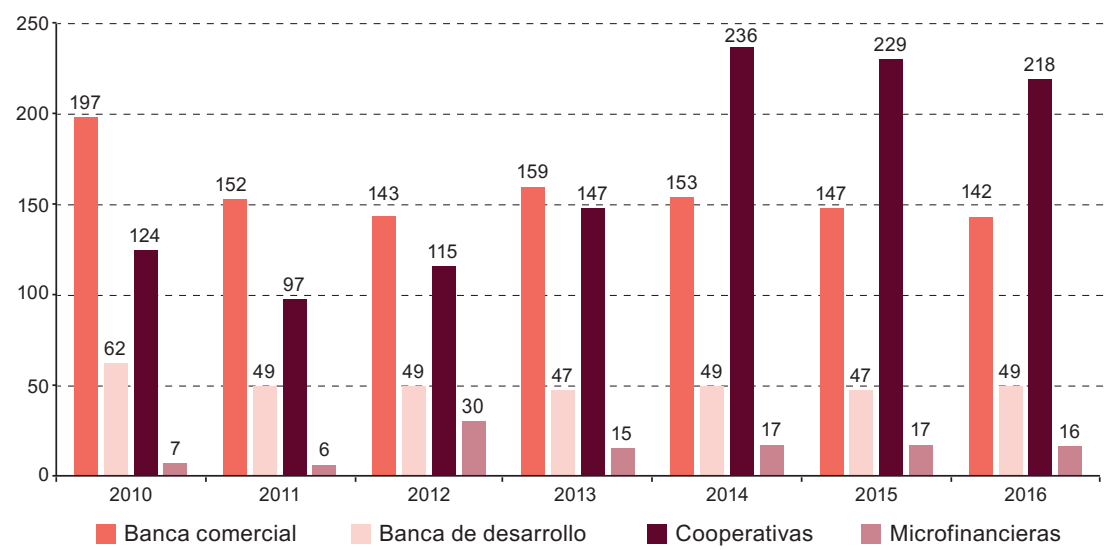

Fuente: Elaboración propia, sobre la base de cifras del Consejo Nacional de Inclusión Financiera (CONAIF).

Además de la reducción de las sucursales, el número de corresponsales bancarios en el sector rural sigue a la baja. Esta caída se viene presentando desde 2012. En 2016 se contaba con casi la mitad de los corresponsales en los municipios con menos de 5.000 habitantes, pues el número se redujo de 179 a 91. El CONAIF explica la salida de los corresponsales del sector rural por el complicado proceso de autorización, que requiere de una espera significativa, a diferencia de las redes de comercios urbanos, que permiten habilitar muchos puntos simultáneamente (CONAIF, 2016a). 
Los únicos puntos de acceso que aumentaron a nivel nacional entre 2011 y 2016 fueron los cajeros automáticos. Cabe mencionar que el número máximo de cajeros automáticos en las localidades más rurales se alcanzó en 2010. No obstante, en 2011 hubo una caída marcada del 60\% en los municipios con menos de 5.000 habitantes — de 118 a 50-y del 30\% en los municipios con menos de 15.000 habitantes — de 687 a 479—. Las dificultades de los cajeros automáticos para expandirse en el sector rural están relacionadas con los costos que su uso implica para los usuarios y con el punto de equilibrio de las transacciones que requieren las sociedades financieras para que estos sean un negocio rentable ${ }^{17}$. De acuerdo con cifras de la Encuesta Nacional de Inclusión Financiera (ENIF) 2015 (INEGI/CNBV, 2016), solo el 2\% de la población rural utiliza los cajeros automáticos.

Entre las regiones del país se refleja claramente la disparidad entre los municipios rurales y urbanos en cuanto a los puntos de acceso al sector financiero. Como muestran los resultados del séptimo Reporte Nacional de Inclusión Financiera (CONAIF, 2016b), en 2015 el número de sucursales, cajeros y corresponsales por cada 10.000 adultos era más bajo en los estados del sur que en otras regiones. Ese año el promedio nacional era de 1,9 sucursales por cada 10.000 adultos, mientras que en el sur era de 1,6. En el caso de los corresponsales, esta cifra era de 3,1 a nivel nacional, pero apenas alcanzaba 2 en el sur. De igual forma, el promedio nacional de cajeros era de 5,1 por cada 10.000 adultos, al tiempo que en el sur del país era 3,7.

Si bien ha habido avances netos en la inclusión financiera rural a lo largo de los últimos seis años, estos han sido muy lentos o tuvieron un buen inicio que luego se diluyó, como sucedió con los corresponsales, los cajeros e, incluso, el número de sucursales, particularmente en los municipios con menos de 5.000 habitantes.

\section{Sobre los productos y los usuarios}

De acuerdo a las cifras de la ENIF (INEGI/CNBV, 2016), en 2015 el 44\% de los mexicanos a nivel nacional respondieron tener una cuenta en una institución financiera formal. Esta cifra contrasta con la obtenida en 2012, cuando el 36\% de la población dijo contar con ella. El cambio se originó en el sector rural, donde la proporción de titulares de cuentas aumentó del 23\% al $35 \%$ en esos años.

Sin embargo, según las cifras del CONAIF, durante el mismo período el número de cuentas de ahorro y transaccionales se redujo de 5.590 .292 a 5.072 .930 en los municipios con menos de 50.000 habitantes, mientras que en aquellos con menos de 15.000 el número de cuentas pasó de 917.699 a 785.388.

17 Entrevista con María O’Keefe, experta en finanzas rurales en México, agosto de 2016. 
La discrepancia puede deberse, entre otros, a aspectos relacionados con la redacción de las preguntas en ambos años y con la contabilización de las cuentas asociadas a programas sociales.

Respecto al crédito obtenido de una institución formal, los datos de la ENIF 2015 indican una baja incidencia, tanto en el sector rural como urbano. El panorama cambia cuando se observan los patrones regionales, ya que el crédito y el microcrédito tienden a estar concentrados en las ciudades grandes y medianas, y en zonas conurbadas. En estas concentraciones se llegan a presentar incluso problemas de sobreendeudamiento por el exceso de oferta de microcrédito costoso, mientras que otras regiones, principalmente rurales, se mantienen desatendidas (Marulanda Consultores Ltda./DAI, 2011).

En lo que concierne al tipo de créditos, entre 2012 y 2015 se observa una aceleración del crédito personal (del 2,7\% al 3,3\%) y una desaceleración del crédito grupal (del 3,5\% al 2\%) en el sector rural. Ello tal vez se deba al cierre de SOFOM con metodologías de crédito grupal, pero también a una tendencia de todas las microfinancieras a trasladar su cartera de créditos al crédito personal e individual. La buena noticia puede ser un mejor producto para el sector rural, ya que el crédito personal tiende a caracterizarse por mayores montos, mayores plazos, menor riesgo para el usuario y, en ocasiones, menores intereses. No obstante, por lo general requiere de garantías con las que no siempre cuentan los usuarios de menores ingresos.

Por su parte, la disponibilidad de tarjetas de crédito se ha acelerado en el medio rural. De acuerdo a la ENIF, en tres años aumentó un tercio el número de personas con este instrumento. En poblaciones semiurbanas, las tarjetas resultan convenientes en comparación con los microcréditos, ya que es posible comprar a plazos sin intereses artículos para el hogar y para el negocio. Sin embargo, el acceso a tarjetas sigue siendo sumamente bajo. El hecho de que las tarjetas de crédito sean casi el único instrumento de financiamiento que ha crecido en los últimos años en el ámbito rural representa un potencial interesante de bancarización que puede verse beneficiado con la tecnología digital y otras acciones conjuntas planteadas en las conclusiones. Lo que los datos muestran es que, si acaso ha habido una sustitución entre productos de crédito, esta ha sido hacia la tarjeta de crédito.

\section{Los retos de las entidades financieras no bancarias en el sector rural}

Como puede observarse en el gráfico VII.2, a partir de municipios con menos de 15.000 habitantes, la presencia de sucursales de SOCAP prevalece entre todas las entidades reguladas, seguida por la banca comercial, la banca de desarrollo y las SOFIPO. A continuación se exponen los principales retos a los que se enfrentan estas instituciones. 
El primer reto es la desconfianza en el sector de ahorro y crédito popular. Para las Entidades de Ahorro y Crédito Popular hay un antes y un después en su relación con la autoridad a partir del fraude de la SOFIPO Ficrea en noviembre de 2014, a raíz del cual en 2015 se planteó la reforma a la Ley de Ahorro y Crédito Popular, conocida coloquialmente como la Ley Ficrea. Esta norma propuso medidas prudenciales que traían aparejados serios riesgos para la viabilidad financiera de las Entidades de Ahorro y Crédito Popular.

También se enfrentan a una normativa regresiva. Como parte de la reforma financiera, la CNBV certifica en materia de prevención de lavado de dinero y financiamiento al terrorismo (PLD/FT) a auditores y oficiales de cumplimiento y a otros profesionales de todas las entidades financieras — reguladas y no reguladas- que operen en el país. Los requisitos exigidos al oficial de cumplimiento son iguales para una institución de banca múltiple que para una caja solidaria. Sin embargo, los costos y las posibilidades de cumplir con estos son difíciles en el sector rural. Además, la normativa vigente no permite que un oficial de cumplimiento ofrezca sus servicios a varias entidades, lo que podría aminorar esta carga. Esto solo es posible si integran el mismo grupo financiero, como puede ser un banco o una SOFOM E.R. Pero en el Sector de Ahorro y Crédito Popular, la enorme mayoría de las entidades no pertenecen a grupos financieros.

Asimismo, la reforma confiere un papel más activo a la CONDUSEF respecto a la regulación de los contratos. Nuevamente, no se discrimina por tamaño de institución, por lo que un banco paga la misma multa que una caja rural. Estas situaciones pueden acabar con las pocas entidades financieras que atienden al sector rural. Por supuesto, el objetivo no es que las Entidades de Ahorro y Crédito Popular rurales no sean multadas o amonestadas en caso de incumplimientos, sobre todo porque atienden a población vulnerable, pero una aplicación proporcional a sus activos podría dar mejores resultados.

Otra cuestión que debe abordarse es la relación con la banca comercial. Las Entidades de Ahorro y Crédito Popular y las SOFOM requieren de los servicios de la banca comercial para realizar sus operaciones. Además de los servicios utilizados como cualquier persona moral — pago de nóminas, rentas o servicios-, se encuentran aquellos fundamentales para atender y ampliar su base de clientes. Estos últimos acuden a los bancos con cheques de las entidades populares para retirar los créditos otorgados, así como para pagarlos mediante depósito en la cuenta de la sociedad financiera popular. Los microcréditos que los clientes reciben de las microfinancieras exigen, generalmente, pagos semanales o quincenales, lo que implica frecuentes transacciones entre los clientes del microcrédito, el banco y la microfinanciera.

Las SOFIPO y las SOCAP no cuentan con una infraestructura de red de sucursales como la banca. La realización de operaciones a través de esta amplía las oportunidades de las entidades financieras populares para atender 
a más clientes con un número considerablemente mayor de puntos de acceso y manejar un monto mayor de transacciones. Por lo anterior, las SOFIPO y las SOFOM necesitan cuentas bancarias para operar y para ampliar su escala.

No obstante, la relación entre las entidades financieras populares y la banca comercial se ha visto afectada en los últimos años. En 2011, a partir de la nueva normativa para combatir el lavado de dinero que obliga a reportar a las autoridades las operaciones sospechosas, la banca comenzó a cerrar cuentas básicas de las Entidades de Ahorro y Crédito Popular y de las SOFOM. No obstante, la gran mayoría de las entidades cumplen al 100\% con las obligaciones relativas a la prevención de lavado de dinero y, aun así, padecen el cierre de cuentas bancarias.

Un caso emblemático de esta situación es el de las entidades afiliadas a ProDesarrollo Finanzas y Microempresa, A.C., la red de microfinancieras y cooperativas más grande del país. Estas cumplen en su totalidad con la normativa vinculada a la prevención del lavado de dinero. Sin embargo, en 2015, el cierre de cuentas bancarias afectó a alrededor de 1 millón de microempresarios clientes de estas entidades (de un total de 6,4 millones) ${ }^{18}$.

Ante esta situación, algunas Entidades de Ahorro y Crédito Popular afiliadas a ProDesarrollo y lideradas por la SOFIPO Solución ASEA, que opera en el sector rural del estado de Chiapas, están creando un modelo para incorporar como comisionistas a las tiendas de microempresarios clientes y adaptando tecnología menos costosa a fin de ampliar su red de atención mediante estos corresponsales, que estarán incluso más cerca de la gente y dependerán menos de los servicios de la banca. Sin embargo, estas acciones no pueden tomarlas las SOFOM, pues no están autorizadas para contar con corresponsales. Tampoco pueden ser clientes de las Entidades de Ahorro y Crédito Popular por ser personas morales. Por lo tanto, independientemente de las estrategias paralelas que puedan emprender algunas figuras jurídicas, el tema de la banca con respecto a esta situación debe ser abordado por las autoridades competentes.

\section{Educación financiera}

Los distintos programas de educación financiera que existen en el país, impartidos por diferentes instancias públicas y privadas, se encuentran poco coordinados.

El BANSEFI es el banco de desarrollo que mayormente ha trabajado el tema de la educación financiera mediante tres líneas de acción. En primer lugar, están los talleres para el sector de ahorro y crédito popular, consistentes en una formación de formadores para impartir los cursos de educación

18 Entrevista con Claudia Revilla, Directora General de ProDesarrollo Finanzas y Microempresa, A.C., 3 de agosto de 2016. 
financiera a los usuarios. Además, se cuenta con unidades móviles, donde se imparten breves talleres directamente a usuarios actuales y potenciales. Finalmente, el banco establece alianzas con instituciones académicas para hacer llegar los cursos a comunidades marginadas. También creó el micrositio "Finanzas para todos", para que las personas obtengan conocimientos en educación financiera y realicen tres niveles de cursos en línea ${ }^{19}$.

En el marco de la Política Nacional de Inclusión Financiera, la principal apuesta del Gobierno federal para avanzar en materia de educación financiera es la llevada a cabo en el marco de la Estrategia Digital Nacional, que es responsabilidad de la Presidencia de la República y aún está en etapa piloto. Como parte de esta estrategia, para las personas de menores ingresos, específicamente para la población beneficiaria de PROSPERA, se está desarrollando el programa piloto Prospera Digital, que está formado por los componentes de salud materna e infantil, e inclusión y educación financieras por medio de una plataforma de comunicación con herramientas y tecnologías móviles.

\section{Conclusiones}

En los últimos 15 años se han registrado significativos avances en materia de inclusión financiera. Sin embargo, los esfuerzos han sido insuficientes, por lo que no se ha logrado consolidar la inclusión financiera rural. Más preocupante aún, en los últimos años parece haberse dado una contracción en el acceso a los servicios financieros rurales y en su utilización.

En general, la justificación del rezago rural radica en la falta de infraestructura y tecnología. Sin embargo, las dificultades y los dilemas de la compleja penetración financiera rural están relacionados fuertemente con variables no tecnológicas. La pobreza del sector rural, el escaso capital humano, la limitada relación con la formalidad, la ausencia de redes de protección, la inseguridad y la variación estacional, entre otros, exigen intervenciones diseñadas con el mayor conocimiento y sensibilidad posibles.

En México se han diseñado diferentes acciones para fortalecer la inclusión financiera rural, ya sea a través de la creación de figuras jurídicas, o bien mediante programas de crédito en el primer y segundo piso, de garantías, de apertura de cuentas de ahorro, o de asistencia técnica para los intermediarios financieros y para los productores rurales, así como diversas iniciativas que promueven la educación financiera. No obstante, los frutos han sido exiguos. Varios motivos han sido abordados a lo largo del documento.

19 Véase Banco del Ahorro Nacional y Servicios Financieros (BANSEFI) [en línea] http://www. bansefi.gob.mx/Finanzasparatodos/Pages/default.aspx. 
Uno de ellos es que las bancas de desarrollo no comparten información básica ni experiencias exitosas o fallidas. Tampoco focalizan ni diferencian estratégicamente muchas de sus acciones. Como se mencionó, no existe un modelo claro sobre el tipo de relación que debe establecerse entre las distintas bancas de desarrollo y las instituciones financieras privadas, los usuarios y otros organismos de desarrollo para potenciar la inclusión financiera rural.

A continuación, se esbozan algunas reflexiones acerca de las posibles medidas relacionadas con los ejes de la Política Nacional de Inclusión Financiera.

El primer eje habla del "desarrollo de conocimientos para el uso eficiente y responsable del sistema financiero de toda la población". A este respecto, es importante que se defina con mayor claridad qué se entiende por educación financiera, así como los materiales relevantes para los diferentes grupos prioritarios. El BANSEFI, como certificador de educación financiera, puede tener un papel más activo en este sentido.

Independientemente del canal por el que se transmita la educación, este servicio debe atender las necesidades y capacidades de su público objetivo. Resultan interesantes y necesarios los proyectos piloto, como el de Prospera Digital, que están involucrando a expertos en economía del comportamiento para desarrollar programas de educación financiera con un mejor entendimiento de las decisiones económicas del grupo objetivo que se incluirá.

Asimismo, es importante que las instituciones financieras y los operadores de programas públicos también reciban esta educación financiera especializada, para que anticipen las respuestas a situaciones y dudas que puedan surgir entre los clientes rurales que atienden.

El segundo y el tercer eje de la PNIF hablan sobre el "uso de innovaciones tecnológicas para la inclusión financiera" y el "desarrollo de la infraestructura financiera en zonas desatendidas". Ambos ejes van de la mano y son relevantes, sobre todo, para las zonas apartadas y rezagadas.

Sin embargo, cabe tomar en cuenta por lo menos dos aspectos que se derivan de este trabajo. El primero es la necesidad de invertir en el desarrollo de productos, es decir, que la innovación tecnológica tenga contenido, por lo que es necesario distinguir entre el canal y el producto. La tecnología puede mejorar el canal de acceso reduciendo los costos de transacción. No obstante, si el diseño del producto no atiende las necesidades de los usuarios, la inclusión financiera se tropezará con problemas de no uso o, peor aún, de un uso de productos que pueden generar mayores problemas. 
Asimismo, la tecnología debe ser asequible. En México ya se cuenta con información para saber qué medios pueden aprovecharse o dónde se necesita invertir y brindar apoyo. En el caso del sector rural, la ENIF 2015 reveló que en las localidades con menos de 15.000 habitantes, el 38,3\% de los adultos no cuentan con teléfono celular. La cifra aumenta al 40,8\% entre las mujeres rurales. Por lo tanto, las innovaciones tecnológicas tendrán que adaptarse a las condiciones vigentes en el ámbito rural, sin descuidar el reto pendiente de ampliar y fortalecer la conectividad en estas zonas.

El cuarto eje se refiere a una "mayor oferta y uso de servicios financieros formales para la población subatendida y excluida". Respecto al uso de los productos financieros, existe la idea en la banca de desarrollo de que mejorar el producto consiste en reducir la tasa de interés activa. De este modo, tanto el PROIIF como el Programa de Financiamiento para Pequeños Productores ofrecen tasas activas por debajo del mercado. Desde luego que las bajas tasas de interés son más atractivas para el usuario. Sin embargo, la tasa de interés no es el único atributo del producto financiero. Por años se ha estudiado cómo el fácil uso del sistema, la accesibilidad, la seguridad, la oportunidad para disponer de dinero, el modelo de pagos, los plazos e, incluso, el trato juegan un papel crucial en la confianza y utilización de los productos (Adams y Fitchett, 1992). El problema de ver la mejora del producto exclusivamente por la reducción de la tasa de interés es que afecta la oferta de crédito, debido a que los fondos de los programas tienen recursos limitados (Yaron, Benjamin y Piprek, 1997).

En cuanto a los productos ofrecidos por el sector financiero rural privado, se observa una mejora, ejemplificada principalmente por la sustitución de productos. En los servicios de depósito, las cuentas transaccionales de expediente simplificado han tenido una buena recepción en el sector rural, sobre todo por la facilidad con que estas pueden abrirse, por lo que se perciben como un acierto de la reforma. En los servicios de crédito, se está experimentando una baja en la oferta y uso de metodologías grupales. Junto a la merma del crédito grupal se está dando un aumento del crédito personal y de las tarjetas de crédito, cuyos términos y condiciones de financiamiento son más atractivos que los de los créditos grupales.

No obstante las mejoras en los productos, el acceso a los servicios financieros y su utilización han caído en los municipios y localidades con menos de 50.000 habitantes en los últimos años. He aquí algunas ideas para reflexionar.

Como se trató en el documento, en el sector rural las Entidades de Ahorro y Crédito Popular y las instituciones no reguladas, como las SOFOM, han tenido que hacer frente a los problemas de reputación ocasionados por el fraude de Ficrea, que han afectado la carga regulatoria y su relación con la 
banca comercial. No obstante, estas entidades son los principales oferentes en el sector rural. La norma respecto a la prevención de lavado de dinero y financiamiento al terrorismo (PLD/FT) ha impuesto una carga adicional de costos. Ello plantea la necesidad de esquemas que permitan alcanzar economías de escala en el cumplimiento de la regulación, así como de esquemas de costos regulatorios proporcionales al tamaño de los activos de las entidades financieras, pues, de lo contrario, las reguladas más pequeñas y rurales no soportarán la carga.

El cierre de cuentas bancarias de entidades de ahorro y crédito popular es el factor que más ha afectado al sector. Además de la necesidad de resolver el problema con la banca, se deben buscar alternativas que impongan a los intermediarios no bancarios una menor dependencia de la banca comercial. Los corresponsales de las Entidades de Ahorro y Crédito Popular son un ejemplo de ello: otro acierto de la reforma financiera.

Al cierre de cuentas que afectan las operaciones de entidades no bancarias y a sus usuarios, tanto en el sector rural como urbano, se suma el problema de que la banca comercial ha retirado sucursales y corresponsales del sector rural. Además, un número considerable de SOFOM han sido disueltas y liquidadas, y algunas cajas han sido revocadas por su situación financiera. Esto exige una discusión a fondo sobre los mercados financieros rurales, que involucre a la banca de desarrollo, a la autoridad y a los oferentes privados para revertir la contracción que ha sufrido la oferta financiera rural.

Otra alternativa para fortalecer los puntos de acceso en el sector rural es contemplar el segundo piso como prioridad de la banca de desarrollo, debido a que su cobertura es limitada. Esto reporta beneficios en cuanto al número de usuarios y el fortalecimiento de las instituciones. No obstante, se debe encontrar el equilibrio del nivel de las tasas de interés activas para no beneficiar con un descuento de cartera barata al intermediario en detrimento del usuario, que debe ser el beneficiario objetivo de la banca de desarrollo.

El quinto y el sexto eje de la PNIF buscan aumentar la "confianza en el sector financiero formal a través de mecanismos de protección al consumidor" y la "generación de datos y mediciones para evaluar los esfuerzos de inclusión financiera". En el sector rural, se tendrán que hacer mayores esfuerzos para crear confianza en las instituciones financieras formales. Por obvias razones, la educación financiera desempeña un papel fundamental al respecto. Ahora bien, los contenidos tendrán que reforzar todo lo concerniente a los derechos del usuario, pues es la temática menos conocida por quienes están en situación de pobreza y aislamiento. Para hacerlos efectivos, se deben buscar formas de consulta y denuncia de abusos que sean novedosas, diferentes y fáciles, y que hagan uso de la tecnología disponible. 
Por último, es indudable la riqueza de información que se ha generado en las bases de datos tanto de las instituciones como de los usuarios a partir de la creación del CONAIF y la instrumentación de la ENIF. En pocos años se ha contado con información de un enorme valor para la elaboración de diagnósticos y el diseño de políticas públicas que no se tenía en la década anterior. Las bases han ido creciendo y se han perfeccionado con el tiempo. De su uso surgen dos sugerencias. La primera: cuando se trate de inclusión financiera inducida mediante cuentas de ahorro de programas sociales, es importante separar la información proveniente de las beneficiarias de la información procedente del resto de los usuarios. La segunda sugerencia es que resulta necesario reforzar la planeación, los estudios prospectivos y las evaluaciones que llevan a cabo los profesionales académicos y expertos en inclusión financiera.

\section{Bibliografía}

Adams, D. y D. Fitchett (eds.) (1992), Informal Finance in Low-Income Countries, San Francisco, Westview Press.

BANSEFI (Banco del Ahorro Nacional y Servicios Financieros) (2016), Presentación en el Seminario "Promoviendo la inclusión financiera a través de las políticas de innovación de la banca de desarrollo", Ciudad de México, 4 y 5 de julio, Comisión Económica para América Latina y el Caribe (CEPAL).

Campos, P. (2005), El ahorro popular en México: acumulando activos para superar la pobreza, Ciudad de México, Centro de Investigación para el Desarrollo, A.C. (CIDAC)/ Editorial Porrúa.

Campos, P. (2012), “Estudio de benchmarking: trayectoria de las microfinanzas y la participación del PRONAFIM (2000-2012) como insumo para la planeación futura", Programa Nacional de Financiamiento al Microempresario (PRONAFIM).

CONAIF (Consejo Nacional de Inclusión Financiera) (2016a), Política nacional de inclusión financiera, Ciudad de México, junio. (2016b), Reporte Nacional de Inclusión Financiera, Nº 7, Ciudad de México.

CONDUSEF (Comisión Nacional para la Protección y Defensa de los Usuarios de Servicios Financieros) (2012), "La importancia de las SOFOM ENR para la CONDUSEF", Comunicado, $\mathrm{N}^{\circ} 47$, Ciudad de México.

DICONSA (Sistema de Distribuidoras Conasupo, S.A. de C.V.) (2016), “Metodología de Evaluación de Propuestas para la prestación del Servicio de Plataforma de Pagos en Tiendas Comunitarias de DICONSA", agosto.

FMI (Fondo Monetario Internacional) (2015), Financial Access Survey 2015, Washington, D.C.

Gutiérrez, J. y E. Servan (2012), "Análisis descriptivo de los cuestionarios de medios de pago para la titular beneficiaria de Oportunidades y operadores. Versión final", Cuernavaca, Instituto Nacional de Salud Pública (INSP), octubre.

INEGI/CNBV (Instituto Nacional de Estadística y Geografía/Comisión Nacional Bancaria y de Valores) (2016), Encuesta Nacional de Inclusión Financiera 2015, Ciudad de México. 
Mansell, C. (1995), Las finanzas populares en México: el redescubrimiento de un sistema olvidado, Ciudad de México, Instituto Tecnológico Autónomo de México (ITAM) / Editorial Milenio.

Marulanda Consultores Ltda./Development Alternatives Inc. (DAI) (2011), Estudio: microfinanzas en México [en línea] http:/ / www.microfinancegateway.org/sites / default/files/mfg-es-documento-estudio-microfinanzas-en-mexico-3-2011.pdf.

Maxfield, S. (1993), "The Politics of Mexican Financial Policy", The Politics of Finance in Developing Countries, S. Haggard, C. Lee y S. Maxfield (eds.), Ithaca y Londres, Cornell University Press.

Merino, G. (2011), "Financiamiento al sector rural", documento presentado ante la Cámara de Diputados, Ciudad de México, Financiera Rural, agosto.

México, Presidencia de la República (2011), “Acuerdo por el que se crea el Consejo Nacional de Inclusión Financiera", Diario Oficial de la Federación, Ciudad de México, 3 de octubre.

Moody's Investor Service (2014), “El fracaso de Banco Bicentenario expone debilidades de la estrategia de bancos de nicho en México", 12 de agosto.

ProDesarrollo (ProDesarrollo Finanzas y Microempresa, A.C.) (2015), Benchmarking de las microfinanzas en México 2014-2015, Ciudad de México.

Román, R. (2014), “Bancos de nicho son los más vulnerables”, El Economista, Ciudad de México, 18 de noviembre.

Trivelli, C. y H. Venero (2007), "Banca de desarrollo para el agro: ¿qué podemos aprender de la experiencia latinoamericana?", Debate Agrario: Análisis y Alternativas, $\mathrm{N}^{\mathrm{o}}$ 42, Lima, Centro Peruano de Estudios Sociales (CEPES), noviembre.

Yaron J., M. Benjamin y G. Piprek (1997), "Rural finance: issues, design and best practice", Environmentally and Socially Sustainable Development Studies and Monograph Series, vol. 14, Washington, D.C., Banco Mundial. 



\section{Publicaciones recientes de la CEPAL ECLAC recent publications}

\section{www.cepal.org/publicaciones}

\section{Informes periódicos / Annual reports}

\section{También disponibles para años anteriores / Issues for previous years also available}

- Estudio Económico de América Latina y el Caribe 2016, 236 p. Economic Survey of Latin America and the Caribbean 2016, 232 p.

- La Inversión Extranjera Directa en América Latina y el Caribe 2016, 170 p. Foreign Direct Investment in Latin America and the Caribbean 2016, $164 \mathrm{p}$.

- Anuario Estadístico de América Latina y el Caribe 2016 / Statistical Yearbook for Latin America and the Caribbean 2016, $132 \mathrm{p}$.

- Balance Preliminar de las Economías de América Latina y el Caribe 2016, 132 p. Preliminary Overview of the Economies of Latin America and the Caribbean 2016, $124 \mathrm{p}$.

- Panorama Social de América Latina 2015, 226 p. Social Panorama of Latin America 2015, 222 p.

- Panorama de la Inserción Internacional de América Latina y el Caribe 2016, 174 p. Latin America and the Caribbean in the World Economy 2015, 170 p.

\section{Libros y documentos institucionales / Institutional books and documents}

- Panorama fiscal de América Latina yel Caribe 2017: la movilización de recursos para el financiamiento del desarrollo sostenible, 2017, $115 \mathrm{p}$.

Fiscal Panorama of Latin America and the Caribbean 2017: Mobilizing resources to finance sustainable development, 2017, 108 p.

- ECLAC Thinking. Selected Texts (1948-1998), 2016, 520 p.

- La matriz de la desigualdad en América Latina, 2016, 96 p. The social inequality matrix in Latin America, 2016, 94 p.

- Autonomía de las mujeres e igualdad en la agenda de desarrollo sostenible, 2016, 184 p. Equality and women's autonomy in the sustainable development agenda, 2016, 168 p. Autonomia das mulheres e igualdade na agenda de desenvolvimento sustentável. Sintese, 2016, $106 \mathrm{p}$.

- La Unión Europea y América Latina y el Caribe ante la Agenda 2030 para el Desarrollo Sostenible: el gran impulso ambiental, 2016, $112 \mathrm{p}$.

The European Union and Latin America and the Caribbean vis-à-vis the 2030 Agenda for Sustainable Development: The environmental big push, 2016, 112 p.

- Horizontes 2030: la igualdad en el centro del desarrollo sostenible, 2016, $176 \mathrm{p}$. Horizons 2030: Equality at the centre of sustainable development, 2016, $174 \mathrm{p}$. Horizontes 2030: a igualdade no centro do desenvolvimento sustentável, 2016, 176 p.

- 40 años de agenda regional de género, 2016, $130 \mathrm{p}$. 40 years of the regional gender agenda, 2016,128 p.

- La nueva revolución digital: de la Internet del consumo a la Internet de la producción, 2016, 100 p. The new digital revolution: From the consumer Internet to the industrial Internet, 2016, $100 \mathrm{p}$. 


\section{Libros de la CEPAL / ECLAC books}

144 Desde el gobierno abierto al Estado abierto en América Latina y el Caribe, Alejandra Naser, Álvaro Ramírez-Alujas, Daniela Rosales (eds.), 2017, 466 p.

143 Protección social en América Latina: la desigualdad en el banquillo, Ana Sojo, 2017, 246 p.

142 Consensos y conflictos en la política tributaria de América Latina, Juan Carlos Gómez Sabaini, Juan Pablo Jiménez y Ricardo Martner (eds.), 2017, 446 p.

141 Brechas y transformaciones: la evolución del empleo agropecuario en América Latina, Jürgen Weller (ed.), 2016, $274 \mathrm{p}$.

140 Protección y formación: instituciones para mejorar la inserción laboral en América Latina y Asia, Alberto Isgut, Jürgen Weller (eds.), 2016, 428 p.

Protection and training: Institutions for improving workforce integration in Latin America and Asia, Alberto Isgut, Jürgen Weller (eds.), 2016, 428 p.

139 Hacia una nueva gobernanza de los recursos naturales en América Latina y el Caribe, Hugo Altomonte, Ricardo J. Sánchez, 2016, 256 p.

138 Estructura productiva y política macroeconómica: enfoques heterodoxos desde América Latina, Alicia Bárcena, Antonio Prado, Martín Abeles (eds.), 2015, 282 p.

\section{Páginas Selectas de la CEPAL / ECLAC Select Pages}

- Planificación y prospectiva para la construcción de futuro en América Latina y el Caribe. Textos seleccionados 2013-2016, Jorge Máttar y Mauricio Cuervo (comps.), 2016, 222 p.

- Desarrollo inclusivo en América Latina. Textos seleccionados 2009-2016, Ricardo Infante (comp.), 2016, $294 \mathrm{p}$.

- Globalización, integración y comercio inclusivo en América Latina. Textos seleccionados 2010-2014, Osvaldo Rosales (comp.), 2015, 326 p.

- El desafío de la sostenibilidad ambiental en América Latina y el Caribe. Textos seleccionados 2012-2014, Carlos de Miguel, Marcia Tavares (comps.), 2015, 148 p.

\section{Copublicaciones / Co-publications}

- El imperativo de la igualdad, Alicia Bárcena, Antonio Prado, CEPAL/Siglo Veintiuno, Argentina, 2016, 244 p.

- Gobernanza global y desarrollo: nuevos desafíos y prioridades de la cooperación internacional, José Antonio Ocampo (ed.), CEPAL/Siglo Veintiuno, Argentina, 2015, 286 p.

- Decentralization and Reform in Latin America: Improving Intergovernmental Relations, Giorgio Brosio and Juan Pablo Jiménez (eds.), ECLAC/Edward Elgar Publishing, United Kingdom, 2012, 450 p.

- Sentido de pertenencia en sociedades fragmentadas: América Latina desde una perspectiva global, Martín Hopenhayn y Ana Sojo (comps.), CEPAL/Siglo Veintiuno, Argentina, 2011, 350 p.

\section{Coediciones / Co-editions}

- Perspectivas económicas de América Latina 2017: Juventud, Competencias y Emprendimiento, 2016, 338 p. Latin American Economic Outlook 2017: Youth, Skills and Entrepreneurship, 2016, 314 p.

- Desarrollo e integración en América Latina, 2016, 314 p.

- Hacia un desarrollo inclusivo: el caso del Uruguay, 2016, 174 p.

- Perspectivas de la agricultura y del desarrollo rural en las Américas: una mirada hacia América Latina y el Caribe 2015-2016, CEPAL/FA0/IICA, 2015, 212 p. 


\section{Documentos de Proyectos / Project Documents}

- La transversalización del enfoque de género en las políticas públicas frente al cambio climático en América Latina, Marina Casas Varez, 2017, 101 p.

- Financiamiento para el cambio climático en América Latina y el Caribe en 2015, Joseluis Samaniego y Heloísa Schneider, 2017, 76 p.

- El cambio tecnológico y el nuevo contexto del empleo: tendencias generales y en América Latina, Sebastian Krull, 2016, 48 p.

- Cambio climático, políticas públicas y demanda de energía y gasolinas en América Latina: un meta-análisis, Luis Miguel Galindo, Joseluis Samaniego, Jimy Ferrer, José Eduardo Alatorre, Orlando Reyes, 2016, 68 p.

- Estado de la banda ancha en América Latina y el Caribe 2016, 2016, 46 p.

\section{Cuadernos Estadísticos de la CEPAL}

44 Las cuentas de los hogares y el bienestar en América Latina. Más allá del PIB, 2016.

43 Estadísticas económicas de América Latina y el Caribe: Aspectos metodológicos y resultados del cambio de año base de 2005 a 2010

\section{Series de la CEPAL / ECLAC Series}

Asuntos de Género / Comercio Internacional / Desarrollo Productivo / Desarrollo Territorial / Estudios Estadísticos / Estudios y Perspectivas (Bogotá, Brasilia, Buenos Aires, México, Montevideo) / Studies and Perspectives (The Caribbean, Washington, D.C.) / Financiamiento del Desarrollo / Gestión Pública / Informes y Estudios Especiales / Macroeconomía del Desarrollo / Medio Ambiente y Desarrollo / Población y Desarrollo / Política Fiscal / Políticas Sociales / Recursos Naturales e Infraestructura / Seminarios y Conferencias.

\section{Manuales de la CEPAL}

5 Estimación de las erogaciones sociales a partir del sistema de cuentas nacionales: una propuesta para las funciones de educación, salud y protección social, María Paz Colinao, Federico Dorin, Rodrigo Martínez y Varinia Tromben, 2016, 63 p.

4 Territorio e igualdad: planificación del desarrollo con perspectiva de género, 2016, 84 p.

3 Manual de formación regional para la implementación de la resolución 1325 (2000) del Consejo de Seguridad de las Naciones Unidas relativa a las mujeres, la paz y la seguridad, María Cristina Benavente R., Marcela Donadio, Pamela Villalobos, 2016, 126 p.

2 Guía general para la gestión de residuos sólidos domiciliarios, Estefani Rondón Toro, Marcel Szantó Narea, Juan Francisco Pacheco, Eduardo Contreras, Alejandro Gálvez, 2016, 212 p.

\section{Revista CEPAL / CEPAL Review}

La Revista se inició en 1976, con el propósito de contribuir al examen de los problemas del desarrollo socioeconómico de la región. La Revista CEPAL se publica en español e inglés tres veces por año.

CEPAL Review first appeared in 1976, its aim being to make a contribution to the study of the economic and social development problems of the region. CEPAL Review is published in Spanish and English versions three times a year. 


\title{
Observatorio demográfico / Demographic Observatory
}

Edición bilingüe (español e inglés) que proporciona información estadística actualizada, referente a estimaciones y proyecciones de población de los países de América Latina y el Caribe. Desde 2013 el Observatorio aparece una vez al año.

Bilingual publication (Spanish and English) proving up-to-date estimates and projections of the populations of the Latin American and Caribbean countries. Since 2013, the Observatory appears once a year.

\section{Notas de población}

Revista especializada que publica artículos e informes acerca de las investigaciones más recientes sobre la dinámica demográfica en la región. También incluye información sobre actividades científicas y profesionales en el campo de población. La revista se publica desde 1973 y aparece dos veces al año, en junio y diciembre.

Specialized journal which publishes articles and reports on recent studies of demographic dynamics in the region. Also includes information on scientific and professional activities in the field of population. Published since 1973, the journal appears twice a year in June and December.

\section{Las publicaciones de la CEPAL están disponibles en: ECLAC publications are available at: www.cepal.org/publicaciones}

También se pueden adquirir a través de: They can also be ordered through: www.un.org/publications

\author{
United Nations Publications \\ PO Box 960 \\ Herndon, VA 20172 \\ USA
}

Tel. (1-888)254-4286

Fax (1-800)338-4550

Contacto / Contact. publications@un.org

Pedidos / Orders: order@un.org 


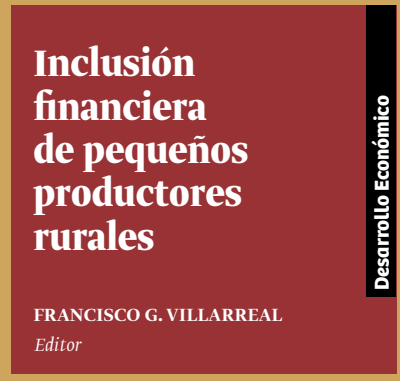

Cada vez existe más evidencia empírica sobre el impacto positivo de la provisión y el uso responsable de servicios financieros formales, tanto en el bienestar de los hogares como en el desempeño de las empresas. A nivel individual, la inclusión financiera beneficia a hogares y pequeños productores rurales al facilitar la acumulación segura de activos, el apalancamiento de dichos activos para realizar inversiones en capital humano y físico, y una mejor gestión de riesgos. A nivel agregado, los efectos positivos están vinculados con la mejora en la asignación de recursos escasos entre las distintas actividades.

No obstante los recientes avances en diferentes dimensiones de la inclusión financiera en América Latina y el Caribe, persisten importantes brechas que se acentúan en el ámbito rural, que históricamente ha sido desatendido por los proveedores tradicionales de servicios financieros. En este volumen se reseña la evolución reciente de las principales brechas en cinco países - Costa Rica, El Salvador, Honduras, México y República Dominicana- que se encuentran en diferentes fases del diseño y la implementación de estrategias integrales de inclusión financiera. A partir del diagnóstico en una perspectiva comparada de la arquitectura institucional disponible, se identifican las principales barreras que impiden que pequeños productores del medio rural tengan acceso a los diversos servicios financieros ofrecidos y hagan un uso efectivo de ellos, con la finalidad de formular recomendaciones de políticas públicas orientadas a superar las restricciones detectadas. 